\title{
Synthesis of new, rigid and conformation stabilizing spin labels for analysis of the orientation of transmembrane domains
}

\section{Dissertation}

\author{
for the award of the degree \\ "Doctor rerum naturalium" \\ of the Georg-August-University Göttingen
}

within the doctoral program Chemistry

of the Georg-August-University School of Science (GAUSS)

\author{
submitted by \\ Iryna Portnova \\ from Charkow (Ukraine)
}

Göttingen, 2021 


\section{Thesis Committee}

Prof. Dr. Ulf Diederichsen

Institute of Organic and Biomolecular Chemistry, Georg-August-University Göttingen

Prof. Dr. Marina Bennati

Max Planck Institute for Biophysical Chemistry, Göttingen

\section{Members of the Examination Board}

Reviewer:

Prof. Dr. Ulf Diederichsen

Institute of Organic and Biomolecular Chemistry, Georg-August-University Göttingen

Second Reviewer:

Prof. Dr. Marina Bennati

Max Planck Institute for Biophysical Chemistry, Göttingen

\section{Further Members of the Examination Board}

Dr. Holm Frauendorf

Institute of Organic and Biomolecular Chemistry, Georg-August-University Göttingen

Prof. Dr. Konrad Koszinowski

Institute of Organic and Biomolecular Chemistry, Georg-August-University Göttingen

PD Dr. Michael John

Institute of Organic and Biomolecular Chemistry, Georg-August-University Göttingen

Prof. Dr. Kai Tittmann

Department of Molecular Enzymology, Georg-August-University Göttingen

Date of Oral Examination: $6^{\text {th }}$ October 2021 
The following work was performed at the Institute for Organic and Biomolecular Chemistry of the Georg-August University Göttingen from April 2017 until August 2021 under the supervision of Prof. Dr. Ulf Diederichsen.

The work was supported by the Deutsche Forschungsgemeinschaft (DFG) in the context of the collaborative research center 803 (SFB 803, Probing membrane-peptide and membrane-protein interactions by pulsed EPR spectroscopy). 


\section{Declaration of Authorship}

I hereby declare that I prepared the following dissertation with the title "Synthesis of new, rigid and conformation stabilizing spin labels for analysis of the orientation of transmembrane domains" by my own and with no other sources and aids than quoted.

Göttingen, 30.08.2021

Iryna Portnova 




\section{Contents}

1 Introduction . . . . . . . . . . . . . . . . . . . . . . . 1

2 Nitroxides and their Application as Spin Labels for EPR Spectroscopy . . . . . . 3

2.1 Basics of Nitroxide Radicals . . . . . . . . . . . . . . . . . . . . . . . . 3

2.2 Stability of Nitroxides . . . . . . . . . . . . . . . . 5

2.3 Spin Labeling Techniques for Proteins . . . . . . . . . . . . . . . 7

2.3.1 Side-Directed Spin Labeling of Proteins . . . . . . . . . . . . . . . 7

2.3.2 Direct Incorporation of Spin Labeled Noncanonical Amino Acids . . . 10

3 Synthesis of a New, Rigid and Conformation Stabilizing Spin Label . . . . . . . . 13

3.1 First Approach: Synthesis Starting from Carboxy Substituted $\gamma$-Lactam Spin

Label . . . . . . . . . . . . . . . . . . . . . . . . . 15

3.1.1 Synthesis of the Dibromide Spin Label . . . . . . . . . . . . . . 16

3.1.2 Synthesis Starting from Carboxy Substituted $\gamma$-Lactam Spin Label . 18

3.2 Second Approach: Synthesis via Anionic Cyclisation Reaction . . . . . . . . 20

3.2.1 Testing the Anionic Cyclisation Reaction for the Synthesis of the Azabicyclo Spin Label . . . . . . . . . . . . . . . . . . . . . 21

3.2.2 Synthesis of the Azabicyclo Spin Label by the Anionic Cyclisation Using Different Reactants . . . . . . . . . . . . . . . . . 24

4 Synthesis of Spin Labeled Azapeptides . . . . . . . . . . . . . . . . . . . . . . . . 29

4.1 Synthesis of the Nitroxyl Spin Labeled Azapeptide by SPPS . . . . . . . . . 31

4.2 Synthesis of Spin Labeled Azapeptide by the Submonomer Approach . . . . 37

4.2.1 Synthesis of the spin labeled azadipeptide submonomer . . . . . . . . 39

4.2.2 Application of the Spin Labeled Submonomer in SPPS . . . . . . . . 41

4.2.3 Conformational Analysis of Methoxy Protected Azapeptide . . . . . . 44

5 Application of the $\alpha$-TOPP Spin Label in Peptide Synthesis by Native Chemical

Ligation . . . . . . . . . . . . . . . . . . . . . 46

5.1 Synthesis of Photolabile Protected $\alpha$-TOPP Spin Label . . . . . . . . . . . . 49

5.2 Testing the Removal of the 2-Nitrobenzyl and the DMNB Protecting Groups 54

6 Summary and Outlook . . . . . . . . . . . . . . . . . . 58

7 Experimental Part . . . . . . . . . . . . . . . . . . . 63

7.1 Materials and Methods . . . . . . . . . . . . . . . 63

7.2 Analysis . . . . . . . . . . . . . . . . . . . 6 65

7.3 Standard Operating Procedures . . . . . . . . . . . . . . . . 66

7.4 Synthesis of $\beta$-Turn inducing Spin Label . . . . . . . . . . . . . . . . 69

7.5 Synthesis of Spin Labeled Azapeptide . . . . . . . . . . . . . . . . . . 81

7.6 Synthesis of Photolabile Protected TOPP Spin Label . . . . . . . . . . . . . 88 
9 Appendix . . . . . . . . . . . . . . . . . . . . . . . . 97

10 List of Abbreviations . . . . . . . . . . . . . . . . . . 98

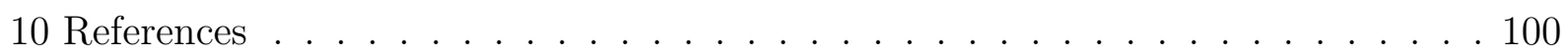




\section{Introduction}

Interactions between peptides and lipids play a crucial role in many processes of living organisms, since they are involved in cell processes such as fusion or transport. One efficient technique to analyze such interactions is the electron paramagnetic resonance (EPR) spectroscopy, in particular double electron electron resonance (DEER) and pulsed electron double resonance (PELDOR) experiments, which allow to investigate the conformation and orientation of model peptides in artificial membranes, to gain a deeper insight into the complex lipid-peptide interactions of natural systems. ${ }^{[1]}$ In order to use this analytical technique, the peptides need to be labeled with molecules bearing a paramagnetic nitroxide radical. This is achieved either by direct incorporation of an amino acid spin label into the peptide by solid phase peptide synthesis (SPPS) or by side-directed spin labeling (SDSL), whereby the spin label is covalently attached to the side-chain of the peptide via a linker. ${ }^{[2]}$

To improve the accuracy of distance and orientation measurements by EPR spectroscopy the semi-rigid 4-(3,3,5,5-tetra-methyl-2,6-dioxo-4-oxylpiperazin-1-yl)-l-phenylglycine (TOPP) spin label was designed and synthesized by Stoller et al., which was successfully incorporated in the transmembrane model peptide WALP by SPPS. ${ }^{[3,4]}$ Studies of the spin labeled WALP peptides revealed the $\alpha$-TOPP spin label to be suitable for investigations of peptide-lipid systems and showed promising results in PELDOR experiments. ${ }^{[4]}$ Therefore, the investigation of more complex protein systems using the the semi-rigid $\alpha$-TOPP spin label is highly desirable. However, this would require a reliable method for the direct incorporation of this spin label into large protein systems. Since an effective SPPS is limitated to peptides consisting up to 100 amino acid residues, the synthesis of larger peptides remains still challenging and requires additional techniques. One synthetical approach to construct large and modified proteins is the ligation of two or more protein fragments. Thereby, the native chemical ligation (NCL) is one of the most used ligation types to construct complex protein systems, since the presence of at least one internal cysteine residue in the target protein is crucial to apply this technique. ${ }^{[5,6]}$ For the purpose to construct complex and $\alpha$-TOPP spin labeled peptides, the NCL is considered to be a promising approach. The introduction of the $\alpha$-TOPP spin label in peptides constructed by NCL would enable to investigate large peptide systems by EPR spectroscopy using the semi-rigid $\alpha$-TOPP spin label. Thus, one goal of this work was to synthesize an $\alpha$-TOPP spin labeled peptide by NCL.

Apart from expanding the application field of the semi-rigid TOPP spin label, the main focus of this work was concentrated on the design and synthesis of a new rigid spin label, that not only fill the role as the carrier of a paramagnetic center, but is additionaly able 
to induce or stabilize a specific conformation in peptides. This additional property would address a common issue of the incorporation of rigid spin labels into peptides, which is the disturbance of the native local conformation. By introduction of the new spin label the local conformation of the peptide could be controlled and predicted.

Therefore, the design of the new spin label is based on the approach to stabilize the peptide conformation by direct incorporation of a rigid spin label by SPPS. Considering the high abundance of different types of turn domains in complex protein systems ${ }^{[7]}$, the $\beta$-turn was chosen as the target conformation.

Hence, the design and synthesis of a new spin label, that comprises an enhanced rigidity and is capable to induce or stabilize $\beta$-turn conformations by geometrical preorganization was attempted in the course of this work. 


\section{Nitroxides and their Application as Spin Labels for EPR Spectroscopy}

The electron paramagnetic resonance (EPR) spectroscopy is an important technique to study the environment of paramagnetic centers within biomolecules according to electronnuclear or electron-electron interactions. Thereby, the pulsed techniques, such as double electron electron resonance (DEER) and pulsed electron double resonance (PELDOR), were developed to detect dipolar interactions between spin pairs within the biomolecule, which are dependent on the distance between the paramagnetic centers and orientation of the spin labeled biomolecule in respect to the magnetic poles during the measurement. ${ }^{[8,9]}$ Therefore, these pulsed techniques allow to receive information about intramolecular distances in the range of $1.8-6 \mathrm{~nm}$ and orientation of the probe. ${ }^{[10]}$ Hence, these are important tools to study conformational changes of peptides or peptide-lipid interactions, since membrane or cell embedded biomolecules can be analysed. ${ }^{[8,10]}$

Besides the pulsed EPR experiments, there are alternative analysis techniques, such as $\mathrm{X}$-ray diffraction or nuclear magnetic resonance (NMR) spectroscopy, which do not require modifications of the biomolecules but have a limited application range. While X-ray diffraction requires the preparation of crystalline biomolecule samples in high quality ${ }^{[8]}$, which is very challenging for proteins, the NMR spectroscopy is restricted to biomolecules with molecular weights up to $30 \mathrm{KDa}^{[11]}$ and requires relatively high amount of the sample for the measurement. ${ }^{[8]}$ In comparison to these techniques, the pulsed EPR spectroscopy has the advantage to be applicable to a wide range of biomolecules, that can be prepared for the measurement by paramagnetic labeling. Additionally, due to high sensitivity, this technique does not require large amounts of the spin labeled biomolecule, so that concentrations of labeled samples in micromolar range are sufficient. ${ }^{[12]}$

In order to introduce paramagnetic centers into the biomolecule, there are two approaches: the direct incorporation of paramagnetic monomers during synthesis or the side-directed spin labeling (SDSL), that is based on the attachement of paramagnetic centers to the biomolecule. ${ }^{[13]}$

In the next sections of this chapter, the basics and properties of the nitroxides, their incorporation into proteins and applications of selected spin labels will be presented.

\subsection{Basics of Nitroxide Radicals}

The commonly known organic radical species, such as carbon-centered radicals generated by homolytical cleavage of azo compounds like azobisisobutyronitrile (AIBN) ${ }^{[14]}$, or oxygen-centered radical species generated from peroxides ${ }^{[15]}$, readily react with electron 
rich functionalities or recombine with further radical species. Thereby, the high reactivity of radical species, such as generated from AIBN, is exploited to initiate radical polymerization reactions. ${ }^{[14]}$

In comparison to these reactive radical species, the nitroxide radicals exhibit an enhanced stability ${ }^{[16,17]}$ and mostly remain unaffected in different environments and under a wide range of conditions during organic synthesis. ${ }^{[18]}$

Therefore, the nitroxide have a wide scope of application, which ranges from co-oxidants ${ }^{[19]}$, mediators in polymerization reactions ${ }^{[20]}$, anti-oxidants ${ }^{[21,22,23]}$ catalysts $^{[24,25]}$ and organic radical batteries ${ }^{[26]}$ to spin labels ${ }^{[27]}$ for EPR spectroscopy.

Due to their unique stability, the nitroxide radicals are the most widly used paramagnetic labels for the analysis of peptides by pulsed EPR techniques. ${ }^{[27]}$ The long shelf life of this species is mainly attributed to the delocalization of the unpaired electron along the $\mathrm{N}-\mathrm{O}$ bond of the nitroxide and to the shielding effect of the four neighboured $\alpha$-methyl groups, that prevent combination and disproportionation of the free-radical species. ${ }^{[17,27,28]}$ Thereby, the introduction of substituents in the $\alpha$-position to the nitroxyl moiety is essential for the stability of the free-radical because the absence of hydrogen atoms in $\alpha$-position prevents the formation of nitrones by disproportionation according to two possible pathways shown in figure $1 .{ }^{[28,29,30]}$

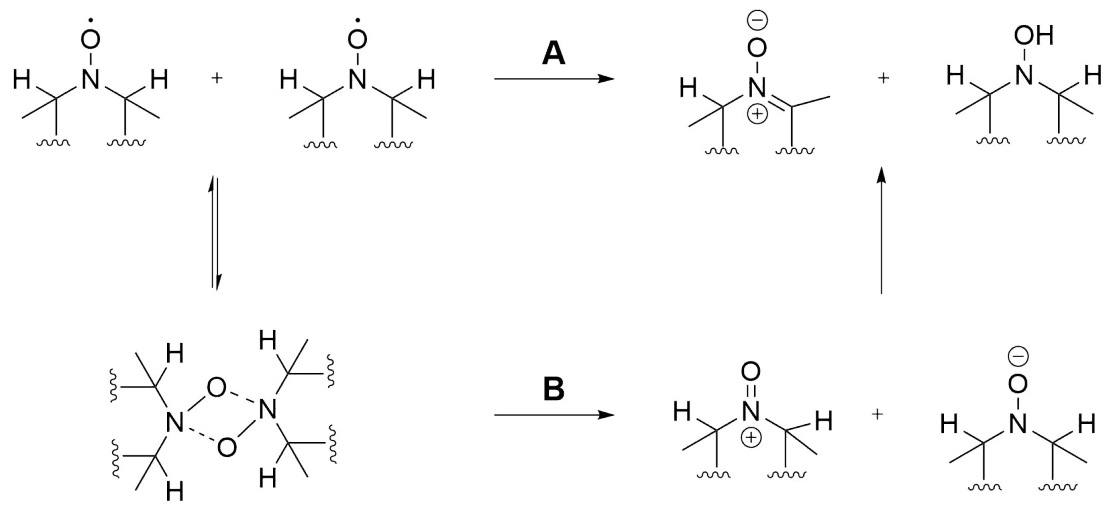

Figure 1: Proposed mechanisms for disproportionation of $\alpha$-hydrogen substituted nitroxides. The mechanism by Ingold et al. is based on a direct H-atom abstraction, while the mechanism proposed by Braslau et al. is based on single electron transfer. ${ }^{[29]}$

In the first proposed mechanism (Figure 1, A) of disproportionation by Ingold et al., a nitrone and hydroxylamine are generated by abstraction of the $\mathrm{H}$-atom in $\alpha$-positon to the nitroxyl moiety. ${ }^{[28,29]}$

The second mechanism, that was assumed by Braslau et al., is based on a two-step process (Figure 1, B): In the first step, a head-to-tail nitroxide dimer is formed, that undergoes single electron transfer (SET), which results in the formation of an oxoammonium ion and a hydroxylamine ion species. In the second step, a proton is transferred from the oxoammonium ion to the hydroxylamine ion to form the hydroxylamine and the nitrone. ${ }^{[28,30]}$ Methyl substituents in $\alpha$-position are the most frequently used substituents, whereby other substituents, such as ethyl ${ }^{[31]}$ or cyclohexyl ${ }^{[32]}$ groups, were also utilized for the design of new spin labels in order to improve the stability of the nitroxides against reduction. ${ }^{[33,34]}$ 
Nevertheless, $\alpha$-substituted nitroxide radicals may also undergo decomposition reactions under certain conditions. In case of alkyl-substituted nitroxide radicals, the corresponding oxoammonium ion, that might be formed under acidic conditions, can decompose at higher temperatures, as it was shown in studies on the (2,2,6,6-tetramethylpiperidin-1yl)oxyl (TEMPO). ${ }^{[35]}$ In addition to that, nitroxide radicals with bulky substituents in $\alpha$-position tend to decompose by fission of the C-N bond. ${ }^{[28]}$

Despite the susceptibility of $\alpha$-hydrogen substituted nitroxyls to decompose, a recent study on the design of new stable nitroxide spin labels shown the possibility to synthesize $\alpha$-hydrogen substituted nitroxide spin labels, that exhibit a high stability against disproportionation. ${ }^{[28]}$ Thereby, the disproportionation could be kinetically hindered by introduction of a co-planar substituent in the $\gamma$-position of the nitroxide skeleton, which stabilizes the nitroxide radical sterically, as well as stereoelectronically, by interacting with the H-atom in $\alpha$-position. ${ }^{[28]}$

Considering the application of the nitroxide radical as spin label, there is one common problem that arises during synthesis under reductive or strongly acidic conditions: the tendency of the nitroxide to convert to hydroxylamine ${ }^{[37]}$, which results in the lost of its paramagnetic property. This is caused by the redox activity of the nitroxide, which results in the formation of an oxoammonium ion species by oxidation or a hydroxylamine by acid catalyzed reduction (Figure 2). ${ }^{[37]}$
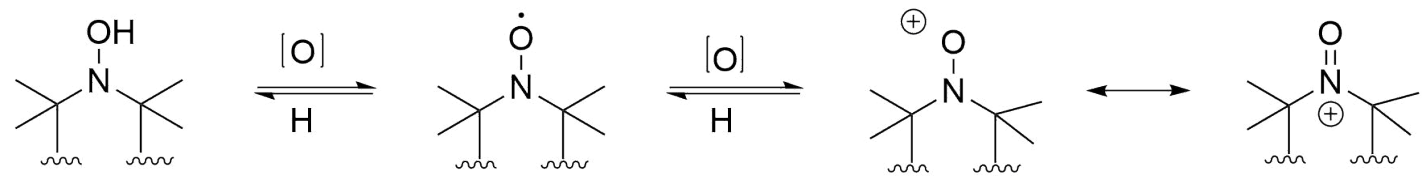

Figure 2: Disproportionation of $\alpha, \alpha$-dimethyl substituted nitroxides. Reduction of the nitroxide results in the formation of a hydroxylamine (left) and oxidation of the nitroxide leads to formation of an oxoammonium ion (right).

Therefore, reactions that involve reducing agents like sodium borohydrate $\left(\mathrm{NaBH}_{4}\right)^{[37]}$ as well as reactions under acidic conditions ${ }^{[36]}$, can lead to the formation of the corresponding hydroxylamine, which is often reversible. ${ }^{[37,39]}$ Thus, the nitroxide radical can be recovered oxidatively by peroxides, such as hydrogen peroxide $\left(\mathrm{H}_{2} \mathrm{O}_{2}\right)$, copper(II)-ions/oxygen ${ }^{[38]}$, manganese dioxide $\left(\mathrm{MnO}_{2}\right)$, sodium periodate $\left(\mathrm{NaIO}_{4}\right)$ or under aerobic conditions by oxygen as oxidant. ${ }^{[37]}$

The first spin labels based on functionalized piperidine, pyrroline or pyrollidine ring structures were prepared by Rozantsev et al. and are the lead structures of the most widly used spin labels for peptides today. ${ }^{[18]}$

\subsection{Stability of Nitroxides}

The stability of the nitroxide unit is correlated to its oxidation potential and reversibility, that are strongly dependent on the chemical structure of the spin label. ${ }^{[37]}$ In general, every structural parameter, that has an influence on the electron distribution along the 
$\mathrm{N}-\mathrm{O}$ bond of the nitroxide, has an impact on the oxidation potential and thus, on the stability of the nitroxide radical. ${ }^{[37]}$

Since different spin labels show a distinct stability and reversibility of the nitroxyl moiety, studies were conducted to explore the influence of the ring size ${ }^{[40]}$, the ring substituents ${ }^{[41]}$ and heteroatoms in the ring ${ }^{[42]}$ on the reduction potential and therefore, the stability of the nitroxide radical.

Considering the ring size, reduction potentials of various nitroxyls were examined in studies, that were based on the reduction rate of the corresponding nitroxyls by ascorbate. ${ }^{[40]}$ In figure 3 the reduction tendency of nitroxide radicals with different skeletons is shown. Thereby, the pyrollidine and pyrroline derived spin labels are more stabile against reduction of the nitroxyl to the corresponding hydroxylamine than the six-membered piperidine nitroxide. ${ }^{[37,40]}$

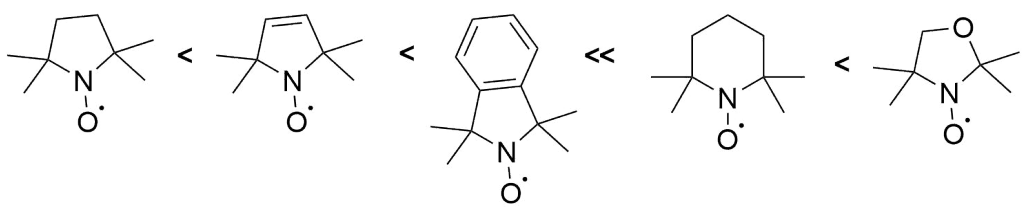

Figure 3: Tendency of nitroxide to reduction increasing from left to right. Five-membered rings (pyrroline, pyrrolidine) are generally more stable against reduction than six-membered nitroxide (TEMPO) or heteroatom substituted nitroxides (oxazolidine). ${ }^{[37]}$

In addition to that, most of the nitroxide radicals are prone to oxidize to the corresponding oxoammonium ion, whereby this process is reversible. It must be considered, that the tendency for oxidation is not the reverse one for the reduction. ${ }^{[37]}$

The prone to reduction or oxidation is related to the ring structure of the nitroxide, which has an influence on the geometry around the nitrogen atom. ${ }^{[37]}$ The nitrogen atom of the oxidized oxoammonium ion species has a trigonal-planar geometry and its formation is therefore, favoured for nitroxides that can easily adopt this geometry. ${ }^{[37]}$ For the formation of hydroxylamine species, the nitrogen amine of the nitroxide is pyramidalized and the reduction of nitroxides is therefore, dependent on the capability of the nitrogen atom to adopt this geometry. ${ }^{[37]}$

Additionally, the substituents in $\alpha$-position to the nitroxide nitrogen atom have an impact on the redox potentials, whereby exchanging the methyl groups by the more sterically demanding ethyl or cyclohexyl groups in piperidine or imidazoline based nitroxides resulted in lower reduction rates (Figure 4). ${ }^{[37]}$

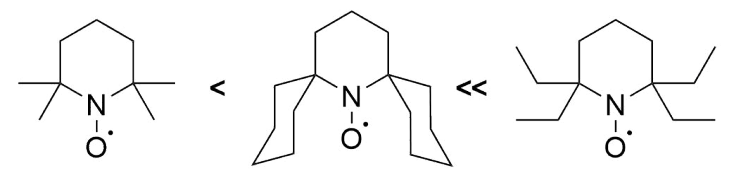

Figure 4: Increasing stability of nitroxide with bulky substituents in $\alpha$-position against reduction. ${ }^{[37]}$ 


\subsection{Spin Labeling Techniques for Proteins}

EPR spectroscopy is a non-invasive and non-destructive technique that allows the analysis of the structure, conformational changes and interactions of biomolecules, such as proteins or nucleic acids. ${ }^{[27]}$ Therefore, the biomolecules need to be modified with a paramagnetic unit, which can be attached covalently to the biomolecule as a spin label or by non-covalent interactions as a spin probe. ${ }^{[27]}$

For EPR analysis of protein systems, the nitroxide spin labels are applied as paramagnetic reporters, due to the unique stability of the nitroxide radical under a broad range of conditions and the various structural motifs. ${ }^{[16,18]}$ Thereby, the nitroxide spin labels can be introduced at specific positions in proteins under different labeling conditions and the EPR analysis of the nitroxide spin labeled probes can be performed in different environments without affecting the paramagnetic properties. However, one disadvantage of using nitroxide spin labels is their relatively bulky structure, which might cause structural perturbation of the protein and should be minimized to draw reliable conclusions from the EPR measurements. Thus, a wide range of spin labels with different structural motifs have been developed and tested for specific applications.

In order to introduce nitroxide spin labels into proteins, two main strategies are employed: the SDSL, using canonical and noncanonical amino acids residues for bioconjugation with nitroxide spin labels, and the direct incorporation of paramagnetic amino acids by SPPS or by direct encoding. ${ }^{[13]}$

In the following sections these labeling strategies will be described in more detail using examples of selected spin labels.

\subsubsection{Side-Directed Spin Labeling of Proteins}

The SDSL approach is one of the most frequently used labeling strategies for proteins, because it allows to label selectively specific sites in proteins under a wide range of conditions, including biological conditions. Thereby, the labeling of specific positions in proteins is based on chemoselective reactions between the nitroxide spin label and the amino acid residues, that can be naturally occuring, as for labeling of cysteine residues by MTSL, or be introduced as noncanonical amino acids bearing modified side-chain functionalities, that undergoe conjugation reactions with spin labels. ${ }^{[43,44]}$

In the following sections SDSL techniques that are based on the canonical cysteine residues and noncanonical amino acid residues are presented.

\subsubsection{Spin Labeling of Cysteine Residues}

The thiol group of the cysteine side-chains is, due to its nucleophilicity and high abundance in proteins, one of the most used target-sites for spin labeling. ${ }^{[43]}$ The thiol group reacts selectively and readily with spin labels bearing either a methanethiosulfonate group (MTSL) to form a disulfide bond ${ }^{[45]}$ (Figure 5, A), or with maleimide functionalized spin 
labels to form a thioether bond ${ }^{[46]}$ (Figure 5, B).

A

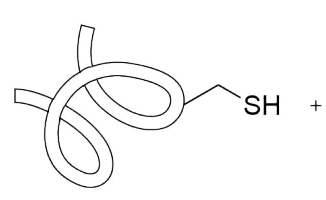

B

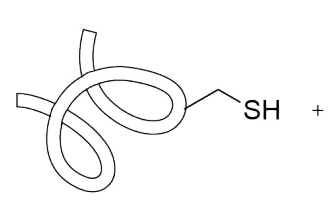

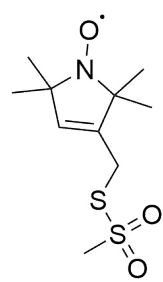
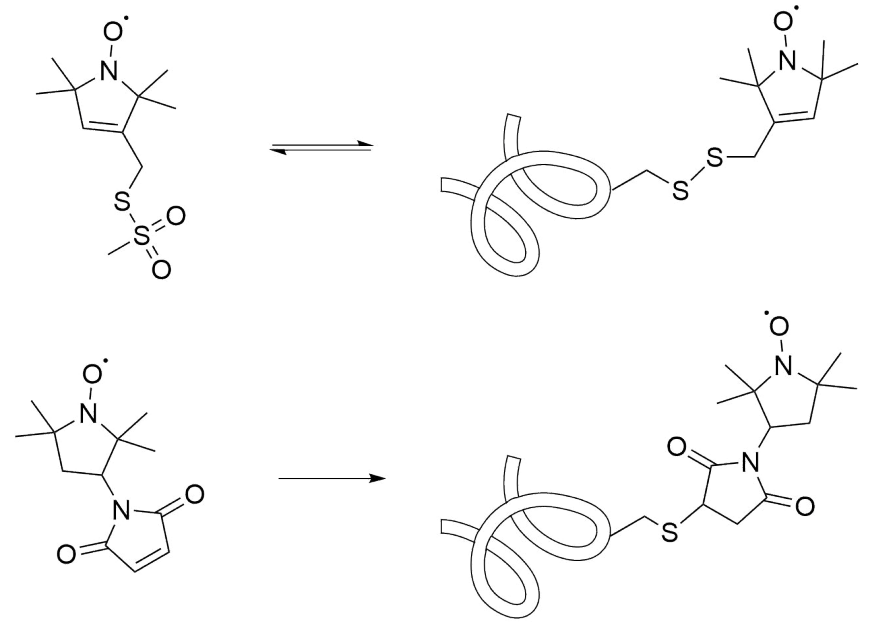

Figure 5: Schematic representation of SDSL of a cysteine containing protein using MTSL spin label (A) and maleimide spin label (B).

However, the disadvantage to utilize cysteine residues as labeling sites is, that they are often responsable for natural conformations of proteins by the formation of disulfide bridges between cysteine residues pairs and are thus, crucial for the biological activity of proteins. ${ }^{[4]}$ For protein systems without cysteine residues, cysteine mutations have to be introduced at the desired positions to employ MTSL or maleimide spin labels. Moreover, if the cysteine residue is not introduced as a modification, the labeling will occur at all cysteine residues, that are present in native proteins. Thus, there is no possibility to choose specific cysteine residues to label, which requires to remove further unwanted cysteine residues. In addition to that, the handling of free cysteine side-chains in proteins is challenging due to their susceptibility to oxidation under aerobic conditions. ${ }^{[48]}$

\subsubsection{Spin Labeling of Noncanonical Amino Acid Residues}

To overcome the limitations of the cysteine labeling, spin labeling strategies utilizing noncanonical amino acids as labeling sites were developed. These labeling strategies are based on chemoselective reactions between the functionalized side-chain of the incorporated non-natural amino acid and the appropriate functionalized spin label. ${ }^{[43]}$ Thereby, these strategies are based on the principles of click reactions, which were defined as chemoselective, biocompatible, fast and highly efficient. ${ }^{[49]}$ Thus, the copper(I)-catalyzed azide-alkyne cycloaddition $(\mathrm{CuAAC})^{[50,51]}$ and the copper-free click reaction, such as the strain-promoted azide-alkyne cycloadditon (SPAAC) ${ }^{[52]}$, are frequently used for spin labeling and are discussed in the following sections.

\subsubsection{Spin Labeling by Click Reactions}

The CuAAC is a suitable reaction to label proteins with incorporated noncanonical amino acid residues bearing an azide or alkyne moiety, that readily reacts with alkyne or azide groups of spin labels (Figure 6). ${ }^{[53]}$ 


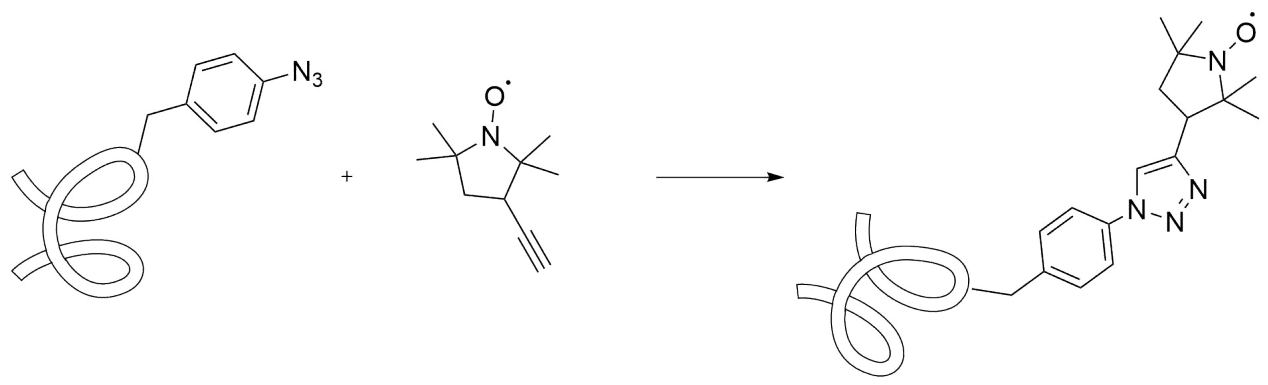

Figure 6: Schematic representation of a $\mathrm{CuAAC}$ reaction between an azide functionalized protein and an alkyne functionalized spin label.

Thereby, the reaction is performed under reducing conditions and is catalyzed by copper(I)ions. ${ }^{[50]}$ The noncanonical amino acids can be introduced to the protein either by SPPS or by genetic encoding, whereby these amino acids are structurally based on tyrosine or lysine.

For example, Kucher et al. achieved quantitative labeling of eGFP, that was modified by exchanging the tyrosine residue in position 39 by either an azide or alkyne functionalized amino acid residue. ${ }^{[54]}$ Therefore, the $\mathrm{CuAAC}$ was performed using $\mathrm{CuSO}_{4}$, benzoic acid and sodium ascorbate as reducing agent to generate the catalytic active copper(I)-ion species $i n$-situ, that promoted the reaction between the alkyne or azide modified protein and the azide or alkyne functionalized spin labels respectively. ${ }^{[54]}$

However, this labeling method has some drawbacks: The labeling reaction is performed under reducing conditions, which might result in the reduction of the nitroxide and therefore, in the loss of the paramagnetic property of the labeled protein. ${ }^{[39]}$ Additionally, considering applications in cells, the azide functionality is known to have a tendency to undergo reduction $^{[55]}$ under the given conditions, which makes the labeling less effective. Moreover, a major drawback of this labeling approach is the formation of a relatively flexible linker ${ }^{[56]}$ between the protein backbone and the spin label, which can cause inaccurate distance measurements by DEER.

To avoid the side-reactions caused by the reducing conditions, the copper-free click reaction SPAAC, that is performed under neutral conditions without the additon of reducing agents, was tested for spin labeling.

Therefore, Kálai et al. designed a cyclooctyne functionalized pyrroline nitroxide spin label, which was successfully conjugated to an azide modified T4 lysozym by SPAAC reaction (Figure 7 ). ${ }^{[57]}$ However, the performance of the relatively bulky spin label in EPR measurements needs to be study. 

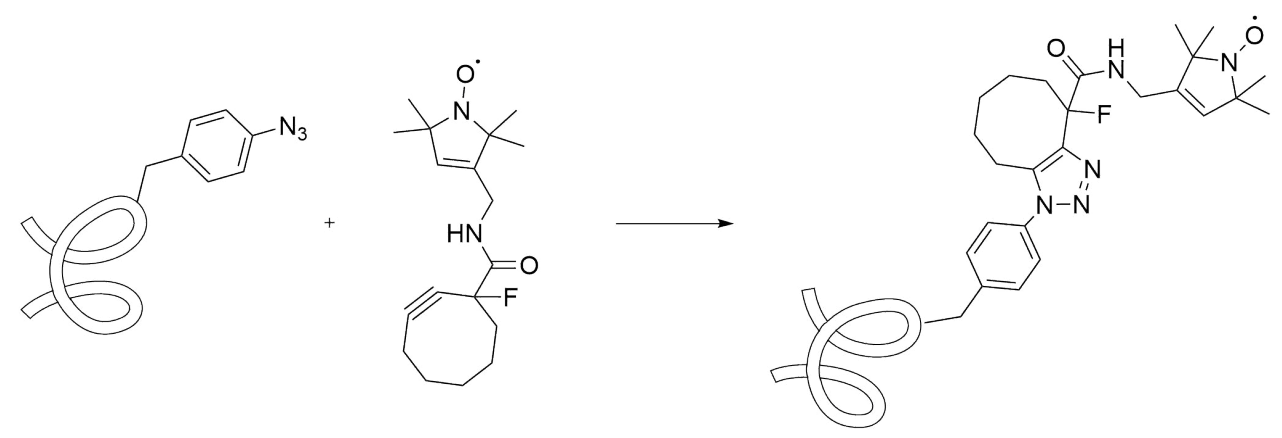

Figure 7: Schematic representation of a SPAAC reaction between an azide functionalized protein and a cyclooctyne functionalized spin label.

\subsubsection{Direct Incorporation of Spin Labeled Noncanonical Amino Acids}

The most SDSL techniques require the introduction of noncanonical amino acids into the protein and subsequent labeling, which leads to the formation of a relatively flexible linker between the protein backbone and the spin label. Due to the flexible bound nitroxide unit, accurate EPR measurements of the orientation of secondary structure motifs in proteins or the alignment of membrane incorporated proteins are not possible.

Therefore, another labeling approach was developed that is based on the direct incorporation of rigid spin labeled amino acids by SPPS. In the next two sections the direct incorporation of spin labels with enhanced rigidity by SPPS will be presented using the examples of the rigid 2,2,6,6-tetramethylpiperidine- $N$-oxyl-4-amino-4-carboxylic acid (TOAC) spin label and the semi-rigid 4-(3,3,5,5-tetra-methyl-2,6-dioxo-4-oxylpiperazin-1yl)-l-phenylglycine (TOPP) spin label (Figure 8). In the third section the direct incorporation of an spin labeled lysine derivative SLK-1 (Figure 8) by genetic encoding will be presented, which enables in vivo spin labeling.
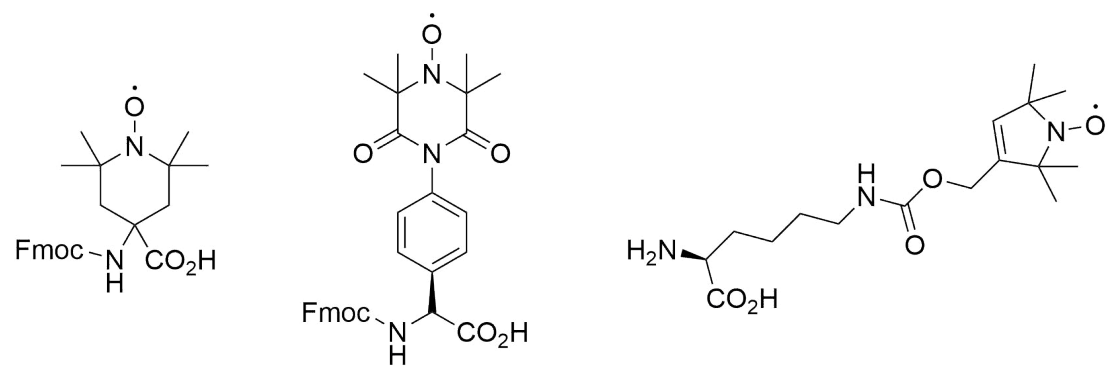

Figure 8: Amino acid derived spin labels TOAC (left) and TOPP (middle) for direct incorporation into peptides by SPPS and the SLK-1 spin label (right) for incorporation by genetic encoding.

\subsubsection{Direct Incorporation of the TOAC Spin Label}

The TOAC spin label was developed by Marchetto et al. as a spin labeled amino acid derivative for the incorporation into peptides by SPPS. ${ }^{[58]}$ Thereby, the amino group of the TOAC spin label was protected by Fmoc to test the solid-supported peptide synthesis ${ }^{[5,60]}$ according to the Fmoc/ $t \mathrm{Bu}$ strategy ${ }^{[61,62]}$, which allowed the introduction of the TOAC spin label at any position of the peptide. ${ }^{[58]}$ 
The TOAC spin label is derived from a $\alpha, \alpha$-disubstituted glycine and is a highly rigid spin label, which was confirmed by conformational analysis of TOAC residues within short peptides using X-ray diffraction. ${ }^{[63]}$ The high rigidity is caused by the direct incorporation of the spin label into the peptide backbone, whereby its motion is restricted to the conformational flipping of the six-membered piperidine ring. Furthermore, the X-ray studies revealed the capability of the TOAC residue to induce or stabilize $\beta$-bends and 310 -helical conformations in double labeled peptides. ${ }^{[63,64]}$

Thus, the TOAC spin label was a promising candidate for the studies of peptide conformation and alignment of membrane incorporated peptides by EPR spectroscopy, because of its high rigidity and ability to stabilize helical or bent structures. However, one drawback of this spin label is its low stability under the final cleavage conditions using high percentage of TFA in the cleavage cocktail, as usually applied in the Fmoc/ $t \mathrm{Bu}$ strategy for SPPS. ${ }^{[58]}$ In addition to that, it is known that the rigid TOAC residue can desturb the local conformation ${ }^{[64]}$ of the peptide, which results in an incorrect interpretation of EPR experiments addressing the analysis of peptide structure or structural dynamics.

\subsubsection{Direct Incorporation of the TOPP Spin Label}

To overcome the drawbacks of already described rigid spin labels, such as the TOAC spin label, Stoller et al. introduced the semi-rigid, chiral nitroxide amino acid 4-(3,3,5,5-tetramethyl-2,6-dioxo-4-oxylpiperazin-1-yl)-l-phenylglycine (TOPP), that was suitable for direct incorporation into peptides by SPPS following standard Fmoc/tBu-strategy. ${ }^{[3]}$ In contrast to the rigid TOAC spin label, the TOPP spin label did not affect the peptide conformation, which allowed its application in conformational studies of peptides. In addition to that, the design of the TOPP spin label was based on the alignment of the nitroxide $\mathrm{N}-\mathrm{O}$ with the $\mathrm{C}_{\alpha}-\mathrm{C}_{\beta}$ bond of the amino acid residue, which led to a defined location of the nitroxide unit, even in the case of rotation about the $\mathrm{C}_{\alpha}-\mathrm{C}_{\beta}$ or the $\mathrm{C}-\mathrm{N}$ bond. ${ }^{[3]}$ Thus, the local assignment of the nitroxide unit simplyfied the interpretation of data obtained from distance measurements.

Due to its high performance in distance measurements, the TOPP spin label was applied for distance measurements of the WALP24 model peptide using the PELDOR/DEER technique. ${ }^{[4]}$ Therefore, distances within the TOPP double labeled transmembrane peptide and the MTSSL double labeled analogue were measured in solution and in lipids to compare the perfomance of both spin labels. Thereby, the distance measurements of the TOPP spin labeled peptide were more accurate than of the MTSL labeled analogue. ${ }^{[4]}$ Moreover, the distances obtained for the TOPP spin labeled peptide did not change upon incorporation into lipids, while the distances of MTSL spin labeled peptide varied in different lipid environment. ${ }^{[4]}$ Hence, the TOPP spin label was considering to be a promising canditate for structural studies of membrane incorporated peptides.

These results led to the development of the $\beta$-analogue of the TOPP spin label, which was applied in studies of lipid incorporated transmembrane $\beta$-peptides, that adopt stable 
helical conformations and serve as structural mimetics. ${ }^{[65]}$ The results obtained from EPR measurement revealed the high potential of the $\beta$-TOPP spin label for the application in transmembrane $\beta$-peptides. ${ }^{[65]}$ The PELDOR studies of $\beta$-TOPP spin labeled WALP $\beta$-peptides, that were integrated into artificial membranes, allowed a detailed analysis of the WALP peptide and supported the assumption of a $33_{14}$-helix type conformation, that was in accordance with the results obtained by circular dichroism (CD) analysis. ${ }^{[65]}$

\subsubsection{Spin Labeling by Direct Encoding}

The direct encoding starategy of noncanonical nitroxide amino acids allows to label expressed proteins by translation, which in turn enables to perform nitroxide labeling in cells and therefore, give a rise to new application fields of EPR experiments.

In the study of Schmidt et al., the nitroxide amino acid SLK-1, which is derived from the amino acid lysine, was successfully introduced by co-translation using a tRNA ${ }^{\text {Pyl }} /$ PylRS- $^{\text {P }}$ SL1 pair to thioredoxin (TRX) in living E. coli cells. ${ }^{[66]}$ Subsequently, the genetically encoded and SLK-1 labeled TRX was compared in further studies to a MTSL labeled TRX mutant to evaluate the applicability of the SLK-1 spin label in distance measurements using the DEER technique. Since the results obtained for the SLK-1 labeled TRX were in a good agreement with the MTSL labeled TRX mutant, the SLK-1 spin is as-

sumed to be a very promising spin label for in-cell DEER experiments. ${ }^{[66]}$ However, the SLK-1 spin label exhibit a moderate stability during the protein expression and purification steps. This was indicated by an integrity degree of 50 to $70 \%$, which defines the content of intact paramagnetic SLK-1 in the protein. ${ }^{[66]}$ 


\section{Synthesis of a New, Rigid and Conformation Stabilizing Spin Label}

The main goal of this work was the design and synthesis of a new rigid spin label, that is able to induce or stabilize a $\beta$-turn conformation in peptides. By the current stage of knowledge, there are not many rigid spin labels, that can stabilize or induce the local conformation of peptides. One example is the 2,2,6,6-tetramethylpiperidine-N-oxyl-4amino-4-carboxylic acid (TOAC) spin label, which represents an $\alpha, \alpha$-disubstituted amino acid and therefore, is helicogenic. ${ }^{[67]}$

However, the TOAC spin label is prone to reduction under acidic conditions, which makes its use in SPPS challenging and its application limited. ${ }^{[68]}$ Therefore, there is a high demand for new rigid spin labels, that are stable under the SPPS conditions.

One challenge in the design of highly constrained spin labels is to avoid conformational disruption by their incorporation into the peptide backbone. This issue can be addressed by creating rigid spin labels that stabilize or induce a specific conformation.

Thus, in the course of this project the design of a new rigid spin label was based on structural frameworks, that mimic the conformation of a $\beta$-turn by geometrical preorganization.

There are several approaches to induce turn structures in peptides, such as macrocyclisation (A), N-methylation (B) or the usage of structural mimetics (D) or turn inducing amino acids (C) (Figure 9). ${ }^{[69]}$ However, considering the aim to use the new spin label for investigation of natural proteins, the application of turn inducing amino acids is the most advantageous approach, since they would closely resemble the native peptide residues.

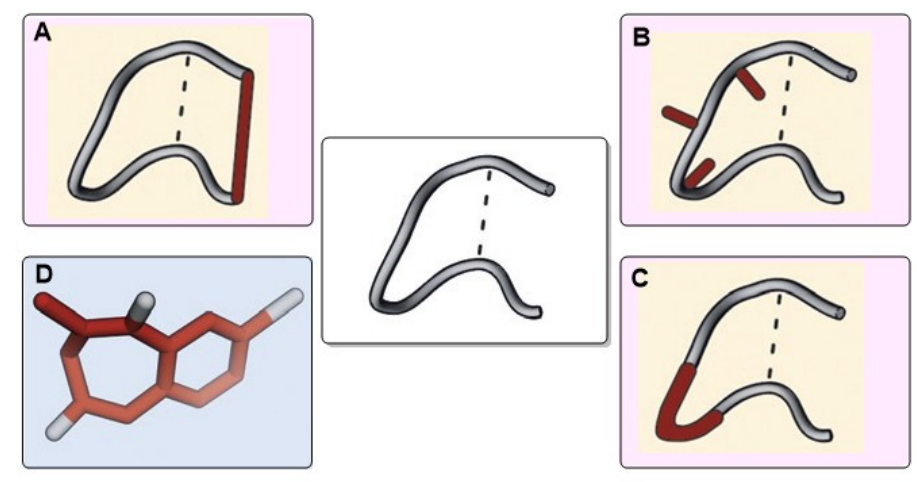

Figure 9: Schematic overview of turn stabilizing approaches. Modified according to Pelay-Gimeno et $a l^{[69]}$

For the design of the new $\beta$-turn stabilizing spin label, the structure of the $\beta$-turn stabilizing dipeptide developed by Sato et al. was adopted (Figure 10). ${ }^{[70]}$ Moreover, to ensure 
high stability of the nitroxide radical under SPPS conditions and high rigidity, a pyrroline based nitroxide radical moiety was annealed to the five-membered ring of the bicyclic skeleton.
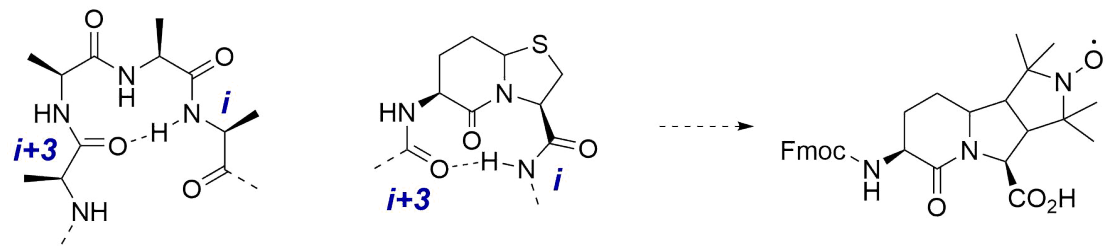

Figure 10: Design of the new $\beta$-turn stabilizing spin label derived from the constrained dipeptide by Sato et al. ${ }^{[70]} \mathrm{H}$-bond between the $\mathrm{i}^{\text {th }}$ and the $3+\mathrm{i}^{\text {th }}$ amino acid as crucial factor for $\beta$-turn formation (left). ${ }^{[69]}$ Structure of the new spin label derived from the azabicyclo amino acid ${ }^{[70]}$ by annealing the pyrroline spin label to the five-membered ring of the lead structure (right).

Thereby, the sulfur atom in the original dipeptide was exchanged by a carbon atom in order to facilitate the synthetic design of the new spin label. By this simplification the synthesis of the new $\beta$-turn inducing spin label could be adopted to the previously described synthesis of an azabicyclic amino acid by Hénichart et al. starting from a $\gamma$ lactam. ${ }^{[71]}$ Thus, the synthesis of the new spin label is modified according to the published procedure and is shown in figure 11. In the next sections of this chapter the development of a strategy towards the synthesis of the new designed spin label will be described and discussed.
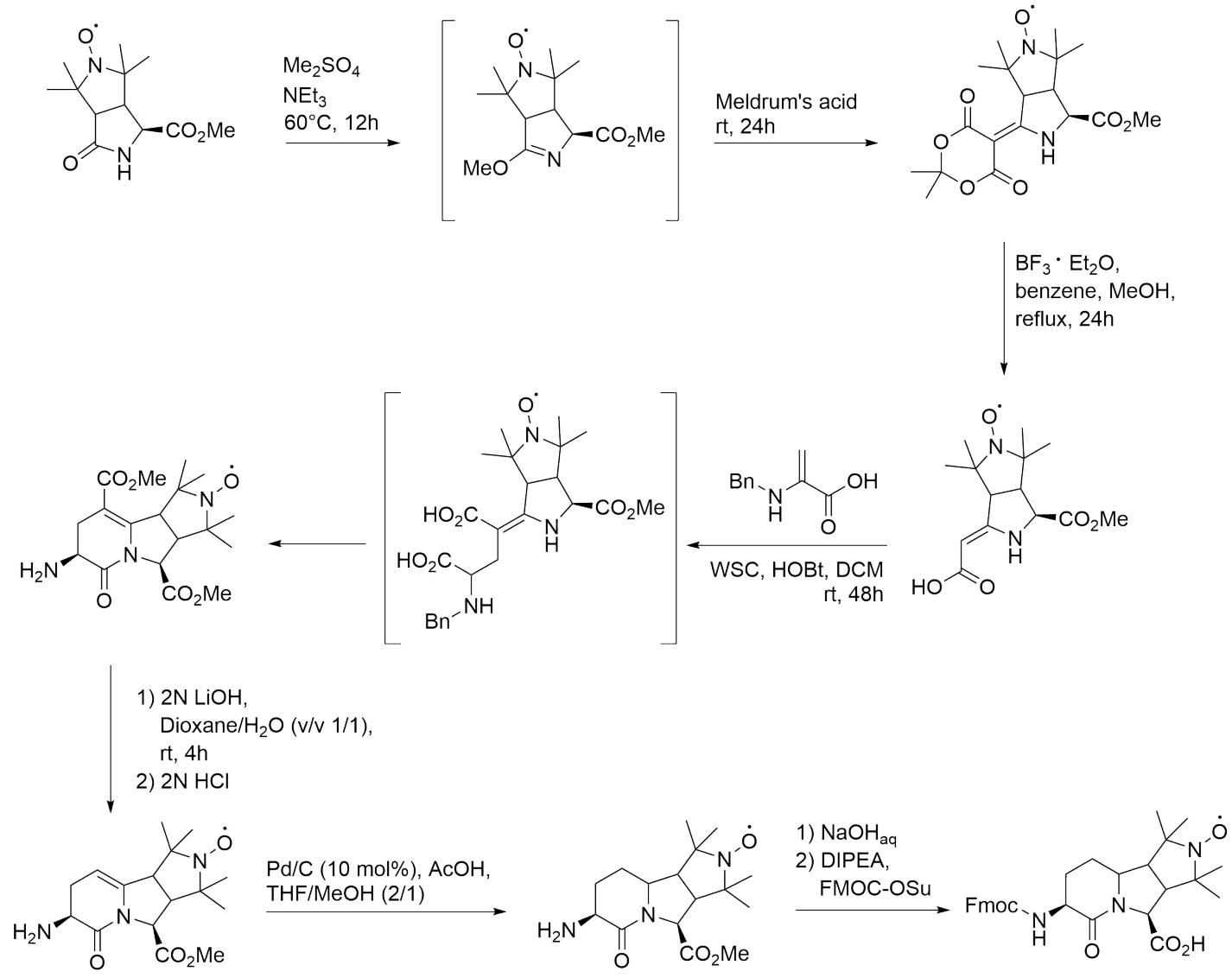

Figure 11: Attempted synthesis of the new $\beta$-turn stabilizing spin label based on the protocol for the synthesis of azabicyclo amino acid by Hénichart et al. ${ }^{[71]}$ 


\subsection{First Approach: Synthesis Starting from Carboxy Substituted $\gamma$-Lactam Spin Label}

In order to obtain the enantiomerically pure target spin label, it was aimed to adopt the original synthetic route of the azabicyclo amino acid by Hénichart et al. for the synthesis of the new spin label. ${ }^{[71]}$ Since the original synthesis started from a carboxy substituted $\gamma$ lactam, the preparation of the corresponding $\gamma$-lactam spin label was required. Therefore, a synthetic route that is illustrated in figure 12 was developed.

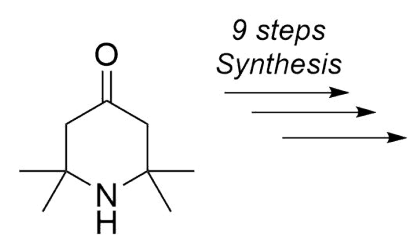<smiles>CC1(C)C(CBr)=C(CBr)C(C)(C)N1O</smiles>
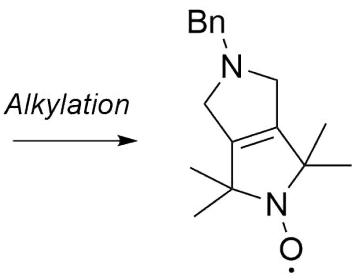

Oxidation<smiles>CC1(C)C2=C(C(=O)N1Cc1ccccc1)C(C)(C)N(O)C2C(=O)O</smiles>
Hydrolysis<smiles>CN1C(C)(C)C2=C(C(C#N)N(Cc3ccccc3)C2=O)C1(C)C</smiles>

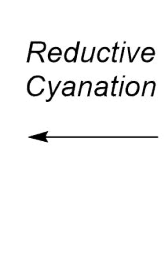<smiles>CC1(C)C2=C(C(=O)N1Br)C(C)(C)N(O)C2(C)C</smiles>

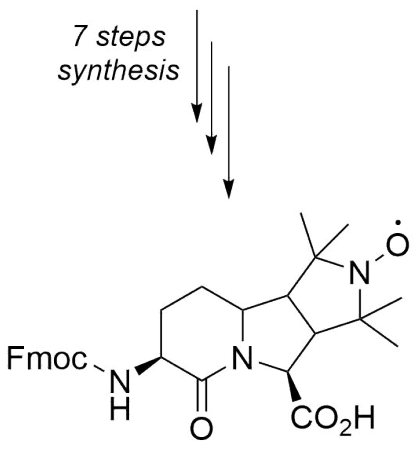

Figure 12: Schematic representation of the synthesis of the new $\beta$-turn stabilizing spin label.

The synthesis of the $\gamma$-lactam spin label started from an unsaturated dibromide spin label, that could be prepared in nine steps from the commercial available cyclic amine according to previously published procedures. ${ }^{[22,73,74]}$ In the next step the dibromide undergoes a double alkylation with benzyl amine and is subsequently oxidized in $\alpha$-position to yield an imide spin label. Then, the imide spin label is transferred into the nitrile spin label by reductive cyanation and is finally hydrolyzed to form the desired carboxy substituted $\gamma$-lactam.

In the following sections of this chapter the preparation of the dibromide spin label and the carboxy substituted $\gamma$-lactam spin label is described. 


\subsubsection{Synthesis of the Dibromide Spin Label}

The first step of this project was the synthesis of the dibromide spin label following previously described protocols. ${ }^{[72,73,74]}$

Starting from the commercial available piperidone $\mathbf{1}$, a dibromo ketone $\mathbf{2}$ was synthesized by bromination of the cyclic ketone in $\alpha$-position (Figure 13). ${ }^{[72]}$ Therefore, a solution of bromine in glacial acetic acid (HOAc) was added at $0{ }^{\circ} \mathrm{C}$ to the cyclic ketone $\mathbf{1}$ dissolved in glacial HOAc and the reaction was stirred at room temperature for $18 \mathrm{~h}$. The dibromo ketone $\mathbf{2}$ was isolated in a good yield and used in the next step without further purification.

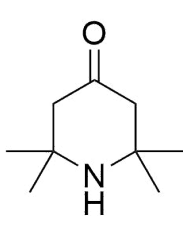

1

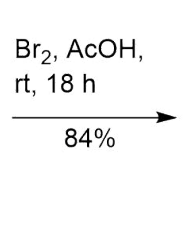

$\mathrm{Br} \odot$

2

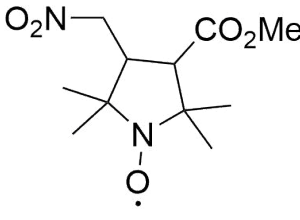

5
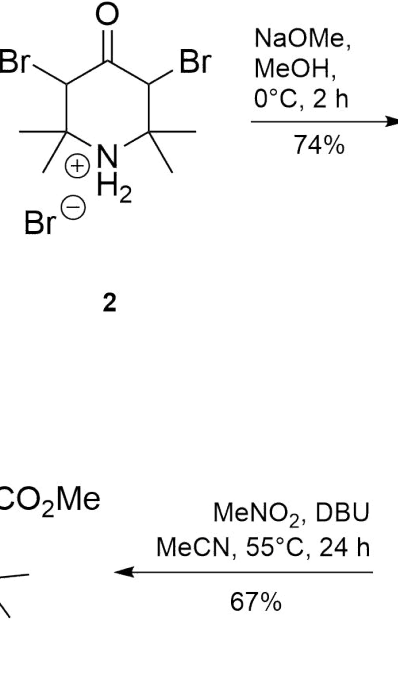

$\mathrm{MeO}_{2} \mathrm{C}$

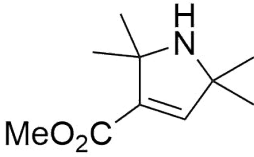

3

$$
\text { 86\% } \mid \begin{aligned}
& m-\mathrm{CPBA}, \\
& \mathrm{DCM}, \\
& 0^{\circ} \mathrm{C}, 2 \mathrm{~h}
\end{aligned}
$$

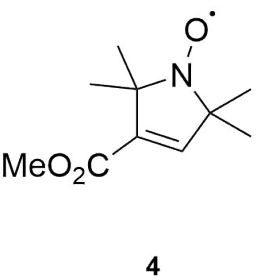

Figure 13: Synthesis of the Michael product 5 from commercially available 2,2,6,6-tetramethylpiperidin4-one 1.

In the next step the hydrobromine salt $\mathbf{2}$ was converted by a Favorskii type reaction into the vinyl methyl ester 3 using sodium methoxide (NaOMe) as nucleophilic agent. ${ }^{[72]}$ For the synthesis, the dibromide ketone 2 was dissolved at $0{ }^{\circ} \mathrm{C}$ in $\mathrm{MeOH}$ and treated with a methanolic $2 \mathrm{M} \mathrm{NaOMe}$ solution. The reaction was stirred at $0^{\circ} \mathrm{C}$ for $2 \mathrm{~h}$ and the crude product was purified by column chromatography to yield the unsaturated methyl ester $\mathbf{3}$ in a good yield.

Then, the unsaturated methyl ester 3 was oxidized by meta-chloroperbenzoic acid $(m$ $\mathrm{CPBA})$ in dichlormethane (DCM) at $0{ }^{\circ} \mathrm{C}$ for $2 \mathrm{~h}$ to yield the paramagnetic methyl ester spin label 4. ${ }^{[72]}$ The nitroxyl spin label 4 was purified by column chromatography and obtained in a good yield. The synthesis was continued with a Michael addition between the vinyl methyl ester 4 and nitromethane $\left(\mathrm{MeNO}_{2}\right) .{ }^{[74]}$ Therefore, $\mathrm{MeNO}_{2}$ was added to a solution of the vinyl methyl ester $\mathbf{4}$ and the base diazabicycloundecene (DBU) in acetonitrile (MeCN) and the reaction was stirred for $24 \mathrm{~h}$ at $50^{\circ} \mathrm{C}$. The desired Michael product $\mathbf{5}$ was obtained in a good yield by column chromatography.

With the Michael product $\mathbf{5}$ in hands, the synthesis of the dibromide spin label $\mathbf{1 0}$ was 
started (Figure 14). ${ }^{[73]}$ Starting by a Nef reaction, the nitroalkane moiety of the Michael product 5 was converted into an aldehyde $\mathbf{6}$ by hydrolysis of the nitronate salt intermediate under oxidative conditions. First, the Michael product 5 was dissolved in $\mathrm{MeOH}$ and reacted upon addition of $\mathrm{KOH}$ at $0{ }^{\circ} \mathrm{C}$ to the nitronate salt intermediate. After stirring for $1.5 \mathrm{~h}$ a solution of potassium permanganate $\left(\mathrm{KMnO}_{4}\right)$ and manganese sulfate $\left(\mathrm{MgSO}_{4}\right)$ in water was added and the reaction was stirred at $0{ }^{\circ} \mathrm{C}$ for additional $2 \mathrm{~h}$. The crude aldehyde 6 was purified by column chromatography and isolated in a moderate yield.

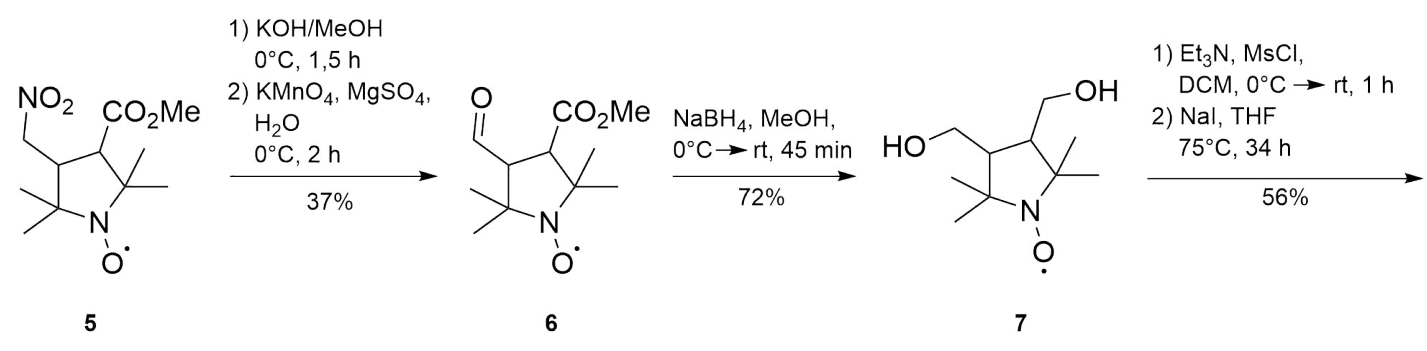

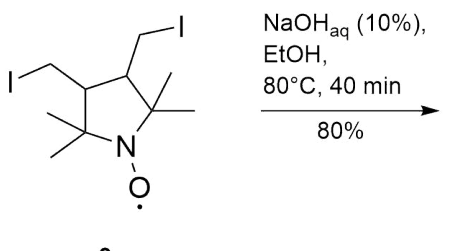

8

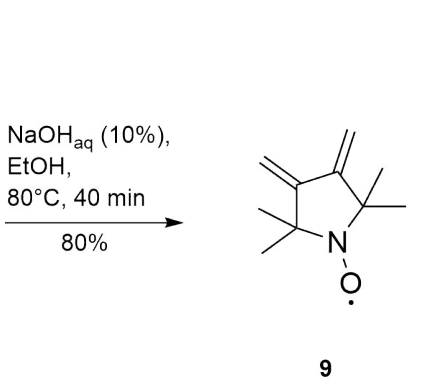

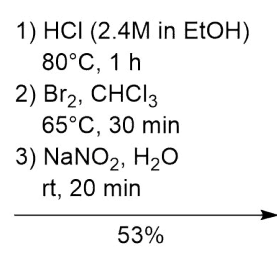

9

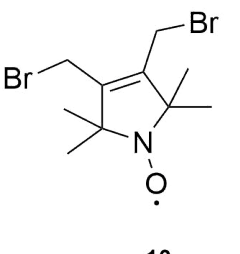

10

Figure 14: Synthesis of the dibromide spin label $\mathbf{1 0}$ from the Michael product $\mathbf{5}$.

In the next steps, the aldehyde and the methyl ester group of the spin label 6 were reduced to primary alcohol groups, that were converted into iodide alkanes by nucleophilic substitution via the corresponding methanesulfonates intermediates.

To obtain the reduced spin label $7, \mathrm{NaBH}_{4}$ was added to a solution of the spin label 6 in $\mathrm{MeOH}$ at $0{ }^{\circ} \mathrm{C}$ and the reaction was stirred at room temperature for $45 \mathrm{~min}$. After purification by column chromatography the dihydroxyl spin label $\mathbf{7}$ was isolated in a good yield.

Afterwards, the dihydroxyl spin label 7 was converted into the diiodide spin label 8 in a two-step process. Therefore, the hydroxyl groups of spin label 7 were converted to good leaving groups by adding methanesulfonyl chloride $(\mathrm{MsCl})$ to a solution of the dihydroxyl spin label 7 and the base triethyl amine $\left(\mathrm{Et}_{3} \mathrm{~N}\right)$ in $\mathrm{DCM}$ at $0{ }^{\circ} \mathrm{C}$. The crude dimethanesulfonate was formed after $1 \mathrm{~h}$ at room temperature and was used in the next step without further purification. Next, the crude dimethanesulfonate and sodium iodide (NaI) were dissolved in $\mathrm{MeCN}$ and the reaction was stirred at $75^{\circ} \mathrm{C}$ for $34 \mathrm{~h}$. After the purification by column chromatography the diiodide 8 was obtained in a good yield.

In order to synthesize the unsaturated dibromide spin label $\mathbf{1 0}$ the diiodide spin label $\mathbf{8}$ was applied in a base mediated elimination to yield the diene spin label $\mathbf{9}$. The latter was 
converted into the unsaturated dibromide $\mathbf{1 0}$ by electrophilic addition in three steps.

For the elimination reaction the diiodide spin label $\mathbf{8}$ was dissolved in ethanol (EtOH) and stirred at $80^{\circ} \mathrm{C}$ upon the addition of $10 \%$ aqueous sodium hydroxide $(\mathrm{NaOH})$ solution for $40 \mathrm{~min}$. After purification by column chromatography the diene spin label $\mathbf{9}$ was isolated in a good yield.

Before performing the electrophilic addition, the nitroxide radical unit was converted to its hydrochloric salt in order to prevent nitroxide radical mediated side-reactions with the bromine. Therefore, the diene spin label 9 was heated for $1 \mathrm{~h}$ at $80^{\circ} \mathrm{C}$ in a $2.4 \mathrm{M}$ solution of hydrogen chloride in methanol to yield the hydrochloric salt after evaporation of the solvent.

The hydrochloric salt was dissolved in chloroform and stirred upon the addition of bromine for 30 min at $65^{\circ} \mathrm{C}$ to yield the crude dibromide salt.

To recover the nitroxide radical, the hydrochloric salt was oxidized by sodium nitrite $\left(\mathrm{NaNO}_{2}\right)$ in water for 20 min. Finally, purification by column chromatography yield the desired spin label 10.

\subsubsection{Synthesis Starting from Carboxy Substituted $\gamma$-Lactam Spin Label}

After the successful preparation of the unsaturated dibromide spin label 10, the imide spin label $\mathbf{1 2}$ was prepared from a cyclic amine $\mathbf{1 1}$ by iodine mediated oxidation (Figure 15).



Figure 15: Synthesis of the imide spin label 12 from the dibromide spin label $\mathbf{1 0 .}$

Therefore, nucleophilic substitution of the unsaturated dibromide spin label $\mathbf{1 0}$ with benzyl amine $\left(\mathrm{BnNH}_{2}\right)$ and $\mathrm{K}_{2} \mathrm{CO}_{3}$ as a base in $\mathrm{MeCN}$ was performed at $80^{\circ} \mathrm{C}$ for $20 \mathrm{~h}$. After purification by column chromatography, the cyclic amine $\mathbf{1 1}$ was obtained in a moderate yield.

For the oxidation to the imide 12, the secondary amine $\mathbf{1 1}$ was stirred with iodine and $\mathrm{NaHCO}_{3}$ in a mixture of $\mathrm{THF} / \mathrm{H}_{2} \mathrm{O}$ at room temperature for $14 \mathrm{~h}$. The imide $\mathbf{1 2}$ was obtained in a moderate yield after purification by column chromatography.

Finally, the reductive cyanation ${ }^{[5]}$ of the imide spin label $\mathbf{1 2}$, followed by acidic hydrolysis, should result in the formation of the carboxyl substituted $\gamma$-lactam spin label 14 (Figure 16). Therefore, a $1 \mathrm{M}$ solution of DIBAL-H in hexane was added to the imide 


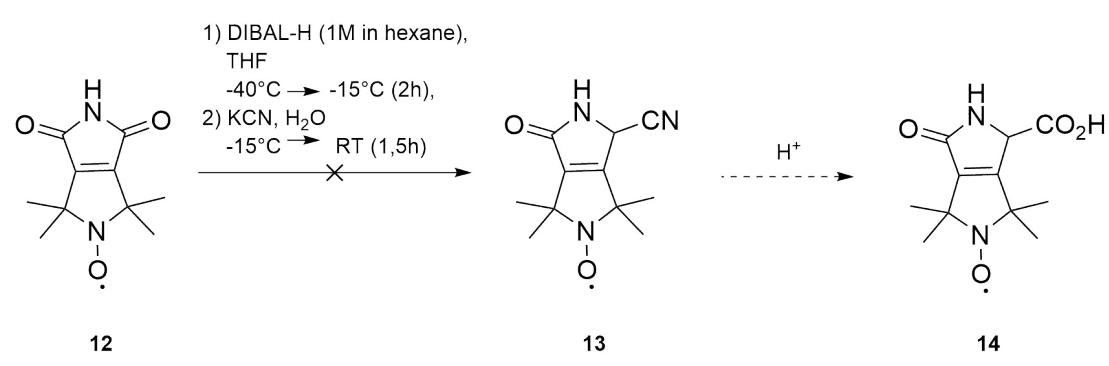

Figure 16: Attempted reductive cyanation of the imide $\mathbf{1 2}$ and subsequent hydrolysis to form the carboxy $\gamma$-lactam spin label 14.

spin label 12 in $\mathrm{THF}$ at $-40^{\circ} \mathrm{C}$. The reaction mixture was allowed to warm up to $-15^{\circ} \mathrm{C}$ and was stirred at this temperature for $2 \mathrm{~h}$. Then, potassium cyanide (KCN) was added to the crude intermediate at $-15{ }^{\circ} \mathrm{C}$ and the reaction was continued for $1.5 \mathrm{~h}$.

However, the reductive cyanation reaction failed and no formation of the desired product 13 could be detected by ESI-MS analysis of the crude reaction mixture. A possibile reason for the failure could be the decomposition of the spin label 12 under the relatively harsh reductive conditions, because the analysis of the crude reaction mixture by TLC revealed the formation of multiple side-products.

Since the reductive cyanation is crucial for the synthetic route and the reaction requires the usage of DIBAL-H as reducing agent, which was probably responsable for the decomposition of the imide spin label 12, possible approaches were considered to mask the nitroxide unit.

Therefore, the usage of a nitroxide protecting group was taken into account. In general, two different classes of protection groups for nitroxides were considered: the methoxy protection group and the 2-nitrobenzyl derived group. However, these protecting groups are not compatible with the spin label at this stage.

Protection of the nitroxide by the methoxy would require oxidative removal of these groups, using hydrogen peroxide. Thus, performing the nitroxide deprotection in the next step of the reaction sequence could lead to side reactions with the double bond or result in cleavage of the lactam bond. On the other hand, utilizing a 2-nitrobenzyl group could lead to reduction of the carbonyl groups, because the protecting group is installed in a two-step process, whereby the nitroxide needs to be reduced hydrogenolytically to the corresponding hydroxylamine in the first step. Thus, at this stage of the synthesis, there was no possibility to modify the synthetic route in order to continue the synthesis from the imide $\mathbf{1 2}$ and a new synthesis approach for the desired $\gamma$-lactam was required.

Generally, there is one other possible route for the synthesis of the desired $\gamma$-lactam derivative, which seems to be simpler in terms of synthetical effort at first glance. This retrosynthetical approach is presented in figure 17, whereby the retrosynthetical cut is set on the amide bond, so that the desired $\gamma$-lactam is synthesized by a condensation reaction between a carboxyl and the amine group of an amino acid moiety. 


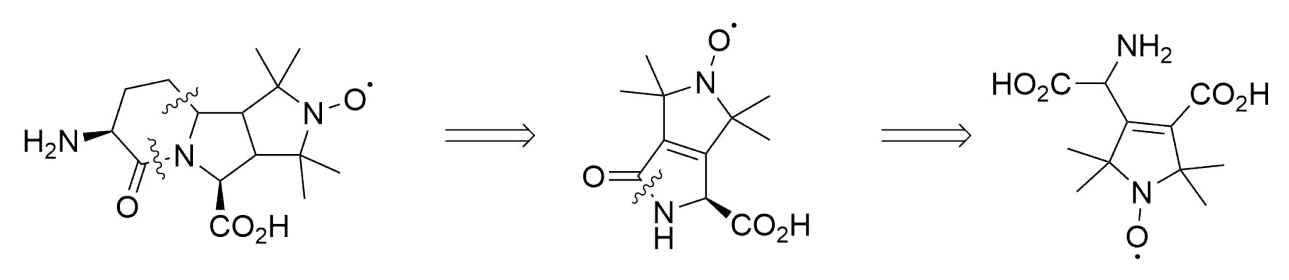

Figure 17: Retrosynthetic design of the $\beta$-turn stabilizing spin label. The key step of the synthesis is the formation of an carboxy $\gamma$-lactam spin label via a condensation reaction between the carboxyl and the amine group of the pyrroline substituents.

However, this approach has a big disadvantage, because it requires the installation of an amino acid substituent and an carboxyl substituent that are either oriented in one direction or are in one plane with the double bond of the pyrroline nitroxide. Thereby, the formation of an appropriate enantiomer in case of a pyrrolidine nitroxide, or the cisisomer in case of a pyrroline nitroxide, is crucial for the formation of the annealed lactam, because the ring substituents need to come in close proximity to undergo the condensation reaction.

Considering the synthesis of the cis-isomer, one main challenge needs to be considered: the introduction of the relatively complex and bulky amino acid residue directly on the double bond in cis-position to the carboxyl substituent. One the one hand, it is very challenging to install an amino acid moiety in few steps and on the other hand, the strerical demand of the amino acid residue might be too big to be installed on the relatively bulky pyrroline nitroxide with four methyl substituents in $\alpha$-position to the nitroxide. If the installation fails due to sterical reasons, a step-wise formation of the amino acid substituent could also fail.

Apart from the sterical demand of the amino acid substituent, this intermediate shows another synthetical challenge, which is difficult to accomplish: the installation of the substituents in cis-position. This requirement is not easy to realize, due to the size of the substituents, which would rather force the substituents in trans-position.

Therefore, the overall synthesis route might become even more complex than the previous one, starting from a dibromine, because an appropriate synthetic strategy for the preparation of the cis-isomer is highly restricted by the sterical demand of the bulky substituents. Taking all these considerations into account, synthesis of the azabiciclo amino acid derived spin label is dependent on the sterical compatibility in each step of the synthesis.

Therefore, a completely new synthetic approach was developed that was not based on the preparation of a substituted $\gamma$-lactam and is presented in the next section of this chapter.

\subsection{Second Approach: Synthesis via Anionic Cyclisation Reaction}

The previous approach to synthesize the $\beta$-turn inducing spin label via a carboxy substituted $\gamma$-lactam spin label $\mathbf{1 4}$ was not continued due to the unsuccessful preparation of 
the latter. In addition to that, the overall synthesis of the target spin label would require 22 reaction steps, which makes the preparation very elaborate and time consuming.

Therefore, a new approach for the synthesis of the $\beta$-turn inducing spin label was developed, that is shown in figure 18.

Thereby, the key step of the new synthesis route is an intramolecular anionic cyclisation between a vinyl bromide and the carbonyl of an imide. The developed approach required the synthesis of a suitable vinyl bromide spin label, which was prepared using previously published procedures. ${ }^{[76,15]}$
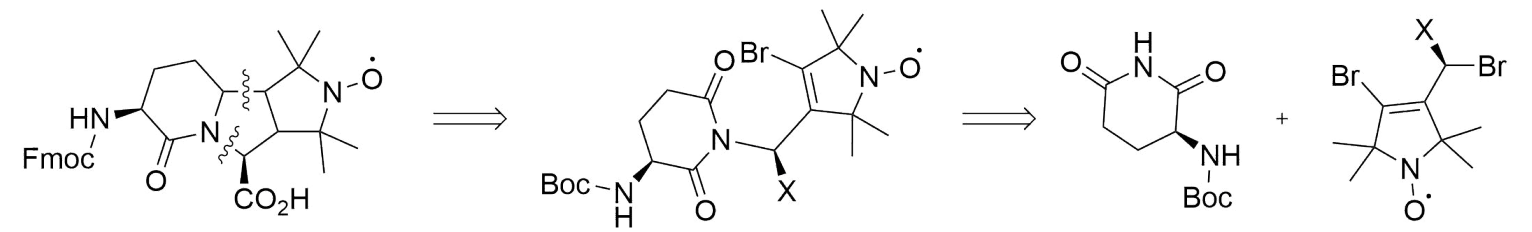

Figure 18: Retrosynthetic design of the $\beta$-turn stabilizing spin label. The key step of the synthesis is an intramolecular anionic cyclisation of an imide substituted spin label, that is synthesized from a vinyl bromide spin label. The substituent $\mathrm{x}$ represents a suitable carboxyl precursor.

First, the anionic cyclisation reaction was tested using a less complex imide spin label, that could be prepared in a few steps. In case of a successfull cyclisation reaction, the synthetic route would be redesigned in terms of a suitable substituted spin label intermediate for the synthesis of the $\beta$-turn inducing spin label.

\subsubsection{Testing the Anionic Cyclisation Reaction for the Synthesis of the Azabicyclo Spin Label}

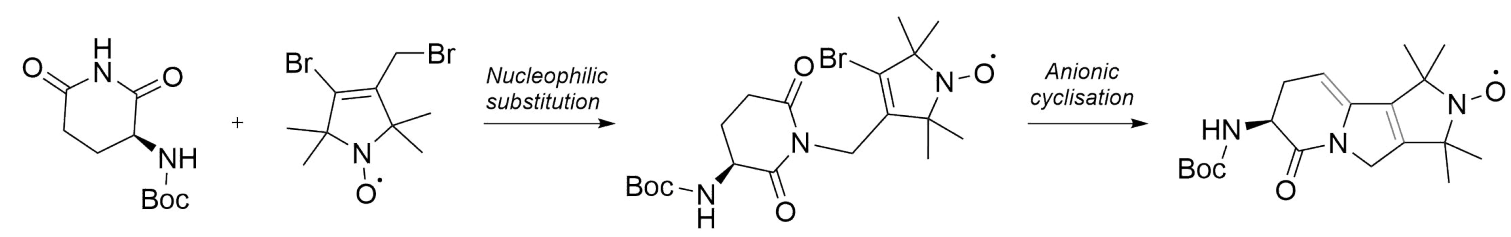

Figure 19: Schematic representation of testing the anionic cyclisation reaction for the synthesis of the $\beta$ turn inducing spin label. The reactant for the anionic cyclisation is prepared from previously synthesized vinyl bromide and imide by nucleophilic substitution.

To test the new approach for the synthesis of the $\beta$-turn inducing spin label precursor (Figure 19), a bromide spin label 18 was prepared from the commercially available cyclic ketone 15 (Figure 20), which was applied in a Favorskii reaction using sodium hypobromite $(\mathrm{NaOBr})$ to form the ring contracted spin label 16. ${ }^{[76]}$

Therefore, the cyclic ketone $\mathbf{1 5}$ was dissolved in a mixture of 1,4-dioxane/water and added at $-5{ }^{\circ} \mathrm{C}$ to a solution of in-situ generated $\mathrm{NaOBr}$ in water. The reaction was stirred at $-5^{\circ} \mathrm{C}$ for $30 \mathrm{~min}$ and the formed vinyl bromide 16 was isolated by filtration. Due to formation of several side-products, such as a vinylic dibromide and saturated compounds, ${ }^{[76]}$ the yield of the spin label $\mathbf{1 6}$ was low.

In the next step, the carboxyl group was converted into a primary alcohol in a two-step 
synthesis to reduce the carboxylic group without affecting the double bond of the spin label 17. Thereby, the carboxyl group was converted by ethyl chloroformate $\left(\mathrm{ClCO}_{2} \mathrm{Et}\right)$ into the corresponding carboxylic anhydride intermediate, that was reduced by sodium borohydride $\left(\mathrm{NaBH}_{4}\right)$ to the primary alcohol $\mathbf{1 7 .}{ }^{[77]}$

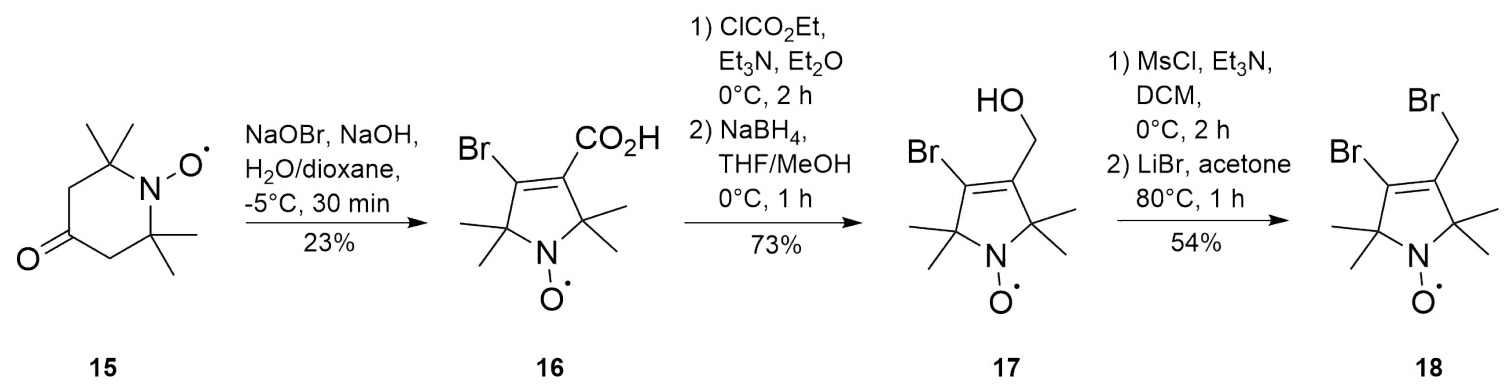

Figure 20: Synthesis of the vinyl bromide spin label 18 starting from the commercially available 4-oxoTEMPO 15.

For the synthesis of the carboxylic anhydride intermediate, the carboxylic acid $\mathbf{1 6}$ was dissolved in diethyl ether $\left(\mathrm{Et}_{2} \mathrm{O}\right)$ and stirred upon the addition of ethyl chloroformate and the base $\mathrm{Et}_{3} \mathrm{~N}$ at $0{ }^{\circ} \mathrm{C}$ for $2 \mathrm{~h}$. Afterwards, the crude intermediate was used immediately without further purification in the next step. Therefore, the crude anhydride intermediate and $\mathrm{NaBH}_{4}$ were reacted in $\mathrm{THF} / \mathrm{MeOH}$ for $1 \mathrm{~h}$ at $0{ }^{\circ} \mathrm{C}$. The primary alcohol 17 was isolated by column chromatography in a good yield.

Then, the bromide $\mathbf{1 8}$ was formed by nucleophilic substitution of a methanesulfonate intermediate, that was previously prepared from the primary alcohol 17, with lithium bromide ( $\mathrm{LiBr}) .{ }^{[77]}$ In the first step, the methanesulfonate intermediate was formed by the reaction of the alcohol $\mathbf{1 7}$ and $\mathrm{MsCl}$ upon addition of the base $\mathrm{Et}_{3} \mathrm{~N}$ in dichlormethane $(\mathrm{DCM})$ at $0{ }^{\circ} \mathrm{C}$ for $2 \mathrm{~h}$. Then, the crude methansulfonate intermediate and $\mathrm{LiBr}$ were stirred in acetone at $80^{\circ} \mathrm{C}$ for $1 \mathrm{~h}$ to form the bromide spin label 18 , that was isolated by column chromatography in a moderate yield.

To perform the intramolecular anionic cyclisation, an functionalized cyclic imide $\mathbf{2 0}$ was attached to the spin label $\mathbf{1 8}$ by nucleophilic substitution. Therefore, the imide $\mathbf{2 0}$ was prepared following a previously described procedure (Figure 21). ${ }^{[78]}$

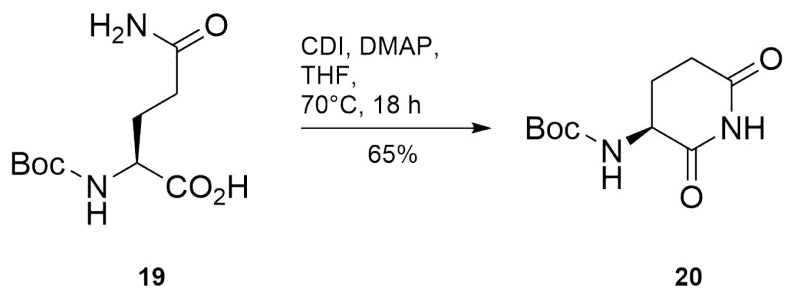

Figure 21: Preparation of the cyclic imide 20 from commercially available Boc-L-glutamine 19.

The Boc-L-glutamine (Boc-Gln-OH) 19 was activated by 1,1'-carbonyldiimidazole (CDI) upon the addition of a catalytic amount of 4-(dimethylamino)pyridine (DMAP) in THF and was subsequently heated at $70^{\circ} \mathrm{C}$ for $18 \mathrm{~h}$ to form the cyclic imide $\mathbf{2 0}$. The cyclic imide 20 was purified using column chromatography and could be obtained in a good 
yield.

Then, the synthesis of the $\beta$-turn inducing spin label was continued by a nucleophilic substitution of the bromide spin label $\mathbf{1 8}$ to prepare the imide functionalized spin label $\mathbf{2 1}$ (Figure 22). Therefore, the bromide spin label 18, the imide $\mathbf{2 0}$ and the base potassium carbonate $\left(\mathrm{K}_{2} \mathrm{CO}_{3}\right)$ were reacted in DMF at $90{ }^{\circ} \mathrm{C}$ for $2 \mathrm{~h}$. After aqueous work-up, the formed imide $\mathbf{2 1}$ was used in the next step without further purification, because attempts to find a suitable condition for chromatographical separation of the imide $\mathbf{2} \mathbf{1}$ from a byproduct with a similar polarity failed. Thus, the crude imide $\mathbf{2 1}$ was applied in the anionic cyclisation reaction to form the basic framework of the desired $\beta$-turn inducing spin label.

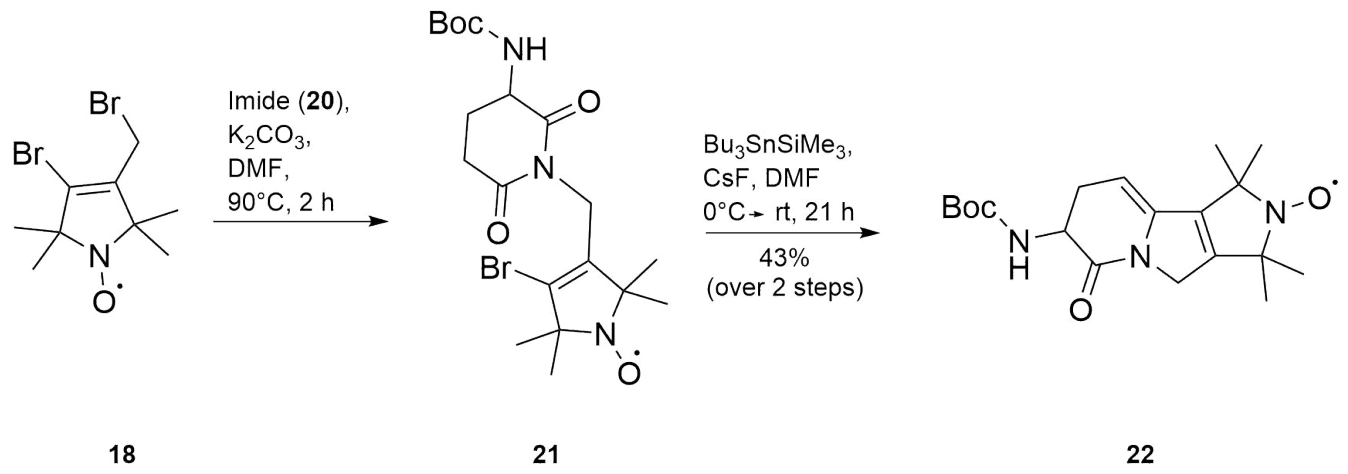

Figure 22: Synthesis of the azabicyclo spin label precursor 22 to test the anionic cyclisation reaction.

The anionic cyclisation is an intramolecular reaction, that leads to the formation of cyclic products from carbonyls bearing either aryl or vinyl halides. During the reaction, a stannyl anion is produced in-situ from $\mathrm{Bu}_{3} \mathrm{SnSiMe}_{3}$, which reacts with the aryl or vinyl halide to form the corresponding aryl or vinyl anion. The generated aryl or vinyl anion readily attacks the carbonyl group to form a cyclic product. In some cases, the cyclic product can subsequently eliminate water to yield the unsaturated cyclic product. ${ }^{[0,81]}$

To test the anionic cyclisation for the formation of the framework of the $\beta$-turn inducing spin label 22 , the crude imide spin label 21 was added at $0{ }^{\circ} \mathrm{C}$ to a solution of $\mathrm{Bu}_{3} \mathrm{SnSiMe}_{3}$ and $\mathrm{CsF}$ in DMF. The reaction was allowed to stirr a room temperature for $21 \mathrm{~h}$ and the cyclic product 22 could be isolated by chromatographic purification in a moderate yield over two steps from the bromide spin label 18. Due to the successful construction of the spin label framework 22, the reaction should be performed with a suitable substituted imide to incorporate the missing carboxyl functionality to the spin label $\mathbf{2 2}$. 


\subsubsection{Synthesis of the Azabicyclo Spin Label by the Anionic Cyclisation Using Different Reactants}

In order to introduce a carboxyl group, different $\mathrm{C}-\mathrm{C}$ bond formation strategies for the preparation of a carboxy functionalized reactant for the anionic cyclisation were considered and are summerized in figure 23.

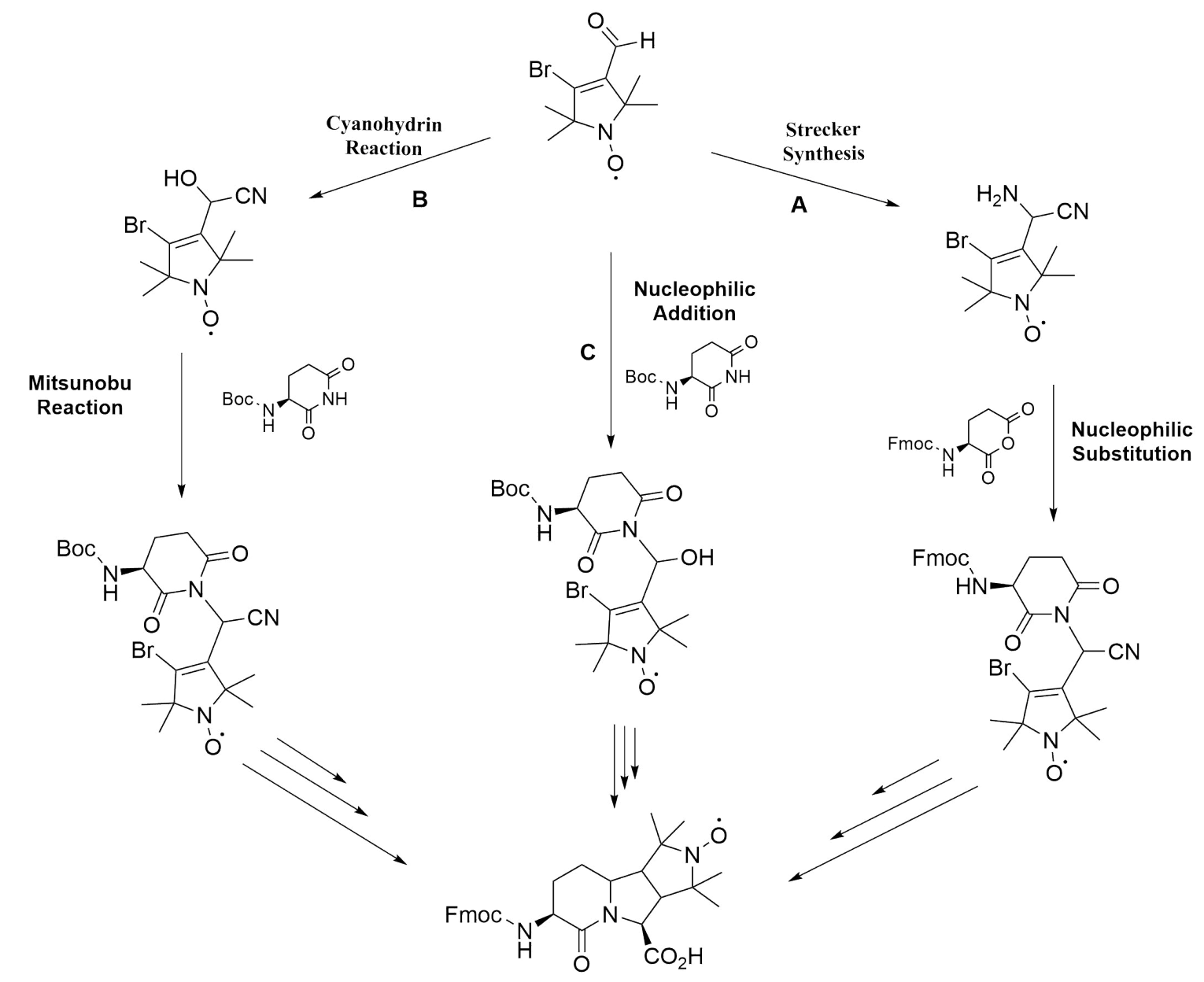

Figure 23: Attempted synthetic strategies for C-C bond formation. Routes A and B aim to introduce a nitrile group as carboxyl acid precursor via Strecker or a cyanohydrin reaction. Route $\mathbf{C}$ is based on the direct nucleophilic addition of the cyclic imide to the carbonyl $\mathrm{C}$ to form a secondary alcohol.

Thereby, the synthesis of the functionalized reactants started from the aldehyde 23, whose synthesis was previoulsy described. ${ }^{[81]}$

The aldyhede $\mathbf{2 3}$ was synthesized from the previously described primary alcohol $\mathbf{1 7}$ by oxidation (Figure 24). ${ }^{[82]}$ Therefore, the primary alcohol 17 was stirred with manganese dioxide $\left(\mathrm{MnO}_{2}\right)$ in chloroform for $4 \mathrm{~h}$ at $70^{\circ} \mathrm{C}$. The aldehyde spin label 17 was purified by column chromatography and isolated in a good yield. 


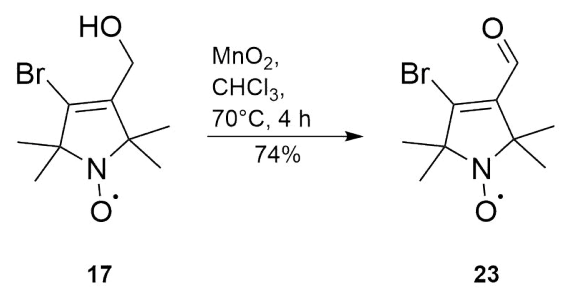

Figure 24: Synthesis of the aldehyde $\mathbf{2 3}$ from the previously described alcohol $\mathbf{1 7}$ by oxidation.

It has to be noted, that the reactions described in the following sections of this chapter are not enantioselective and would lead to formation of different diastereomers of the target spin label. This would require the separation of these diastereomers by reverse-phase high performance liquid chromatography (RP-HPLC). However, the overall aim of this project was to establish a synthesis of the $\beta$-turn inducing spin label for incorporation into model peptides, in order to evaluate its ability to induce or stabilize turn conformations. Thus, no optimization efforts were made to achieve enantiometric pure compounds.

The synthesis of the $\beta$-turn inducing spin label was tested using an approach, that was based on the introduction of a nitrile group as carboxyl group precursor by a Strecker reaction of the aldehyde spin label 23 (Figure 23, A). Using this transformation, a new synthesis route for the azobicyclo spin label was developed (Figure 25). Thereby, the Strecker product $\mathbf{2 4}$ is applied in a nucleophilic substitution with a cyclic anhydride $\mathbf{2 5}$ to form the nitrile substituted imide $\mathbf{2 6}$, which is capable to undergo the anionic cyclisation to yield cyclic framework of the target spin label. Finally, the desired $\beta$-turn inducing spin label is obtained by acidic hydrolysis of the nitrile group.

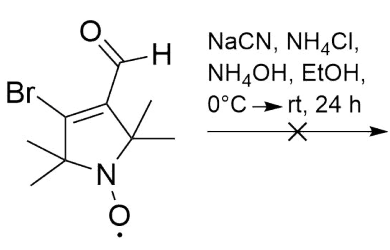

23

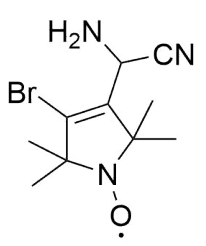

24

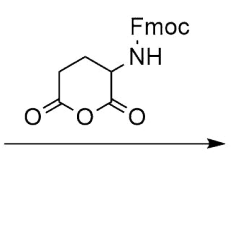

25

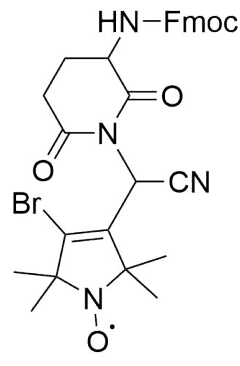

26

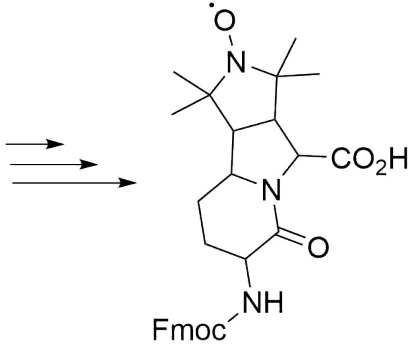

27

Figure 25: Synthesis of the target spin label from an amino nitrile $\mathbf{2 4}$ prepared by Strecker synthesis.

Following approach $\mathbf{A}$, the aldehyde $\mathbf{2 3}$ was treated with sodium cyanide $(\mathrm{NaCN})$ and ammonium chloride $\left(\mathrm{NH}_{4} \mathrm{Cl}\right)$ in ethanol upon addition of an aqueous ammonia solution for $24 \mathrm{~h}$ at room temperature to form the amino nitrile $\mathbf{2 4}$. However, the reaction did not succeed and the formation of an imine was observed by ESI-MS analysis. Several attempts to optimize the reaction conditions by performing the reaction at low temperature $\left(0{ }^{\circ} \mathrm{C}\right)$ or by reducing the reaction time stepwise to $2 \mathrm{~h}$ also failed and led to the formation of an imine. It is assumed, that the formed Strecker product $\mathbf{2 4}$ decomposes under the applied reaction conditions upon elimination of hydrogen cyanide to form the observed imine. Thus, the synthesis approach via the Strecker reaction was not continued, since 
the efforts to optimize the reaction failed.

Since the functionalization of the spin label by a nitrile group was highly preferable due to its simple transformation into the carboxylic acid by hydrolysis, a synthesis approach using the cyanohydrin reaction was used, which is shown in figure 26. Thereby, the imide $\mathbf{2 9}$ is formed in a Mitsunobu reaction between the cyanohydrine $\mathbf{2 8}$ and the cyclic imide 20. Then, the imide $\mathbf{2 9}$ undergoes the anionic cyclisation to yield the desired spin label after hydrolysis of the nitrile group.

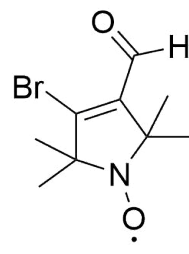

23

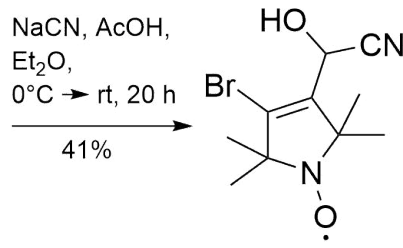

28

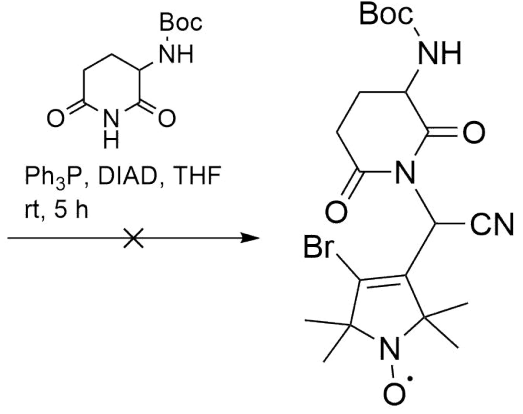

29

Figure 26: Synthesis of the target spin label from a cyanohydrin $\mathbf{2 8}$ prepared from the aldehyde $\mathbf{2 3}$.

The synthesis started with the formation of the cyanohydrin 28. Therefore, NaCN and $\mathrm{AcOH}$ were added to a solution of the aldehyde $\mathbf{2 3}$ in diethylether $\left(\mathrm{Et}_{2} \mathrm{O}\right)$ and the reaction was stirred at room temperature for $20 \mathrm{~h}$. Analysis of the crude reaction by thin layer chromatography (TLC) revealed the quantitative formation of the desired cyanohydrin $\mathbf{2 8}$, which was also supported by ESI-MS analysis of the crude reaction. However, attempts to purify the product by column chromatography failed, since the isolated fraction was identified as the starting material 23. Thus, the formation of the cyanohydrin might be reversible and the formed product 28 easily undergoes elimination of HCN to convert back to the aldehyde $23{ }^{[83]}$

To prevent the conversion to the aldehyde $\mathbf{2 3}$, the cyanohydrin $\mathbf{2 8}$ was applied immediately without any further purification in the Mitsunobu reaction. Therefore, the crude cyanohydrin 28, cyclic imide 20 and triphenylphosphine $\left(\mathrm{PPh}_{3}\right)$ were dissolved at $0{ }^{\circ} \mathrm{C}$ in THF and after addition of diisopropyl azodicarboxylate (DIAD), the reaction was stirred at room temperature for $24 \mathrm{~h}$. However, no product formation was observed by TLC and ESI-MS analysis of the crude reaction revealed the presence of the aldehyde 23. A possible reason for the failed Mitsunobu reaction might be a fast transformation of the cyanohydrin $\mathbf{2 8}$ back to the aldehyde $\mathbf{2 3}$, whereby no reactant for the Mitsunobu reaction remains. Therefore, the reaction was performed using diethyl azodicarboxylate (DEAD) in order to achieve faster reaction rate due to the less sterically hindered DEAD. Nevertheless, this attempt also failed and the cyanohydrin based synthesis approach was not continued, due to the instability of the cyanohydrin, which makes further transfomations of this reactant extremely challenging. 
Therefore, the third synthesis approach $\mathbf{C}$ was applied, which was based on the addition of the cyclic imide $\mathbf{2 0}$ to the carbonyl group of the aldehyde $\mathbf{2 3}$ to form a secondary alcohol 30. The latter could be transformed to carboxylic acid in further steps, as shown in the developed synthesis approach (Figure 27).

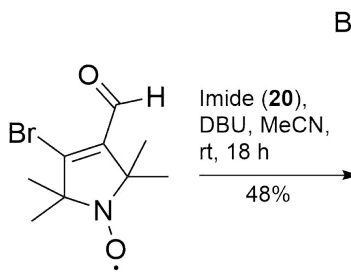

23

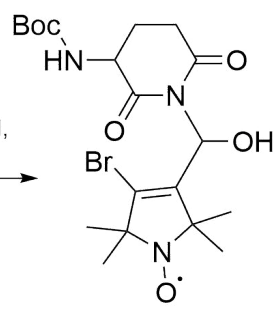

30

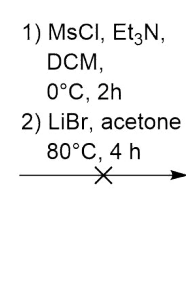

$0^{\circ} \mathrm{C}, 2 \mathrm{~h}$

$\mathrm{LiBr}$, acetone

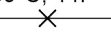

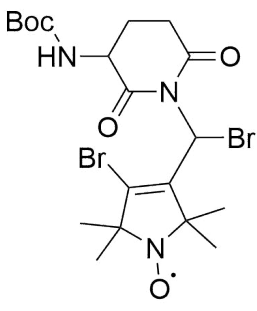

31

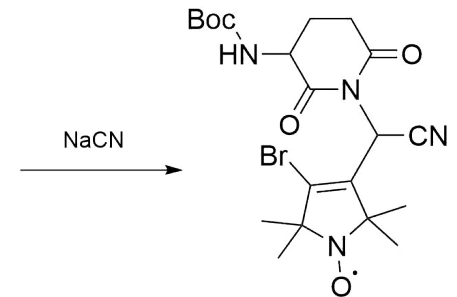

29

Figure 27: Synthesis of the target spin label from an imide $\mathbf{3 0}$ prepared by nucleophilic addition.

To form the hydroxyl stubstituted imide 30, the cyclic imide $\mathbf{2 0}$ was deprotonated by the base DBU to generate a nucleophile, that attacks the carbonyl group of the aldehyde $\mathbf{2 3}$. Therefore, the aldehyde $\mathbf{2 3}$ was added to a solution of the cyclic imide $\mathbf{2 0}$ and DBU in $\mathrm{MeCN}$ and the reaction was stirred at room temperature for $18 \mathrm{~h}$. The product $\mathbf{3 0}$ was isolated by column chromatography in a moderate yield.

Before performing the anionic cyclisation reaction, the secondary alcohol group should be transformed into a carboxyl acid precursor, such as nitrile. Therefore, the alcohol $\mathbf{3 0}$ was converted to a bromide 31 via a methanulfonate intermediate. The generated bromide 31 could then undergo nucleophilic substitution to form a nitrile $\mathbf{2 9}$, that could be hydrolysed to generate the carboxylic acid in later stage of the synthesis.

Thus, $\mathrm{MsCl}$ was added to a solution of the alcohol $\mathbf{3 0}$ and the base $\mathrm{Et}_{3} \mathrm{~N}$ in DCM to form the methansulfonate intermediate, that reacts in the next step to form the bromide 31. The reaction was stirred at $0{ }^{\circ} \mathrm{C}$ for $2 \mathrm{~h}$ but no formation of the methansulfonate intermediate could be observed by TLC. Therefore, the reaction time was extended to achieve the formation of the methansulfonate intermediate. However, the activation of the secondary alcohol $\mathbf{3 0}$ was not successful propably due to the high sterical impact of the neighboured cyclic imide and the pyrroline residue. Hence, because of the sterical hindrance a successful nucleophilic substitution of the secondary alcohol $\mathbf{3 0}$ was highly unlikely.

Thus, the synthesis was continued by the anionic cyclisation using the imide $\mathbf{3 0}$ as reactant. Applying the same reaction conditions for the anionic cyclisation as described before lead not to the formation of the desired cyclic product. The TLC and ESI-MS analysis of the crude reaction revealed the formation of multiple side-products. Hence, it could be assumed that the anionic cyclisation does not tolerate additional substituents in the allylic position of the reactant, since the reaction was successfully performed using the imide 21. Therefore, the synthesis approach via an anionic cyclisation was not continued. 
Taken into account all attempts to synthesize the desired $\beta$-turn inducing spin label, there were no promising synthetical approaches left to test. Since the annealed ring system of the target spin label needs to be constructed in a stepwise manner and a late-stage functionalization by the carboxyl acid group is not possible, the synthesis of the desired spin label is very challenging and highly limited in the design. Therefore, the design of an alternative and readily accessible spin label was aimed, which is presented in the next chapter of this work. 


\section{Synthesis of Spin Labeled Azapeptides}

As an alternative to the synthesis of the azabicyclo $\beta$-turn inducing spin label, an azapeptide based spin labeling approach was developed. This approach is inspired from the work of Lubell et al., who demonstrated the versatile possibilities of modifying azapeptides by alkylation creating conformational constrained azapeptides by standard SPPS (Figure 28). ${ }^{[84]}$

A<smiles>[R]C(NC(=O)C([R])NC(C)=O)C(C)=O</smiles>

I

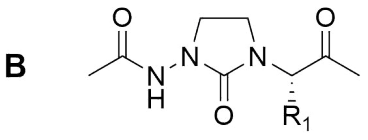

IV<smiles>[R]C(NC(=O)NNC(C)=O)C(C)=O</smiles>

II<smiles>[R]Cc1cn(NC(C)=O)c(=O)n1C([R7])C(C)=O</smiles>

$\mathrm{v}$<smiles>[R]C(C)C(=O)N1CCCC1NC(C)=O</smiles>

III<smiles>[R3]C(NC(=O)NNC(C)=O)C(C)=O</smiles>

$\mathrm{VI}$

Figure 28: (A) Structural comparison between a natural peptide I, an azapeptide II and a Freidinger lactam $^{[85]}$ III as lead structure for development of constrained azapeptides. (B) A selection of constrained azapeptides, that can be prepared by modification of azaresidues. The compounds $\mathbf{I V}, \mathbf{V}$ and $\mathbf{V I}$ represent $\mathrm{Aid}^{[86]}, \mathrm{Nai}^{[87]}$ and alkylated residues.

Therefore, the idea of this labeling approach is based on the alkylation of an azapeptide by a nitroxide spin label, which would adopt a $\beta$-turn conformation by incorporation of a spin labeled aza amino acid residue.

Following the approaches of Lubell et al. ${ }^{[84,88]}$, two different pathways for the synthesis of the spin labeled azapeptide could be considered: One possibility is to perform the alkylation on resin bound azapeptide and to cleave the desired spin labeled azapeptide after elongation from the resin. The second, a submonomer based approach, would require the synthesis of a spin labeled azadipeptide that is coupled to a peptidyl resin. The azapeptide is then subsequently elongated by standard SPPS and yield the desired azapeptide after cleavage from the resin.

In comparison to the submonomer approach, the SPPS based approach requires less synthetical effort and makes the spin labeled azapeptides easily accessible. Since the spin label can be attached by alkylation of the resin bound semicarbazone peptide, there is no need of synthesizing a spin labeled amino acid for incorporation into the azapeptide, as in the submonomer approach. The latter would require additional steps for the synthesis of the spin labeled submonomer and optimization of the coupling conditions for the submonomer by SPPS. Thus, the SPPS based approach of the spin labeled azapeptide was 
the method of choice.

Considering the SPPS based approach, the first step of the project design was to determine a suitable spin label for the alkylation of the aza subunit.

Therefore, the following requirements for the spin label were taken into account: Most importantly, the nitroxide spin label should possess a good leaving group to react in a nucleophilic substitution with the deprotonated semicarbazone amine. In addition to that, the spin label should be compatible with the conditions of microwave assistant SPPS, since it is aimed to establish a reliable and general method for spin labeling of azapeptides. Thus, the spin label should exhibit a high nitroxyl stability to exclude reduction or decomposition of the nitroxyl during synthesis. Moreover, the complexity of the spin label should be minimal to make the spin label readily accessible. Finally, the attached spin label should be conformationally rigid to ensure a fixed location of the nitroxide radical unit and therefore, enable accurate EPR measurements of the target azapeptide.

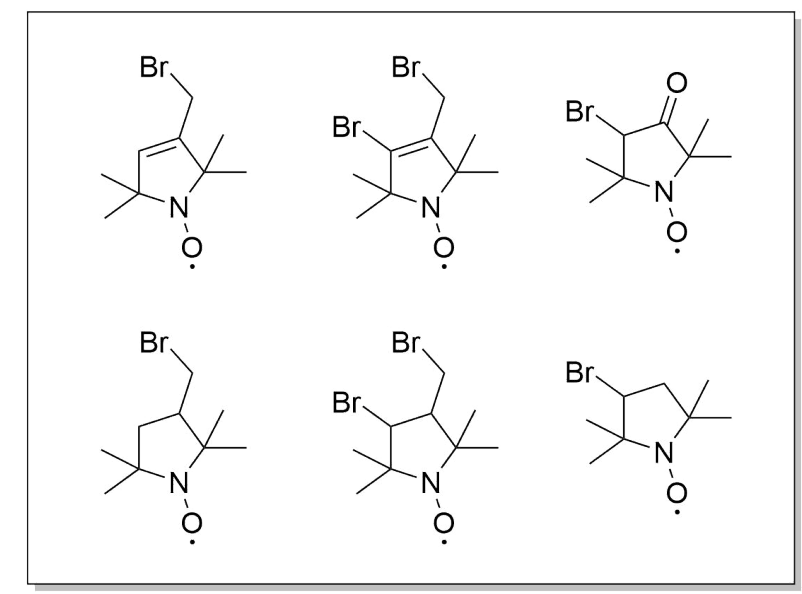

Figure 29: Selection of suitable halide spin labels for the synthesis of spin labeled azapeptides by alkylation.

To match these requirements a range of spin labels were considered, that are illustrated in figure 29. All spin labels are derived from the pyrroline or pyrrolidine structure due to higher stability of five membered spin labels regarding reduction of the nitroxyl unit under acidic or reductive conditions. ${ }^{[37]}$ The pyrroline based spin labels were considered to be promising candidates for the alkylation of the azapeptides, besause they match the above mentioned criteria best. The bromide functionality is not sterically shielded, as in the case of the spin labels in the third column and can be easily attacked by the nucleophile. In addition to that, these spin labels could be readily prepared in few steps according to already described procedures.

Finally, the conformational rigidity of these spin labels after their incorporation into the peptide should be considered. Since both spin labels are based on the five membred pyrroline, that will be linked via a methylene to the azapeptide subunit, the rotation about the $\mathrm{C}-\mathrm{N}$ axis needs to be restricted. Therefore, the vinyl bromide pyrroline spin label turned out to be the most promising candidate for the spin labeling of the azapeptide due to the 
vinylic bromide which could hinder the free rotation of the bound spin label around the C-N axis by its sterical demand.

In the next step of the project an amino acid sequence for the spin labeled azapeptide was developed. With the aim to estabilsh a general protocol for introduction of the spin labeled aza residue, a short polyglycine peptide sequence was developed (Figure 30). Since the $\beta$-turn conformation is stabilized by a H-bond between the amide $\mathrm{N}-\mathrm{H}$ of the $\mathrm{i}^{\text {th }}$ residue and the carbonyl $\mathrm{O}$ of the $\mathrm{i}+3^{\text {th }}$ residue, the peptide should contain at least four amino acid residues to enable preliminary structural analysis by CD spectroscopy. Additionally, with the aim to establish a general synthetic protocol for spin labeled azapeptides, the peptide should contain some side-chain functionalities to test the applicability of standard SPPS conditions according to the Fmoc/tBu protection group strategy. Therefore, a 10-mer polyglycine based peptide flanked by two lysine residues and containing a tryptophane residue at the N-terminus was chosen as model peptide.

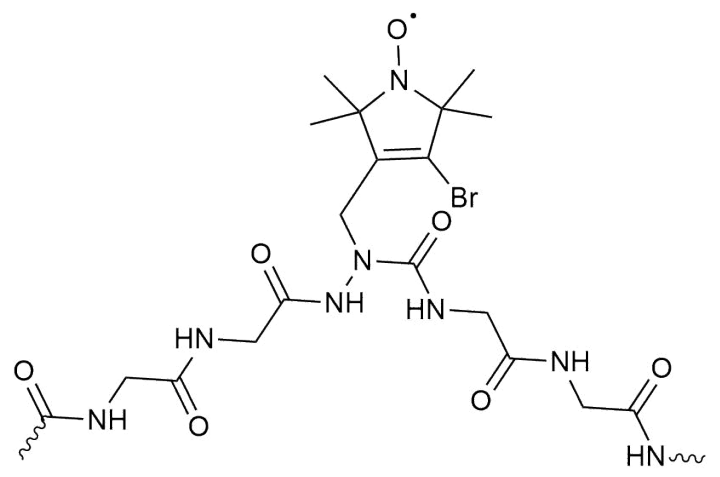

Figure 30: Design of the model peptide to test the spin labeling approach of azapeptides.

Moreover, the incorporation of the basic amino acid lysine and the aromatic tryptophane improves on the one hand the solubility of the peptide in aqueous solution and allows on the other hand the calculation of the peptide concentration by $\mathrm{UV} /$ vis spectroscopy. In the next sections of this chapter the synthesis of the designed spin labeled azapeptide will be presented and discussed.

\subsection{Synthesis of the Nitroxyl Spin Labeled Azapeptide by SPPS}

The synthesis of a spin labeled azapeptide by SPPS was perfomed according to a modified approach of Lubell et al., that comprises five main steps and is shown in figure 31. ${ }^{[91]}$ In the first step, a semicarbazone protected aza glycine is coupled to a resin bound peptide yielding the aza-peptidyl resin. In the next step, the aza-peptidyl resin is treated with the base trieethylammonium hydroxide (TEAH) to generate a nucleophile by deprotonation of the acidic semicarbazone nitrogen, which undergoes a nucleophilic substituion with the halogenated nitroxide spin label. After successfull alkylation of the azapeptide unit, the N-terminal semicarbazone group is selectively cleaved under mild acidic conditions using hydroxyl ammonium hydrochloride in pyridine. The next amino acid is coupled to the 
spin labeled aza-peptidyl resin using DIC as activating agent. In the next step, the azapeptidyl resin is elongated by microwave assistant SPPS to yield the desired azapeptide sequence. Finally, the spin labeled azapeptide is cleaved from the resin by TFA with addition of scavengers.
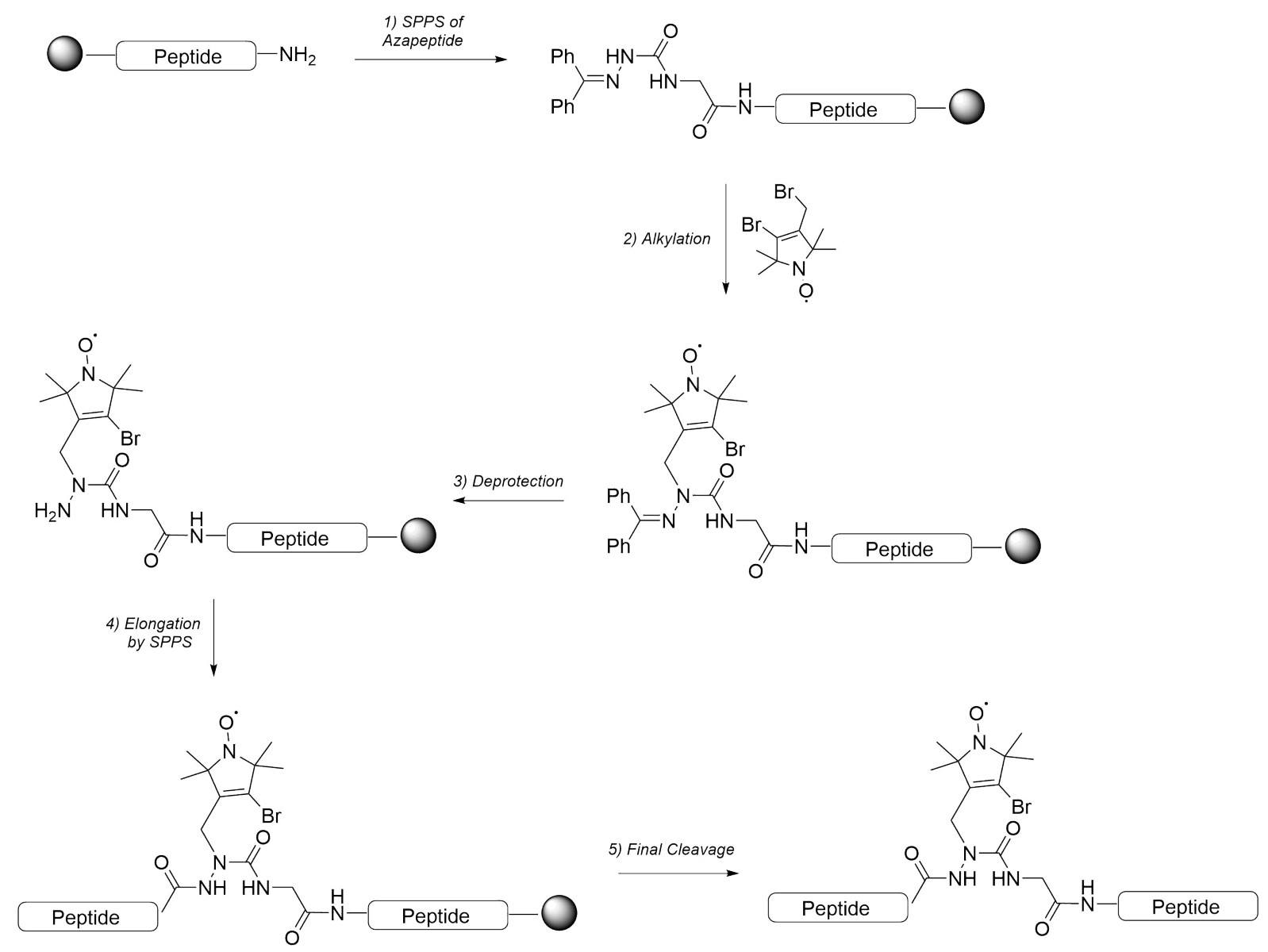

Figure 31: General scheme for the synthesis of a spin labeled azapeptide by alkylation.

For the beginning of the project, a semicarbazone protected aza glycyl residue was prepared following the protocol of Lubell and coworkers. ${ }^{[91]}$ Therefore, the semicarbazone protected hydrazine 33 was reacted with chloroformate and DIPEA in DCM at $0{ }^{\circ} \mathrm{C}$. The reaction was stirred for $30 \mathrm{~min}$ at room temperature to form an activated amine, that was added to the Fmoc deprotected peptidyl resin 32. After agitating the peptidyl resin 32 for $18 \mathrm{~h}$, a semicarbazone protected aza-peptidyl resin $\mathbf{3 4}$ was obtained (Figure 32). To monitor the reaction process a test-cleavage was performed and and the crude azapeptide was analysed by ESI-MS. Therefore, a small amount of the alkylated aza-peptidyl resin was agitated for $2 \mathrm{~h}$ at room temperature in a mixture of $2.5 \%$ water and $2.5 \%$ TIS in TFA. The ESI-MS analysis revealed a quantitative reaction of the N-terminal glycine residue.

After the formation of the semicarbazone protected aza-peptidyl resin 34 the spin label was attached to the resin bound azapeptide by alkylation (Figure 32). The bromide nitroxyl spin label was prepared according to previously published procedures and was 
already described in chapter 3 of this work.

In the first step, the protected aza-peptidyl resin $\mathbf{3 4}$ was treated for $30 \mathrm{~min}$ at room temperature with TEAH in THF. Afterwards, the bromide spin label dissolved in THF was added subsequently to the deprotonated semicarbazone aza-peptidyl resin. After agitation of the mixture for $20 \mathrm{~h}$ at room temperature, a test-cleavage of the azapeptide 35 was performed to prove the formation of the alkylated azapeptide (Figure 32).

The ESI-MS analysis of the crude azapeptide revealed besides the spin labeled azapeptide 35 also the unreacted azapeptide $\mathbf{3 4}$. Thus, the conditions of the azapeptide alkylation were optimized to reach a quatitative reaction conversion and to exclude the formation of the unalkylated azapeptide during further synthesis.



Figure 32: Preparation of the aza-peptidyl resin by SPPS and the alkylation by the bromide spin label.

To optimize the alkylation step, variation of the following three reaction parameters was considered: reaction time, amount of the bromide spin label and the choice of the base. In a first approach, the alkylation was repeated under the same reaction condition as described above, but the reaction time was elongated from $18 \mathrm{~h}$ to $72 \mathrm{~h}$. However, the ESI-MS analysis of the crude azapeptide from the test-cleavage revealed still the presence of unalkylated azapeptide.

Therefore, the added amount of the bromide spin label was increased from 3 to 5 equivalents, but the analysis by ESI-MS showed the presence of unreacted aza peptide $\mathbf{3 4}$. The alkylation was additionally performed using 5 equivalents of the bromide spin label for $72 \mathrm{~h}$ and $96 \mathrm{~h}$. Nevertheless, unreacted azapeptide $\mathbf{3 4}$ was still detected by ESI-MS analysis.

In the last approach, the base TEAH was exchanged with alternative bases. Therefore, two bases were choisen, that were employed for the alkylation of azapeptides in previously described procedures. ${ }^{[92]}$ 
The first alternative was TBAH that has been tested by Lubell et al. in the course of their azapeptide alkylation studies. ${ }^{[92]}$ The base showed a lower conversion in comparison to the TEAH, but still lead to product formation. The second alternative was $t \mathrm{BuOK}$, which has been employed for the deprotonation of protected aza dipeptides in solution phase and also to perform bisalkylation of resin bound aza peptides. ${ }^{[92]}$ The deprotonation of the resin bound azapeptide was perfomed respectively using two fold molar excess of TBAH and $t \mathrm{BuOK}$ in THF at room temperature for $30 \mathrm{~min}$. Afterwards, 3 equivalents of the bromide spin label in THF were added and the peptidyl resin was agitated for $24 \mathrm{~h}$ at room temperature.

However, none of these reaction conditions led to complete alkylation of the aza peptidyl resin 34, as revealed by ESI-MS analysis.

The low conversion of the alkylation reaction could be attributed to the sterical impact of the nitroxide spin label and the N-terminal benzophenone protecting group. In the course of the nucleophilic substitution the deprotonated and sterically hindered semicarbazone nitrogen attacks the bromide spin label, which has also a quite big sterical demand due to its four methyl group substituents.

Therefore, elongation of reaction time and increasement of the amount of the bromide spin label were probably ineffective. To address the incomplete alkylation, the sterical demand of at least one reactant has to be reduced, which could be achieved by exchange of the semicarbazone protecting group by a carbazone protection group. However, since carbazone protected azapeptides are in general less stable, ${ }^{[93]}$ the synthesis of the spin labeled azapeptide was designed using a semicarbazone protecting azapeptidyl resin.

Since the alkylation of the resin bound azapeptide remained incomplete despite numerous optimization efforts, the synthesis of the spin labeled azapeptide was continued (Figure 33).

In the next step, the N-terminal semicarbazone protecting group should be cleaved using mild acidic conditions to avoid deprotection of the acid labile $t \mathrm{Bu}$ and Boc protecting groups of the lysine and tryptophane residues and the cleavage of the azapeptide from the resin.

Therefore, the semicarbazone protected aza-peptidyl resin 35 was agitated at $60{ }^{\circ} \mathrm{C}$ for $18 \mathrm{~h}$ in a $1.5 \mathrm{M}$ solution of the hydrochloric salt of ammonium hydroxide in pyridine (Figure 33). Test-cleavage of the azapeptide $\mathbf{3 5}$ revealed neither the deprotected azapeptide nor the semicarbazone azapeptide.

A possible reason for the failure of the semicarbazone deprotection might be the incompatibility of the nitroxyl spin label residue with the reaction conditions. Incubation of nitroxyl spin labels in alcoholic solutions, that are saturated with hydrogen chloride, is a common procedure to convert nitroxide radical to hydroxylamines. ${ }^{[94]}$

Therefore, the nitroxyl unit of the spin label residue was probably reduced to hydroxy- 


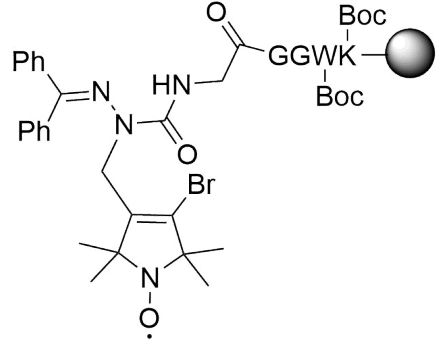

35
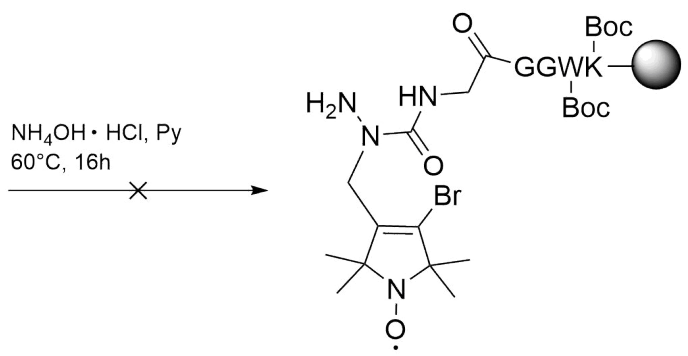

36

Elongation of Semicarbazide Fmoc-Gly-OH, DIC,

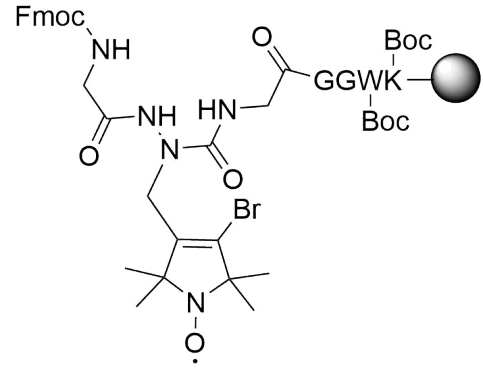

37

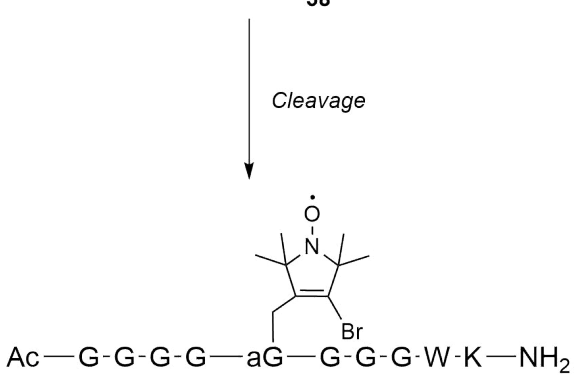

39

Figure 33: Attempted steps for the preparation of the spin labeled azapeptide.

lamine due to presence of hydrochloride in the deprotection solution and was subsequently decomposed due to long exposure at elevated temperature in pyridine. The attempt to perform the deprotection at room temperature and to reduce the reaction time to $5 \mathrm{~h}$ in order to avoid the decomposition of the spin label also failed.

Thus, alternative deprotection conditions, as hydrogenolytic cleavage catalysed by $\mathrm{Pd} / \mathrm{C}$ or acidic cleavage by hydrochloric acid, were considered. ${ }^{[95,96]}$ However, these were not suitble for the SPPS of spin labeled azapeptides. Because the designed SPPS approach is based on the Fmoc/ $t \mathrm{Bu}$ protection strategy and a Rink amide resin was used, strong acidic conditions during deprotection would leave to deprotection of the $t \mathrm{Bu}$ and Boc protecting groups and to the cleavage of the azapeptide from the resin.

The cleavage of the semicarbazone protecting group under hydrogenolytic conditions would be compatible with the SPPS approach, but not with the unsaturated spin label residue. The reduction of the double bond of the spin label would occur, which would enhance the flexibility of the attached spin label. 
Since the alternative reaction conditions were not suitable for the initial SPPS approach, the synthesis of the spin labeled azapeptide had to be redesigned. Therefore, the synthetic approach was modified and a submonomer based strategy was developed, which is introduced and discussed in the next sections. 


\subsection{Synthesis of Spin Labeled Azapeptide by the Submonomer Approach}

In order to address the incompatibility of the semicarbazone deprotection conditions with the nitroxyl spin label, the synthesis of the spin labeled azapeptide had to be modified. Therefore, the application of a bromide spin label with a protected nitroxide radical, which would avoid the side-reaction of the spin label residue during the semicarbazone deprotection, was considered. Hence, a suitable protection group for the nitroxide radical had to be chosen, that one the one hand is stable under the conditions of the SPPS and on the other hand can be deprotected to recover the nitroxide radical in high yields. To match these criteria two classes of protecting groups were taken into account: photolabile and alkoxyamine protecting groups.

The protection of nitroxide radicals by photolabile protecting groups has been previously described, whereby 2-nitrobenzyl or coumarine derivatives are utilized as protection groups. ${ }^{[97]}$ The photolabile protection of nitroxide radicals would be advantageous in terms of the orthogonality and the mild cleavage conditions, since the deprotection is achieved by irradiation of the protected molecule in solution without the addition of any further reagents.

The protection of the nitroxide radical by 2-nitrobenzyl derivatives takes place in a twostep process, whereby the nitroxide radical is first converted into a hydroxylamine by reduction and then, undergoes a nucleophilic substitution with a 2-nitrobenzyl bromide. ${ }^{[97]}$ Since the nitroxide radical is reduced hydrogenolytically, the photolabile protection of the bromide spin label would lead to reduction of the unsturated bond and therefore, to a higher flexibility of the spin label linker. Thus, a modified synthesis route for the preparation of the photolabile protected bromide spin label would be required to maintain the structure of the spin label.

In addition to that, the removal of the photolabile protection group results in the formation of a hydroxylamine which is oxidized back to the nitroxide radical either spontaniously upon exposure to air oxygen or by additional oxidant such as $\mathrm{Cu}(\mathrm{OAc})_{2} \cdot{ }^{[97]}$ Thus, the conditions for the removal of the photolabile protecting group need to be tested and optimized for the spin label.

In contrast to the photolabile protection group strategy, the alkoxyamine protection is a one-step procedure based on a radical recombination reaction between a nitroxide radical and one in-situ generated methoxy radical. ${ }^{[98]}$ Therefore, the nitroxide radical of the bromide spin label could be protected directly as methoxyamine without affecting the double bond. Thereby, the rigidified linker of the spin label would maintain unaffected. The removal of the methoxy protection group occurs oxidatively by treatment of the protected molecule with $m$-CPBA and results in formation of the nitroxide radical. ${ }^{[98]}$ In contrast to the deprotection conditions of a photolabile protecting group, the conditions of the oxidative cleavage are harsher and might be problematic in the presence of oxida- 
tion prone functionalities in the target molecule.

However, taking into account the requirement to develop a modified synthetic route for a photolabile protected spin label and to establish optimized conditions for nitroxyl recovery, the alkoxyamine protection group strategy was considered to be a better alternative. After determining a suitable protecting group for the nitroxide radical, the incomplete alkylation of the resin bound semicarbazone protected azapeptide had to be addressed. Since the low reaction conversion could be mainly attributed to the sterical impact of both reactants, performing the alkylation between the methoxy protected bromide spin label and a protected azadipeptide might enhance the reaction yields. The protected spin labeled azadipeptide would serve as a building block for incorporation into the peptide by SPPS. Thus, the initially designed SPPS approach was exchanged by a submonomer approach, that is illustrated in figure 34 .
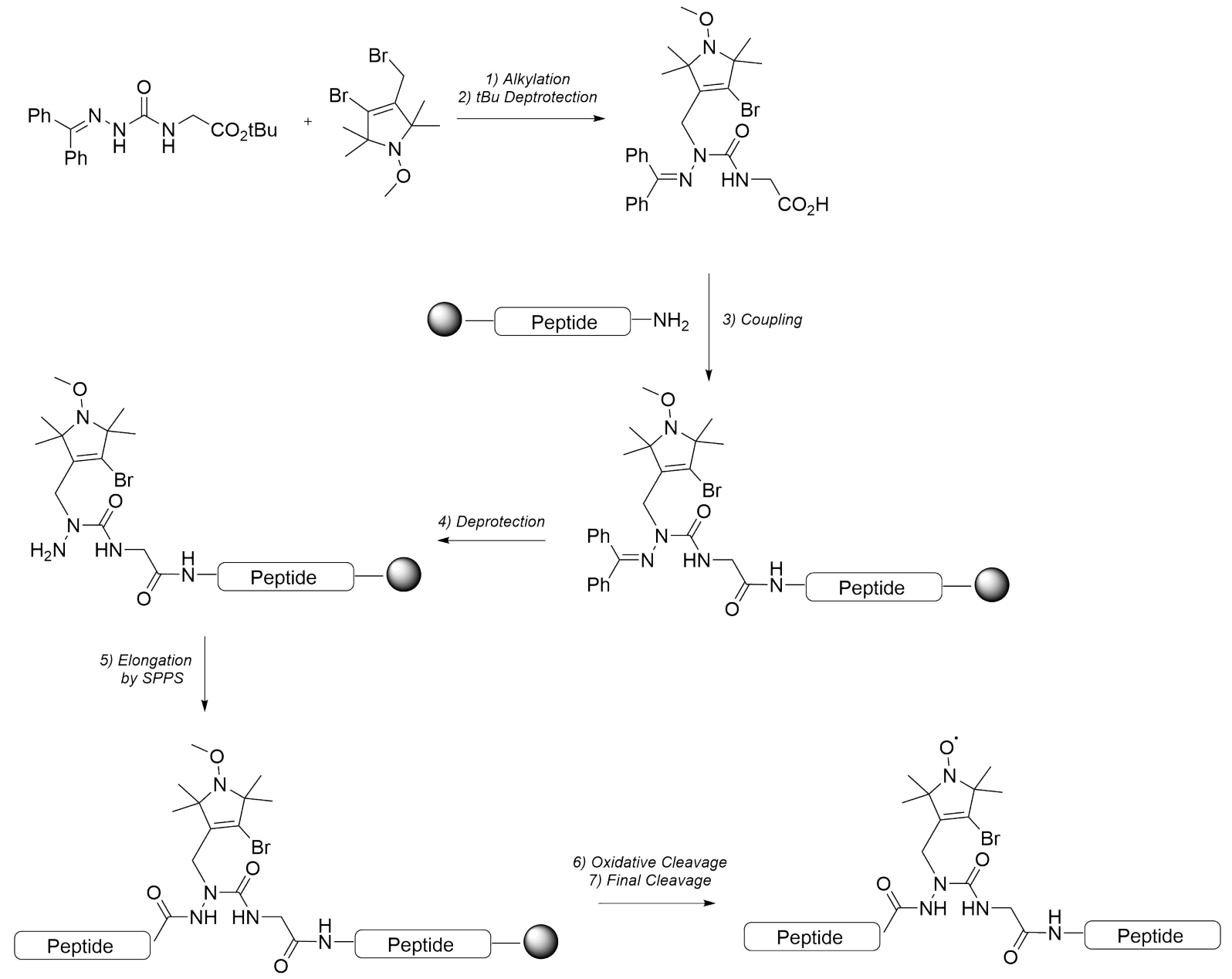

Figure 34: General scheme for the preparation of the spin labeled azapeptide by the submonomer approach via SPPS.

In the first step, a methoxy protected bromide spin label reacts under basic conditions with a semicarbazone azadipeptide to form the alkylated azadipeptide submonomer followed by treatment with TFA to remove the $t$ Bu protection group. The submonomer is then coupled to the resin bound peptide to yield a semicarbazone protected alkylated 
aza-peptidyl resin. In the next step, the semicarbazone is cleaved under mild acidic conditions and the deprotected azapeptide is elongated by the next amino acid using DIC as activation agent. Afterwards the azapeptide is elongated by standard microwave assistant SPPS. Since the methoxy protecting group needs to be removed oxidatively by $m$-CPBA, it was decided to perform the oxidative cleavage with the side-chain protected and resin bound azapeptide to avoid side reactions.

Finally, the spin labeled azapeptide is cleaved from the resin by TFA.

In the next sections the synthesis of the methoxy protected spin label and the spin labeled azapeptide will be presented, followed by the discussion of the CD spectroscopic analysis of the alkylated azapeptide.

\subsubsection{Synthesis of the Spin Labeled Azadipeptide Submonomer}

First, the spin label $\mathbf{1 8}$ was protected according to a previously published procedure. ${ }^{[98]}$ Therefore, $\mathrm{H}_{2} \mathrm{O}_{2}$ was added to a mixture of $\mathrm{FeSO}_{4}$ and the spin label 18 in DMSO at $15^{\circ} \mathrm{C}$ to generate in-situ the methoxy radical, which subsequently reacted with the nitroxide radical of the spin label 18 (Figure 35). The reaction was carried out for $30 \mathrm{~h}$ and the methoxy protected spin label $\mathbf{4 0}$ was obtained in a good yield after chromatographic purification.

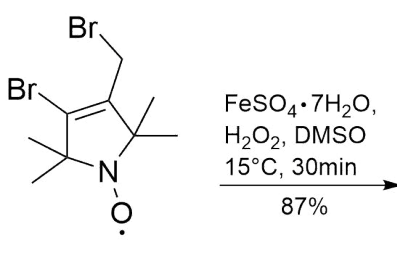

18

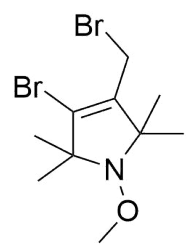

40

Figure 35: Synthesis of the methoxy protected bromide spin label.

Then, the azadipeptide submonomer 42 was syntesized by a previously published protocol (Figure 36). ${ }^{[96]}$ In the first step, benzophenone hydrazine $4 \mathbf{1}$ reacted with benzyl chloroformate for $1 \mathrm{~h}$ at $0^{\circ} \mathrm{C}$ to form the activated intermediate, that was treated with DIPEA and reacted finally with $t \mathrm{Bu}$ protected glycine for $16 \mathrm{~h}$ to form the semicarbazone protected azadipeptide $t$ Bu ester 42 (Figure 36).

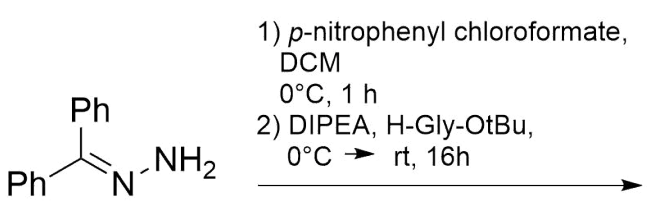

41<smiles>CCCCOC(=O)CNC(=O)OC(=O)NN=C(c1ccccc1)c1ccccc1</smiles>

42

Figure 36: Synthesis of the $t \mathrm{Bu}$ protected azadipeptide.

With the methoxy protected spin label $\mathbf{4 0}$ and the semicarbazone protected azadipeptide 42 in hands the alkylation (Figure 37) could be perfomed following a modified 
procedure. ${ }^{[91]}$

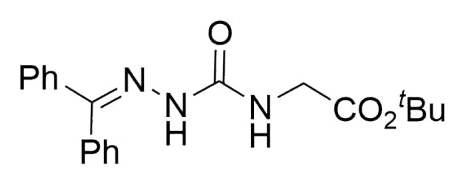

42



43

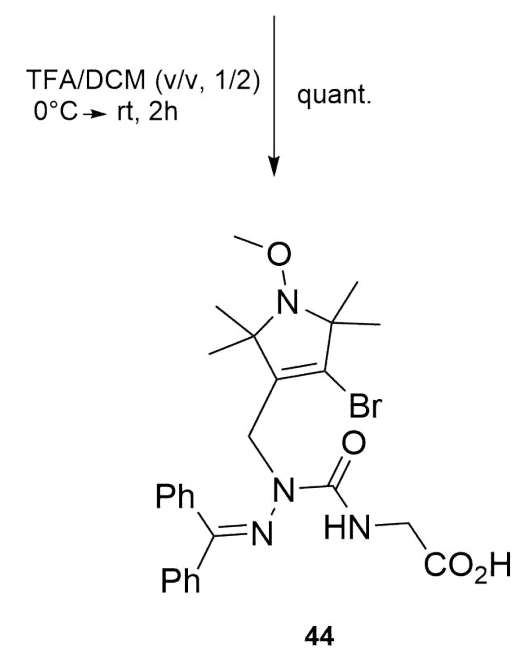

Figure 37: Alkylation of the azadipeptide by the methoxy protected spin label and the subsequent deprotection of the $t \mathrm{Bu}$ group.

Therefore, 2 equivalents of TEAH were added to a solution of the semicarbazone protected azadipeptide $\mathbf{4 2}$ in THF at $0{ }^{\circ} \mathrm{C}$ and the reaction was stirred for $30 \mathrm{~min}$. After the deprotonation of the semicarbazone protected azadipeptide, the methoxy protected bromide spin label $\mathbf{4 0}$ was added in a 3-fold excess and the reaction was stirred for $20 \mathrm{~h}$ at room temperature. TLC analysis of the crude product revealed the formation of one main product, which was identified as the alkylated azadipepde $\mathbf{4 3}$ after chromatographic purification.

Finally, the $t \mathrm{Bu}$ protection group was removed by stirring the alkylated azadipeptide in a mixture of TFA/DCM at room temperature for $2 \mathrm{~h}$. After the removal of the solvent, the deprotected azadipeptide $\mathbf{4 3}$ was obtained in a quantitative yield and used without further purification.

After the successful synthesis of the methoxy protected spin labeled azadipeptide $\mathbf{4 4}$, the incorporation of the alkylated monomer into the model peptide by SPPS was performed. 


\subsubsection{Application of the Spin Labeled Submonomer in SPPS}

To test the the compatibility of the spin label protected azadipeptide $\mathbf{4 4}$ under SPPS conditions and to establish a general protocol for its incorporation, the spin label protected azadipeptide $\mathbf{4 4}$ was incorporated into the polyglycine based model peptide (Figure 38).

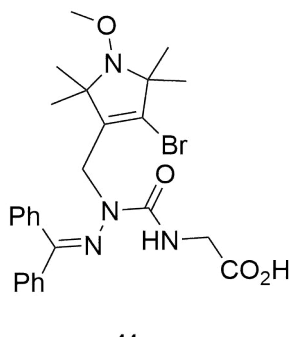

44

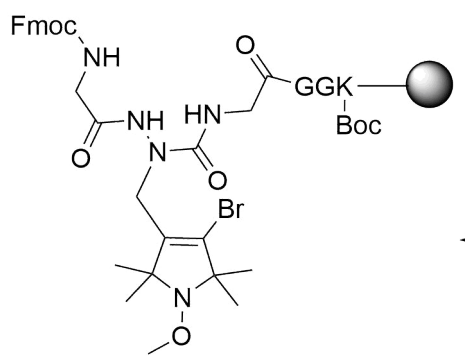

47

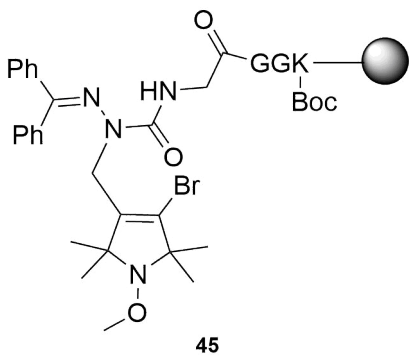

$\mathrm{NH}_{4} \mathrm{OH} \cdot \mathrm{HCl}, \mathrm{Py}$
$60^{\circ} \mathrm{C}, 16 \mathrm{~h}$

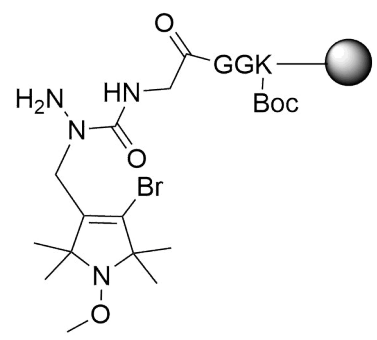

46

-O

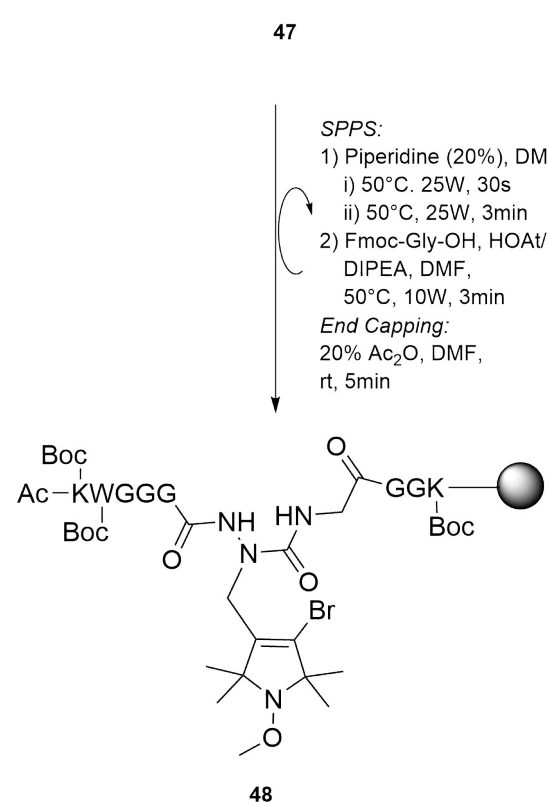

rt, 19h Boc

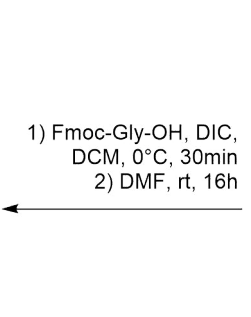

Figure 38: Coupling of the methoxy protected and spin labeled azadipeptide to the peptidyl resin followed by SPPS of the spin labeled azapeptide.

Therefore, a peptidyl resin was prepared by microwave assistant SPPS (for more details, see chapter 7) on a Rink amide MBHA resin with a low loading capacity. The low loading capacity of the resin was important to minimize aggregation of the growing peptide chains and therefore, sterical hindrance during the coupling steps. Thus, the choice of a low loaded resin could enhance the coupling efficiency of the bulky alkylated azadipeptide. 
After the successful preparation of the peptidyl resin the alkylated azadipeptide $\mathbf{4 4}$ was attached using HOAt/HATU as activation agents and DIPEA as base for the coupling reaction (Figure 38). In the first step, the building block 44 was treated with HOAt/HATU upon addition of DIPEA in DMF for 5 min at room temperature. Subsequently, the preactivated monomer was added to the peptidyl resin and the mixture was agitated for $19 \mathrm{~h}$ at room temperature until the completion of the coupling reaction was indicated by the ninhydrin color test ${ }^{[99]}$ (for detailes, see chapter 7). Finally, the ESI-MS analysis of the crude peptide $\mathbf{4 5}$ from a test-cleavage revealed the formation of the alkylated azapeptide 45.

In the next step, the semicarbazone protecting group was removed using the hydrochloric salt of ammonium hydroxide in pyridine at $60{ }^{\circ} \mathrm{C}$ for $16 \mathrm{~h}$ (Figure 38). The reaction perceed quntitatively yielding the deprotected azapeptide 46, which was proved by ESIMS analysis of the crude peptide from a test-cleavage.

Then, the alkylated azapeptide $\mathbf{4 6}$ was elongated by the next glycine residue under mild conditions, by employing a symmetric anhydride activation strategy (Figure 38). The usage of DIC as activating agent was considered to result in a higher coupling efficiency due to the formation of relatively compact anhydride, which could approach the sterical demanded aza glycine residue easily.

For the formation of the anhydride, Fmoc-Gly-OH was reacted for $30 \mathrm{~min}$ with DIC at $0{ }^{\circ} \mathrm{C}$ in DCM. Then, the crude glycine anhydride was added in 5 -fold excess to the azapeptidyl resin 46 in DMF and was agitated for $16 \mathrm{~h}$ at room temperature. The reaction was monitored by the ninhydrin color test ${ }^{[99]}$ and the ESI-MS analysis of the crude azapeptide from a test-cleavage approved a complete conversion of the aza amino group.

After the successful attachment of the glycine residue to the azapeptidyl resin 46, the azapeptide 47 was elongated using standard microwave assistant SPPS (Figure 38). Therefore, the amino acids glycine, tryptophane and lysine were employed in 4-fold excess using HAOt/HATU as activating agents and DIPEA as base in DMF. The coupling and deprotectetion conditions are described in more detail in chapter 7.

Afterwards, N-terminal capping was performed by treating the aza-peptidyl resin $\mathbf{4 7}$ for 5 min in a solution of $20 \%$ acetic acid anhydride in DMF to protect the N-terminus from side-reactions during remaining synthesis.

The formation of the desired azapeptide 48 was confirmed by ESI-MS analysis of the crude peptide from a test-cleavage. 
Finally, the methoxy protection group of the spin labeled residue should be removed under oxidative cleavage conditions (Figure 39).

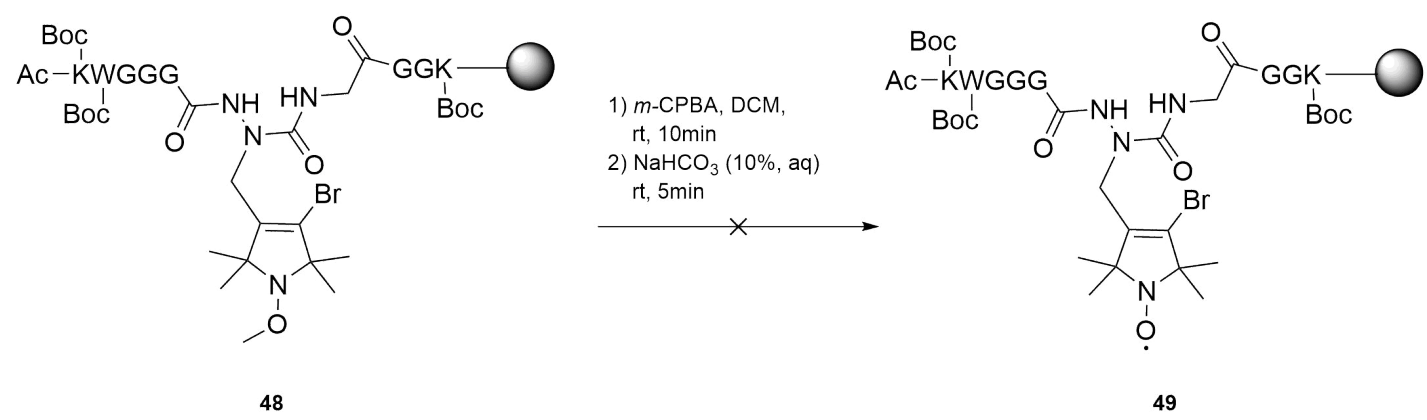

Figure 39: Attempted deprotection of the methoxy protection group on resin bound azapeptide.

According to the general procedure, the methoxy group deprotection is carried out in solution phase using a 2-fold excess of $m$-CPBA in DCM at room temperature. However, to prevent side-reactions with the side-chains of the azapeptide the oxidative cleavage was attempted on the resin bound azapeptide.

Therefore, the azapeptidyl resin $\mathbf{4 8}$ was incubated at room temperature with a solution of $m$-CPBA in DCM for 10 min, whereby the deprotection was monitored by a test-cleavage after 5 and $10 \mathrm{~min}$. ESI-MS analysis of the crude azapeptide revealed no formation of the nitroxyl labeled azapeptide $\mathbf{4 9}$ and no presence of the methoxy protected azapeptide $\mathbf{4 8}$.

A possible reason for the failure of the deprotection could be side-reactions with the spin label residue, such as epoxidation of the double bond moiety. Additionally, the incompatibility of the resin bound azapeptide under the oxidative conditons could lead to degradation of the azapeptide.

However, the alkylated azapeptide was cleaved from the resin by incubating the peptidyl resin in a TFA cleavage coctail for $2 \mathrm{~h}$ at room temperature (Figure 40 ).

Afterwards, the isolated crude azapeptide $\mathbf{5 0}$ was purified by reverse-phase high pressure liquid chromatography (RP-HPLC) to eluate the desired azapeptide 50, which was confirmed by ESI-MS analysis.

After the successful isolation of the methoxy protected azapeptide, a further attempt to remove the methoxy group from the purified azapeptide $\mathbf{5 0}$ was made. Therefore, the oxidative cleavage was performed at lower temperature $\left(0^{\circ} \mathrm{C}\right)$ and a solution of $m$-CPBA in DCM was added slowly to keep the concentration of the oxidant low and avoid sidereactions with the tryptophane and lysine side-chains (Figure 40).

However, the oxidative cleavage failed to yield the desired spin labeled azapeptide $\mathbf{5 1}$. Since tryptophane residues are commonly known to be sensitive towards oxidation, ${ }^{[100]}$ the ESI-MS spectrum of the crude azapeptide was analyzed for products containing an additional hydroxyl functionality, but there was no corresponding $m / z$ ratio found in the spectrum. 

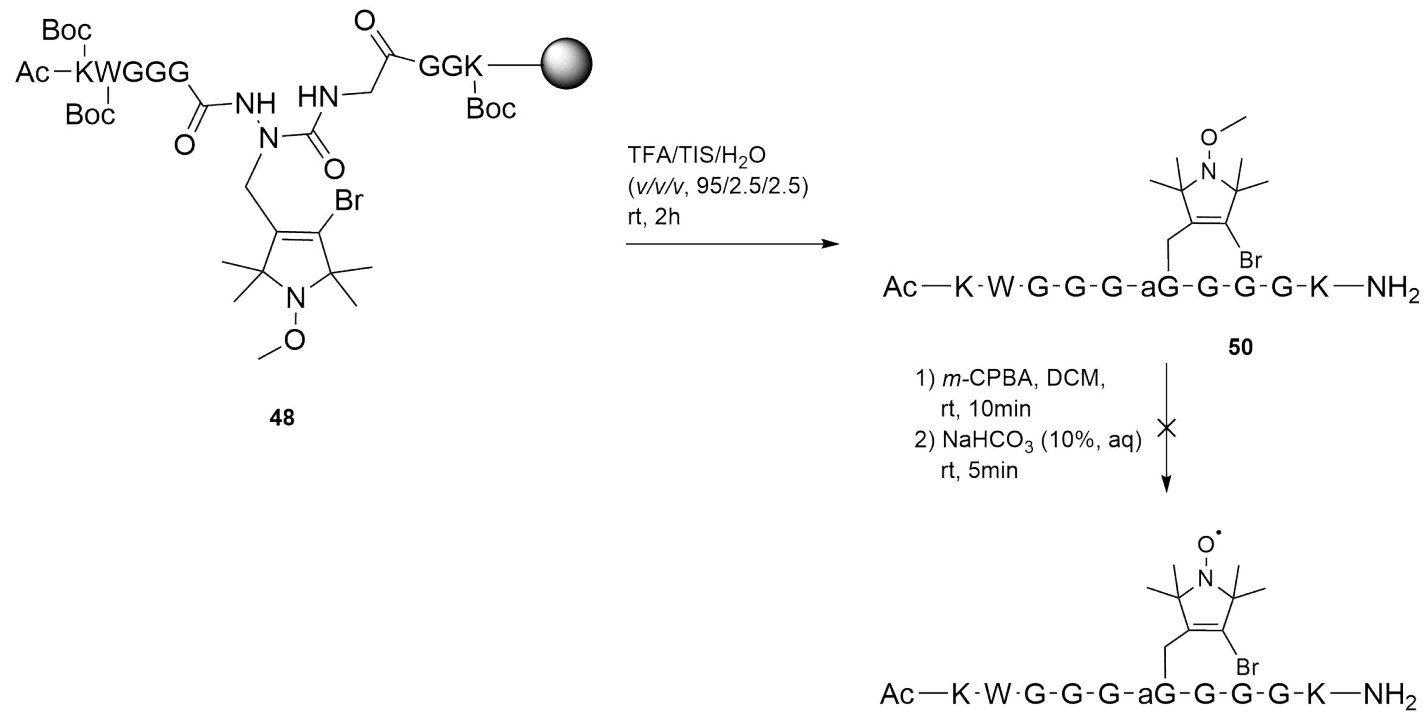

51

Figure 40: Cleavage of the azapeptide from the resin and the attempted deprotection of the methoxy protection group in solution phase using the purified azapeptide.

Another possible side-reaction was a epoxidation of the double bond of the spin label, but analysis of the ESI-MS spectrum showed no formation of the corresponding sideproduct.

Therefore, it can be concluded that the conditions of the oxidative cleavage are not compatible with the alkylated azapeptide and lead probably to decomposition of the azapeptide during the deprotection. Since there are no alternative deprotection conditions, except using $\mathrm{H}_{2} \mathrm{O}_{2}$ as oxidant, which would result in the same reaction outcome, no further attempts were made to remove the methoxy protection group.

\subsubsection{Conformational Analysis of Methoxy Protected Azapeptide}

After the synthesis of the methoxy protected spin labeled azapeptide was completed, the purified azapeptide $\mathbf{5 0}$ was analyzed by circular dichroism (CD) spectroscopy to evaluate the conformation inducing properties of the alkylated aza residue. According to the findings of Lubell et al., alkylated azaglycine residues induce or stabilize different types of $\beta$-turn conformations, which is strongly dependent on the peptide sequence and the position of the aza amino acid residue. ${ }^{[101]}$ Therefore, to evaluate the conformational effect of the alkylated aza residue, it would be necessary to synthesize a set of different spin labeled azapeptides, that are derived from peptides showing a certain degree of $\beta$-turn conformation.

In natural proteins segments with turn conformations are often identified as connecting units between higher ordered domains, as $\alpha$-helices or $\beta$-sheets. ${ }^{[7]}$ Therefore, the stability and conformation of the turn motif is strongly influenced by the overall structure of the protein. 
There are only a few examples of peptides known, that posses an isolated $\beta$-turn conformation, like the 6-mer GhRP peptide, that served as model peptide in several conformational azapeptide studies. ${ }^{[101]}$

Thus, it is fairly unlikely to see the turn inducing effect of the aza residue in relatively short peptides, unless the peptide sequence itself exhibit a high propensity to adopt a turn conformation.

Taking these aspects into account, the synthesiszed methoxy protected azapeptide was analyzed by CD-spectroscopy with the aim to receive first hints regarding the inducing properties of the alkylated aza residue. Additionally, the methoxy protection group of the nitroxyl unit was assumed to have no effect on the peptide conformation, because of the small size and the position on the side-chain of the turn inducing residue.

For the CD-spectroscopical analysis a $50 \mu \mathrm{M}$ solution of the methoxy protected azapeptide in $\mathrm{MeOH}$ was employed and the measurement was perfomed in a wavelength range between 260 and $190 \mathrm{~nm}$ to cover the absorption region of the conformation dependent chromophors. Analysis of the resulting CD-spectrum (see chapter 8) gave no hint on the presence of a $\beta$-turn or other types of turn conformation.

For a $\beta$-turn conformation a maximum in the wavelength range between 190-200 $\mathrm{nm}$ and a minimum at $210 \mathrm{~nm}$ would be expected according to the literature. ${ }^{[102]}$ The CD-spectrum of the methoxy protected azapeptide showed a minimum at $190 \mathrm{~nm}$, which is typically for unordered structures, and a maximum at $226 \mathrm{~nm}$, which can be assigned to absorbtion of the tryptophane side chain. ${ }^{[103]}$

Since the sequence of the synthesized azapeptide is rather short and exhibit no turn propensity, the results from the measurement were not surprising.

Thus, to receive information regarding the inducing effect of the spin labeled aza residue a set of spin labeled azapeptides with distinct turn conformation should be prepared and analyzed. By this, no conclusions on a stabilizing or destabilizing effect of the spin labled aza residue could be drawn. 


\section{Application of the $\alpha$-TOPP Spin Label in Peptide Synthesis by Native Chemical Ligation}

EPR spectroscopy is a widly used technique to analyse interactions or structural changes in protein systems. Therefore, the analysed proteins need to be labeled by paramagnetic labels, which are often based on nitroxide radicals. Nitroxide radical spin labels can be detected by EPR spectroscopy, which enables to measure distances within double spin labeled proteins or to examine the orientation of spin labeled transmembrane proteins by double pulsed EPR techniques such as PELDOR or DEER. ${ }^{[1]}$

To obtain accurate measurements by EPR spectroscopy, the incorporated spin labels have to fullfill two crucial requirements: One the one hand the used spin label should exhibit a high degree of rigidity to avoid movement of the paramagnetic unit and on the other hand the disturbance of the local peptide structure by incorporation of the spin label should be as minimal as possible. This would allow to tranfer the structural data obtained from EPR measurements of spin labeled proteins to the native proteins.

The labeling of peptides can be achieved either by direct incorporation of spin lables, based on amino acids bearing a nitroxide unit, or by side-directed spin labeling (SDSL). ${ }^{[13]}$

The SDSL approach is based on click reactions between the side-chains of the peptide and the appropriate spin label. ${ }^{[49,106]}$ One of the most applied SDSL approaches utilizes the methanethiosulfonate (MTSL) nitroxide spin label, that readily reacts with the thiol groups of cysteine containing peptides to form a disulfide bond and thereby attaches to the peptide. ${ }^{[45,107]}$

Whereas smaller protein systems can be labeled either by direct incorporation through SPPS or by SDSL, the spin labeling of larger protein systems is mostly restricted to the SDSL approach. This is caused by the limitations of the automated SPPS for proteins containing more than 100 amino acids.

In terms of rigidity, the amino acid spin labels are superior to the spin labels that are attached through a flexible linker via SDSL. Therefore, the analysis of larger protein systems by EPR spectroscopy could be further improved by using rigid amino acid spin labels.

A possibility to circumvent the limitations of the SPPS of spin labeled peptides is to combine the spin labeling with the native chemical ligation (NCL). ${ }^{[04]}$ NCL is a technique to synthesize large proteins in a stepwise manner by ligation of two or more protein fragments. ${ }^{[6,105]}$ This technique not only provides the synthetic access to large naturally occuring protein systems, but allows also to manipulate the protein system by different labels depending on the further application. 
A crucial requirement to use this approach is the presence of cysteine residues in the protein, because the ligation is based on the reaction between the thiol group of an Nterminal cysteine residue and a C-terminal thiolester, which leads to the formation of an amide bond. ${ }^{[6,105]}$

However, the usage of spin labeled peptide fragments for NCL might be problematic due to the required coexistence of free thiol groups and nitroxide radical containing spin labels, that are both redox active. Whereas the cysteine residues are prone to oxidation by formation of disulfide bridges ${ }^{[08]}$, some nitroxide radicals are susceptible to convert to nitroxyl amines under reductive conditions and therefore to lose their paramagnetic property. ${ }^{[89]}$

Therefore, to synthesize spin labeled and cysteine containing proteins by SPPS, both redox processes should be suppressed to preserve the thiol group and the nitroxide radical. To maintaine the thiol groups of cysteine residues, the ligation is performed upon addition of reducing agents, like TCEP, and under unaerobic conditions. ${ }^{[109,110]}$

However, these conditions are incompatible with the nitroxide radical spin labels, due to their propensity to be reduced to the corresponding hydroxyl amines. Thus, to keep the nitroxide radical unaffected during the synthesis of the spin labeled peptide and the NCL, the nitroxide radical needs to be protected by an orthogonal protecting group.

This protecting group should be stabile under the standard SPPS conditions using the Fmoc/tBu protecting group strategy. Furthermore, the protecting group should be removed selectively to recover the nitroxide radical. Taking these requirements into account, the photolabile protecting group strategy developed by Seven et al. is a promising tool to protect nitroxide radicals during the SPPS and the NCL. ${ }^{[97]}$ The photolabile protecting groups, such as 2-nitrobenzyl, can be easily removed by irradiation without generating side-products or affecting the unprotected peptide.

Thus, in the course of this project, a protocol for the application of the photolabile protected $\alpha$-TOPP spin label in peptide synthesis by NCL should be established (Figure 41). Therefore, the semi-rigid $\alpha$-TOPP spin label, that was a promising candidate for studying peptide conformations in fromer studies ${ }^{[4]}$, should be synthesized and protected by a 2-nitrobenzyl based protecting group. Afterwards, the photolabile protected $\alpha$-TOPP spin label should be incorporated into a model peptide with a N-terminal cysteine residue via SPPS and finally, be applied in NCL (Figure 41). 

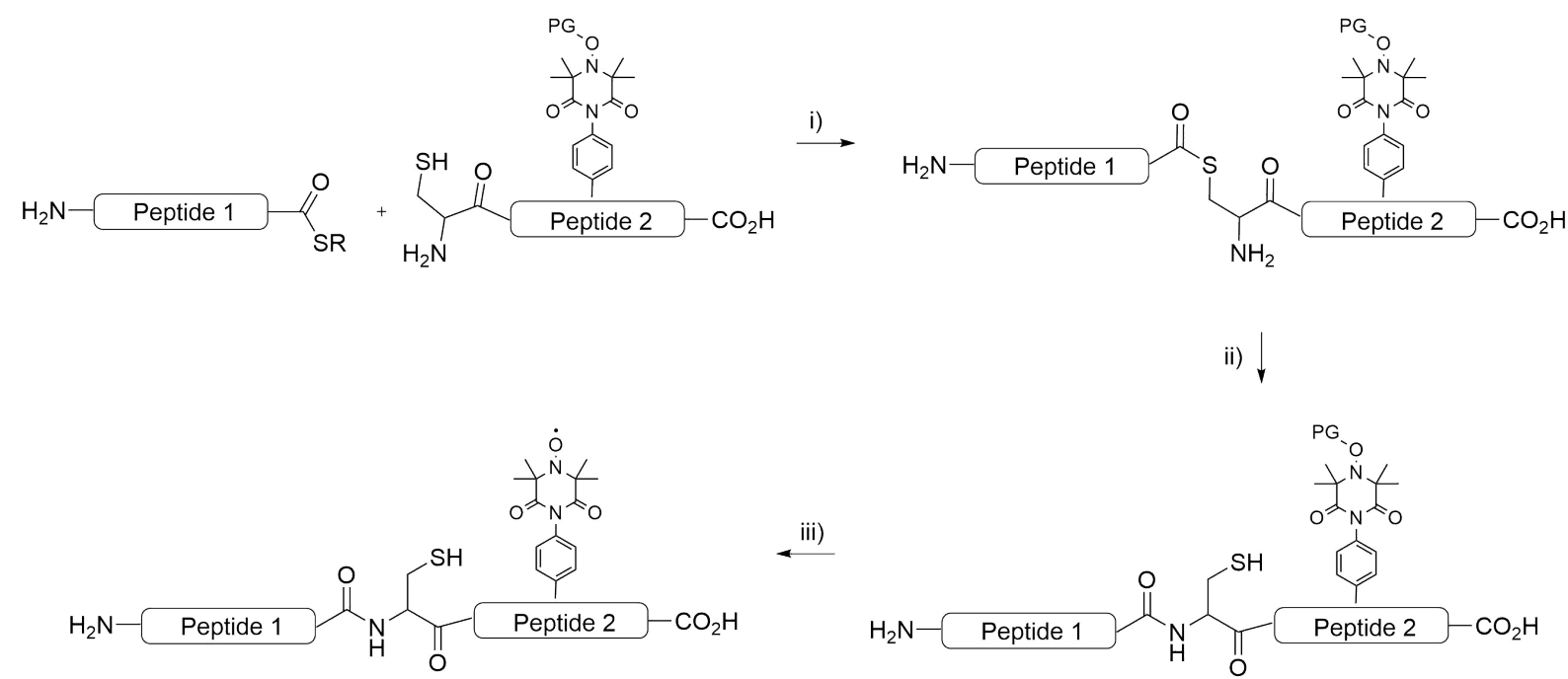

Figure 41: General scheme for the application of the $\alpha$-TOPP spin label in peptide synthesis by NCL.

To test the NCL, two peptide fragments should be synthesized, that would recombine by NCL to the model peptide B (Figure 42). After successfull ligation of the two peptide fragments, the photolabile protecting group should be removed by irraditon with UV light (365 nm) yielding a spin labeled cysteine containing peptide.

For the start, the $\alpha$-TOPP spin label was synthesized following the procedures described by Stoller et al. and Halbmair et al. ${ }^{[3,4]}$ However, it was aimed to optimize the synthesis process in terms of time efficiency and purification, since some transformations in the the linear synthesis of the $\alpha$-TOPP spin label require long reaction times and elaborate purification steps.

For the nitroxyl protection of $\alpha$-TOPP spin label a 2-nitrobenzyl based protection group was chosen, that can be installed in a two-step process described by Seven et al. ${ }^{[97]}$

In the next step, an appropriate model peptide was chosen to proof the concept. The modified transmembrane model peptide WALP24 was considered to be a suitable candidate, since it was labeled by the $\alpha$-TOPP spin label in previous studies. ${ }^{[4]}$

Therefore, the sequence of the modified WALP24 peptide was slightly changed by substitution of the leucine residue in position 12 by a cysteine residue to enable its synthesis via NCL. Additionally, the leucine residue in position 14 should be substituted by the photolabile protected $\alpha$-TOPP spin label, which led to the model peptide illustrated in figure 42 .
$\begin{array}{llllllllll}1 & 2 & 3 & 4 & 5 & 6 & 7 & 8 & 9 & 10\end{array}$
11121314151617181920
21222324
A $\quad \mathrm{H}-\mathrm{K}-\mathrm{W} \cdot \mathrm{W}-\mathrm{L}-\mathrm{A}-\mathrm{L}-\mathrm{A}-\mathrm{L}-\mathrm{A}-\mathrm{L}-\mathrm{A}-\mathrm{L}-\mathrm{A}-\mathrm{L}-\mathrm{A}-\mathrm{L}-\mathrm{A}-\mathrm{L}-\mathrm{A}-\mathrm{L}-\mathrm{A}-\mathrm{W} \mathrm{W}-\mathrm{A}-\mathrm{OH}$

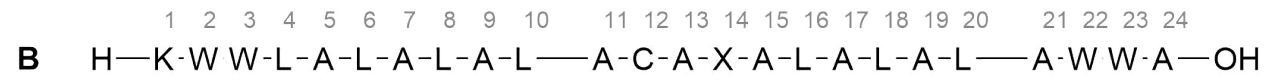

Figure 42: Designed peptides for the application of the $\alpha$-TOPP spin label in peptide synthesis by NCL. A represents the sequence of the WALP24 model peptide and $\mathbf{B}$ is the cysteine and $\alpha$-TOPP (X) spin labeled peptide sequence derived from the WALP24 peptide. 
In the next sections of this chapter the synthesis of the photolabile protected $\alpha$-TOPP spin label and the cleavage of the photolabile protecting group will be discussed.

\subsection{Synthesis of Photolabile Protected $\alpha$-TOPP Spin Label}

The synthesis of the $\alpha$-TOPP spin label was performed according to the protocols of Stoller et al. and Halbmair et al. ${ }^{[3,4]}$, whereby some attempts were made to make the liniar synthesis more time efficient.

In the first steps of the synthesis, the amino and carboxyl group of the commercial available L-4-hydroxyphenylglycine $\mathbf{5 2}$ were protected in a two-step procedure by a benzylester and a benzyl group. Then, the hydroxyl group was converted into a triflte $\mathbf{5 5}$, that serves as good leaving group in the subsequent synthesis steps (Figure 43).

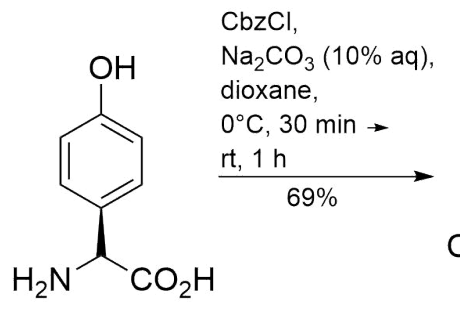

52

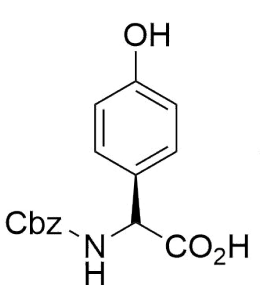

53

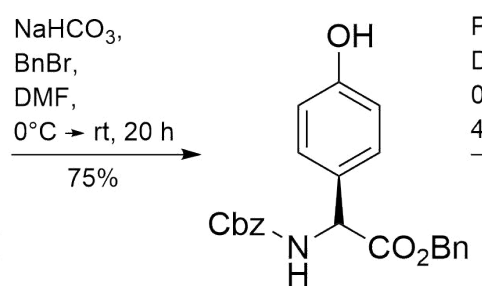

54

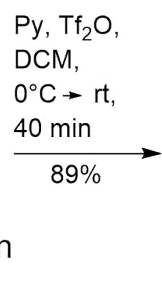

Cbz-

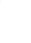

Figure 43: Synthesis of the triflate spin label from the commercial available L-4-hydroxyphenylglycine.

First, the amino group of the L-4-hydroxyphenylglycine $\mathbf{5 2}$ was protected under Schotten Baumann conditions. Thereby, the glycine derivative $\mathbf{5 2}$ was treated with $\mathrm{CbzCl}$ in a mixture of 1.4-dioxane and aqueous sodiumbicarbonate solution for $1 \mathrm{~h}$ at room temperature.

Next, benzyl bromide and $\mathrm{NaHCO}_{3}$ were added to the crude Cbz protected intermediate in DMF and after stirring the reaction for $20 \mathrm{~h}$ at room temperature, the benzyl protected intermediate $\mathbf{5 4}$ was isolated after purification by column chromatography in a good yield (Figure 43).

After the protection of the amino and the carboxyl group, the hydroxyl group was converted to a triflate by nucleophilic substitution with trifluoromethanesulfonic anhydride $\left(\mathrm{Tf}_{2} \mathrm{O}\right)$. Therefore, the protected intermediate $\mathbf{5 4}$ was treated with pyridine in DCM to deprotonate the hydroxyl group, which readily react with $\mathrm{Tf}_{2} \mathrm{O}$ to yield the corresponding triflate $\mathbf{5 5}$ in $40 \mathrm{~min}$ at room temperature (Figure 43). Since some by-products were detected by TLC analysis, the crude product $\mathbf{5 5}$ was purified by column chromatography to obtain the desired triflate in a good yield.

In the next steps of the synthesis, the triflate group was converted in a Miyaura crosscoupling reaction to a boronic ester, that was hydrolyzed to obtain the boronic acid (Figure 44). However, before performing the borylation reaction, the Cbz protection group of the intermediate $\mathbf{5 5}$ had to be exchanged by the Bn protecting group (Figure 44) in order 
to avoid the formation of a racemic product. ${ }^{[3]}$

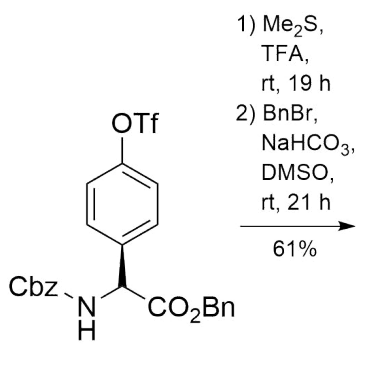

55

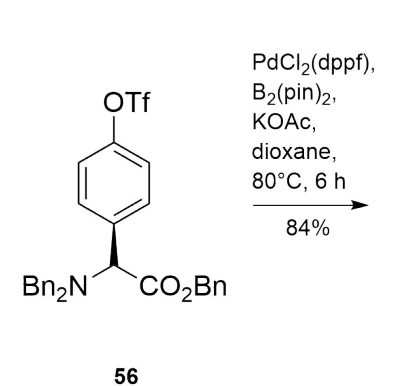

56

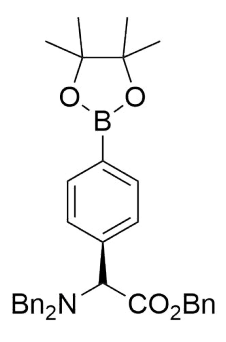

57

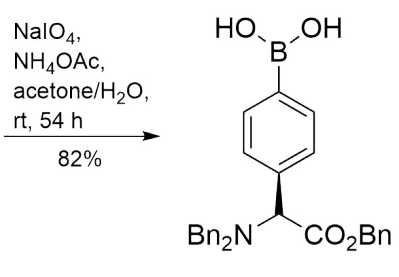

58

Figure 44: Synthesis of the boronic acid spin label from the triflate spin label.

Following a two-step procedure, the protected glycine derivative $\mathbf{5 4}$ was first stirred upon addition of a high excess of dimethyl sulfide $\left(\mathrm{Me}_{2} \mathrm{~S}\right)$ in TFA for $19 \mathrm{~h}$ at room temperature. Afterwards, the unprotected glycine intermediate was used without any further purification. In the next step, the amino and the carboxy group of the crude intermediate were protected by benzyl groups. Therefore, the crude intermediate and $\mathrm{NaHCO}_{3}$ were dissolved in dimethyl sulfoxide (DMSO) and after the addition of benzyl bromide (BnBr) the reaction was stirred for $21 \mathrm{~h}$ at room temperature to yield the benzyl protected product 56 in a moderate yield after purification by column chromatography (Figure 44).

In the next step, the benzyl protected triflate $\mathbf{5 6}$ was converted into the boronic ester $\mathbf{5 7}$ by Miyaura borylation.

Therefore, the triflate $5 \mathbf{6}$ was dissolved under dry and anaerobic conditions in 1,4-dioxane and after the addition of $\mathrm{B}_{2}(\mathrm{pin})_{2}$, the base KOAc, 1,1'-bis(phenylphosphino)ferrocene (dppf) and the catalyst $\mathrm{PdCl}_{2}$ (dppf) the reaction was stirred for $6 \mathrm{~h}$ at $80^{\circ} \mathrm{C}$ (Figure 44 ). The desired boronic ester 57 could be obtained in a good yield after purification by column chromatography.

Since boronic acids are superior to boronic esters in Chan-Lam cross-coupling reactions in terms of reactivity, the boronic ester $\mathbf{5 7}$ was transformed into the corresponding boronic acid 58 .

For the hydrolysis, the boronic ester 57 was stirred with ammonium acetate $\left(\mathrm{NH}_{4} \mathrm{OAc}\right)$ and sodium periodine $\left(\mathrm{NaIO}_{4}\right)$ in a mixture of water/acetone for $54 \mathrm{~h}$ at room temperature (Figure 44). Thereby, the $\mathrm{NaIO}_{4}$ was used as a mild oxidant to convert the formed pinacol into acetone. The desired boronic acid $\mathbf{5 8}$ was obtained without further purification in a good yield. 
The following Chan-Lam coupling of the boronic acid 58 with the piperazine-2,6-dione 61 is the key step in the synthesis towards the $\alpha$-TOPP spin label, since the framework of the $\alpha$-TOPP spin label is formed.

Therefore, the piperazine-2,6-dione $\mathbf{6 1}$ was synthesized in two steps by a modified synthesis route. Although the preparation of the nitroxyl precursor $\mathbf{6 1}$ has been described by Stoller et al. and Wegner ${ }^{[111]}$, it was aimed to optimize the original synthesis (Figure 45) by usage of more benign starting materials.

A:

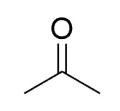

59

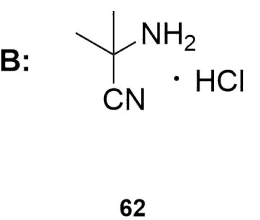

62

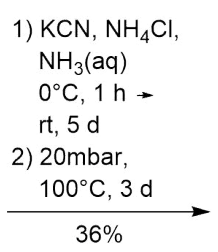

$\mathrm{NH}_{3}(\mathrm{aq})$

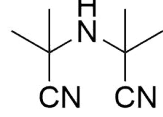

60

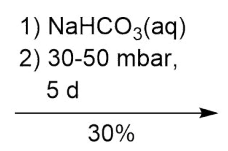

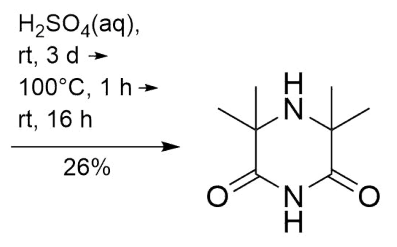

61

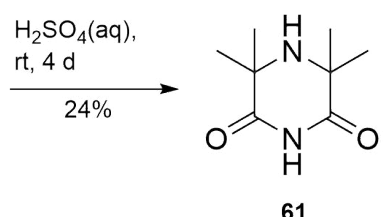

Figure 45: Comparison of the original preparation of the piperazine-2,6-dione by Wegner (A) with the optimized synthesis (B).

Thus, the synthesis started with the commercially available hydrochloride salt $\mathbf{6 2}$ that was converted into the free amine and subsequently dimerized to form the dinitrile intermediate 60, which was converted to the target nitroxide precursor $\mathbf{6 1}$ following the described procedure by Wegner (Figure 45). ${ }^{[111]}$

In the first step, the commercial available hydrochloride $\mathbf{6 2}$ was dissolved in water and treated with a $10 \%$ aqueous solution of $\mathrm{NaHCO}_{3}$, until the reaction solution reached $\mathrm{pH} 7$. Afterwards, the desalted amine was extracted with ethyl acetate (EtOAc) and isolated by removal of the solvent under reduced pressure (Figure 45).

For the formation of the dinitrile $\mathbf{6 0}$, the amine was allowed to stand at room temperature under reduced pressure (30-50 mbar). After $5 \mathrm{~d}$ of reaction quantitative formation of the dimer 60 was observed (Figure 45). The dinitrile 60 was obtained without further purification in a moderate yield of $30 \%$ over two steps from the hydrochloride $\mathbf{6 2}$. Thereby, the low yield is mainly caused by the volatility of the desalted amine.

The isolated dinitrile $\mathbf{6 0}$ was hydrolysed and subsequently converted to the desired cyclic dione $\mathbf{6 1}$ by condensation according to the protocol of Wegner ${ }^{[111]}$. Therefore, the dimer 60 was dissolved in $68 \%$ aqueous sulfuric acid and stirred at room temperature for $4 \mathrm{~d}$. The cyclic dione was isolated after basic work-up in a moderate yield of $24 \%$, which is probably caused by its instability ${ }^{[11]}$ under basic conditions (Figure 45 ).

However, the attempt to optimize the procedure for the synthesis of the cyclic dione can 
be assumed as successfull. By modifying the synthesis of the dinitrile 60, the usage of KCN and purification steps by destillation could be avoided.

After the successful synthesis of the cyclic dione $\mathbf{6 1}$, the linear synthesis of the $\alpha$-TOPP spin label was continued with the Chan-Lam amination of the boronic acid $\mathbf{5 8}$.

The Chan-Lam cross coupling is a N-arylation reaction of amines, amides or imides and is performed under mild conditions. The reaction works at room temperature upon the addition of weak bases and $\mathrm{Cu}^{2+}$ salts as catalyst. Moreover, the reaction is performed under aerobic conditions, since the atmospheric oxygen serves as oxidant for the re-oxidation of the copper catalyst to maintain the catalytic process. ${ }^{[112]}$

According to the procedures by Stoller et al. and Halbmair et al. the desired crosscoupling product 63 was formed in $14 \mathrm{~d}$, which makes the synthesis of the $\alpha$-TOPP spin label quite time consuming. ${ }^{[3,4]}$

Hence, to reduce the reaction time an optimization of the reaction conditions was attempted. During research on the Chan-Lam cross-coupling reaction, a published study turned out to be particularly interesting regarding optimization of reaction conditions. ${ }^{[12]}$ The study revealed the oxygen pressure to be an important reaction parameter, that have a big impact on the yield. ${ }^{[12]}$

Briefly, the authors found out, that the yields of the Chan-lam coupling increased at higher oxygen pressures. ${ }^{[12]}$ Since the oxygen pressure might also have an effect on the reaction rate, the Chan-Lam coupling of the cyclic imide $\mathbf{6 1}$ with the boronic acid $\mathbf{5 8}$ was performed applying the same reaction conditions as described by Halbmair et al. ${ }^{[4]}$ but under higher oxygen pressure (Figure 46).

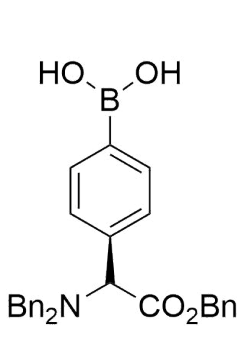

58

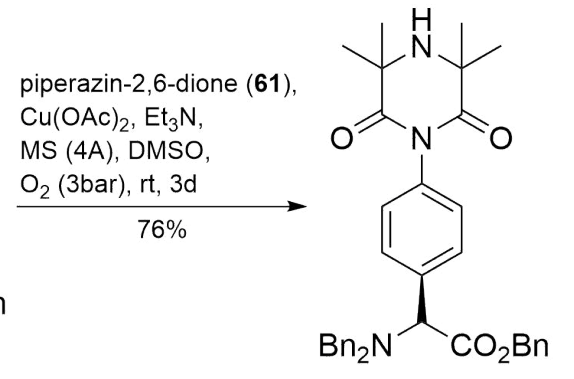

63

Figure 46: Chan-Lam coupling between the boronic acid spin label and the piperazin-2,6-dione.

Therefore, the boronic acid $\mathbf{5 8}$ and the cyclic imide $\mathbf{6 1}$ were stirred upon addition of triethylamine, anhydrous $\mathrm{Cu}(\mathrm{OAc})_{2}$ and molecular sieves in DMSO at room temperature under an oxygen pressure of 3 bar (Figure 46). The reaction was monitored by TLC and showed a complete conversion after $3 \mathrm{~d}$.

The coupling product $\mathbf{6 2}$ was isolated after purification by column chromatography in a good yield. By performing the reaction under the same conditions as described by Halbmair et al., only traces of the desired coupling product 63 were detected by TLC after 
$3 \mathrm{~d}$ of reaction.

Thus, the attempt to optimize the rate of the key reaction was successful, since it was possible to reduce the reaction time from 14 to $3 \mathrm{~d}$.

In the next steps of the synthesis, the preparation of the photolabile proteted $\alpha$-TOPP spin label was completed (Figure 47).

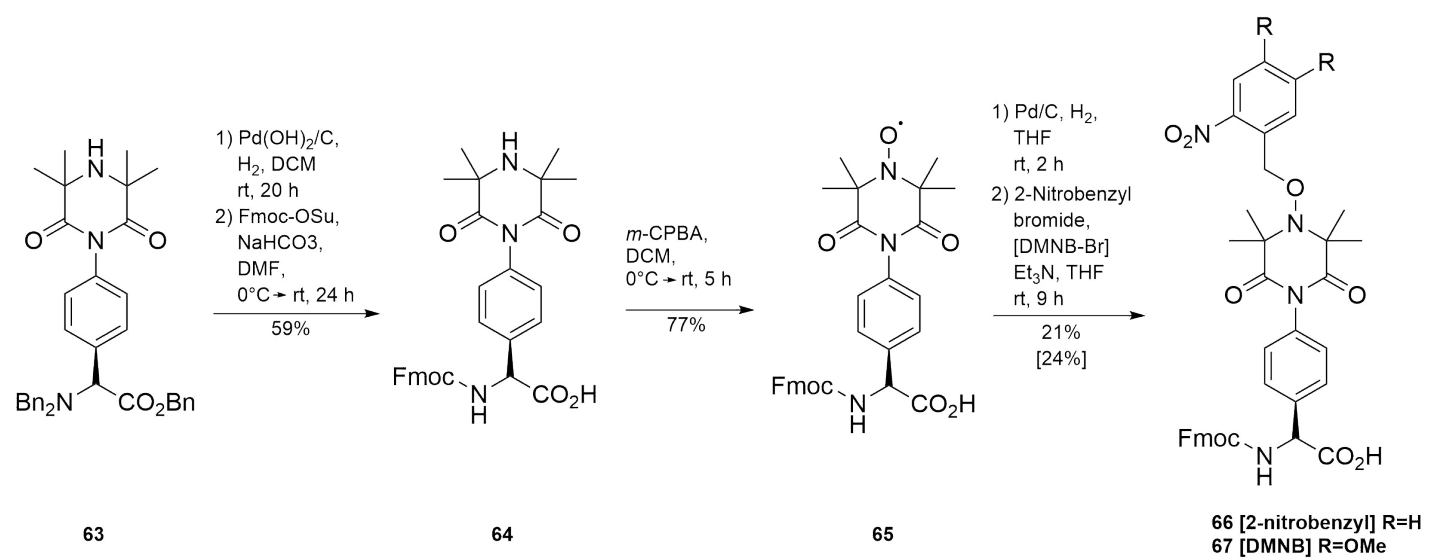

Figure 47: Synthesis of the 2-nitrobenzyl and DMNB protected $\alpha$-TOPP spin label from the cyclic amine.

Therefore, the benzyl protecting groups of the coupling product 3 were removed to protect the amino group by the base labile Fmoc group, which is suitable for the standard SPPS.

The removal of the benzyl groups was achieved hydrogenolytically using the Pearlman's catalyst $\left(\mathrm{Pd}(\mathrm{OH})_{2} / \mathrm{C}\right)$. For the benzyl deprotection, the coupling product 63 was dissolved in a mixture of $\mathrm{MeOH} / \mathrm{DCM}$ and stirred upon addition of the palladium catalyst at room temperature for $20 \mathrm{~h}$ under a hydrogen atmosphere (Figure 47). Afterwards, the crude intermediate was used in the next step without any further purification.

To install the Fmoc protecting group, the deprotected intermediate was reacted with $\mathrm{N}$ (9-fluorenylmethoxycarbonyloxy)succinimide (Fmoc-OSu) and $\mathrm{NaHCO}_{3}$ in $\mathrm{DMF}$ at room temperature for $24 \mathrm{~h}$ (Figure 47). Afterwards, the Fmoc protected spin label precursor 64 was isolated by column chromatography in a moderate yield.

In the last two steps of the linear synthesis, the nitroxide radical was generated by oxidation and finally, protected by the photolabile nitrobenzyl protecting group (Figure 47). For the oxidation of the secondary amine, the spin label precursor 64 was reacted with $m$-CPBA in DCM at room temperature for $5 \mathrm{~h}$ (Figure 47 ). After the conversion to the corresponding nitroxide radical the crude $\alpha$-TOPP spin label 65 was purified by column chromatography.

The spin label 65 was obtained in a good yield and was subsequently protected in the next step by a 2-nitrobenzyl group following the published two-step procedure by Seven et al. ${ }^{[97]}$

First, the nitroxide radical 65 was converted by hydrogenation into hydroxyl amine to react in the following nucleophilic substitution reaction with 2-nitrobenzyl bromide. 
Therefore, the spin label 65 was dissolved in THF and stirred upon addition of Pd/C under a hydrogen atmosphere for $2 \mathrm{~h}$ at room temperature (Figure 47 ). The reduction of the nitroxide radical 65 was monitored by TLC and after the conversion was complete, the reaction mixture was flushed with argon to remove the hydrogen and prevent oxidation of the hydroxyl amine.

Then, $\mathrm{Et}_{3} \mathrm{~N}$ and 2-nitrobenzyl bromide were added to the reaction mixture and the reaction was stirred for $9 \mathrm{~h}$ at room temperature (Figure 47). The photolabile protected spin label 66 was obtained after purification by column chromatography in a low yield.

The low yield could be explained by the formation of the 2-nitrobenzyl protected carboxyl by-product. Hence, a suitable carboxyl protecting group would be required to supress the side-reaction.

Additionally, the photolabile protection of the nitroxide radical was performed using the same conditions as described before, but using 4,5-dimethoxy-nitrobenzyl bromide (DMNB-Br) for protection (Figure 47). Since the DMNB group is known to have higher cleavage rates in comparison to the 2-nitrobenzyl group, the DMNB protected spin label 67 was synthesized as an alternative for the 2-nitrobenzyl protected spin label 66 .

\subsection{Testing the Removal of the 2-Nitrobenzyl and the DMNB Protecting Groups}

In the next step of the project, the cleavage conditions for the two photolabile protected spin labels 66 and $\mathbf{6 7}$ were tested. This step was crucial for the project, since the usage of the photolabile protected $\alpha$-TOPP spin label in NCL relies on the efficient recovery of the paramagnetic nitroxide radical after the ligation reaction.

In the studies of Seven et al. various spin labels were protected by photocleavable groups and the nitroxide radical could be readily recovered in high yields by a two-step process. ${ }^{[97]}$ After irradiation of the samples with UV light (365nm) a hydroxylamine intermediate is formed, which is usually easily oxidized to the corresponding nitroxide radical by air oxygen without the usage of additional oxidants, such as $\mathrm{PbO}_{2}$ or $\mathrm{Cu}(\mathrm{OAc})_{2} \cdot{ }^{[97]}$ To find the optimum cleavage conditions, the two photolabile protected spin labels $\mathbf{6 6}$ and $\mathbf{6 7}$ were irradited for $2 \mathrm{~h}$ with UV light $(365 \mathrm{~nm})$ in different solvent systems. Thereby, the cleavage process was monitored by RP-HPLC analysis of samples, that were taken in 10 min intervalls from the reaction mixture, to observe the formation of the nitroxide radical 65.

Due to better solubility of the protected spin labels $\mathbf{6 5}$ and $\mathbf{6 6}$, the reaction was performed in a mixture of $\mathrm{MeCN} / \mathrm{H}_{2} \mathrm{O}(v / v, 60 / 40)$ and in a mixture of basic carbonate buffer $(\mathrm{pH}=8.4)$ and $\mathrm{MeOH}(v / v, 1 / 3)$. The latter was expected to yield the better results, since the recovery of the nitroxide radical 65 from the hydroxylamine intermediate is more efficient under basic conditions. ${ }^{[97]}$ Figure 48 shows the RP-HPLC analysis of cleavage process for the 2-nitrobenzyl protected spin label 66 in the $\mathrm{MeCN} / \mathrm{H}_{2} \mathrm{O}$ mixture. The 
HPLC analysis was performed using an analytical C18 column and the solvents A (didemineralized water containing $0.1 \% \mathrm{TFA}$ ) and $\mathrm{B}$ (MeCN containing $0.1 \% \mathrm{TFA}$ ). For a good seperation of the reaction products a gradient from 10 to $40 \% \mathrm{~B}$ in 30 min was applied.

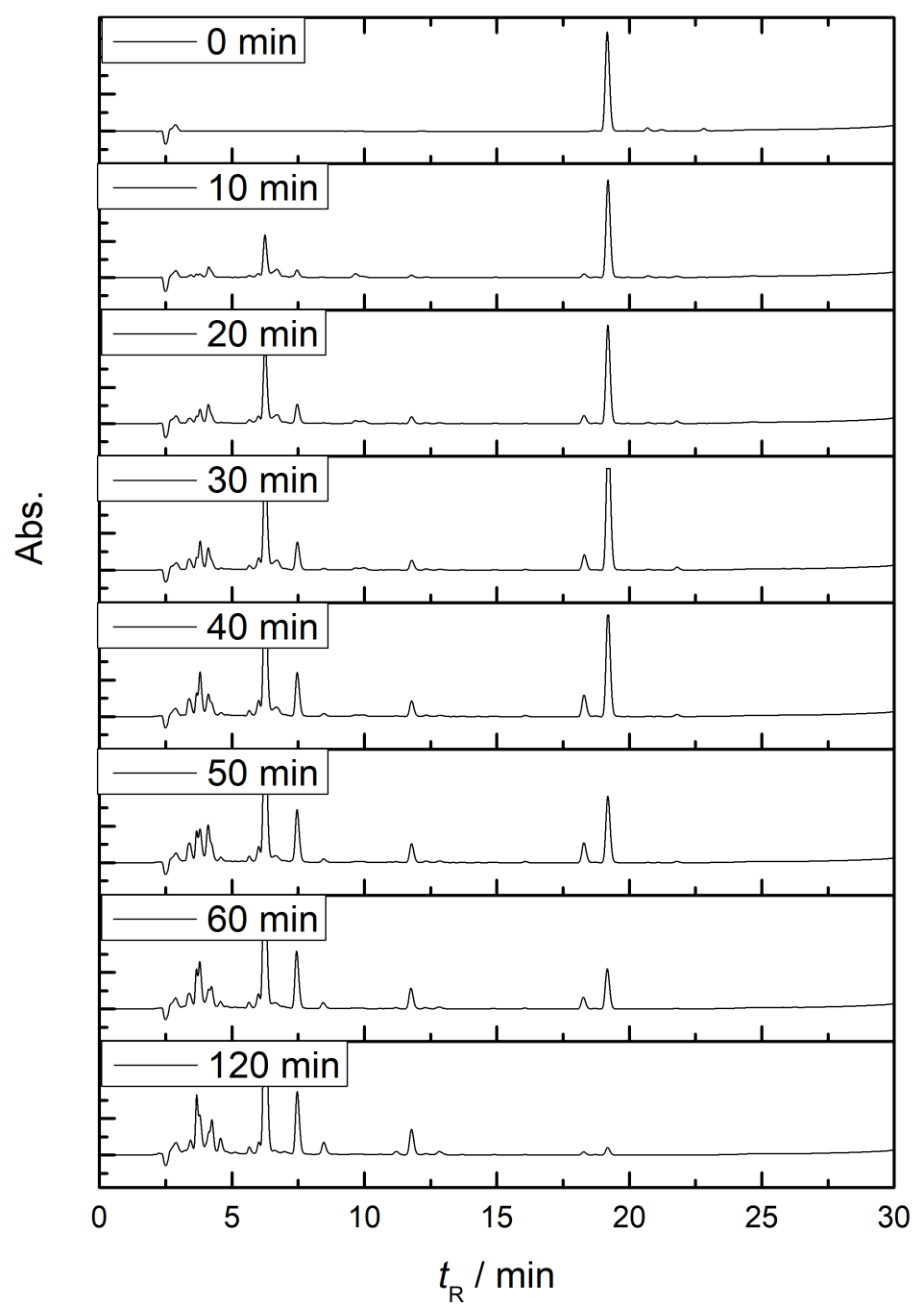

Figure 48: Monitoring of the 2-nitrobenzyl deprotection reaction by RP-HPLC.

Before irradiation with UV light (0 min), the HPLC-chromatogram shows one signal at a retention time $\left(t_{R}\right)$ of $19.2 \mathrm{~min}$ which corresponds to the 2-nitrobenzyl protected spin label 66. After irradiation of the sample for $10 \mathrm{~min}$, the formation of another product with a retention time of $6.3 \mathrm{~min}$ is observed, but the fraction was not identified as the desired nitroxide radical by ESI-MS analysis.

During the first $40 \mathrm{~min}$ of irradiation only a slight decrease of the protected spin label $\mathbf{6 6}$ could be observed, which indicated a bad cleavage efficiency of the 2-nitrobenzyl group. After $50 \mathrm{~min}$ of irradition, the intensity of the signal corresponding to the protected spin label dropped and a nearly complete disappearance of the signal was observed after $2 \mathrm{~h}$ of irradiation. 
However, no of the fractions corresponding to the signals at retention times of $18.3 \mathrm{~min}$, $11.4 \mathrm{~min}, 8.4 \mathrm{~min}, 7.5 \mathrm{~min}$ or $6.3 \mathrm{~min}$ could be identified by ESI-MS analysis as the desired nitroxide radical 65 or the hydroxylamine species.

Performing the irradiation in a mixture of carbonate buffer and $\mathrm{MeOH}$ led to the same results, whereby no formation of the nitroxide spin label 65 could be detected.

Therefore the deprotection was tested using the same conditions, but with the DMNB protected spin label 67. The DMNB protected spin label 67 was dissolved in a mixture of carbonate buffer and $\mathrm{MeOH}(v / v, 1 / 3)$ and was irradiated at $365 \mathrm{~nm}$ for $2 \mathrm{~h}$, whereby the first three samples of the reaction mixture were taken in 5 min intervals and the remaining samples in intervalls of $30 \mathrm{~min}$. The shorter intervals for the analysis during the first 15 min of reaction were chosen, because the cleavage of the DMNB protecting group is in general faster than of the 2-nitrobenzyl group. Therefore, to identify the optimum irraditiation time the first 15 min of irradiation were monitored in more detail.

The RP-HPLC analysis of the cleavage progress for the DMNB protected spin label 67 is illustrated in figure 49. The HPLC-analysis was performed using the same conditions as for the 2-nitrobenzyl protected spin label 66.

Before irradiation with UV light (0 min), the HPLC-chromatogram shows a main signal at a retention time of $18.5 \mathrm{~min}$, which corresponds to the DMNB protected spin label $6 \mathbf{6 7}$. After irradiation of the sample for $5 \mathrm{~min}$, a significant decrease of the signal corresponding to the DMNB protected spin label 67 could be observed. In addition to that, formation of other products with retention times of $14.9 \mathrm{~min}, 12.3 \mathrm{~min}$ and $6.3 \mathrm{~min}$ could be observed. After 30 min of irradiation, the signal corresponding to the protected spin label 67 nearly disappeared, which indicated a better cleavage efficiency in contrast to the 2-nitrobenzyl group.

During the next $90 \mathrm{~min}$ of irradition no changes of the signals corrsponding to the formed products could be observed, which indicates an optimum cleavage time of $30 \mathrm{~min}$.

However, no of the fractions corresponding to the signals at retention times of $14.9 \mathrm{~min}$, $12.3 \mathrm{~min}, 6.3 \mathrm{~min}, 4.8 \mathrm{~min}$ or $4.1 \mathrm{~min}$ could be identified as the nitroxide radical $\mathbf{6 5}$ or the hydroxylamine species.

The results obtained from the cleavage reactions of the 2-nitrobenzyl and the DMNB protected spin labels $\mathbf{6 6}$ and $\mathbf{6 7}$ show that these photolabile protection groups are not suitable for the $\alpha$-TOPP spin label, since the nitroxide radical could not be recovered after irradiation.

Probably the spin label is not stable under the irradiation conditions and is decomposed upon the cleavage of the protecting groups.

Taking these results into account, there was no point to incorporate these photolabile protected spin labels into peptide fragments to test ligation reactions, because the removal of the 2-nitrobenzyl and DMNB groups would probably also fail for peptide incorporated spin labels. 


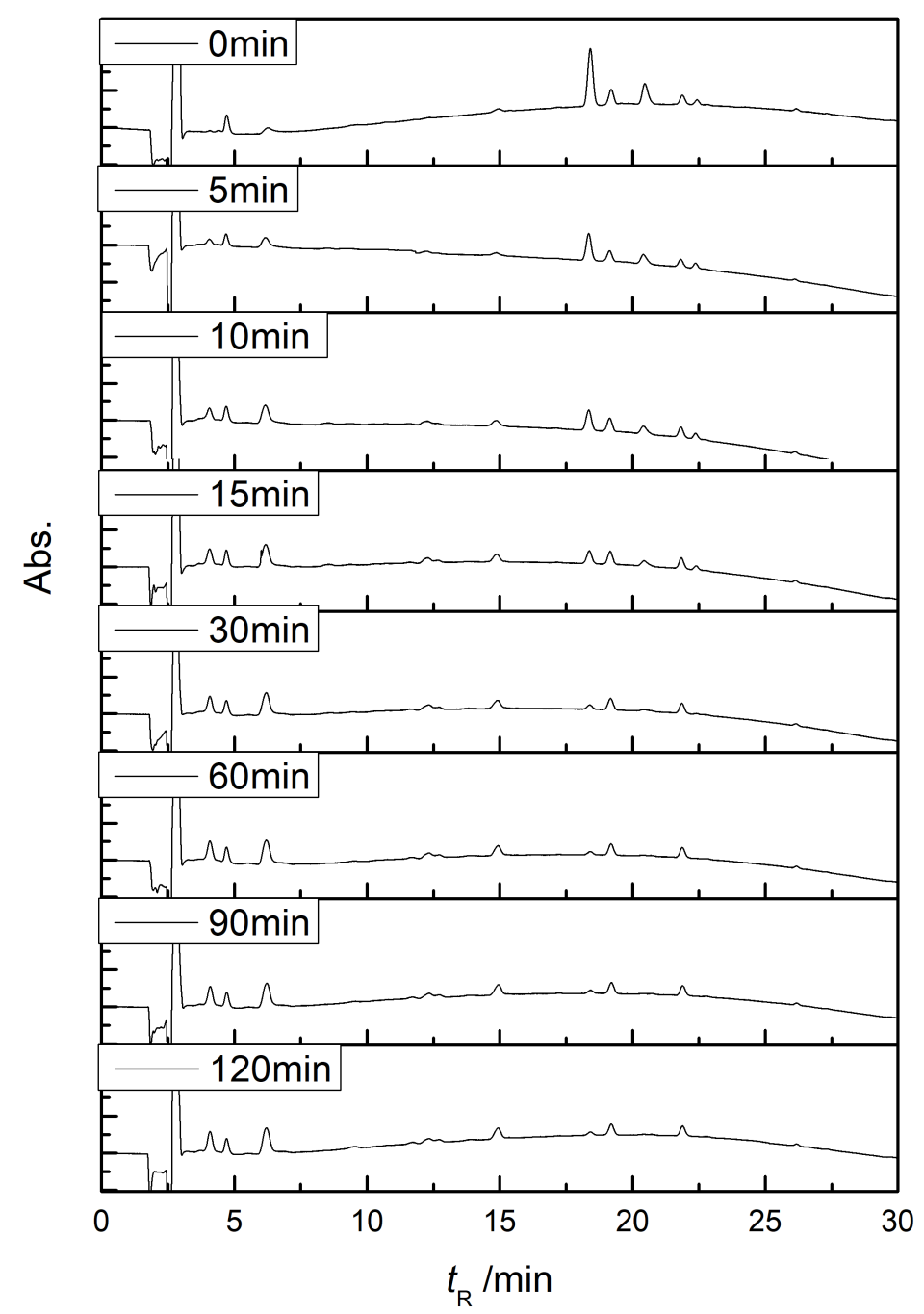

Figure 49: Monitoring of the DMNB deprotection reaction by RP-HPLC.

However, continuing the project without the usage of a nitroxide protecting group, would lead to a peptide fragment containing a reduced nitroxide radical, since previous research on the $\alpha$-TOPP spin label revealed the reduction of the nitroxide radical under the final cleavage conditions. Thereby, the reduction of the nitroxyl is caused by the reducing agents TIS and EDT, which are important additives to prevent oxidative side-reactions during the final peptide cleavage.

Since there are cysteine and tryptophane residues in the peptide fragment, the addition of these reducing agents cannot be avoided. Otherwise, oxidation of the tryptophane residues and disulfide bond formation between cysteine residues would readily occur.

Thus, an unmasked nitroxide radical in the peptide fragment would be converted into the reduced hydroxylamine during final cleavage and could not be recovered back by oxidation, without oxidizing the free thiol group of the cysteine residues. 


\section{Summary and Outlook}

The main aim of this work was to design and synthesize a $\beta$-turn inducing or stabilizing spin label which could be directly incorporated into peptides by SPPS. Therefore, based on the idea to stabilize or induce $\beta$-turn conformations in peptides by geometrical preorganization, an azabicyclo amino acid derived spin label was designed (Figure 50) and suitable synthesis approaches were developed.

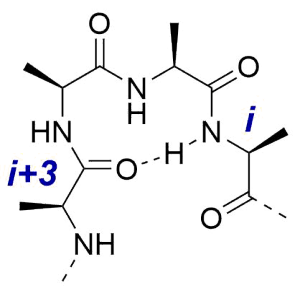<smiles>CNC(=O)C1CSC2CCC(NC(C)C)C(=O)N21</smiles><smiles>CC1(C)C2C3CC[C@H](NC(F)F)C(=O)N3C(C(=O)O)C2C(C)(C)N1O</smiles>

Figure 50: Design of the azabicyclo derived $\beta$-turn stabilized spin label.

In the course of this work, two retrosynthetical approaches for the synthesis of the $\beta$-turn inducing spin label were developed and tested.

The first approach was based on the previously described synthesis ${ }^{[71]}$ of the azabicyclo amino acid and required the preparation of a carboxyl substituted $\gamma$-lactam spin label (Figure 51).
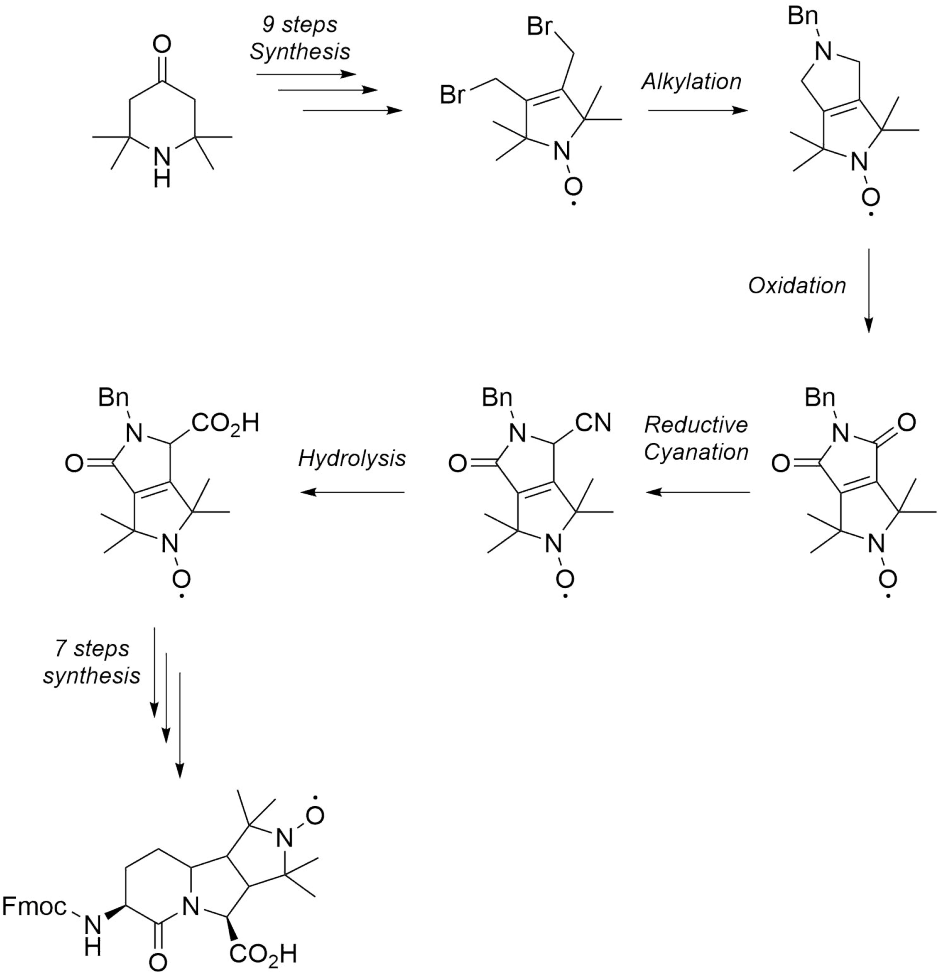

Figure 51: Schematic representation of the synthesis of the new $\beta$-turn stabilizing spin label. 
The $\gamma$-lactam spin label was aimed to be synthesized from a dibromide spin label, whose preparation was previously described. ${ }^{[77]}$ Following the developed synthesis route, the preparation of the desired $\gamma$-lactam spin label could not be completed successfully, since the reductive cyanation of the cyclic imide failed probably due to decomposition of the reactant under the applied reaction conditions.

Thus, a second approach for the synthesis of the azabicyclo spin label was developed and tested, which utilized a stannyl anion mediated cyclization reaction to form the annealed ring system of the target spin label (Figure 52).

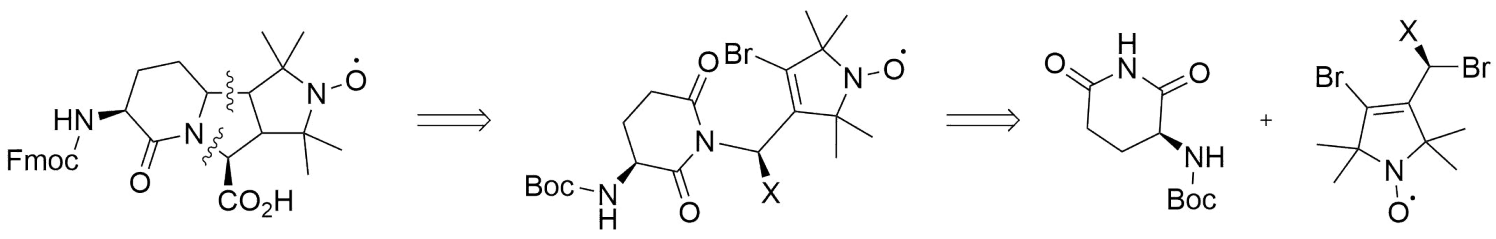

Figure 52: Retrosynthetic design of the $\beta$-turn stabilizing spin label. The key step of the synthesis is an intramolecular anionic cyclisation of an imide substituted spin label, that is synthesized from a vinyl bromide spin label. The substituent $\mathrm{x}$ represents a suitable carboxyl precursor.

As a principle of proof, anionic cyclisation between a vinylbromide spin label and a cyclic imide was performed successfully yielding the new bicyclic spin label, that lacked at this stage of the synthesis a carboxyl moiety (Figure 53).

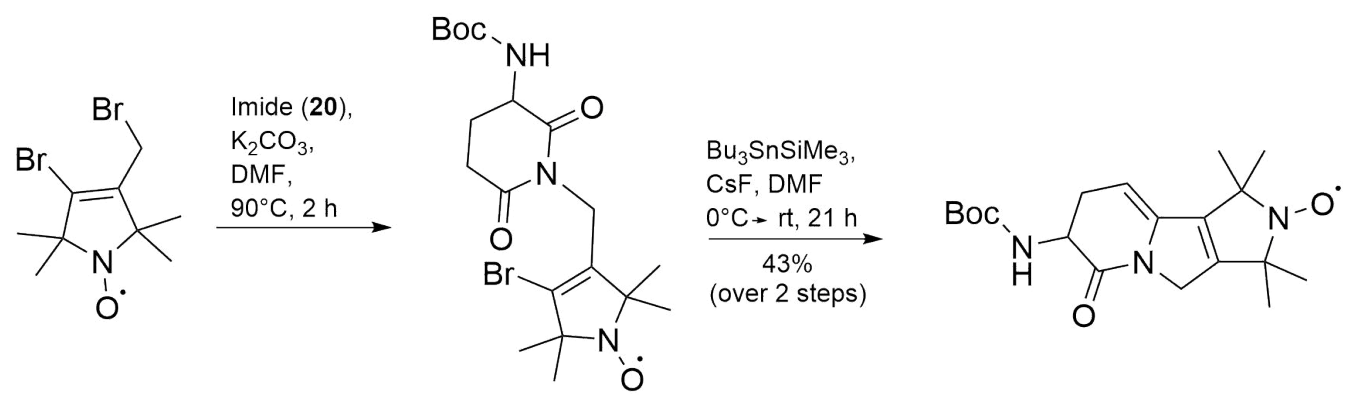

Figure 53: Synthesis of the azabicyclo spin label to test the anionic cyclisation reaction.

Therefore, synthetical strategies for the functionalization of the bicyclic spin label by a carboxyl acid group were developed (Figure 54). The first approach A was based on the usage of an amino nitrile spin label prepared by a Strecker reaction.

However, the approach revealed to be not suitable, since the attempted amino nitrile spin label turned out to be not stabile and converted to the corresponding imine by HCN elimination. Thus, the functionalization was continued using the second approach $\mathbf{B}$.

For the second approach, the preparation of a cyanohydrin spin label was required. The desired cyanohydrin spin label could be prepared from the aldehyde spin label but not be isolated, due to fast conversion into the starting material. 


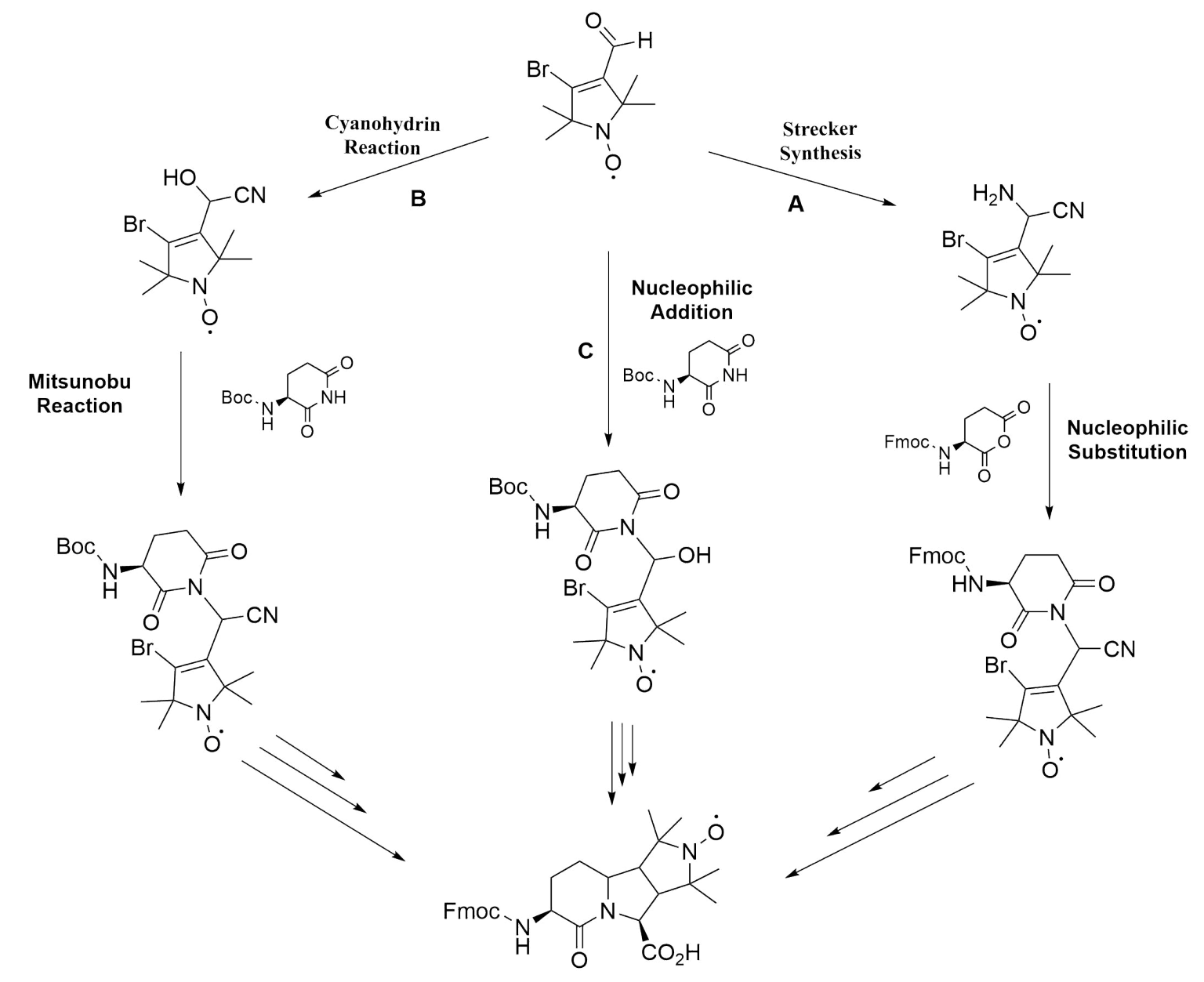

Figure 54: Attempted synthetic strategies for C-C bond formation. Routes A and B aim to introduce a nitrile group as carboxyl acid precursor via Strecker or a cyanohydrin reaction. Route $\mathbf{C}$ is based on the direct nucleophilic addition of the cyclic imide to the carbonyl $\mathrm{C}$ to form a secondary alcohol.

Therefore, another approach $\mathbf{C}$ for the functionalization was tested, whereby a hydroxyl group functionalized imide was successfully synthesized and utilized for the anionic cyclization reaction. However, the reactant was not tolerated by the cyclization reaction, so that the synthesis of the target spin label could not be accomplished.

Thus, an easier accessible $\beta$-turn conformation stabilizing spin label for the SPPS using a completely different spin label design was synthesized.

The new design was inspired by azapeptides that are known to adopt different types of $\beta$-turn conformations due to the conformationally constrained aza residue. In addition to that, they can be easily modified by side-chain mimetics or different functinalities during the azapeptide synthesis. ${ }^{[84-89]}$ Thus, an azadipeptide based protected spin label was developed and could be successfully synthesized by alkylation of an azadipeptide monomer (Figure 55). Furthermore, the nitroxyl protected spin labeled azadipeptide could be incorporated into a model peptide by SPPS leading to a new class of spin labled azapeptides (Figure 55). However, at the current stage the removal of the nitroxyl protecting group failed due to the incompatibility of the azapeptide with the conditions of its deprotec- 


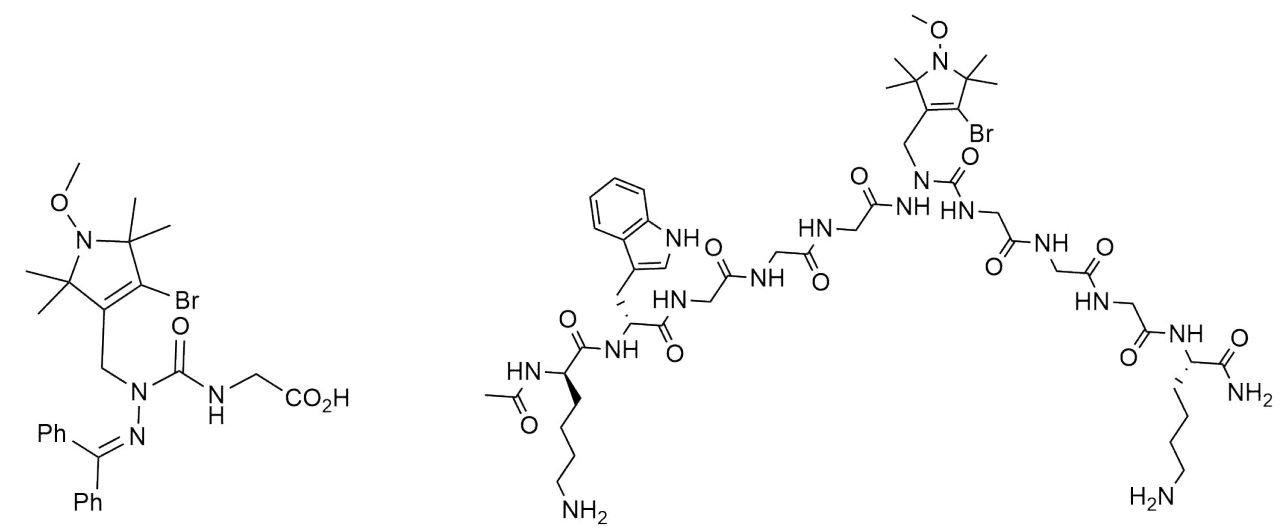

Figure 55: Synthesized azadipeptide spin label (left) and the prepared azapeptide using the new methoxy protected spin label (right).

tion. Nevertheless, the synthesized spin label could be a promising canditate for further studies on the conformational effect of spin labeled aza residues in peptides in terms of stabilization or induction of turn structures.

Therefore, in order to use the new nitroxide protected spin labeled azadipeptide in further applications, a new protecting group strategy is required to recover the paramagnetic nitroxyl group. Therefore, a photolabile protecting group such as 2-nitrobenzyl could be applied.

In the course of this work, a photolabile protecting group approach for the synthesis of $\alpha$-TOPP spin labeled peptides by NCL should be established. The NCL is one of the most used techniques to synthesize large proteins from two or more protein fragments by a selective reaction between a C-terminal thiolester residue and a $\mathrm{N}$-terminal thiol residue. ${ }^{[6]}$

Since the semi-rigid $\alpha$-TOPP spin label showed promising results in conformational EPR studies of transmembrane model peptides ${ }^{[4]}$, its application in larger protein systems is highly desirable.

To incorporate the $\alpha$-TOPP spin label into a cysteine containing peptide fragment by SPPS, the nitroxide radical needs to be masked by a photolabile protecting group to avoid side-reaction with the redox active cysteine residue. Moreover, photolabile protecting groups for nitroxide radicals are suitable due to their compatibility with the Fmoc/ $t \mathrm{Bu}$ protecting group strategy for SPPS and the easy recovery of the nitroxide radical by irradiating the protected peptide with UV light.

For the synthesis of the 2-nitrobenzyl and DMNB protected $\alpha$-TOPP spin labels, the $\alpha$-TOPP spin label was synthesized in nine steps according to previously published procedures. ${ }^{[3,4]}$ Thereby, the synthesis of the $\alpha$-TOPP spin label could be optimized in terms of time efficiency and usage of benign starting material for the preparation of the cyclic imide. The Chan-Lam cross-coupling, that is crucial for the formation of the spin label framework, could be successfully optimized by performing the reaction under oxygen pressure. The change of this reaction parameter led to a reduction of the reaction 
time from $14 \mathrm{~d}$ to $3 \mathrm{~d}$. In addition to that, the preparation of the cyclic imide could be optimized by using more benign starting material and avoid time consuming purification steps. Finally, the $\alpha$-TOPP spin label was successfully protected by the 2-nitrobenzyl and the DMNB photolabile groups (Figure 56). However, the 2-nitrobenzyl derived pho-

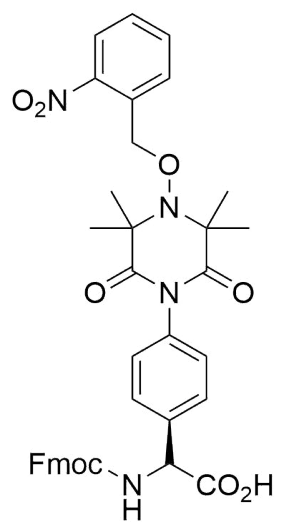<smiles>COc1cc(CON2C(C)(C)C(=O)N(c3ccc(C(NC(F)F)C(=O)O)cc3)C(=O)C2(C)C)c([N+](=O)[O-])cc1OC</smiles>

Figure 56: Synthesized 2-nitrobenzyl protected (left) and DMNB protected (right) $\alpha$-TOPP spin label.

tolabile protecting groups turned out to be not suitable for the synthesis of $\alpha$-TOPP spin labeled peptides, which was revealed by preliminary deprotection studies of the 2nitrobenzyl and DMNB protected $\alpha$-TOPP spin labels. For the complete removal of the protection groups, the 2-nitrobenzyl protected spin label was irradiated for $2 \mathrm{~h}$ and the DMNB protected spin label for $30 \mathrm{~min}$, which is quite long.

In addition to that, neither the nitroxide radical species nor the corresponding hydroxylamine intermediate could be isolated after irradiation, which could indicate the instability of the $\alpha$-TOPP spin label under the applied cleavage conditions.

Therefore, for future attempts a coumarine based protecting group could be tested, which might result in higher cleavage rates and be therefore, a suitable protection group. ${ }^{[97]}$ 


\section{Experimental Part}

\subsection{Materials and Methods}

\subsubsection{Reagents and Solvents}

The reactions were performed using commercial available reagents without any further purification that were provided by ABCR (Karlsruhe, Germany), ACROS ORGANICS (Geel, Belgium), ALFA AESAR (Karlsruhe, Germany), BACHEM (Bubendorf, Switzerland), CARL ROTH (Karlsruhe, Germany), FISCHER SCIENTIFIC (Nidderau, Germany), FLUKA (Taufkirchen, Germany), MERCK (Darmstadt, Germany), RIEDEL-DE HAËN (Seelze, Germany), TCI (Eschborn, Germany) and VWR (Darmstadt, Germany).

The Fmoc-protected amino acids, coupling reagents and the Rink amide MBHA resin were purchased from GL BIOCHEM (Shanghai, China), IRIS (Marktredwitz, Germany), ACROs ORGAniCs (Geel, Belgium) and MERCK (Darmstadt, Germany).

Reactions under standard aerobic conditions were performed in p.a. grade solvents, while reactions with oxygen or water sensitive components were performed in commercially available extra-dry solvents. The solvents were obtained from SIGMA-ALDRICH (Taufkirchen, Germany) and ACROs ORGAniCs (Geel, Belgium). Solvents for HPLC purification and analysis were purchased from FLUKA (Taufkirchen, Germany), VWR INTERNATIONAL

(Fontenay-sous-Bois, France), ACROS ORGANICS (Geel, Belgium) and SIGMA-ALDRICH (Taufkirchen, Germany). Ultra-pure water (MilliQ) was prepared from demineralised water using the purification systems SYMPLICITY from MERCK MILLIPORE (Bedford, UK) and arium ${ }^{\circledR}$ mini from SATORIUS (Göttingen, Germany).

Deuterated chloroform $\left(\mathrm{CDCl}_{3}\right)$ and dimethyl sulfoxide (DMSO- $\left.\mathrm{d}_{6}\right)$ for the NMR analysis were obtained from DEUTERIO (Kastellaun, Germany).

\subsubsection{Methods}

\section{Reactions}

Reactions utilizing oxygen or water sensitive reagents or intermediates were carried out in dried glassware under an argon or nitrogen atmosphere. To remove residual moisture and air, the glass apparatus was heated in vacuo and was allowed to cool to room temperature, before purging with argon or nitrogen. Thereby, this process was repeated three times. All reagents were added to the apparatus either in a counter stream of argon or nitrogen or through a septum via a syringe cannula. 


\section{Lyophilization}

The aqueous solution of the sample was frozen in liquid nitrogen and freeze-dried in high vacuum. Thereby, fractions collected from RP-HPLC purification were concentrated in a nitrogen stream to remove MeCN and TFA from the solution. For the lyophilization a CHRIST ALPHA-2-4 lyophiliser (Osterode am Harz, Germany) equipped with a high vacuum pump was employed. Samples containing a volume up to $1.5 \mathrm{~mL}$ were freeze-dried in microcentrifuge tubes in speedvac device RVC 2-18 CD plus of CHRIST (Osterode am Harz, Germany) connected to the lyophiliser.

\section{Thin Layer Chromatography}

For analysis of samples by thin layer chromatography (TLC), silica coated aluminiumbacked TLC-plates (0.2 $\mu \mathrm{m}$, silica gel 60 F254) from MERCK (Darmstadt, Germany) were used as stationary phase. After applying the sample on the bottom of the plate and developing the TLC-plate in the appropriate solvent mixture, the substances were visualized on the plate by fluorescence quenching at $254 \mathrm{~nm}$ or by staining. Therefore, the plate was immersed in a ninhydrin solution (3\% ninhydrin in EtOH) and was subsequently heated, whereby compounds containing amine groups appeared red on the TLC-plate. The retention factor $\left(\mathrm{R}_{f}\right)$ of a compound is defined as the ratio of the compound's front distance to the solvent front distance.

\section{Flash Column Chromatography}

For purification of compounds flash column chromatography was performed by applying pressure in a range from 0.1 to 0.8 bar. For the chromatography glass columns equipped with a frit were used and filled with silica gel (Type 60, 40-63 nm, from MERCK (Darmstadt, Germany)) suspended in an appropriate solvent mixture.

\section{High Performance Liquid Chromatography}

High performance liquid chromatography (HPLC) was carried out on JASCO (GrossUmstadt, Germany) instruments equipped with an analytical reversed phase column (Nucleodur ${ }^{\circledR}$ RP C-18 analytical HPLC column, $250 \mathrm{~nm}$ x $4.6 \mathrm{~mm}, 5 \mu \mathrm{m}$ ) from MACHEREYNAGEL (Düren, Germany) with a flow of $0.5 \mathrm{~mL} / \mathrm{min}$. For the detection of the compounds, UV absorptions at 215, 254 and $280 \mathrm{~nm}$ were utilized. For the elution of the compounds, the solvent $\mathrm{A}$ : bi-demineralised $\mathrm{H}_{2} \mathrm{O}+0.1 \% \mathrm{TFA}$ and solvent $\mathrm{B}$ : $\mathrm{MeCN}+0.1 \%$ TFA were used, whereby a concentration gradient of solvent B was applied, as defined in experimental procedure. Reaction monitoring was performed on a JASCO system equipped with a MD-2010plus multiwavelength detector, LC-Net II/ADC, CO-2060plus intelligent column thermostat, AS-2055plus intelligent sampler and two PU-2085plus semi-micro HPLC pumps. Peptides were purified on analytical scale using a JASCO system equipped 
with a MD-2010plus multiwavelength detector, LC-Net II/ADC, a DG-2080-53 3-line degasser and two PU 2086plus intelligent HPLC pumps. The samples were dissolved in an appropriate mixture of bi-demineralised water and MeCN followed by filtering using a CHROMAFIL ${ }^{\circledR}$ RC-45/15 MS filter from MACHERY-NAGEL.

\subsection{Analysis}

\section{Nuclear Magnetic Resonance}

Nuclear magnetic resonance NMR experiments for the characterisation of synthesized compounds were performed on VARIAN (California, USA) instruments (Mercury (VX) 300, Unity 300, Inova-500). The sample temperature was set for $\mathrm{CDCl}_{3}$ to $298 \mathrm{~K}$ and for DMSO- $\mathrm{d}_{6}$ to either $298 \mathrm{~K}$ or $308 \mathrm{~K}$. The frequencies used in the measurements are given in the analytic data section of the corresponding compound. The ${ }^{13} \mathrm{C}-\mathrm{NMR}$ experiments were proton-decoupled and the chemical shift $\delta$ is indicated in part per million (ppm). The chemical shift of the solvents was used as the internal standard with $\delta=7.26 \mathrm{ppm}\left({ }^{1} \mathrm{H}\right)$ and $77.16 \mathrm{ppm}\left({ }^{13} \mathrm{C}\right)$ for $\mathrm{CDCl}_{3}$ and $\delta=2.50 \mathrm{ppm}\left({ }^{1} \mathrm{H}\right)$ and $39.52 \mathrm{ppm}\left({ }^{13} \mathrm{C}\right)$ for DMSO$\mathrm{d}_{6}$. The following abbreviation for the multiplicities of the signals were used: $\mathrm{s}=$ singlet, $\mathrm{d}=$ doublet, $\mathrm{t}=$ triplet, $\mathrm{q}=$ quartet, hept $=$ heptet, $\mathrm{m}=$ multiplet and $\mathrm{sbr}=$ broadened singlet. The coupling constant ${ }^{n} \mathrm{~J}_{x, y}$ was calculated using the measuring frequency in Hertz, whereby $\mathrm{n}$ is the number of the bonds between the coupling nuclei and $\mathrm{x}$ and $\mathrm{y}$ represent the coupling nuclei.

\section{Mass Spectrometry}

For the analysis of the compounds, mass spectrometry was performed using the ionisation technique electrospray ionisation (ESI). The data obtained from the mass spectrum was in mass-to-charge ratio $(\mathrm{m} / z)$. The ESI and high resolution ESI (HR-ESI) measurements were performed using either a BRUKER (Massachusetts, USA) micrOTOF-Q II or a BRUKER maXis ESI-QTOF-MS instrument.

\section{UV/Vis Spectroscopy}

The concentration of peptide solutions were calculated according to the absorption of the amino acid tryptophane at $280 \mathrm{~nm}\left(\epsilon=5600 \mathrm{~cm}^{-1} \mathrm{M}^{-1}\right)^{[113]}$ using the Lambert-Beer law:

$$
c=\frac{A}{\epsilon \cdot d}
$$

Thereby, $A$ is defined as the measured absorption at $280 \mathrm{~nm}, \epsilon$ as the molar extinction coefficient in $\mathrm{cm}^{-1} \mathrm{M}^{-1}$ and $d$ as the path length in $\mathrm{cm}$. Reference spectra were obtained from pure solvents. The UV/vis measurements were performed on a V-650 JASCO spectrometer equipped with a JASCO temperature controller ETCS-761 and a thermostat 
from JULABO F250 (Seelbach, Germany) in glass cuvettes Suprasil ${ }^{\circledR}$ (QS) from HELLMA (Müllheim, Germany).

\section{Circular Dichroism Spectroscopy}

For the analysis of the secondary structure in peptide, circular dichroism (CD) spectroscopy was applied using a JASCO J-1500 spectropolarimeter equipped with a cell holder and an installed peltier thermostat JASCO PTC-510 connected to a JULABO F250 thermostat. Before and during the measurement, the device was purged with nitrogen. The measurement of the $50 \mu \mathrm{mol}$ solution of the peptide in $\mathrm{MeOH}$ was performed in $1.0 \mathrm{~mm}$ quartz glass cuvette from HELLMA (Suprasil ${ }^{\circledR}$ QS) and the temperature during the measurement was controlled by the sensor in the holder. For the CD measurement, a measurement range from $260-190 \mathrm{~nm}$, a data pitch of $0.1 \mathrm{~nm}$, the CD scale of 200/0.1 mdeg/dOD, the FL scale of 200/0.1 mdeg/dOD, a digital integration time (D.I.T) of $1 \mathrm{~s}$, a bandwidth of $1 \mathrm{~nm}$, a scanning speed of $50 \mathrm{~nm} / \mathrm{min}$ and accumulation number of 10 were applied. The measurement of the pure solvent served as reference. The CD signal was obtained as the relative ellipticity $\Theta$ in mdeg, which was converted into the molar ellipticity $\Theta_{M}$ in $\operatorname{deg} \cdot \mathrm{cm}^{2} \cdot \mathrm{dmol}^{-1}$ using the following equation:

$$
\Theta_{M}=\frac{\Theta}{100 \cdot c \cdot d}
$$

Thereby, $\Theta$ is the elipticity in mdeg, $c$ is the peptide concentration in mol/L and $d$ is the path length in $\mathrm{cm}$.

\subsection{Standard Operating Procedures}

\subsubsection{Ninhydrin Color Test}

The ninhydrin color test ${ }^{[99]}$ is a method to detect free primary amine groups in resin bound peptide and is performed to monitor N-terminal Fmoc deprotection and attachement of amino acid residues. Therefore, 2-3 drops of solution I ( $5 \mathrm{~g}$ ninhydrin dissolved in $100 \mathrm{~mL}$ EtOH), solution II ( $80 \mathrm{~g}$ phenol dissolved in $20 \mathrm{~mL}$ EtOH) and solution III ( $2 \mathrm{~mL}$ of an aqueous KCN solution $\left(1 \cdot 10^{-3} \mathrm{M}\right)$ in $98 \mathrm{~mL}$ pyridine) were added to few peptidyl resin beads in a $1 \mathrm{~mL}$ glass vessel and the suspension was warmed on a heating plate to approximately $120^{\circ} \mathrm{C}$. Thereby, in case of free primary amino groups, the color of the solution and the resin beads turns blue, as a result of an reaction between the in-situ generated ninhydrin reagent and the amine group. The solution and the resin beads remain yellow to colorless in the case of a negative result.

\subsubsection{Manual Solid-Phase Peptide Synthesis}

The manual synthesis of side-chain protected peptides according to the Fmoc/ $t$ Bu strategy was performed microwave (CEM Discover, Kamp-Lintfort, Germany) assisted applying 
the following parameters and settings for the double deprotection and coupling steps:

\begin{tabular}{lll}
\hline Process & Monomer & Parameters \\
\hline $\begin{array}{l}\text { Deprotection } \\
\text { (Two-Stage Deprotection) }\end{array}$ & & $50^{\circ} \mathrm{C}, 30 \mathrm{~s}, 25 \mathrm{~W}$ \\
\hline Coupling & $50{ }^{\circ} \mathrm{C}, 180 \mathrm{~s}, 25 \mathrm{~W}$ \\
\hline & & $50^{\circ} \mathrm{C}, 3 \mathrm{~min}, 10 \mathrm{~W}$ \\
& & (Double Coupling) \\
\hline
\end{tabular}

Thereby, the SPPS was performed on a Fmoc protected low loaded Rink amide MBHA resin with a loading capacity of $0.36 \mathrm{mmol} / \mathrm{g}$ on the scale, as stated in experimental procedure, using 4 equivalents of the following standard Fmoc protected amino acids (Fmoc-AA-OH)) in DMF:

- Fmoc-L-Gly-OH

- Fmoc-L-Lys(Boc)-OH

- Fmoc-L-Trp(Boc)-OH

Before synthesis, the Rink amide MBHA resin was placed in a syringe (BD Discardit II) equipped with a stopper and an polyethylene frit. Then, DMF was added until the resin was covered by the solvent and the resin was swollen for 30 min at room temperature by agitating on an automated shaker. Afterwards, the solvent was discarded and the synthesis started with the removal of the Fmoc protection group from the Rink amide resin using a $20 \mathrm{vol} \%$ deprotection solution of piperidine in DMF.

Thereby, a two-stage deprotection was performed applying the microwave settings from the table above by adding the deprotection solution to the resin until it was covered by the solvent. Between the first and the second stage of deprotection, the resin was washed with DMF three times. After the deprotection of the Fmoc group, the resin was washed with DMF, DCM and DMF three times each and the first amino acid was attached subsequently to the resin in the next step.

Therefore, the carboxyl group of the Fmoc protected amino acid was activated by the activating agents HOAt and HATU, 4 and 3.9 equivalents each, in DMF upon addition of 4 equivalents of the activator base DIPEA. The Fmoc protected amino acid (Fmoc-AA-OH) was dissolved in the activator solution and transfered to the swollen resin, followed by the addition of the activator base. After irradiating the resin in the coupling solution, using the settings defined in table above, the resin was washed with DMF, DCM and DMF three times each. The coupling step was performed twice for each amino acid to ensure good coupling efficiency. For the attachement of the next amino acid residue, double deprotection was performed to cleave the Fmoc group from the N-terminus and subsequently the double coupling of the next amino acid was performed. This deprotection-coupling cycle was repeated until the desired sequence was synthesized.

Finally, the N-terminal Fmoc protection group was removed and capping of the terminal amino group was performed. Therefore, a freshly prepared solution of $20 \mathrm{vol} \%$ acetic 
anhydride in DMF was added to the peptidyl resin and the mixture was agitated on an automated shaker for 5 min at room temperature. Afterwards, the peptidyl resin was washed with DMF, DCM and MeOH three times each and dried in vacuo.

\subsubsection{Final Peptide Cleavage and Work-Up}

For the cleavage of the peptide from the resin and removal of the side-chain protection groups, the peptidyl resin was agitated for $2 \mathrm{~h}$ at room temperature in a cleavage cocktail containing $2.5 \mathrm{vol} \%$ TIS and $2.5 \mathrm{vol} \% \mathrm{H}_{2} \mathrm{O}$ in TFA. Afterwards, the filtrate was collected and the TFA was removed in a nitrogen stream. The residue was suspended in cold diethyl ether and the resulting suspension was centrifugated to yield a pellet of the precipitated peptide after decanting of the supernatant. Then, the peptide was resuspended in cold diethyl ether, centrifugated and the supernatant was discarded to wash the crude peptide. The washing procedure was repeated three times and afterwards, the crude peptide was dried under reduced pressure. 


\subsection{Synthesis of $\beta$-Turn inducing Spin Label}

\section{3,5-Dibromo-2,2,6,6-tetramethylpiperidinium bromide $(2)^{[72]}$}

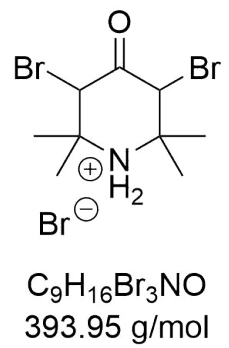

A solution of $\mathrm{Br}_{2}(0.50 \mathrm{~mL}, 1.54 \mathrm{~g}, 19.3 \mathrm{mmol}, 2.00 \mathrm{eq})$ in glacial $\mathrm{AcOH}(10 \mathrm{~mL})$ was added dropwise to a pre-cooled solution of 2,2,6,6-tetramethyl-4-piperidone $(1.50 \mathrm{~g}, 9.66 \mathrm{mmol}$, $1.00 \mathrm{eq})$ in glacial $\mathrm{AcOH}(20 \mathrm{~mL})$ at $0{ }^{\circ} \mathrm{C}$. After complete addition the mixture was allowed to warm up to room temperature and was stirred for $18 \mathrm{~h}$. The precipitated hydrobromide salt 2 was filtered and washed with glacial $\mathrm{AcOH}(2 \times 50 \mathrm{~mL})$ and $\mathrm{Et}_{2} \mathrm{O}(2 \times 50 \mathrm{~mL})$. The hydrobromide salt (mixture as diastereomers) $\mathbf{2}$ was obtained after drying in vacuum as colorless solid $(2.21 \mathrm{~g}, 8.11 \mathrm{mmol}, 84 \%)$.

${ }^{1} \mathbf{H}-\mathbf{N M R}\left(300 \mathrm{MHz}, \mathrm{DMSO}_{6}\right): \delta[\mathrm{ppm}]=9.68\left(\mathrm{~s}, 2 \mathrm{H}, 2 \times \mathrm{NH}_{2}{ }^{+}\right), 5.58(\mathrm{~s}, 2 \mathrm{H}, 2 \times \mathrm{CH})$, $5.48(\mathrm{~s}, 2 \mathrm{H}, 2 \times \mathrm{CH}), 1.72-1.65\left(\mathrm{~m}, 12 \mathrm{H}, 4 \times \mathrm{CH}_{3}\right), 1.50-1.41\left(\mathrm{~m}, 12 \mathrm{H}, 4 \mathrm{xCH}_{3}\right)$.

\section{Methyl-2,2,5,5-tetramethyl-2,5-dihydropyrrole-3-carboxylate (3) ${ }^{[72]}$}

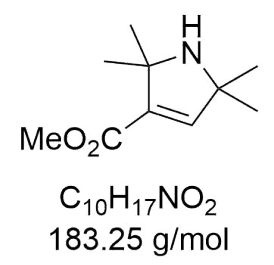

A NaOMe solution in $\mathrm{MeOH}(2.4 \mathrm{M}, 9.53 \mathrm{~mL}, 22.9 \mathrm{mmol}, 3.00 \mathrm{eq})$ was added to pre-cooled dry $\mathrm{MeOH}(10 \mathrm{~mL})$ under an argon atmosphere. Then, the hydrobromide salt (2) (3.04 g, $7.62 \mathrm{mmol}, 1.00 \mathrm{eq}$ ) was added in portions to the $\mathrm{NaOMe}$ solution and the reaction was stirred at room temperature for $2 \mathrm{~h}$. The solvent was removed under reduced pressure and the residue was dissolved in $\mathrm{Et}_{2} \mathrm{O}(30 \mathrm{~mL})$, washed with $5 \%$ aq. $\mathrm{NaHCO}_{3}$ solution $(2 \times 20 \mathrm{~mL})$ and the combined aqueous fractions were extracted with $\mathrm{Et}_{2} \mathrm{O}(2 \times 20 \mathrm{~mL})$. After drying the combined organic fraction over $\mathrm{MgSO}_{4}$ the solvent was removed under high pressure. Finally, the methyl ester 3 was obtained after purification with flash column chromatography on $\mathrm{SiO}_{2}$ (Pe/EtOAc, 60/40, v/v) as a yellowish oil (1.03 g, $5.63 \mathrm{mmol}$, $74 \%)$. 
ESI-MS: $\mathrm{m} / z=184.1[\mathrm{M}+\mathrm{H}]^{+}$.

ESI-HRMS: $\mathrm{m} / z$ calcd. for $\mathrm{C}_{10} \mathrm{H}_{17} \mathrm{~N}_{1} \mathrm{O}_{2} \mathrm{H}[\mathrm{M}+\mathrm{H}]^{+}: 184.1332$ found: 184.1335 .

Methyl-2,2,5,5-tetramethyl-2,5-dihydropyrrole-3-carboxylate-1-oxyl (4) ${ }^{[72]}$

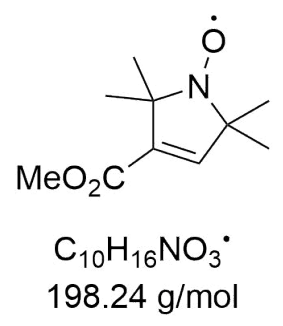

The amine $3(2.50 \mathrm{~g}, 13.6 \mathrm{mmol}, 1.00 \mathrm{eq})$ was dissolved in dry $\mathrm{Et}_{2} \mathrm{O}(50 \mathrm{~mL})$ under an argon atmosphere and the solution was cooled to $0{ }^{\circ} \mathrm{C}$. Then, a solution of $m$-CPBA $(77 \mathrm{w} \%, 6.15 \mathrm{~g}, 27.3 \mathrm{mmol}, 2.00 \mathrm{eq})$ in dry $\mathrm{Et}_{2} \mathrm{O}(40 \mathrm{~mL})$ was added dropwise and the reaction mixture was stirred at $0{ }^{\circ} \mathrm{C}$ for $2 \mathrm{~h}$. Afterwards, $10 \%$ aq. $\mathrm{Na}_{2} \mathrm{CO}_{3}$ solution $(50 \mathrm{~mL})$ was added and the mixture was extracted with $\mathrm{Et}_{2} \mathrm{O}(3 \times 50 \mathrm{~mL})$. The combined organic fractions were dried over $\mathrm{MgSO}_{4}$ and the solvent was removed in vacuo. The purification of the crude product by flash column chromatography on $\mathrm{SiO}_{2}$ (Pe/EtOAc, 70/30, v/v) yielded the desired nitroxide 4 as a yellow solid (2.32 g, $11.7 \mathrm{mmol}, 86 \%$ ).

ESI-MS: $\mathrm{m} / z=199.1[\mathrm{M}+\mathrm{H}]^{+}, 221.1[\mathrm{M}+\mathrm{Na}]^{+}$.

ESI-HRMS: $\mathrm{m} / z$ calcd. for $\mathrm{C}_{11} \mathrm{H}_{19} \mathrm{~N}_{1} \mathrm{O}_{3} \mathrm{H}[\mathrm{M}+\mathrm{H}]^{+}$: 199.1203 found: 199.1196, calcd. for $\mathrm{C}_{11} \mathrm{H}_{19} \mathrm{~N}_{1} \mathrm{O}_{3} \mathrm{Na}[\mathrm{M}+\mathrm{Na}]^{+}: 221.1022$ found: 221.1020 .

trans-3-Methoxycarbonyl-2,2,5,5-tetramethyl-4-nitromethyl-pyrrolidin-1-oxyl (5) ${ }^{[74]}$

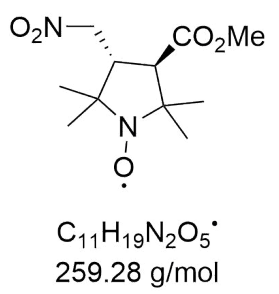

The methyl ester $4(2.00 \mathrm{~g}, 10.0 \mathrm{mmol}, 1.00 \mathrm{eq})$ and nitromethane (1.07 mL, $1.22 \mathrm{~g}$, $20.0 \mathrm{mmol}, 2.00 \mathrm{eq})$ were dissolved under an argon atmosphere in dry MeCN $(20 \mathrm{~mL})$. Then, DBU (1.49 mL, $1.52 \mathrm{~g}, 10.0 \mathrm{mmol}, 1.00 \mathrm{eq})$ was added and the reaction solution was stirred at $55^{\circ} \mathrm{C}$ for $24 \mathrm{~h}$. Afterwards, the solution was dilluted by the addition of $\mathrm{CHCl}_{3}$ $(20 \mathrm{~mL})$ and the resulting solution was washed with $3 \%$ aq. $\mathrm{H}_{2} \mathrm{SO}_{4}(3 \times 20 \mathrm{~mL})$ and with saturated aq. $\mathrm{NaCl}$ solution $(3 \times 20 \mathrm{~mL})$. The organic layer was dried over $\mathrm{MgSO}_{4}$ and the solvent was removed in vacuum. Finally, the crude product was purified by flash column chromatography on $\mathrm{SiO}_{2}(\mathrm{Pe} /$ EtOAc, $70 / 30, v / v)$ to yield the desired nitroxide $\mathbf{5}$ as a 
yellow solid (1.74g, $6.70 \mathrm{mmol}, 67 \%)$.

ESI-MS: $\mathrm{m} / z=260.1[\mathrm{M}+\mathrm{H}]^{+}, 225.1[\mathrm{M}+\mathrm{Na}]^{+}$.

ESI-HRMS: $\mathrm{m} / z$ calcd. for $\mathrm{C}_{11} \mathrm{H}_{19} \mathrm{~N}_{2} \mathrm{O}_{5} \mathrm{H}[\mathrm{M}+\mathrm{H}]^{+}: 260.1367$ found: 260.1365, calcd. for $\mathrm{C}_{11} \mathrm{H}_{19} \mathrm{~N}_{2} \mathrm{O}_{5} \mathrm{Na}[\mathrm{M}+\mathrm{Na}]^{+}: 282.1186$ found: 282.1183 .

trans-4-Formyl-3-methoxycarbonyl-2,2,5,5-tetramethylpyrrolidin-1-yloxyl Radical (6) ${ }^{[73]}$

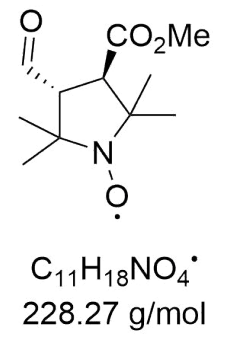

A solution of the $\gamma$-nitro methyl ester 5 (2.00 g, $7.72 \mathrm{mmol}, 1.00 \mathrm{eq})$ in $\mathrm{MeOH}(40 \mathrm{~mL})$ was cooled to $0^{\circ} \mathrm{C}$ and subsequently a solution of $\mathrm{KOH}(540 \mathrm{mg}, 9.65 \mathrm{mmol}, 1.25 \mathrm{eq})$ in $\mathrm{MeOH}$ $(100 \mathrm{~mL})$ was added dropwise. After completion of the addition, the mixture was stirred at $0{ }^{\circ} \mathrm{C}$ for further $15 \mathrm{~min}$ and then a solution of $\mathrm{KMnO}_{4}(850 \mathrm{mg}, 5.33 \mathrm{mmol}, 0.74 \mathrm{eq})$ and MgSO4 (927 g, $7.72 \mathrm{mmol}, 1.00 \mathrm{eq})$ in $\mathrm{H}_{2} \mathrm{O}(100 \mathrm{~mL})$ was added. Afterwards, the mixture was stirred $0{ }^{\circ} \mathrm{C}$ for $1.5 \mathrm{~h}$, filtered through a pad of celite and the filtrate cake was washed thoroughly with $\mathrm{CHCl}_{3}(70 \mathrm{~mL})$. After separation of the organic phase, the aqueous phase was extracted with $\mathrm{CHCl}_{3}(3 \times 50 \mathrm{~mL})$ and the combined organic phase was dried over $\mathrm{MgSO}_{4}$. After removal of the solvent in vacuo, the residue was purified by flash column chromatography on $\mathrm{SiO}_{2}(\mathrm{Pe} / \mathrm{EtOAc}, 60 / 40, v / v)$ to yield the desired aldehyde nitroxide 6 as a yellow solid (653 mg, $2.86 \mathrm{mmol}, 37 \%$ ).

ESI-MS: $\mathrm{m} / z=228.1[\mathrm{M}]$.

ESI-HRMS: $\mathrm{m} / z$ calcd. for $\mathrm{C}_{11} \mathrm{H}_{18} \mathrm{~N}_{1} \mathrm{O}_{4}$ [M]: 228.1230 found: 228.1234.

trans-3,4-Bis(hydroxymethyl)-2,2,5,5-tetramethylpyrrolidin-1-yloxyl Radical (7) ${ }^{[73]}$

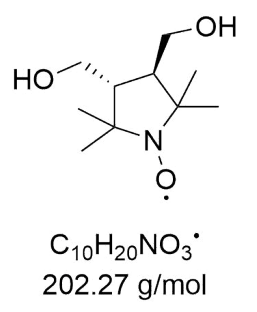

The aldehyde methyl ester 6 (2.00 g, $8.75 \mathrm{mmol}, 1.00 \mathrm{eq})$ was dissolved in EtOH $(30 \mathrm{~mL})$ and $\mathrm{NaBH}_{4}(1.00 \mathrm{~g}, 26.5 \mathrm{mmol}, 3.00 \mathrm{eq})$ was added in portions at $0{ }^{\circ} \mathrm{C}$. After the addition was completed, the mixture was allowed to stand at room temperature for $45 \mathrm{~min}$. 
Then, the solvent was removed under high pressure and the residue was dissolved in saturated aq. $\mathrm{NH}_{4} \mathrm{Cl}$ solution $(20 \mathrm{~mL})$. The reaction solution was extracted with $\mathrm{CHCl}_{3}$ $(3 \times 20 \mathrm{~mL})$ and the combined organic layers were dried over $\mathrm{MgSO}_{4}$. After removal of the solvent in vacuo, the residue was purified by flash column chromatography on $\mathrm{SiO}_{2}$ $(\mathrm{Pe} / \mathrm{EtOAc}, 50 / 50, v / v)$. The desired 1,4-diol nitroxide 7 was obtained as yellow solid $(1.27 \mathrm{~g}, 6.30 \mathrm{mmol}, 72 \%)$.

ESI-MS: $\mathrm{m} / z=203.2[\mathrm{M}+\mathrm{H}]^{+}, 225.1[\mathrm{M}+\mathrm{Na}]^{+}$.

ESI-HRMS: $\mathrm{m} / z$ calcd. for $\mathrm{C}_{10} \mathrm{H}_{20} \mathrm{~N}_{1} \mathrm{O}_{3} \mathrm{H}[\mathrm{M}+\mathrm{H}]^{+}$: 203.1516 found: 203.1510, calcd. for $\mathrm{C}_{10} \mathrm{H}_{20} \mathrm{~N}_{1} \mathrm{O}_{3} \mathrm{Na}[\mathrm{M}+\mathrm{Na}]^{+}$: 225.1335 found: 225.1334 .

trans-3,4-Bis(iodomethyl)-2,2,5,5-tetramethylpyrrolidin-1-yloxyl Radical (8) ${ }^{[73]}$

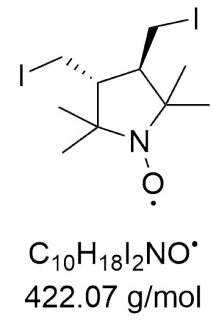

A solution of 1,4-diol 7 (2.00 g, $10.0 \mathrm{mmol}, 1.00 \mathrm{eq})$ and $\mathrm{Et}_{3} \mathrm{~N}(3.01 \mathrm{~mL}, 2.20 \mathrm{~g}, 22.0 \mathrm{mmol}$, $2.20 \mathrm{eq})$ in $\mathrm{DCM}(70 \mathrm{~mL})$ was pre-cooled to $0{ }^{\circ} \mathrm{C}$ under an argon atmosphere. Then, $\mathrm{MsCl}$ $(1.69 \mathrm{~mL}, 2.50 \mathrm{~g}, 22.0 \mathrm{mmol}, 2.20 \mathrm{eq})$ was added dropwise to the solution at $0{ }^{\circ} \mathrm{C}$ and the reaction mixture was stirred at room temperature for $1 \mathrm{~h}$. Afterwards, the mixture was washed with saturated aq. $\mathrm{NaCl}$ solution $(40 \mathrm{~mL})$ and the organic layer was dried over $\mathrm{MgSO}_{4}$. After removal of the solvent under reduced pressure the bis(mesylate) intermediate was immediately dissolved in dry THF $(60 \mathrm{~mL})$ and upon addition of $\mathrm{NaI}(7.50 \mathrm{~g}$, $50.0 \mathrm{mmol}, 5.00 \mathrm{eq})$ the mixture was stirred at $75^{\circ} \mathrm{C}$ for $34 \mathrm{~h}$. The mixture was diluted with $\mathrm{Et}_{2} \mathrm{O}(50 \mathrm{~mL})$ and the organic layer was washed with $10 \%$ aq. $\mathrm{Na}_{2} \mathrm{~S}_{2} \mathrm{O}_{3}$ solution $(50 \mathrm{~mL})$ and saturated aq. $\mathrm{NaCl}$ solution $(3 \times 30 \mathrm{~mL})$. After drying the organic layer over $\mathrm{MgSO}_{4}$ and removing the solvent under reduced pressure, the residue was purified by flash column chromatography on $\mathrm{SiO}_{2}(\mathrm{Pe} / \mathrm{EtOAc}, 60 / 40, v / v)$ to yield the diiodide 8 as a yellow solid $(2.36 \mathrm{~g}, 5.60 \mathrm{mmol}, 56 \%)$.

ESI-MS: $\mathrm{m} / z=423.0[\mathrm{M}+\mathrm{H}]^{+}, 444.9[\mathrm{M}+\mathrm{Na}]^{+}$.

ESI-HRMS: $\mathrm{m} / z$ calcd. for $\mathrm{C}_{10} \mathrm{H}_{18} \mathrm{~N}_{1} \mathrm{O}_{1} \mathrm{I}_{2} \mathrm{H}[\mathrm{M}+\mathrm{H}]^{+}: 422.9551$ found: 422.9559, calcd. for $\mathrm{C}_{10} \mathrm{H}_{18} \mathrm{~N}_{1} \mathrm{O}_{1} \mathrm{I}_{2} \mathrm{Na}[\mathrm{M}+\mathrm{Na}]^{+}: 444.9370$ found: 444.9378 .

\section{3,4-Bis(methylene)-2,2,5,5-tetramethylpyrrolidin-1-yloxyl Radical (9) ${ }^{[73]}$}

The diiodide 9 (1.00 g, $2.37 \mathrm{mmol}, 1.00 \mathrm{eq})$ was dissolved in EtOH (15 mL) and a 10\% aq. $\mathrm{NaOH}$ solution $(5 \mathrm{~mL})$ was added. Then the reaction mixture was stirred at $80{ }^{\circ} \mathrm{C}$ for 


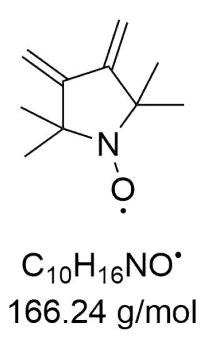

$40 \mathrm{~min}$. Afterwards, the solvent was removed in vacuo and the aqueous solution was extracted with $\mathrm{Et}_{2} \mathrm{O}(2 \times 20 \mathrm{~mL})$. The organic phase was dried over $\mathrm{MgSO}_{4}$ and the solvent was removed under reduced pressure. Finally, purification of the residue by flash column chromatography on $\mathrm{SiO}_{2}$ (Pe/EtOAc, 60/40, $v / v$ ) gave the desired diene nitroxide 9 as an orange solid (316 mg, $1.90 \mathrm{mmol}, 80 \%$ ).

ESI-MS: $\mathrm{m} / z=167.1[\mathrm{M}+\mathrm{H}]^{+}, 189.1[\mathrm{M}+\mathrm{Na}]^{+}$.

ESI-HRMS: $\mathrm{m} / z$ calcd. for $\mathrm{C}_{10} \mathrm{H}_{16} \mathrm{~N}_{1} \mathrm{O}_{1} \mathrm{H}[\mathrm{M}+\mathrm{H}]^{+}: 167.1305$ found: 167.1297, calcd. for $\mathrm{C}_{10} \mathrm{H}_{16} \mathrm{~N}_{1} \mathrm{O}_{1} \mathrm{Na}[\mathrm{M}+\mathrm{Na}]^{+}: 189.1124$ found: 189.1122 .

\section{3,4-Bis(dibromomethyl)-2,5-dihydro-2,2,5,5-tetramethyl-1H-pyrrol-1-yloxyl Radical (10) ${ }^{[73]}$}

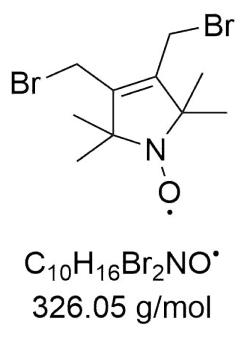

To reduce the nitroxide radical the diene nitroxide 9 (500 $\mathrm{mg}, 3.00 \mathrm{mmol}, 1.00 \mathrm{eq})$ was dissolved in a $2.4 \mathrm{M}$ ethanolic $\mathrm{HCl}$ solution $(6 \mathrm{~mL})$ and stirred at $80^{\circ} \mathrm{C}$ for $1 \mathrm{~h}$. Afterwards, the solvent was removed under reduced pressure to give the colorless hydroxylamine intermediate that was immediately dissolved in $\mathrm{CHCl}_{3}(20 \mathrm{~mL})$. Then, a solution of $\mathrm{Br}_{2}$ $(0.32 \mathrm{~mL}, 1.00 \mathrm{~g}, 6.00 \mathrm{mmol}, 2.00 \mathrm{eq})$ dissolved in $\mathrm{CHCl}_{3}(3 \mathrm{~mL})$ was added dropwise and the reaction mixture was stirred at $65^{\circ} \mathrm{C}$ for $30 \mathrm{~min}$. Afterwards, the solution was allowed to warm up to room temperature and a solution of $\mathrm{NaNO}_{2}$ (415 mg, $6.00 \mathrm{mmol}$, $2.00 \mathrm{eq})$ in $\mathrm{H}_{2} \mathrm{O}(5 \mathrm{~mL})$ was added dropwise to oxidize the hydroxylamine to the nitroxide radical. After the addition was completed, the mixture was stirred for $20 \mathrm{~min}$ at room temperature. Then, the organic layer was separated, washed with $10 \%$ aq. $\quad \mathrm{Na}_{2} \mathrm{~S}_{2} \mathrm{O}_{3}$ solution $(20 \mathrm{~mL})$ and dried over $\mathrm{MgSO}_{4}$. The solvent was removed under reduced pressure and the residue was purified by flash column chromatography on $\mathrm{SiO}_{2}$ (Pe/EtOAc, $60 / 40, v / v)$ to give the dibromide nitroxide 10 as a yellow solid (518 mg, $1.59 \mathrm{mmol}, 53 \%$ ).

ESI-MS: $\mathrm{m} / z=325.0[\mathrm{M}+\mathrm{H}]^{+}, 347.0[\mathrm{M}+\mathrm{Na}]^{+}$. 
ESI-HRMS: $\mathrm{m} / z$ calcd. for $\mathrm{C}_{10} \mathrm{H}_{16} \mathrm{~N}_{1} \mathrm{O}_{1} \mathrm{Br}_{2} \mathrm{H}[\mathrm{M}+\mathrm{H}]^{+}: 324.9671$ found: 324.9676 , calcd. for $\mathrm{C}_{10} \mathrm{H}_{16} \mathrm{~N}_{1} \mathrm{O}_{1} \mathrm{Br}_{2} \mathrm{Na}[\mathrm{M}+\mathrm{Na}]^{+}$: 346.9491 found: 346.9491 .

\section{Phenyl(4,4,6,6-tetramethyl-5-(yloxyl)-3,4,5,6-tetrahydropyrrolo[3,4-c]pyrrol-2(1H)- yl)methanone Radical}

(11)

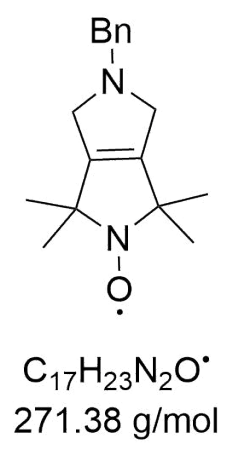

Benzylamine (0.15 mL, $148 \mathrm{mg}, 1.38 \mathrm{mmol}, 0.90 \mathrm{eq}$ ) and $\mathrm{K}_{2} \mathrm{CO}_{3}$ (423 mg, $3.06 \mathrm{mmol}, 2.00 \mathrm{eq}$ ) were added to a solution of dibromide nitroxide 10 (500 mg, 1.53 mmol, $1.00 \mathrm{eq})$ in MeCN $(10 \mathrm{~mL})$ and the reaction mixture was stirred at $80^{\circ} \mathrm{C}$ for $20 \mathrm{~h}$. Afterwards, the mixture was filtered and the solvent was removed under reduced pressure. The residue was dissolved in DCM $(20 \mathrm{~mL})$, washed with water $(2 \times 20 \mathrm{~mL})$ and the combined aqueous phases were extracted with DCM $(3 \times 20 \mathrm{~mL})$. Then the combined organic phase was dried over $\mathrm{MgSO}_{4}$ and the solvent was removed under reduced pressure. Finally, the purification of the crude product by flash column chromatography on $\mathrm{SiO}_{2}(\mathrm{DCM} / \mathrm{MeOH}, 98 / 2, v / v)$ yield the bicyclic nitroxide 11 as a brown solid (166 mg, 0.61 mmol, 40\%).

ESI-MS: $\mathrm{m} / z=272.2[\mathrm{M}+\mathrm{H}]^{+}, 294.2[\mathrm{M}+\mathrm{Na}]^{+}$.

ESI-HRMS: $\mathrm{m} / z$ calcd. for $\mathrm{C}_{17} \mathrm{H}_{23} \mathrm{~N}_{2} \mathrm{O}_{2} \mathrm{H}[\mathrm{M}+\mathrm{H}]^{+}: 272.1883$ found: 272.1885, calcd. for $\mathrm{C}_{17} \mathrm{H}_{23} \mathrm{~N}_{2} \mathrm{O}_{2} \mathrm{Na}[\mathrm{M}+\mathrm{Na}]^{+}$: 294.1703 found: 294.1703 . 


\section{4,4,6,6-Tetramethyl-5-(yloxyl)-5,6-dihydropyrrolo[3,4-c]pyrrole-1,3(2H,4H)-dione Radical (12)}

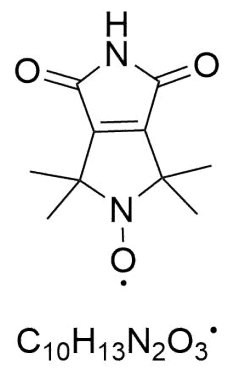

$209.23 \mathrm{~g} / \mathrm{mol}$

Cyclic amine nitroxide 11 (200 mg, $0.74 \mathrm{mmol}, 1.00 \mathrm{eq})$ and $\mathrm{Na}_{2} \mathrm{CO}_{3}$ (0.74 g, $7.00 \mathrm{mmol}$, $10.0 \mathrm{eq})$ were dissolved in $\mathrm{THF} / \mathrm{H}_{2} \mathrm{O}(v / v, 2.5 / 1,5 \mathrm{~mL})$ and iodine $(667 \mathrm{mg}, 5.25 \mathrm{mmol}$, $7.50 \mathrm{eq})$ was added to the solution. Then, the reaction mixture was stirred at room temperature for $14 \mathrm{~h}$ and a saturated aq. $\mathrm{Na}_{2} \mathrm{~S}_{2} \mathrm{O}_{4}$ solution $(1 \mathrm{~mL})$ and subsequently a saturated aq. $\mathrm{Na}_{2} \mathrm{CO}_{3}$ solution $(1 \mathrm{~mL})$ were added to the reaction solution. Afterwards, the reaction solution was extracted with DCM $(3 \times 10 \mathrm{~mL})$ and the combined organic layers were dried over $\mathrm{MgSO}_{4}$. After removal of the solvent in vacuo, the residue was purified by flash column chromatography on $\mathrm{SiO}_{2}(\mathrm{DCM} / \mathrm{MeOH}, 98 / 2, v / v)$ to give the imide nitroxide $\mathbf{1 2}$ as a brown oil (92.8 $\mathrm{mg}, 0.31 \mathrm{mmol}, 42 \%)$.

ESI-MS: $\mathrm{m} / z=210.1[\mathrm{M}+\mathrm{H}]^{+}$.

ESI-HRMS: $\mathrm{m} / z$ calcd. for $\mathrm{C}_{10} \mathrm{H}_{13} \mathrm{~N}_{2} \mathrm{O}_{3} \mathrm{H}[\mathrm{M}+\mathrm{H}]^{+}: 210.0999$ found: 210.1266 .

\section{(3-Carboxy-4-bromo-2,2,5,5-tetramethyl-2,5-dihydro-1H-pyrrol-1-yl)oxidanyl Radical (16) ${ }^{[76]}$}

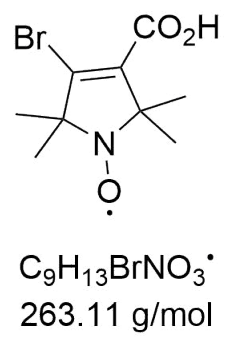

Bromine $(5.27 \mathrm{~mL}, 16.4 \mathrm{~g}, 206 \mathrm{mmol}, 3.50 \mathrm{eq})$ was added slowly to a precooled solution $\left(0^{\circ} \mathrm{C}\right)$ of $\mathrm{NaOH}(39.2 \mathrm{~g}, 980 \mathrm{mmol}, 16.7 \mathrm{eq})$ in $\mathrm{H}_{2} \mathrm{O}(300 \mathrm{~mL})$ and the resulting $\mathrm{NaOBr}$ solution was stirred at $0{ }^{\circ} \mathrm{C}$ for $20 \mathrm{~min}$. Then, the $\mathrm{NaOBr}$ solution was cooled to $-5^{\circ} \mathrm{C}$ and a solution of 4-Oxo-TEMPO 1 (10.0 g, $58.7 \mathrm{mmol}, 1.00 \mathrm{eq})$ and $\mathrm{NaOH}$ (9.80 g, $245 \mathrm{mmol}$, $4.17 \mathrm{eq})$ in 1,4-dioxane $/ \mathrm{H}_{2} \mathrm{O}(v / v, 4 / 1,250 \mathrm{~mL})$ was added dropwise. After the addition was complete, the reaction solution was stirred for additional $30 \mathrm{~min}$ at room temperature. The insolubilities were filtered off and the filtrate was acidified by concentrated $\mathrm{HCl}$ to a $\mathrm{pH}$ of 2 . The precipitated yellowish solid was filtered off and washed thoroughly with 
cold water $(20 \mathrm{~mL})$ and $\mathrm{Et}_{2} \mathrm{O}(3 \times 50 \mathrm{~mL})$. The desired carboxy nitroxide $\mathbf{1 6}$ was obtained after drying in vacuo as a light yellow solid (3.55 g, $13.5 \mathrm{mmol}, 23 \%$ ).

ESI-MS: $\mathrm{m} / z=262.0[\mathrm{M}], 285.0[\mathrm{M}+\mathrm{Na}]^{+}$.

ESI-HRMS: $\mathrm{m} / z$ calcd. for $\mathrm{C}_{9} \mathrm{H}_{13} \mathrm{NO}_{3} \mathrm{Br}[\mathrm{M}]: 262.0073$ found: 262.0075, calcd. for $\mathrm{C}_{9} \mathrm{H}_{13} \mathrm{NO}_{3} \mathrm{BrNa}[\mathrm{M}+\mathrm{Na}]^{+}: 284.9971$ found: 284.9972 .

(3-Hydroxymethyl-4-bromo-2,2,5,5-tetramethyl-2,5-dihydro-1H-pyrrol-1-yl)oxidanyl Radical (17) ${ }^{[77]}$

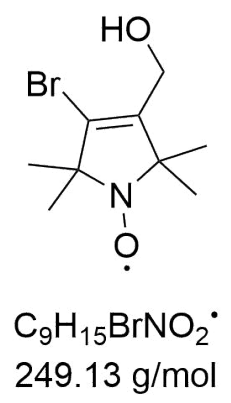

To a solution of carboxyl nitroxide $16(600 \mathrm{mg}, 2.28 \mathrm{mmol}, 1.00 \mathrm{eq})$ and $\mathrm{Et}_{3} \mathrm{~N}(0.40 \mathrm{~mL}$, $288 \mathrm{mg}, 2.85 \mathrm{mmol}, 1.25 \mathrm{eq})$ in dry $\mathrm{Et}_{2} \mathrm{O}(30 \mathrm{~mL})$ was added slowly ethyl chloroformate $(0.25 \mathrm{~mL}, 285 \mathrm{mg}, 2.62 \mathrm{mmol}, 1.15 \mathrm{eq})$ at $0{ }^{\circ} \mathrm{C}$. The reaction mixture was stirred at $0{ }^{\circ} \mathrm{C}$ for $2 \mathrm{~h}$. The precipitated salts were filtered off and the filtrate was concentrated under reduced pressure. Then the residue was dissolved in dry THF $(10 \mathrm{~mL})$ and the reaction mixture was cooled to $0{ }^{\circ} \mathrm{C} . \mathrm{NaBH}_{4}(95.0 \mathrm{mg}, 2.51 \mathrm{mmol}, 1.10 \mathrm{eq})$ and $\mathrm{EtOH}(0.5 \mathrm{~mL})$ were added and the reaction was stirred at $0^{\circ} \mathrm{C}$ for $2 \mathrm{~h}$. The reaction mixture was quenched with saturated aq. $\mathrm{NH}_{4} \mathrm{Cl}$ solution $(10 \mathrm{~mL})$ and extracted with $\mathrm{CHCl}_{3}(3 \times 20 \mathrm{~mL})$. The combined organic phase was dried over $\mathrm{MgSO}_{4}$ and the solvent was removed under reduced pressure. The residue was purified by flash column chromatography on $\mathrm{SiO}_{2}$ (Pe/EtOAc, $60 / 40, v / v)$ to give the hydroxyl nitroxide $\mathbf{1 7}$ as a yellow solid (415 mg, $1.66 \mathrm{mmol}, 73 \%$ ).

ESI-MS: $\mathrm{m} / z=249.0[\mathrm{M}+\mathrm{H}]^{+}, 271.0[\mathrm{M}+\mathrm{Na}]^{+}$.

ESI-HRMS: $\mathrm{m} / z$ calcd. for $\mathrm{C}_{9} \mathrm{H}_{15} \mathrm{~N}_{1} \mathrm{O}_{2} \mathrm{BrH}[\mathrm{M}+\mathrm{H}]^{+}: 249.0359$ found: 249.0354, calcd. for $\mathrm{C}_{9} \mathrm{H}_{15} \mathrm{~N}_{1} \mathrm{O}_{2} \mathrm{BrNa}[\mathrm{M}+\mathrm{Na}]^{+}: 271.0178$ found: 271.0178 .

\section{3-Bromomethyl-4-bromo-2,2,5,5-tetramethyl-2,5-dihydro-1H-pyrrol-1-yl)oxidanyl Radical (18) ${ }^{[77]}$}

To a solution of alcohol 17 (500 mg, $2.01 \mathrm{mmol}, 1.10 \mathrm{eq})$ and $\mathrm{Et}_{3} \mathrm{~N}$ (0.31 mL, $224 \mathrm{mg}$, $2.21 \mathrm{mmol}, 1.10 \mathrm{eq})$ in $\mathrm{DCM}(10 \mathrm{~mL})$ was added dropwise a solution of $\mathrm{MsCl}(252 \mathrm{mg}$, $2.21 \mathrm{mmol}, 1.10 \mathrm{eq})$ in $\mathrm{DCM}(5 \mathrm{~mL})$ at $0{ }^{\circ} \mathrm{C}$ and the reaction mixture was stirred for $2 \mathrm{~h}$. Then, the reaction mixture was washed with $\mathrm{H}_{2} \mathrm{O}(10 \mathrm{~mL})$ and the organic layer was separated, dried over $\mathrm{MgSO}_{4}$ and the solvent was removed under reduced pressure. 


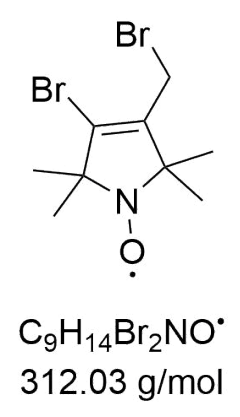

The intermediate was immediately dissolved in dry acetone $(20 \mathrm{~mL})$ and upon addition of $\mathrm{LiBr}(350 \mathrm{mg}, 4.02 \mathrm{mmol}, 2.00 \mathrm{eq})$ the mixture was stirred at $80^{\circ} \mathrm{C}$ for $1 \mathrm{~h}$. Afterwards, the solvent was removed in vacuo and the residue was partitioned between $\mathrm{H}_{2} \mathrm{O}(10 \mathrm{~mL})$ and EtOAc $(20 \mathrm{~mL})$. The organic layer was separated and the aqueous layer was extracted with EtOAc $(3 \times 10 \mathrm{~mL})$. The combined organic layer was dried over $\mathrm{MgSO}_{4}$ and the solvent was removed under reduced pressure. The residue was purified by flash column chromatography on $\mathrm{SiO}_{2}(\mathrm{Pe} / \mathrm{EtOAc}, 70 / 30, v / v)$ to give the bromide nitroxide 18 as an orange solid (0.34 g, $1.09 \mathrm{mmol}, 54 \%)$.

ESI-MS: $\mathrm{m} / z=311.9[\mathrm{M}+\mathrm{H}]^{+}$.

ESI-HRMS: $\mathrm{m} / z$ calcd. for $\mathrm{C}_{9} \mathrm{H}_{16} \mathrm{~N}_{1} \mathrm{O}_{1} \mathrm{Br}_{2}[\mathrm{M}+\mathrm{H}]^{+}: 311.9593$ found: 311.9586 .

tert-Butyl-(S)-(2,6-dioxopiperidin-3-yl)carbamate $(20)^{[79]}$

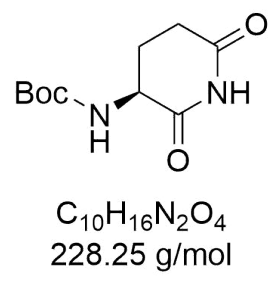

To a solution of Boc-Gln-OH (2.00 g, $8.13 \mathrm{mmol}, 1.00 \mathrm{eq})$ in THF (45 mL) was added CDI $(1.59 \mathrm{~g}, 9.76 \mathrm{mmol}, 1.20 \mathrm{eq})$ and a few crystalls of 4-(dimethylamino)pyridine. Afterwards, the reaction was stirred at $70^{\circ} \mathrm{C}$ for $18 \mathrm{~h}$. Then, the solvent was removed under reduced pressure and EtOAc $(150 \mathrm{~mL})$ was added to the residue. After washing the organic layer with $\mathrm{H}_{2} \mathrm{O}(50 \mathrm{~mL})$ and saturated aq. $\mathrm{NaCl}$ solution $(50 \mathrm{~mL})$ the organic layer was dried over $\mathrm{MgSO}_{4}$. The solvent was removed in vacuo and the crude product was purified by flash column chromatography on $\mathrm{SiO}_{2}(\mathrm{DCM} / \mathrm{MeOH}, 95 / 5, v / v)$ to give the imide 20 as a colorless solid $(1.21 \mathrm{~g}, 5.28 \mathrm{mmol}, 65 \%)$.

${ }^{1} \mathbf{H}-\mathbf{N M R}\left(300 \mathrm{MHz}, \mathrm{CDCl}_{3}\right): \delta[\mathrm{ppm}]=7.171(\mathrm{~s}, 1 \mathrm{H}, \mathrm{NH}), 5.37(\mathrm{~s}, 1 \mathrm{H}), 4.33-4.28(\mathrm{~m}$, $1 \mathrm{H}), 2.78-2.75(\mathrm{~m}, 1 \mathrm{H}), 2.73-2.76(\mathrm{~m}, 1 \mathrm{H}), 2.54-2.49(\mathrm{~m}, 1 \mathrm{H}), 1.90-1.84(\mathrm{~m}, 1 \mathrm{H}), 1.46$ $\left(\mathrm{s}, 9 \mathrm{H}, 3 \times \mathrm{CH}_{3}\right)$.

ESI-MS: $\mathrm{m} / z=251.1[\mathrm{M}+\mathrm{Na}]^{+}$.

ESI-HRMS: $\mathrm{m} / z$ calcd. for $\mathrm{C}_{10} \mathrm{H}_{16} \mathrm{~N}_{2} \mathrm{O}_{4} \mathrm{Na}[\mathrm{M}+\mathrm{Na}]^{+}: 251.1002$ found: 251.1006 . 
tert-Butyl-(1-((4-bromo-2,2,5,5-tetramethyl-1-(yloxyl)-2,5-dihydro-1H-pyrrol-3yl)(hydroxy)methyl)-2,6-dioxopiperidin-3-yl)carbamate Radical

(21)

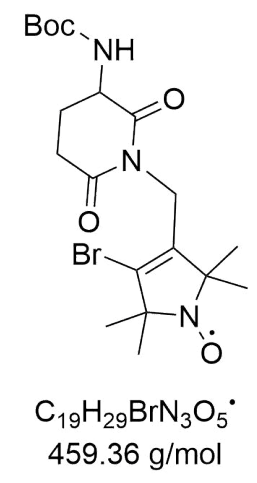

The cyclic imide 20 (248 mg, $1.06 \mathrm{mmol}, 1.10 \mathrm{eq}$ ) and $\mathrm{K}_{2} \mathrm{CO}_{3}$ (146 mg, $1.06 \mathrm{mmol}, 1.10 \mathrm{eq}$ ) were added to a solution of bromide nitroxide 18 (300 $\mathrm{mg}, 0.96 \mathrm{mmol}, 1.00 \mathrm{eq})$ in DMF $(10 \mathrm{~mL})$ and the reaction mixture was stirred at $90^{\circ} \mathrm{C}$ for $2 \mathrm{~h}$. Afterwards, the mixture was filtered and the solvent was removed under reduced pressure. The residue was dissolved in DCM $(20 \mathrm{~mL})$, washed with water $(2 \times 20 \mathrm{~mL})$ and the combined aqueous phases were extracted with DCM $(3 \times 20 \mathrm{~mL})$. Then the combined organic phase was dried over $\mathrm{MgSO}_{4}$ and the solvent was removed under reduced pressure. The crude imide nitroxide $\mathbf{2 1}$ was obtained as a brown solid (166 mg, $0.61 \mathrm{mmol}$ ) and was used without further purification in the next step.

ESI-MS: $\mathrm{m} / z=459.1[\mathrm{M}+\mathrm{H}]^{+}, 481.1[\mathrm{M}+\mathrm{Na}]^{+}$.

ESI-HRMS: $\mathrm{m} / z$ calcd. for $\mathrm{C}_{19} \mathrm{H}_{29} \mathrm{~N}_{3} \mathrm{O}_{5} \mathrm{BrH}[\mathrm{M}+\mathrm{H}]^{+}$: 459.1363 found: 459.1357, calcd. for $\mathrm{C}_{19} \mathrm{H}_{29} \mathrm{~N}_{3} \mathrm{O}_{5} \mathrm{BrNa}[\mathrm{M}+\mathrm{Na}]^{+}$: 481.1183 found: 481.1181 .

tert-Butyl-(1,1,3,3-tetramethyl-2-(yloxyl)-6-oxo-2,3,4,6,7,8-hexahydro-1Hpyrrolo[3,4-a]indolizin-7-yl)carbamate Radical

(22)

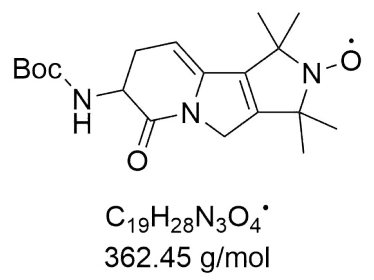

The imide radical 21 (0.31 g, $0.67 \mathrm{mmol}, 1.00 \mathrm{eq})$ was dissolved in DMF ( $5 \mathrm{~mL})$ and the solution was precooled to $0{ }^{\circ} \mathrm{C}$. Then, $\mathrm{Bu}_{3} \mathrm{SnSiMe}_{3}(0.45 \mathrm{~mL}, 0.47 \mathrm{~g}, 1.29 \mathrm{mmol}, 1.92 \mathrm{eq})$ and $\mathrm{CsF}$ (196 mg, $1.29 \mathrm{mmol}, 1.92 \mathrm{eq})$ were added and the reaction solution was stirred at room temperature for $21 \mathrm{~h}$. Afterwards, $\mathrm{H}_{2} \mathrm{O}(5 \mathrm{~mL})$ and EtOAc $(5 \mathrm{~mL})$ were added to the reaction solution and the organic layer was separated and washed with saturated aq. 
$\mathrm{NaCl}$ solution $(3 \times 10 \mathrm{~mL})$. After removal of the solvent in vacuo, the residue was purified by flash column chromatography on $\mathrm{SiO}_{2}(\mathrm{DCM} / \mathrm{MeOH}, 98 / 2, v / v)$ to give the azabicyclo nitroxide 22 as a brown oil (105 $\mathrm{mg}, 0.29 \mathrm{mmol}, 43 \%$ ).

ESI-MS: $\mathrm{m} / z=363.2[\mathrm{M}+\mathrm{H}]^{+}, 385.2[\mathrm{M}+\mathrm{Na}]^{+}$.

ESI-HRMS: $\mathrm{m} / z$ calcd. for $\mathrm{C}_{19} \mathrm{H}_{28} \mathrm{~N}_{3} \mathrm{O}_{4} \mathrm{H}[\mathrm{M}+\mathrm{H}]^{+}: 363.2153$ found: 363.2139, calcd. for $\mathrm{C}_{19} \mathrm{H}_{28} \mathrm{~N}_{3} \mathrm{O}_{4} \mathrm{Na}[\mathrm{M}+\mathrm{Na}]^{+}$: 385.1972 found: 385.1967 .

4-Bromo-3-formyl-2,2,5,5-tetramethyl-2,5-dihydro-1 $H$-pyrrol-1-yloxyl Radical (23)

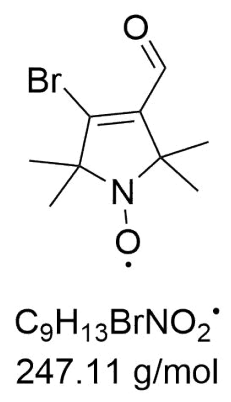

Activated $\mathrm{MnO}_{2}(1.00 \mathrm{~g}, 11.5 \mathrm{mmol}, 14.4 \mathrm{eq})$ was added to a solution of the alcohol $\mathbf{1 7}$ (200 mg, $0.80 \mathrm{mmol}, 1.00 \mathrm{eq})$ in $\mathrm{CHCl}_{3}(20 \mathrm{~mL})$ and the mixture was stirred at $70^{\circ} \mathrm{C}$ for $4 \mathrm{~h}$. Then, the insolubilities were filtered off and the solvent was removed under reduced pressure. The residue was purified by flash column chromatography on $\mathrm{SiO}_{2}$ (Pe/EtOAc, $60 / 40, v / v)$ to give the aldehyde nitroxide 23 as a yellow solid (162 $\mathrm{mg}, 0.59 \mathrm{mmol}, 74 \%$ ).

ESI-MS: $\mathrm{m} / z=269.0[\mathrm{M}+\mathrm{Na}]^{+}$.

ESI-HRMS: $\mathrm{m} / z$ calcd. for $\mathrm{C}_{9} \mathrm{H}_{13} \mathrm{~N}_{1} \mathrm{O}_{2} \mathrm{BrNa}[\mathrm{M}+\mathrm{Na}]^{+}: 269.0022$ found: 269.0019 .

\section{2-(4-Bromo-2,2,5,5-tetramethyl-1-(yloxyl)-2,5-dihydro-1H-pyrrol-3-yl)-2- hydroxyacetonitrile Radical}

(28)

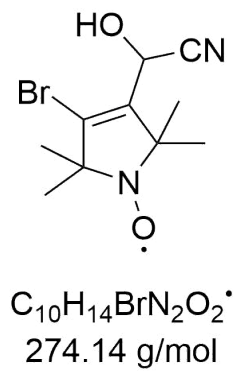

To a solution of the aldehyde nitroxide $23(100 \mathrm{mg}, 0.40 \mathrm{mmol}, 1.00 \mathrm{eq})$ in $\mathrm{MeOH}(5 \mathrm{~mL})$ $\mathrm{NaCN}$ (21.8 mg, $0.44 \mathrm{mmol}, 1.10 \mathrm{eq}$ ), $\mathrm{NaHSO}_{3}$ (45.8 mg, $\left.0.44 \mathrm{mmol}, 1.10 \mathrm{eq}\right)$ and $\mathrm{AcOH}$ $(25.2 \mu \mathrm{L}, 0.44 \mathrm{mmol}, 1.10 \mathrm{eq})$ were added at $0{ }^{\circ} \mathrm{C}$ and the mixture was stirred under an argon atmosphere at room temperature for $20 \mathrm{~h}$. Then the solvent was removed under 
reduced pressure and the residue was redissolved in DCM $(5 \mathrm{~mL})$. The organic phase was washed with saturated aq. $\mathrm{NaCl}$ solution $(3 \times 5 \mathrm{~mL})$ and the solvent was removed in vacuo. The crude cyanohydrin nitroxide was was obtained as a orange oil $(44 \mathrm{mg}$, $0.16 \mathrm{mmol}, 41 \%$ ) and was used due to fast decomposition without further purification.

ESI-MS: $\mathrm{m} / z=275.0[\mathrm{M}+\mathrm{H}]^{+}$.

ESI-HRMS: $\mathrm{m} / z$ calcd. for $\mathrm{C}_{10} \mathrm{H}_{14} \mathrm{~N}_{2} \mathrm{O}_{2} \mathrm{BrH}[\mathrm{M}+\mathrm{H}]^{+}: 275.0390$ found: 275.0381 .

tert-Butyl-(1-((4-bromo-2,2,5,5-tetramethyl-1-(yloxyl)-2,5-dihydro-1H-pyrrol-3yl)(hydroxy)methyl)-2,6-dioxopiperidin-3-yl)carbamate Radical

(30)

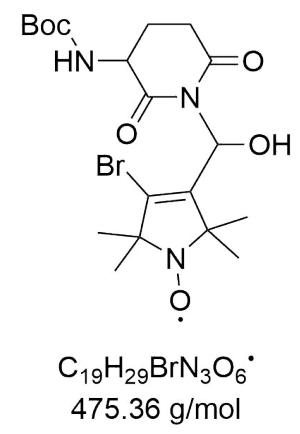

To a solution of the aldehyde nitroxide $23(27.3 \mathrm{mg}, 0.41 \mathrm{mmol}, 1.00 \mathrm{eq})$ in MeCN (1 mL) the imide 20 (25.3 mg, $0.41 \mathrm{mmol}, 1.00 \mathrm{eq})$ and $\mathrm{DBU}(18.2 \mu \mathrm{L}, 0.45 \mathrm{mmol}, 1.10 \mathrm{eq})$ were added and the mixture was stirred at room temperature for $18 \mathrm{~h}$. Then the solvent was removed under reduced pressure and the residue was redissolved in EtOAc $(5 \mathrm{~mL})$. The organic phase was washed with saturated aq. $\mathrm{NaCl}$ solution $(3 \times 10 \mathrm{~mL})$ and the solvent was removed in vacuo. After purification of the residue by flash column chromatography on $\mathrm{SiO}_{2}(\mathrm{Pe} /$ EtOAc, 70/30, $v / v)$ the imide nitroxide 30 was obtained as a orange solid (95 mg, $0.20 \mathrm{mmol}, 48 \%$ ).

ESI-MS: $\mathrm{m} / z=475.1[\mathrm{M}+\mathrm{H}]^{+}, 497.1[\mathrm{M}+\mathrm{Na}]^{+}, 492.2\left[\mathrm{M}+\mathrm{NH}_{4}\right]^{+}$.

ESI-HRMS: $\mathrm{m} / z$ calcd. for $\mathrm{C}_{19} \mathrm{H}_{29} \mathrm{~N}_{3} \mathrm{O}_{6} \mathrm{BrH}[\mathrm{M}+\mathrm{H}]^{+}: 475.1312$ found: 475.1323, calcd. for $\mathrm{C}_{19} \mathrm{H}_{29} \mathrm{~N}_{3} \mathrm{O}_{6} \mathrm{BrNa}[\mathrm{M}+\mathrm{Na}]^{+}$: 497.1132 found: 497.1131, calcd. for $\mathrm{C}_{19} \mathrm{H}_{29} \mathrm{~N}_{3} \mathrm{O}_{6} \mathrm{BrN}_{1} \mathrm{H}_{4}\left[\mathrm{M}+\mathrm{NH}_{4}\right]^{+}$: 492.1578 found: 492.1572. 


\subsection{Synthesis of Spin Labeled Azapeptide}

Benzhydrylidene Protected azaGly-Peptide Resin (34)<smiles>O=C([O-])NC(=O)CNC(=O)c1ccccc1</smiles>

To a precooled solution of benzophenone hydrazone $(19.7 \mathrm{mg}, 0.10 \mathrm{mmol}, 3.00 \mathrm{eq})$ in DCM $(0.5 \mathrm{~mL})$ a solution of $p$-nitrophenyl chloroformate $(20.8 \mathrm{mg}, 102 \mu \mathrm{mol}, 3.20 \mathrm{eq})$ in DCM $(1 \mathrm{~mL})$ was added dropwise under an argon atmosphere and the reaction solution was stirred for $2 \mathrm{~h}$ at $0^{\circ} \mathrm{C}$. Then, upon slowly addition of DIPEA $(35.0 \mu \mathrm{L}, 0.20 \mathrm{mmol}$, $6.00 \mathrm{eq}$ ) over $20 \mathrm{~min}$ at $0^{\circ} \mathrm{C}$ the mixture was immedeately transferred to the H-Gly-GlyGly-Trp(Boc)-Lys(Boc)-Rink amide resin in DCM (1 mL). The latter was previously prepared according to the standard operation procedure 7.3.2 on a scale of $0.1 \mathrm{mmol}$ using a Rink amide MBHA resin with a loading capacity of $0.36 \mathrm{mmol} / \mathrm{g}$, whereby the N-terminal Fmoc protection group was cleaved. The peptidyl resin was agitated in the solution of the preactivated benzophenone hydrazone intermediate at room temperature for $18 \mathrm{~h}$. Afterwards, the azapeptidyl resin was filtered and washed subsequently with DMF $(5 \times 2 \mathrm{~mL})$, $\mathrm{MeOH}(5 \times 2 \mathrm{~mL})$ and DCM $(5 \times 2 \mathrm{~mL})$. After drying the azapeptidyl resin in vacuo, testcleavage was performed by subjecting a small amount of the peptidyl resin to a mixture of TFA/TIS $/ \mathrm{H}_{2} \mathrm{O}(v / v / v, 95 / 2.5 / 2.5,1 \mathrm{~mL})$ and the cleavage was performed according to the standard operating procedure 7.3.3.

ESI-MS: $\mathrm{m} / z=725.3[\mathrm{M}+\mathrm{H}]^{+}, 747.3[\mathrm{M}+\mathrm{Na}]^{+}, 769.3\left[\mathrm{M}+\mathrm{H}+\mathrm{CO}_{2}\right]^{+}$.

ESI-HRMS: $\mathrm{m} / z$ calcd. for $\mathrm{C}_{37} \mathrm{H}_{44} \mathrm{~N}_{10} \mathrm{O}_{6} \mathrm{H}[\mathrm{M}+\mathrm{H}]^{+}: 725.3518$ found: 725.3512 , calcd. for $\mathrm{C}_{37} \mathrm{H}_{44} \mathrm{~N}_{10} \mathrm{O}_{6} \mathrm{Na}[\mathrm{M}+\mathrm{Na}]^{+}: 747.3338$ found: 747.3337 , calcd. for $\mathrm{C}_{37} \mathrm{H}_{44} \mathrm{~N}_{10} \mathrm{O}_{6} \mathrm{C}_{1} \mathrm{O}_{2} \mathrm{H}$ $\left[\mathrm{M}+\mathrm{H}+\mathrm{CO}_{2}\right]^{+}: 769.3416$ found: 769.3409 .

\section{Alkylation of Benzhydrylidene Protected azaGly-Peptide Resin (35)}

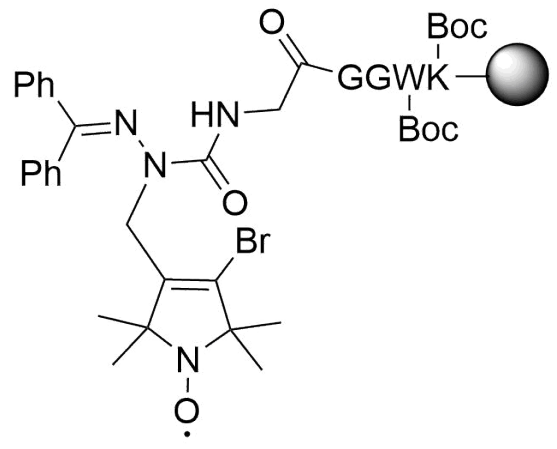

The benzhydrylidene-azaGly-Gly-Gly-Gly-Trp(Boc)-Lys(Boc)-resin 34 (0.1 mmol, 1.00 eq) was swollen for $30 \mathrm{~min}$ in THF $(2 \mathrm{~mL})$. Then, a $40 \%$ aq. TEAH solution $(64.7 \mu \mathrm{L}$, 
$0.1 \mathrm{mmol}, 3.00 \mathrm{eq})$ in THF $(0.1 \mathrm{~mL})$ was added to the peptidyl resin and the mixture was agitated for $30 \mathrm{~min}$ at room temperature. Afterwards, the bromide nitroxide $\mathbf{1 8}$ (62.4 mg, $0.2 \mathrm{mmol}, 2.00 \mathrm{eq})$ dissolved in THF $(0.2 \mathrm{~mL})$ was added to the mixture and the peptidyl resin was agitated in the alkylation solution at room temperature for $20 \mathrm{~h}$. The azapeptidyl resin was filtered and washed subsequently with THF ( $5 \times 2 \mathrm{~mL}), \mathrm{MeOH}$ $(5 \times 2 \mathrm{~mL})$ and DCM $(5 \times 2 \mathrm{~mL})$. After drying the alkylated azapeptidyl resin 35 in vacuo, test-cleavage was performed by subjecting a small amount of the peptidyl resin to a mixture of TFA/TIS $/ \mathrm{H}_{2} \mathrm{O}(v / v / v, 95 / 2.5 / 2.5,1 \mathrm{~mL})$ and the cleavage was performed according to the standard operating procedure 7.3 .3 .

ESI-MS: $\mathrm{m} / z=485.7[\mathrm{M}+2 \mathrm{H}]^{2+}, 970.4[\mathrm{M}+\mathrm{H}]^{+}, 1014.4\left[\mathrm{M}+\mathrm{H}+\mathrm{CO}_{2}\right]^{+}$.

ESI-HRMS: $\mathrm{m} / z$ calcd. for $\mathrm{C}_{47} \mathrm{H}_{60} \mathrm{Br}_{1} \mathrm{~N}_{11} \mathrm{O}_{7} \mathrm{H}[\mathrm{M}+\mathrm{H}]^{+}$: 970.3933 found: 970.3923, calcd. for $\mathrm{C}_{47} \mathrm{H}_{60} \mathrm{Br}_{1} \mathrm{~N}_{11} \mathrm{O}_{7} \mathrm{H}_{2}[\mathrm{M}+2 \mathrm{H}]^{2+}$ : 485.7003 Found: 485.7000,

calcd. for $\mathrm{C}_{47} \mathrm{H}_{60} \mathrm{Br}_{1} \mathrm{~N}_{11} \mathrm{O}_{7} \mathrm{C}_{1} \mathrm{O}_{2} \mathrm{H}\left[\mathrm{M}+\mathrm{H}+\mathrm{CO}_{2}\right]^{+}: 1014.3832$ found: 1014.3818 .

\section{3-Bromo-4-(bromomethyl)-1-methoxy-2,2,5,5-tetramethyl-2,5-dihydro-1 $\mathrm{H}$-pyrrole (40) $)^{[98]}$}

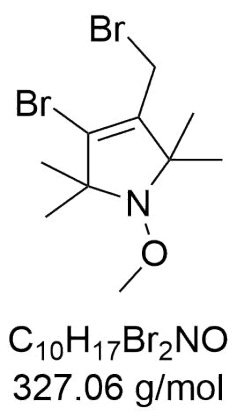

To a solution of bromide nitroxide 18 (90.3 mg, $0.29 \mathrm{mmol}, 1.00 \mathrm{eq})$ in DMSO (3 mL) $\mathrm{FeSO}_{4} \cdot 7 \mathrm{H}_{2} \mathrm{O}(201 \mathrm{mg}, 0.73 \mathrm{mmol}, 2.50 \mathrm{eq})$ was added at $10{ }^{\circ} \mathrm{C}$ and subsequently a $35 \%$ aq $\mathrm{H}_{2} \mathrm{O}_{2}$ solution $(150 \mu \mathrm{L}, 1.45 \mathrm{mmol}, 5.00 \mathrm{eq})$ was added dropwise over $30 \mathrm{~min}$. After the addition was complete, the reaction mixture was stirred for further $30 \mathrm{~min}$ at $15^{\circ} \mathrm{C}$. Then $\mathrm{H}_{2} \mathrm{O}(3 \mathrm{~mL})$ was added to the solution, the aqueous layer extracted with $\mathrm{Et}_{2} \mathrm{O}(3 \times 5 \mathrm{~mL})$, dried over $\mathrm{MgSO}_{4}$ and the solvent was removed in vacuo. The residue was purified by flash column chromatography on $\mathrm{SiO}_{2}(\mathrm{Pe} /$ EtOAc, 90/10, $v / v)$ to give the methoxy protected nitroxide $\mathbf{4 0}$ as a clear oil $(82.5 \mathrm{mg}, 0.25 \mathrm{mmol}, 87 \%)$.

ESI-MS: $\mathrm{m} / z=328.0[\mathrm{M}+\mathrm{H}]^{+}$.

ESI-HRMS: $\mathrm{m} / z$ calcd. for $\mathrm{C}_{10} \mathrm{H}_{17} \mathrm{Br}_{2} \mathrm{~N}_{1} \mathrm{O}_{1} \mathrm{H}[\mathrm{M}+\mathrm{H}]^{+}: 327.9729$ found: 327.9731 . 

(42) $)^{[96]}$

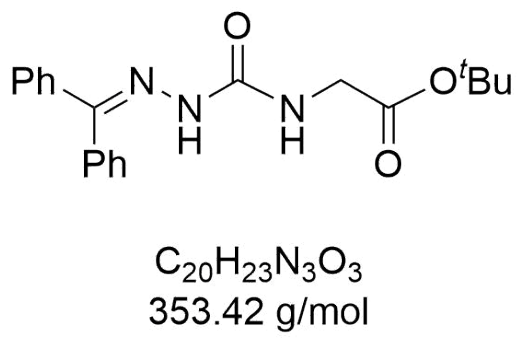

To a precooled solution of benzophenone hydrazone (703 mg, $3.57 \mathrm{mmol}, 3.00 \mathrm{eq})$ in DCM $(2 \mathrm{~mL})$ was added dropwise a solution of $p$-nitrophenyl chloroformate $(777 \mathrm{mg}, 3.81 \mathrm{mmol}$, $3.20 \mathrm{eq})$ in DCM (1 mL) under an argon atmosphere and the reaction solution was stirred for $2 \mathrm{~h}$ at $0^{\circ} \mathrm{C}$. Then, upon slowly addition of DIPEA $(1.25 \mathrm{~mL}, 7.14 \mathrm{mmol}, 6.00 \mathrm{eq})$ over $20 \mathrm{~min}$ at $0{ }^{\circ} \mathrm{C}$ the mixture was immedeately added to $\mathrm{H}-\mathrm{Gly}-\mathrm{OtBu}$ hydrochloride $(200 \mathrm{mg}$, $1.19 \mathrm{mmol}, 1.00 \mathrm{eq})$ in DCM $(5 \mathrm{~mL})$ and the reaction solution was stirred at room temperature for $16 \mathrm{~h}$. The solvent was removed in vacuo and the residue was purified by flash column chromatography on $\mathrm{SiO}_{2}(\mathrm{DCM} / \mathrm{MeOH}, 95 / 5, v / v)$ to give the benzhydrylideneazaGly-Gly-OtBu 42 as a colorless solid (263 mg, $0.69 \mathrm{mmol}, 58 \%$ ).

${ }^{1} \mathbf{H}-\mathbf{N M R}\left(400 \mathrm{MHz}, \mathrm{CDCl}_{3}\right): \delta[\mathrm{ppm}]=7.54-7.50\left(\mathrm{~m}, 5 \mathrm{H}, \mathrm{C}_{a r} \mathrm{H}\right), 7.36-7.32(\mathrm{~m}, 3 \mathrm{H}$, $\left.\mathrm{C}_{a r} \mathrm{H}\right), 7.25-7.23\left(\mathrm{~m}, 2 \mathrm{H}, \mathrm{C}_{a r} \mathrm{H}\right), 4.04\left(\mathrm{~s}, 2 \mathrm{H}, \mathrm{CH}_{2}\right), 1.51\left(\mathrm{~s}, 9 \mathrm{H}, 3 \times \mathrm{CH}_{3}\right)$.

${ }^{13}$ C-NMR $\left(100 \mathrm{MHz}, \mathrm{CDCl}_{3}\right): \delta[\mathrm{ppm}]=169.5\left(\mathrm{C}_{t B u}(\mathrm{O})\right), 155.6\left(\mathrm{C}_{\text {urea }}\right), 149.1\left(\mathrm{C}_{\text {imin }}\right)$, $136.9\left(\mathrm{C}_{a r}\right), 131.8\left(\mathrm{C}_{a r}\right), 130.0\left(\mathrm{C}_{a r}\right), 129.9\left(\mathrm{C}_{a r}\right), 129.6\left(\mathrm{C}_{a r}\right), 128.5\left(\mathrm{C}_{a r}\right), 128.4\left(\mathrm{C}_{a r}\right)$, $127.3\left(\mathrm{C}_{a r}\right), 126.2\left(\mathrm{C}_{a r}\right), 115.7\left(\mathrm{C}_{a r}\right), 82.4\left(\mathrm{C}_{t B u}\right), 42.6\left(\mathrm{CH}_{2}\right), 28.2\left(\mathrm{CH}_{3}\right)$.

ESI-MS: $\mathrm{m} / z=354.2[\mathrm{M}+\mathrm{H}]^{+}, 376.2[\mathrm{M}+\mathrm{Na}]^{+}$.

ESI-HRMS: $\mathrm{m} / z$ calcd. for $\mathrm{C}_{20} \mathrm{H}_{23} \mathrm{~N}_{3} \mathrm{O}_{3} \mathrm{H}[\mathrm{M}+\mathrm{H}]^{+}: 354.1812$ found: 354.1812, calcd. for $\mathrm{C}_{20} \mathrm{H}_{23} \mathrm{~N}_{3} \mathrm{O}_{3} \mathrm{Na}[\mathrm{M}+\mathrm{Na}]^{+}: 376.1632$ found: 376.1630 .

\section{Alkylation of Benzhydrylidene Protected azaGly-Gly-OtBu (43)}

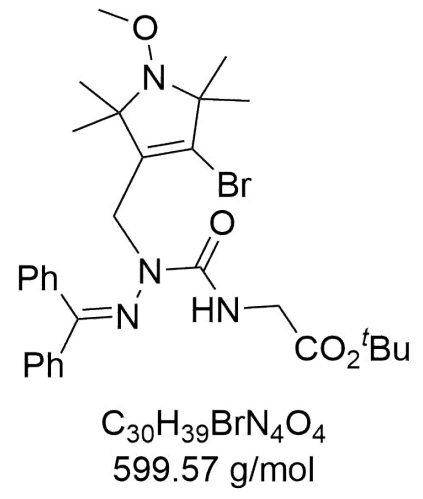

The benzhydrylidene-azaGly-Gly-OtBu 42 (50.0 mg, $0.13 \mathrm{mmol}, 1.00 \mathrm{eq})$ was dissolved in THF $(2 \mathrm{~mL})$ at $0{ }^{\circ} \mathrm{C}$. Then, a $40 \%$ aq. TEAH solution $(168.2 \mu \mathrm{L}, 0.26 \mathrm{mmol}, 2.00 \mathrm{eq})$ 
was added and the reaction solution was stirred for $30 \mathrm{~min}$ at $0{ }^{\circ} \mathrm{C}$. Subsequently, the methoxy protected bromide nitroxide 40 (122 $\mathrm{mg}, 0.39 \mathrm{mmol}, 3.00 \mathrm{eq})$ dissolved in THF $(0.5 \mathrm{~mL})$ was added slowly and the reaction solution was stirred at room temperature for $20 \mathrm{~h}$. Afterwards, saturated aq. solution of citric acid $(2 \mathrm{~mL})$ and saturated aq. $\mathrm{NaCl}$ solution $(2 \mathrm{~mL})$ were added. Then the organic layer was separated and the aqueous layer was extracted by EtOAc $(3 \times 5 \mathrm{~mL})$. The combined organic layers were dried over $\mathrm{MgSO}_{4}$ and the solvent was removed under reduced pressure. Finally, the residue was purified by flash column chromatography on $\mathrm{SiO}_{2}$ (DCM/MeOH, 95/5, v/v) to give the alkylated benzhydrylidene-azaGly-Gly-OtBu 43 as a colorless solid (41.3 mg, $68.9 \mu \mathrm{mol}, 53 \%$ ).

${ }^{1} \mathbf{H}-\mathbf{N M R}\left(400 \mathrm{MHz}, \mathrm{CDCl}_{3}\right): \delta[\mathrm{ppm}]=7.52-7.51\left(\mathrm{~m}, 2 \mathrm{H}, \mathrm{C}_{a r} \mathrm{H}\right), 7.47-7.44(\mathrm{~m}, 6 \mathrm{H}$, $\left.\mathrm{C}_{a r} \mathrm{H}\right), 7.36$ - $7.34\left(\mathrm{~m}, 2 \mathrm{H}, \mathrm{C}_{a r} \mathrm{H}\right), 6.25-6.23\left(\mathrm{~m}, 1 \mathrm{H}, \mathrm{CH}_{\text {urea }}\right), 4.00-3.98\left(\mathrm{~m}, 4 \mathrm{H}, 2 \mathrm{x} \mathrm{CH}_{2}\right)$, $3.67\left(\mathrm{~s}, 3 \mathrm{H}, \mathrm{CH}_{3}\right), 1.45\left(\mathrm{~s}, 9 \mathrm{H}, 3 \times \mathrm{x}_{t B u} \mathrm{H}_{3}\right), 1.25$ (s, $\left.12 \mathrm{H}, 4 \mathrm{x} \mathrm{CH}_{3}\right)$.

${ }^{13} \mathrm{C}-\mathrm{NMR}\left(100 \mathrm{MHz}, \mathrm{CDCl}_{3}\right): \delta[\mathrm{ppm}]=169.5,168.6,157.8,138.4,137.0,134.6,131.0$, 130.4, 129.6, 128.7, 128.3, 126.3, 115.9, 81.9, 65.4, 43.8, 43.2, 28.2.

ESI-MS: $\mathrm{m} / z=599.2[\mathrm{M}+\mathrm{H}]^{+}, 621.2[\mathrm{M}+\mathrm{Na}]^{+}$.

ESI-HRMS: $\mathrm{m} / z$ calcd. for $\mathrm{C}_{30} \mathrm{H}_{39} \mathrm{Br}_{1} \mathrm{~N}_{4} \mathrm{O}_{4} \mathrm{H}[\mathrm{M}+\mathrm{H}]^{+}: 599.2227$ found: 599.2231, calcd. for $\mathrm{C}_{30} \mathrm{H}_{39} \mathrm{Br}_{1} \mathrm{~N}_{4} \mathrm{O}_{4} \mathrm{Na}[\mathrm{M}+\mathrm{Na}]^{+}$: 621.2047 found: 621.2037 .

\section{Deprotection of Alkylated Benzhydrylidene Protected azaGly-Gly-OtBu (44)}

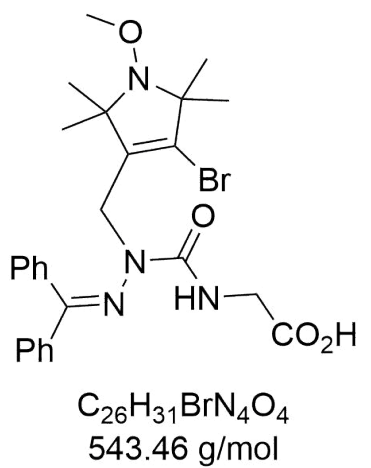

The alkylated benzhydrylidene-azaGly-Gly-OtBu 43 (30 mg, $50.0 \mu \mathrm{mol}, 1.00 \mathrm{eq})$ was added to a precooled solution of DCM/TFA $(v / v, 2 / 1,1 \mathrm{~mL})$ at $0{ }^{\circ} \mathrm{C}$ and the reaction solution was allowed to warm up to room temperature. Then, the reaction solution was stirred at room temperature for $2 \mathrm{~h}$. After removal of the solvent in a nitrogen stream, the residue was dried in vacuo to yield the alkylated azaGly-Gly-OH dipeptide $44(27.2 \mathrm{mg}$, $50.0 \mu \mathrm{mol}$, quantitative), that was used without further purification in the next step.

ESI-MS: $\mathrm{m} / z=543.2[\mathrm{M}+\mathrm{H}]^{+}, 565.1[\mathrm{M}+\mathrm{Na}]^{+}$.

ESI-HRMS: $\mathrm{m} / z$ calcd. for $\mathrm{C}_{26} \mathrm{H}_{31} \mathrm{Br}_{1} \mathrm{~N}_{4} \mathrm{O}_{4} \mathrm{H}[\mathrm{M}+\mathrm{H}]^{+}: 543.1601$ found: 543.1596 , calcd. for $\mathrm{C}_{26} \mathrm{H}_{31} \mathrm{Br}_{1} \mathrm{~N}_{4} \mathrm{O}_{4} \mathrm{Na}[\mathrm{M}+\mathrm{Na}]^{+}$: 565.1421 found: 565.1408 . 


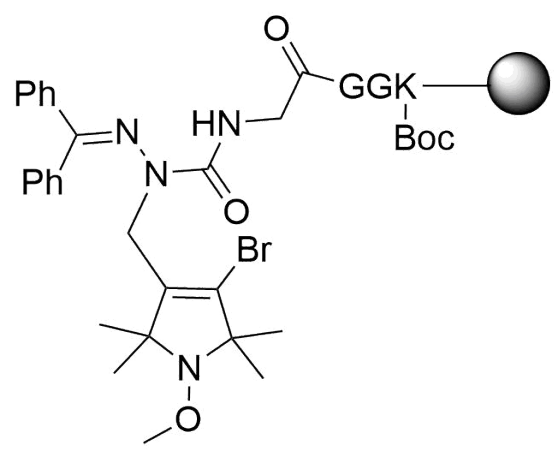

The alkylated azaGly-Gly-OH dipeptide $44(21.8 \mathrm{mg}, 40 \mu \mathrm{mol}, 2.00 \mathrm{eq})$ was dissolved in dry DMF $(1 \mathrm{~mL})$ and HOAt $(5.4 \mathrm{mg}, 40 \mu \mathrm{mol}, 2.00 \mathrm{eq})$ and HATU $(14.4 \mathrm{mg}, 38 \mu \mathrm{mol}$, $1.90 \mathrm{eq})$ were added followed by DIPEA $(6.8 \mu \mathrm{L}, 40 \mu \mathrm{mol}, 2.00 \mathrm{eq})$ under an argon atmosphere. The resulting reaction solution was stirred at room temperature for $5 \mathrm{~min}$ and was added to the swollen H-Gly-Gly-Lys(Boc)-Rink amide resin in DMF (1 mL). The latter was previously prepared according to the standard operation procedure 7.3.2 on a scale of $20 \mu \mathrm{mol}$ using a Rink amide MBHA resin with a loading capacity of $0.36 \mathrm{mmol} / \mathrm{g}$, whereby the N-terminal Fmoc protection group was cleaved. The peptidyl resin was agitated in the solution of the preactivated azadipeptide intermediate at room temperature for $19 \mathrm{~h}$. Afterwards, the azapeptidyl resin was filtered and washed subsequently with DMF $(5 \times 2 \mathrm{~mL}), \mathrm{MeOH}(5 \times 2 \mathrm{~mL})$ and DCM $(5 \times 2 \mathrm{~mL})$. After drying the benzhydrylideneazapeptidyl resin 45 in vacuo, test-cleavage was performed by subjecting a small amount of the peptidyl resin to a mixture of TFA/TIS/ $\mathrm{H}_{2} \mathrm{O}(v / v / v, 95 / 2.5 / 2.5,1 \mathrm{~mL})$ and the cleavage was performed according to the standard operating procedure 7.3 .3 .

ESI-MS: $\mathrm{m} / z=784.3[\mathrm{M}+\mathrm{H}]^{+}, 806.3[\mathrm{M}+\mathrm{Na}]^{+}, 785.3[\mathrm{M}+2 \mathrm{H}]^{2+}$.

ESI-HRMS: $\mathrm{m} / z$ calcd. for $\mathrm{C}_{36} \mathrm{H}_{50} \mathrm{Br}_{1} \mathrm{~N}_{9} \mathrm{O}_{6} \mathrm{H}[\mathrm{M}+\mathrm{H}]^{+}: 784.3140$ found: 784.3143, calcd. for $\mathrm{C}_{36} \mathrm{H}_{50} \mathrm{Br}_{1} \mathrm{~N}_{9} \mathrm{O}_{6} \mathrm{Na}[\mathrm{M}+\mathrm{Na}]^{+}$: 806.2960 found: 806.2948, $\mathrm{C}_{36} \mathrm{H}_{50} \mathrm{Br}_{1} \mathrm{~N}_{9} \mathrm{O}_{6} \mathrm{H}_{2}$ $[\mathrm{M}+2 \mathrm{H}]^{2+}: 392.6606$ found: 392.6608 .

\section{Benzhydrylidene Deprotection of Alkylated azaGly-peptidyl Resin (46)}

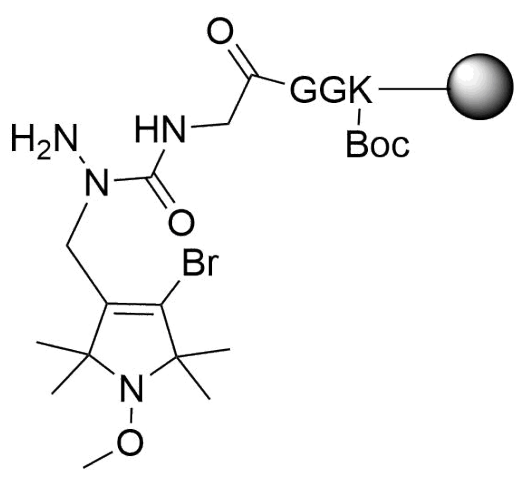


A solution of $1.5 \mathrm{M}$ solution of $\mathrm{NH}_{2} \mathrm{OH} \cdot \mathrm{HCl}$ in pyridine $(3 \mathrm{~mL})$ was added to the dried benzhydrylidene-azapeptidyl resin 45 (20 $\mu \mathrm{mol}, 1.00 \mathrm{eq})$ und the mixture was agitated at $60^{\circ} \mathrm{C}$ for $16 \mathrm{~h}$. Then, the deprotected azapeptidyl resin was filtered and washed subsequently with 10\% DIPEA in DMF ( $5 \times 2 \mathrm{~mL}), \mathrm{DMF}(5 \times 2 \mathrm{~mL}), \mathrm{MeOH}(5 \times 2 \mathrm{~mL})$ and DCM $(5 \times 2 \mathrm{~mL})$. After drying the azapeptidyl resin 46 in vacuo, test-cleavage was performed by subjecting a small amount of the peptidyl resin to a mixture of TFA/TIS $/ \mathrm{H}_{2} \mathrm{O}$ $(v / v / v, 95 / 2.5 / 2.5,1 \mathrm{~mL})$ and the cleavage was performed according to the standard operating procedure $\mathbf{7 . 3 . 3}$.

ESI-MS: $\mathrm{m} / z=620.3[\mathrm{M}+\mathrm{H}]^{+}, 642.2[\mathrm{M}+\mathrm{Na}]^{+}$.

ESI-HRMS: $\mathrm{m} / z$ calcd. for $\mathrm{C}_{23} \mathrm{H}_{42} \mathrm{Br}_{1} \mathrm{~N}_{9} \mathrm{O}_{6} \mathrm{H}[\mathrm{M}+\mathrm{H}]^{+}: 620.2514$ found: 620.2513, calcd. for $\mathrm{C}_{23} \mathrm{H}_{42} \mathrm{Br}_{1} \mathrm{~N}_{9} \mathrm{O}_{6} \mathrm{Na}[\mathrm{M}+\mathrm{Na}]^{+}$: 642.2334 found: 642.2325 .

\section{Coupling of Fmoc-Gly-OH to the Alkylated azaGly-peptidyl Resin (47)}

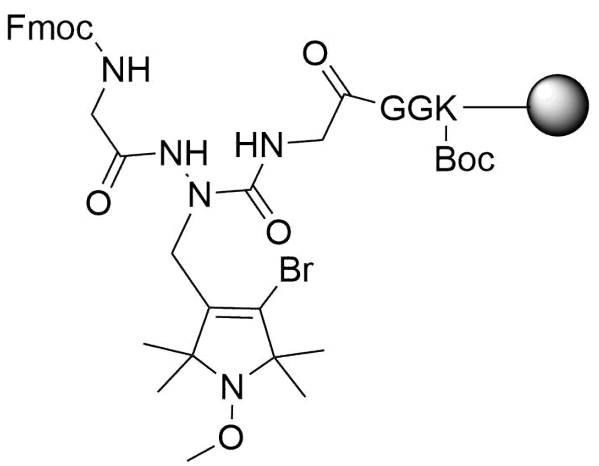

Fmoc-Gly-OH $(29.7 \mathrm{mg}, 100 \mu \mathrm{mol}, 5 \mathrm{eq})$ and DIC $(7.7 \mu \mathrm{L}, 50.0 \mu \mathrm{mol}, 2.50 \mathrm{eq})$ were dissolved in dry DCM $(3 \mathrm{~mL}) 0^{\circ} \mathrm{C}$ and the resulting solution was stirred for $30 \mathrm{~min}$ at room temperature. Then, the solvent was removed under reduced pressure and the residue was redissolved in dry DMF (2 mL). The solution of the pre-activated glycine amino acid was transferred to the azapeptidyl resin 46, that was previously swollen in DMF (1 mL) and the mixture was agitated at room temperature for $16 \mathrm{~h}$. Then, the elongated azapeptidyl resin 47 was filtered and washed subsequently with DMF $(5 \times 2 \mathrm{~mL}), \mathrm{MeOH}(5 \times 2 \mathrm{~mL})$ and DCM $(5 \times 2 \mathrm{~mL})$. After drying the azapeptidyl resin 47 in vacuo, test-cleavage was performed by subjecting a small amount of the peptidyl resin to a mixture of TFA/TIS $/ \mathrm{H}_{2} \mathrm{O}$ $(v / v / v, 95 / 2.5 / 2.5,1 \mathrm{~mL})$ and the cleavage was performed according to the standard operating procedure $\mathbf{7 . 3 . 3}$.

ESI-MS: $\mathrm{m} / z=899.3[\mathrm{M}+\mathrm{H}]^{+}$.

ESI-HRMS: $\mathrm{m} / z$ calcd. for $\mathrm{C}_{40} \mathrm{H}_{55} \mathrm{Br}_{1} \mathrm{~N}_{10} \mathrm{O}_{9} \mathrm{H}[\mathrm{M}+\mathrm{H}]^{+}: 899.3410$ found: 899.3402 . 


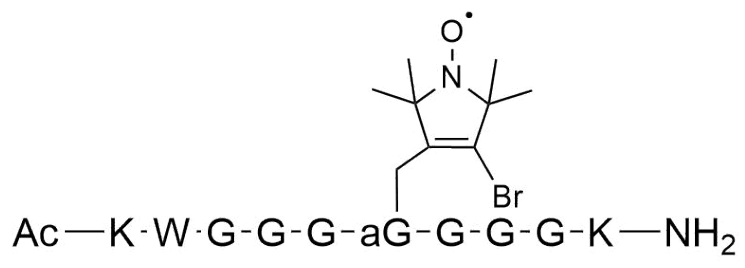

The Fmoc group of the azapeptidyl resin $47(20 \mu \mathrm{mol})$ was deprotected and the azapeptide was subsequently elongated by coupling of the next amino acids according to the standard operating procedure 7.3.2 using the amino acids Fmoc-Gly-OH, Fmoc-Trp(Boc)-OH and Fmoc-Lys(Boc)-OH. After the desired sequence was synthesized, the N-terminus was acetylated. Then, the acetylated azapeptide was cleaved from the resin and isolated following the standard operating procedure 7.3.3 using $2 \mathrm{~mL}$ of the cleavage cocktail. Finally, the freeze-dried crude peptide was purified by RP-HPLC on a C18 analytical column using solvent B (0.1\% TFA in MeCN) in A (0.1\% TFA in di-demineralized water) with a flow of $0.5 \mathrm{~mL}$ per min.

HPLC (Gradient 5 to $50 \% \mathrm{~B}$ in $30 \mathrm{~min}$ ): $t_{R}=12.9 \mathrm{~min}$.

ESI-MS: $\mathrm{m} / z=383.8[\mathrm{M}+3 \mathrm{H}]^{3+}, 575.3[\mathrm{M}+2 \mathrm{H}]^{2+}, 1149.5[\mathrm{M}+\mathrm{H}]^{+}, 1169.5[\mathrm{M}+\mathrm{Na}]^{+}$. ESI-HRMS: $\mathrm{m} / z$ calcd. for $\mathrm{C}_{48} \mathrm{H}_{75} \mathrm{Br}_{1} \mathrm{~N}_{16} \mathrm{O}_{12} \mathrm{H}[\mathrm{M}+\mathrm{H}]^{+}: 1147.5007$ found: 1147.4994, calcd. for $\mathrm{C}_{48} \mathrm{H}_{75} \mathrm{Br}_{1} \mathrm{~N}_{16} \mathrm{O}_{12} \mathrm{H}_{2}[\mathrm{M}+2 \mathrm{H}]^{2+}$ : 574.2540 found: 574.2549, calcd. for $\mathrm{C}_{48} \mathrm{H}_{75} \mathrm{Br}_{1} \mathrm{~N}_{16} \mathrm{O}_{12} \mathrm{H}_{3}[\mathrm{M}+3 \mathrm{H}]^{3+}$ : 383.1717 found: 383.1719 , calcd. for $\mathrm{C}_{48} \mathrm{H}_{75} \mathrm{Br}_{1} \mathrm{~N}_{16} \mathrm{O}_{12} \mathrm{Na}[\mathrm{M}+\mathrm{Na}]^{+}$: 1169.4826 found: 1169.4814 . 


\subsection{Synthesis of Photolabile Protected TOPP Spin Label}

\section{Cbz-L-Hpg-OBn (54) ${ }^{[3,111]}$}

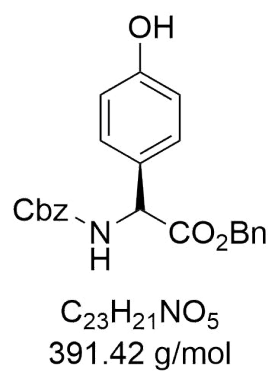

To a solution of 4-hydroxyphenylglycine $\mathbf{5 2}(5.00 \mathrm{~g}, 28.4 \mathrm{mmol}, 1.00 \mathrm{eq})$ in an $10 \%$ aqueous solution of $\mathrm{Na}_{2} \mathrm{CO}_{3}(70 \mathrm{~mL})$ a solution of $\mathrm{CbzCl}(4.41 \mathrm{~mL}, 30.1 \mathrm{mmol}, 1.10 \mathrm{eq})$ in toluene $(5.0 \mathrm{~mL})$ and dioxane $(55.0 \mathrm{~mL})$ was added dropwise at $0^{\circ} \mathrm{C}$. Then, the reaction mixture was stirred at $0^{\circ} \mathrm{C}$ for $30 \mathrm{~min}$ and additional $1 \mathrm{~h}$ at room temperature. The organic solvent was removed in vacuo and cold water $(180 \mathrm{~mL})$ was added to the residual aqueous phase. Subsequently, the aqueous phase was washed with EtOAc $(3 \times 50.0 \mathrm{~mL})$ and was acidified with $2 \mathrm{M}$ aq. $\mathrm{HCl}$ to $\mathrm{pH} 2$. Then, the acid layer was extracted with EtOAc $(3 \times 70 \mathrm{~mL})$ and the combined organci layers were washed with water $(50 \mathrm{~mL})$, saturated aq. $\mathrm{NaCl}$ solution $(50 \mathrm{~mL})$ and then dried over $\mathrm{MgSO}_{4}$. After the removal of the solvent under reduced pressure and drying in vacuo, the Cbz-L-Hpg-OBn $\mathbf{5 3}$ was obtained as a colorless solid (6.99 g, 23.2 mmol, 69\%) and used without further purification. The Cbz-L-Hpg-OBn 53 $(8.00 \mathrm{~g}, 26.5 \mathrm{mmol}, 1.00 \mathrm{eq})$ and $\mathrm{NaHCO}_{3}(2.32 \mathrm{~g}, 27.6 \mathrm{mmol}, 1.00 \mathrm{eq})$ were dissolved in dry DMF $(130 \mathrm{~mL})$ and the mixture was cooled to $0{ }^{\circ} \mathrm{C}$. Then, $\operatorname{BnBr}(5.51 \mathrm{~g}, 32.2 \mathrm{mmol}$, $1.21 \mathrm{eq}$ ) was added dropwise and the reaction mixture was stirred at room temperature for $20 \mathrm{~h}$. Subsequently, $\mathrm{H}_{2} \mathrm{O}(210 \mathrm{~mL})$ was added to the mixture and the aqueous layer was extracted with EtOAc $(3 \times 100 \mathrm{~mL})$. The combined organic layers were washed with $\mathrm{H}_{2} \mathrm{O}(150 \mathrm{~mL})$, saturated aq. $\mathrm{NaCl}$ solution $(3 \times 100 \mathrm{~mL})$, dried over $\mathrm{MgSO}_{4}$ and the solvent was removed in vacuo. Purifying the residue by flash column chromatography on $\mathrm{SiO}_{2}(\mathrm{Pe} / \mathrm{EtOAc}, 70 / 30, v / v)$ gave the Cbz-L-Hpg-OBn 54 as a colourless solid (7.64 g, $19.5 \mathrm{mmol}, 75 \%)$.

${ }^{1} \mathbf{H}-\mathbf{N M R}\left(300 \mathrm{MHz}, \mathrm{DMCO}-\mathrm{d}_{6}\right): \delta[\mathrm{ppm}]=9.51(\mathrm{~s}, 1 \mathrm{H}, \mathrm{OH}), 8.16\left(\mathrm{~d}, 1 \mathrm{H},{ }^{2} J_{H H}=7.8 \mathrm{~Hz}\right.$, $\mathrm{NH}), 7.35-7.32\left(\mathrm{~m}, 10 \mathrm{H}, \mathrm{CH}_{a r}\right), 6.72-6.70\left(\mathrm{~m}, 2 \mathrm{H}, \mathrm{CH}_{a r}\right), 5.19\left(\mathrm{~d},{ }^{3} J_{H H}=7.8 \mathrm{~Hz}, 1 \mathrm{H}\right.$, $\left.\mathrm{C}_{\alpha} \mathrm{H}\right), 5.12\left(\mathrm{~s}, 2 \mathrm{H}, \mathrm{CH}_{2}\right), 5.06\left(\mathrm{~s}, 2 \mathrm{H}, \mathrm{CH}_{2}\right)$.

${ }^{13}$ C-NMR $(126 \mathrm{MHz}$, DMSO-d 6$): \delta[\mathrm{ppm}]=171.0,157.4,155.9,139.9,135.8,129.1,128.5$, $127.9,127.7,127.5,126.2,115.2,66.0,65.6,57.5$.

ESI-MS: $\mathrm{m} / z=392.2[\mathrm{M}+\mathrm{H}]^{+}, 414.1[\mathrm{M}+\mathrm{Na}]^{+}$.

ESI-HRMS: $\mathrm{m} / z$ calcd. for $\mathrm{C}_{23} \mathrm{H}_{21} \mathrm{~N}_{1} \mathrm{O}_{5} \mathrm{H}[\mathrm{M}+\mathrm{H}]^{+}$: 414.1312 found: 414.1318, calcd. for $\mathrm{C}_{23} \mathrm{H}_{21} \mathrm{~N}_{1} \mathrm{O}_{5} \mathrm{Na}[\mathrm{M}+\mathrm{Na}]^{+}$: 409.1758 found: 409.1761 . 


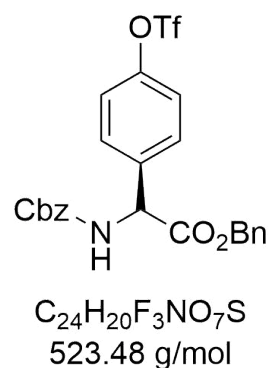

Cbz-L-Hpg-OBn 54 (4.00 g, $9.85 \mathrm{mmol}, 1.00 \mathrm{eq})$ and pyridine $(2.30 \mathrm{~mL}, 29.6 \mathrm{mmol}, 3.00 \mathrm{eq})$ were dissolved in dry DCM $(35 \mathrm{~mL})$ and the reaction solution was cooled to $0^{\circ} \mathrm{C}$. Afterwards, $\mathrm{Tf}_{2} \mathrm{O}(2.41 \mathrm{~mL}, 14.8 \mathrm{mmol}, 1.50 \mathrm{eq})$ was added dropwise and the reaction mixture was stirred at $0{ }^{\circ} \mathrm{C}$ for $15 \mathrm{~min}$ and was allowed to warm up to room temperature and stirred for additional $40 \mathrm{~min}$. Then, saturated aq. $\mathrm{NaHCO}_{3}$ solution $(60 \mathrm{~mL})$ was added and the organic phase was separated. The aqueous phase was extracted with DCM $(3 \times 50 \mathrm{~mL})$ and the combined organic phases were washed with saturated aq. $\mathrm{NaCl}$ solution $(3 \times 50 \mathrm{~mL})$, dried over $\mathrm{MgSO}_{4}$ and the solvent was removed in vacuo. After the removal of the pyridine by coevaporation with toluene, the residue was purified by flash column chromatography on $\mathrm{SiO}_{2}(\mathrm{Pe} / \mathrm{EtOAc}, 70 / 30, v / v)$ to give the Cbz-L-Hpg(Tf)-OBn $5 \mathbf{5}$ as an yellowish solid $(5.63 \mathrm{~g}, 10.4 \mathrm{mmol}, 89 \%)$.

${ }^{1} \mathbf{H}-\mathbf{N M R}\left(300 \mathrm{MHz}, \mathrm{CDCl}_{3}\right): \delta[\mathrm{ppm}]=7.44-7.14\left(\mathrm{~m}, 14 \mathrm{H}, \mathrm{C}_{a r} \mathrm{H}\right), 5.98\left(\mathrm{~d},{ }^{2} J_{H H}=5.7 \mathrm{~Hz}\right.$, $1 \mathrm{H}, \mathrm{NH}), 5.45\left(\mathrm{~d},{ }^{2} J_{H H}=6.3 \mathrm{~Hz}, 1 \mathrm{H}, \mathrm{C}_{\alpha} \mathrm{H}\right), 5.16-5.01\left(\mathrm{~m}, 4 \mathrm{H}, 2 \times \mathrm{CH}_{2}\right)$.

${ }^{13}$ C-NMR $\left(126 \mathrm{MHz}, \mathrm{CDCl}_{3}\right): \delta[\mathrm{ppm}]=169.9,155.4,149.5,137.5,136.0,134.8,129.2$, $128.8,128.5,125.4,121.9,120.5,117.3,68.0,67.5,57.4$.

ESI-MS: $\mathrm{m} / z=524.1[\mathrm{M}+\mathrm{H}]^{+}, 546.1[\mathrm{M}+\mathrm{Na}]^{+}$.

ESI-HRMS: $\mathrm{m} / z$ calcd. for $\mathrm{C}_{24} \mathrm{H}_{20} \mathrm{~N}_{1} \mathrm{O}_{5} \mathrm{SF}_{3} \mathrm{H}[\mathrm{M}+\mathrm{H}]^{+}: 524.0985$ found: 524.0990, calcd. for $\mathrm{C}_{24} \mathrm{H}_{20} \mathrm{~N}_{1} \mathrm{O}_{5} \mathrm{SF}_{3} \mathrm{Na}[\mathrm{M}+\mathrm{Na}]^{+}$: 546.0805 found: 546.0809 .

\section{$\mathrm{Bn}_{2}-\mathrm{L}-\mathrm{Hpg}(\mathrm{Tf})-\mathrm{OBn}(\mathbf{5 6})^{[3,111]}$}

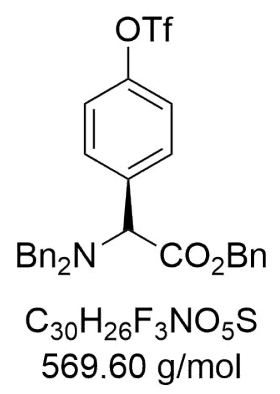

Cbz-L-Hpg(Tf)-OBn 55 (8.00 g, 15.3 mmol, 1.00 eq) and $\mathrm{Me}_{2} \mathrm{~S}$ (33.6 mL, $\left.444 \mathrm{mmol}, 30.0 \mathrm{eq}\right)$ were dissolved in TFA $(180 \mathrm{~mL})$ and the reaction solution was stirred at room temperature for $19 \mathrm{~h}$. Then, TFA was removed by coevaporation with toluene to yield the crude 
deprotected intermediate, that was dissolved in DMSO $(100 \mathrm{~mL})$. Afterwards, $\mathrm{NaHCO}_{3}$ $(7.70 \mathrm{~g}, 91.9 \mathrm{mmol}, 6.00 \mathrm{eq})$ was added to the reaction solution and the reaction mixture was stirred upon dropwise addition of $\mathrm{BnBr}(22.8 \mathrm{~mL}, 275 \mathrm{mmol}, 18.0 \mathrm{eq})$ at room temperature for $21 \mathrm{~h}$. Then, $\mathrm{H}_{2} \mathrm{O}(500 \mathrm{~mL})$ and EtOAc $(150 \mathrm{~mL})$ were added, the organic layer was separated and the aqueous layer was extracted with EtOAc $(3 \times 100 \mathrm{~mL})$. The combined organic layers were washed with $\mathrm{H}_{2} \mathrm{O}(200 \mathrm{~mL})$, saturated aq. NaCl solution $(3 \times 200 \mathrm{~mL})$, dried over $\mathrm{MgSO}_{4}$ and the solvent was removed under reduced pressure. Finally, the residue was purified by flash column chromatography on $\mathrm{SiO}_{2}(\mathrm{Pe} / \mathrm{EtOAc}$, $80 / 20, v / v)$ to give the $\mathrm{Bn}_{2}-\mathrm{L}-\mathrm{Hpg}(\mathrm{Tf})-\mathrm{OBn} 56$ as a colorless solid (3.26 g, $5.73 \mathrm{mmol}$, $61 \%)$.

${ }^{1} \mathbf{H}-\mathbf{N M R}\left(300 \mathrm{MHz}, \mathrm{CDCl}_{3}\right): \delta[\mathrm{ppm}]=7.74-7.72\left(\mathrm{~m}, 14 \mathrm{H}, \mathrm{C}_{a r} \mathrm{H}\right), 7.32-7.23(\mathrm{~m}, 15 \mathrm{H}$, $\left.\mathrm{C}_{a r} \mathrm{H}\right), 7.20-7.18\left(\mathrm{~m}, 2 \mathrm{H}, \mathrm{C}_{a r} \mathrm{H}\right), 5.27\left(\mathrm{~m}, 2 \mathrm{H}, \mathrm{CH}_{2}\right), 4.63\left(\mathrm{~s}, 1 \mathrm{H}, \mathrm{CH}_{\alpha}\right), 3.71-3.70(\mathrm{~m}$, $4 \mathrm{H}, 2 \times \mathrm{CH}_{2}$ ).

ESI-MS: $\mathrm{m} / z=570.2[\mathrm{M}+\mathrm{H}]^{+}, 592.1[\mathrm{M}+\mathrm{Na}]^{+}$.

ESI-HRMS: $\mathrm{m} / z$ calcd. for $\mathrm{C}_{30} \mathrm{H}_{26} \mathrm{~N}_{1} \mathrm{O}_{5} \mathrm{SF}_{3} \mathrm{H}[\mathrm{M}+\mathrm{H}]^{+}: 570.1557$ found: 570.1555 , calcd. for $\mathrm{C}_{30} \mathrm{H}_{26} \mathrm{~N}_{1} \mathrm{O}_{5} \mathrm{SF}_{3} \mathrm{Na}[\mathrm{M}+\mathrm{Na}]^{+}$: 592.1376 found: 592.1370 .

\section{$\mathrm{Bn}_{2}$-4-pinacolboryl-L-Phg-OBn (57) ${ }^{[3,111]}$}

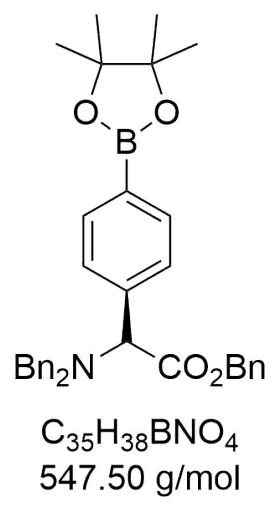

$\mathrm{Bn}_{2}$-L-Hpg(Tf)-OBn 56 (3.00 g, $\left.5.27 \mathrm{mmol}, 1.00 \mathrm{eq}\right), \mathrm{B}_{2} \mathrm{pin}_{2}$ (1.60 g, $\left.6.33 \mathrm{mmol}, 1.20 \mathrm{eq}\right)$, KOAc (1.56 g, $15.9 \mathrm{mmol}, 3.00 \mathrm{eq}), \mathrm{PdCl}_{2}$ (dppf) (388 mg, $\left.530 \mu \mathrm{mol}, 0.10 \mathrm{eq}\right)$ and dppf (293 mg, $530 \mu \mathrm{mol}, 0.10 \mathrm{eq})$ were dissolved in degassed dioxane $(60 \mathrm{~mL})$ under an argon atmosphere and the reaction mixture was stirred at $80^{\circ} \mathrm{C}$ for $6 \mathrm{~h}$. Then, EtOAc $(250 \mathrm{~mL})$ was added to the mixture and the organic phase was washed with saturated aq. $\mathrm{NaCl}$ solution $(3 \times 100 \mathrm{~mL})$ and dried over $\mathrm{MgSO}_{4}$. After removal of the solvent in vacuo, the crude product was purified by flash column chromatography on $\mathrm{SiO}_{2}$ (Pe/EtOAc, 98/2, v/v) to give the $\mathrm{Bn}_{2}$-4-pinacolboryl-L-Phg-OBn 57 as a light yellowish oil $(2.57 \mathrm{~g}, 4.69 \mathrm{mmol}$, $84 \%)$.

${ }^{1} \mathbf{H}-\mathbf{N M R}\left(400 \mathrm{MHz}, \mathrm{CDCl}_{3}\right): \delta[\mathrm{ppm}]=7.73\left(\mathrm{~d}, 2 \mathrm{H},{ }^{3} \mathrm{~J}_{H H}=6.0 \mathrm{~Hz}, 2 \mathrm{xC}_{a r} \mathrm{H}\right), 7.32-$ $7.18\left(\mathrm{~m}, 17 \mathrm{H}, \mathrm{C}_{a r} \mathrm{H}\right), 5.26\left(\mathrm{~d},{ }^{2} J_{H H}=12.4 \mathrm{~Hz}, 1 \mathrm{H}, \mathrm{CH}_{2}\right), 5.14\left(\mathrm{~d},{ }^{2} J_{H H}=12.4 \mathrm{~Hz}, 1 \mathrm{H}\right.$, 
$\left.\mathrm{CH}_{2}\right), 4.62\left(\mathrm{~s}, 1 \mathrm{H}, \mathrm{C}_{\alpha} \mathrm{H}\right), 3.70\left(\mathrm{~s}, 4 \mathrm{H}, 2 \times \mathrm{CH}_{2}\right), 1.40\left(\mathrm{~s}, 12 \mathrm{H}, 4 \times \mathrm{CH}_{3}\right)$.

${ }^{13}$ C-NMR $\left(126 \mathrm{MHz}, \mathrm{CDCl}_{3}\right): \delta[\mathrm{ppm}]=171.8,139.7,139.3,135.8,134.7,128.8,128.5$, 128.4, 128.3, 128.2, 128.2, 127.0, 83.8, 66.2, 65.8, 54.2, 24.9, 24.8, 24.7.

ESI-MS: $\mathrm{m} / z=548.3[\mathrm{M}+\mathrm{H}]^{+}, 570.3[\mathrm{M}+\mathrm{Na}]^{+}$.

ESI-HRMS: $\mathrm{m} / z$ calcd. for $\mathrm{C}_{35} \mathrm{H}_{38} \mathrm{BNO}_{4} \mathrm{H}[\mathrm{M}+\mathrm{H}]^{+}: 548.2973$ found: 548.2979, calcd. for $\mathrm{C}_{35} \mathrm{H}_{38} \mathrm{BNO}_{4} \mathrm{Na}[\mathrm{M}+\mathrm{Na}]^{+}: 570.2792$ found: 570.2790 .

\section{$\mathrm{Bn}_{2}$-4-dihydroxyboron-L-Phg-OBn (58) ${ }^{[3,111]}$}

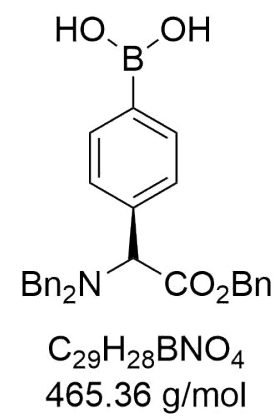

$\mathrm{Bn}_{2}$-4-pinacolboryl-L-Phg-OBn (57) (3.00 g, $\left.5.48 \mathrm{mmol}, 1.00 \mathrm{eq}\right)$ was dissolved in acetone $/ \mathrm{H}_{2} \mathrm{O}(3 / 2.5, v / v, 550 \mathrm{~mL})$, followed by addition of $\mathrm{NaIO}_{4}(3.63 \mathrm{~g}, 17.0 \mathrm{mmol}$, $3.10 \mathrm{eq})$ and $\mathrm{NH}_{4} \mathrm{OAc}(1.27 \mathrm{~g}, 16.5 \mathrm{mmol}, 3.00 \mathrm{eq})$. Then, the reaction mixture was stirred at room temperature for $54 \mathrm{~h}$. After removal of the organic solvent under reduced pressure, the aqueous layer was extracted with $\mathrm{Et}_{2} \mathrm{O}(3 \times 100 \mathrm{~mL})$ and the combined organic layers were washed with saturated aq. $\mathrm{NaCl}$ solution $(3 \times 50 \mathrm{~mL})$ and dried over $\mathrm{MgSO}_{4}$. Finally, the removal of the organic solvent in vacuo gave the $\mathrm{Bn}_{2}$-4-dihydroxyboron-LPhg-OBn 58 as a colorless solid (2.40 g, $5.17 \mathrm{mmol}, 82 \%)$.

${ }^{1} \mathbf{H}-\mathrm{NMR}\left(400 \mathrm{MHz}, \mathrm{CDCl}_{3}\right): \delta[\mathrm{ppm}]=8.17\left(\mathrm{~d}, 2 \mathrm{H},{ }^{3} \mathrm{~J}_{H H}=8.0 \mathrm{~Hz}, \mathrm{C}_{a r} \mathrm{H}\right), 7.47(\mathrm{~d}, 2 \mathrm{H}$, $\left.{ }^{3} \mathrm{~J}_{H H}=8.0 \mathrm{~Hz}, \mathrm{C}_{a r} \mathrm{H}\right), 7.38-7.22\left(\mathrm{~m}, 15 \mathrm{H}, \mathrm{C}_{a r} \mathrm{H}\right) 5.36\left(\mathrm{~d},{ }^{2} J_{H H}=12.0 \mathrm{~Hz}, 1 \mathrm{H}, \mathrm{CH}_{2}\right)$, $5.23\left(\mathrm{~d},{ }^{2} J_{H H}=12.0 \mathrm{~Hz}, 1 \mathrm{H}, \mathrm{CH}_{2}\right), 4.74\left(\mathrm{~s}, 1 \mathrm{H}, \mathrm{CH}_{\alpha}\right), 4.65\left(\mathrm{~s}, 4 \mathrm{H}, 2 \times \mathrm{CH}_{2}\right)$.

${ }^{13}$ C-NMR $\left(126 \mathrm{MHz}, \mathrm{CDCl}_{3}\right): \delta[\mathrm{ppm}]=171.7,141.4,139.3,135.7,135.6,133.5,129.6$, $128.8,128.7,128.6,128.5,128.4,128.4,128.4,128.3,128.3,127.1,127.0,66.3,65.9,65.7$, $54.3,54.2$.

ESI-MS: $\mathrm{m} / z=466.2[\mathrm{M}+\mathrm{H}]^{+}, 480.2\left[\mathrm{M}+\mathrm{CH}_{2}\right]^{+}, 494.3\left[\mathrm{M}+2 \mathrm{CH}_{2}\right]^{+}$.

ESI-HRMS: $\mathrm{m} / z$ calcd. for $\mathrm{C}_{29} \mathrm{H}_{28} \mathrm{BN}_{1} \mathrm{O}_{4} \mathrm{H}[\mathrm{M}+\mathrm{H}]^{+}: 466.2189$ found: 466.2187, calcd. for $\mathrm{C}_{29} \mathrm{H}_{28} \mathrm{BN}_{1} \mathrm{O}_{4} \mathrm{CH}_{2}\left[\mathrm{M}+\mathrm{CH}_{2}\right]^{+}: 480.2346$ found: 480.2350 , calcd. for $\mathrm{C}_{29} \mathrm{H}_{28} \mathrm{BN}_{1} \mathrm{O}_{4} \mathrm{C}_{2} \mathrm{H}_{2}$ $\left[\mathrm{M}+2 \mathrm{CH}_{2}\right]^{+}: 494.2503$ found: 494.2497 . 


\section{2,2'-Imino-bis(2-methylpropionitrile) (60)}

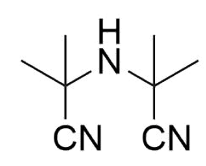

$\mathrm{C}_{8} \mathrm{H}_{13} \mathrm{~N}_{3}$

$151.21 \mathrm{~g} / \mathrm{mol}$

2-Amino-2-methylpropionitrile hydrochloride (10 g, $82.9 \mathrm{mmol}, 1.00 \mathrm{eq})$ was dissolved in EtOAC and subsequently an $10 \%$ aq. solution of $\mathrm{NaHCO}_{3}$ was added until the $\mathrm{pH}=7$ was reached. Then, the organic layer was separated and the aqueous layer was extracted with EtOAc $(3 \times 20 \mathrm{~mL})$. The combined organic layers were dried over $\mathrm{MgSO}_{4}$ and the solvent was removed in vacuo. Afterwards, the residue was kept for $5 \mathrm{~d}$ at 30-50 mbar at room temperature to yield the 2,2'-Imino-bis(2-methylpropionitrile) 60 as a beige solid (1.88 g, $12.4 \mathrm{mmol}, 30 \%)$.

${ }^{1} \mathbf{H}-\mathbf{N M R}\left(300 \mathrm{MHz}, \mathrm{DMSO}-\mathrm{d}_{6}\right): \delta[\mathrm{ppm}]=1.65\left(\mathrm{~s}, 12 \mathrm{H}, 4 \times \mathrm{CH}_{3}\right)$.

${ }^{13} \mathbf{C - N M R}\left(126 \mathrm{MHz}, \mathrm{DMSO}-\mathrm{d}_{6}\right): \delta[\mathrm{ppm}]=123.5,49.2,29.1$.

\section{3,3,5,5-Tetramethylpiperazine-2,6-dione $(61)^{[3,111]}$}

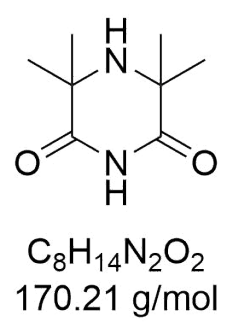

To precooled $68 \% \mathrm{H}_{2} \mathrm{SO}_{4}(7.0 \mathrm{~mL})$ 2,2'-imino-bis(2-methylpropionitrile) 60 (1.00 g, $6.60 \mathrm{mmol}$, $1.00 \mathrm{eq})$ was added in portions over $2 \mathrm{~h}$ at $5^{\circ} \mathrm{C}$. Then, the solution was stirred at room temperature for $4 \mathrm{~d}$, for $1 \mathrm{~h}$ at $100^{\circ} \mathrm{C}$ and for additional $16 \mathrm{~h}$ at room temperature. After the addition of ice $(100 \mathrm{~g})$, a $10 \mathrm{M}$ aq. $\mathrm{NaOH}$ solution was added slowly until the aqueous phase reached the $\mathrm{pH}=7$. Then, the solvent was removed under reduced pressure and the residue was suspended in $\mathrm{MeOH}(5 \mathrm{~mL})$. The precipitate was filtered off and the filtrate was concentrated under reduced pressure. After washing the residue with $\mathrm{H}_{2} \mathrm{O}$ and $\mathrm{Et}_{2} \mathrm{O}$ the 3,3,5,5-Tetramethylpiperazine-2,6-dione $\mathbf{6 1}$ was obtained after drying in vacuo as a colorless solid (269 mg, $1.58 \mathrm{mmol}, 24 \%$ ).

${ }^{1}$ H-NMR $\left(300 \mathrm{MHz}, \mathrm{DMSO}_{6}\right.$ ): $\delta[\mathrm{ppm}]=10.65$ (s (br.), $1 \mathrm{H}, \mathrm{NH}_{\text {imid }}$ ), 2.82 (s (br.), $1 \mathrm{H}, \mathrm{NH}_{\text {amin }}$ ), 1.25 (s, $\left.12 \mathrm{H}, 4 \times \mathrm{CH}_{3}\right)$.

${ }^{13}$ C-NMR $\left(126 \mathrm{MHz}\right.$, DMSO-d $\left.\mathrm{d}_{6}\right): \delta[\mathrm{ppm}]=178.2,55.0,27.9$. 


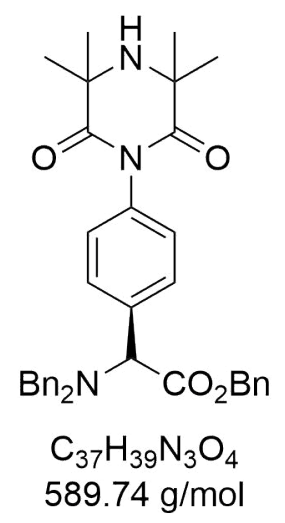

$\mathrm{Bn}_{2}$-4-dihydroxyboron-L-Phg-OBn 58 (2.00 g, $\left.4.30 \mathrm{mmol}, 1.00 \mathrm{eq}\right)$, piperazine-2,6-dion 61 $(730 \mathrm{mg}, 4.30 \mathrm{mmol}, 1.00 \mathrm{eq}), \mathrm{Cu}(\mathrm{OAc})_{2}(781 \mathrm{mg}, 4.30 \mathrm{mmol}, 1.00 \mathrm{eq}), \mathrm{Et}_{3} \mathrm{~N}(0.83 \mathrm{~mL}$, $6.07 \mathrm{mmol}, 1.40 \mathrm{eq})$ and $4 \AA$ molecular sieve pellets $(2 \mathrm{~g})$ were subjected to DMSO $(150 \mathrm{~mL})$ and the reaction mixture was stirred at room temperature under an oxygen atmosphere of 3 bar for $3 \mathrm{~d}$. Then, the reaction mixture was filtered through a pad of celite and the filtrate was portioned between EtOAc $(150 \mathrm{~mL})$ and $\mathrm{H}_{2} \mathrm{O}(150 \mathrm{~mL})$. After the mixture was acidified by addition of $1 \mathrm{M}$ aq. $\mathrm{HCl}$, the organic phase was separated. Then, the aqueous phase was extracted with EtOAc $(3 \times 100 \mathrm{~mL})$, the combined organic phases were washed with saturated aq. $\mathrm{NaCl}$ solution $(3 \times 100 \mathrm{~mL})$ and dried over $\mathrm{MgSO}_{4}$. After removal of the solvent under reduced pressure, the residue was purified by flash column chromatography on $\mathrm{SiO}_{2}(\mathrm{Pe} / \mathrm{EtOAc}, 2 / 1$ to $1 / 1, v / v)$ to yield the $\mathrm{Bn}_{2}-4-(3,3,5,5$-tetramethyl-2,6dioxopiperazine-1-yl)-L-Phg-OBn 63 as a yellowish solid (947 mg, $3.27 \mathrm{mmol}, 76 \%$ ).

${ }^{1} \mathbf{H}-\mathbf{N M R}\left(400 \mathrm{MHz}, \mathrm{CDCl}_{3}\right): \delta[\mathrm{ppm}]=7.42\left(\mathrm{~d}, 2 \mathrm{H},{ }^{3} \mathrm{~J}_{H H}=8.4 \mathrm{~Hz}, \mathrm{C}_{a r} \mathrm{H}\right), 7.35-7.19$ $\left(\mathrm{m}, 15 \mathrm{H}, \mathrm{C}_{a r} \mathrm{H}\right), 7.02\left(\mathrm{~d}, 2 \mathrm{H},{ }^{3} \mathrm{~J}_{H H}=8.4 \mathrm{~Hz}, \mathrm{C}_{a r} \mathrm{H}\right), 5.32\left(\mathrm{~d},{ }^{2} J_{H H}=12.4 \mathrm{~Hz}, 1 \mathrm{H}, \mathrm{CH}_{2}\right)$, $5.15\left(\mathrm{~d},{ }^{2} J_{H H}=12.4 \mathrm{~Hz}, 1 \mathrm{H}, \mathrm{CH}_{2}\right), 4.65\left(\mathrm{~s}, 1 \mathrm{H}, \mathrm{CH}_{\alpha}\right), 3.78\left(\mathrm{~d},{ }^{2} J_{H H}=14.0 \mathrm{~Hz}, 2 \mathrm{H}\right.$, $\left.\mathrm{CH}_{2}\right), 3.69\left(\mathrm{~d},{ }^{2} J_{H H}=14.0 \mathrm{~Hz}, 2 \mathrm{H}, \mathrm{CH}_{2}\right), 1.50\left(\mathrm{~s}, 12 \mathrm{H}, 4 \times \mathrm{CH}_{3}\right)$. ${ }^{13}$ C-NMR $\left(126 \mathrm{MHz}, \mathrm{CDCl}_{3}\right): \delta[\mathrm{ppm}]=176.6,171.6,139.3,135.9,129.6,128.9,128.7$, $128.5,128.4,128.3,127.2,66.5,65.5,56.2,54.3,28.6$.

ESI-MS: $\mathrm{m} / z=590.3[\mathrm{M}+\mathrm{H}]$.

ESI-HRMS: $\mathrm{m} / z$ calcd. for $\mathrm{C}_{37} \mathrm{H}_{39} \mathrm{~N}_{3} \mathrm{O}_{4} \mathrm{H}[\mathrm{M}+\mathrm{H}]^{+}: 590.3013$ found: 590.2991 . 


\section{Fmoc-4-(3,3,5,5-tetramethyl-2,6-dioxopiperazine-1-yl)-L-Phg-OH (64) ${ }^{[3,111]}$}

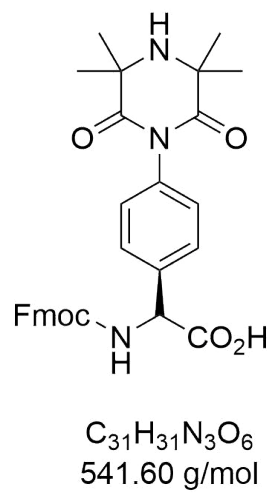

To a solution of $\mathrm{Bn}_{2}$-4-(3,3,5,5-tetramethyl-2,6-dioxopiperazine-1-yl)-L-Phg-OBn 63 $(500 \mathrm{mg}, 850 \mu \mathrm{mol}, 1.00 \mathrm{eq})$ in $\mathrm{MeOH}(20 \mathrm{~mL})$ and $\mathrm{DCM}(3 \mathrm{~mL})$ the $50 \% \mathrm{H}_{2} \mathrm{O}$ containing $\mathrm{Pd}(\mathrm{OH})_{2} / \mathrm{C}(100 \mathrm{mg}, 71.2 \mu \mathrm{mol}, 0.08 \mathrm{eq})$ was added and the solution was purged with hydrogen. Then, the reaction mixture was stirred at room temperature under a hydrogen atmosphere for $20 \mathrm{~h}$. Afterwards, the suspension was filtered through a celite pad and the filtrate was concentrated under reduced pressure to give the unprotected intermediate. Then, the intermediate was redissolved in DMF (6 mL) and $\mathrm{NaHCO}_{3}(143 \mathrm{mg}, 1.70 \mathrm{mmol}$, $2.00 \mathrm{eq})$ and Fmoc-OSu (287 mg, $850 \mu \mathrm{mol}, 1.00 \mathrm{eq})$ were added. The reaction mixture was stirred at room temperature for $24 \mathrm{~h}$. Subsequently, $\mathrm{H}_{2} \mathrm{O}(25 \mathrm{~mL})$ was added and the aqueous phase was acidified with $2 \mathrm{M}$ aq. $\mathrm{HCl}$ to $\mathrm{pH} 2$. After extraction of the organic phase with EtOAc $(5 \times 200 \mathrm{~mL})$, the organic phases were combined, washed with saturated aq. $\mathrm{NaCl}$ solution $(200 \mathrm{~mL})$ and dried over $\mathrm{MgSO}_{4}$. Then, the solvent was removed in vacuo and the residue was purified by flash column chromatography on $\mathrm{SiO}_{2}$ (DCM/MeOH containing 0.1\% AcOH, 98/2 to 90/10, $v / v)$ to yield the Fmoc-4- $(3,3,5,5-$ tetramethyl-2,6-dioxopiperazine-1-yl)-L-Phg-OH 64 as a colorless solid (271 mg, $532 \mathrm{~mol}$, $59 \%)$.

${ }^{1} \mathbf{H}-\mathbf{N M R}\left(400 \mathrm{MHz}, \mathrm{DMSO}_{6}\right): \delta[\mathrm{ppm}]=8.27\left(\mathrm{~d}, 1 \mathrm{H},{ }^{2} \mathrm{~J}_{H H}=8.0 \mathrm{~Hz}, \mathrm{~N}_{a m i d} \mathrm{H}\right), 7.89$ $\left(\mathrm{d}, 2 \mathrm{H},{ }^{3} \mathrm{~J}_{H H}=7.6 \mathrm{~Hz}, \mathrm{C}_{a r} \mathrm{H}\right), 7.78-7.75\left(\mathrm{~m}, 2 \mathrm{H}, \mathrm{C}_{a r} \mathrm{H}\right), 7.52-7.31\left(\mathrm{~m}, 6 \mathrm{H}, \mathrm{C}_{a r} \mathrm{H}\right), 7.11$ $\left(\mathrm{d}, 2 \mathrm{H},{ }^{3} \mathrm{~J}_{H H}=8.4 \mathrm{~Hz}, \mathrm{C}_{a r} \mathrm{H}\right), 5.22\left(\mathrm{~d},{ }^{2} J_{H H}=8.0 \mathrm{~Hz}, 1 \mathrm{H}, \mathrm{C}_{\alpha} \mathrm{H}\right), 4.30-4.23(\mathrm{~m}, 3 \mathrm{H}$, $\left.\mathrm{CH}_{1}, \mathrm{CH}_{2}\right), 1.39\left(\mathrm{~s}, 12 \mathrm{H}, 4 \times \mathrm{CH}_{3}\right)$.

ESI-MS: $\mathrm{m} / z=542.2[\mathrm{M}+\mathrm{H}]^{+}, 564.2[\mathrm{M}+\mathrm{Na}]^{+}$.

ESI-HRMS: $\mathrm{m} / z$ calcd. for $\mathrm{C}_{31} \mathrm{H}_{31} \mathrm{~N}_{3} \mathrm{O}_{6} \mathrm{H}[\mathrm{M}+\mathrm{H}]^{+}: 542.2286$ found: 542.2264, calcd. for $\mathrm{C}_{31} \mathrm{H}_{31} \mathrm{~N}_{3} \mathrm{O}_{6} \mathrm{Na}[\mathrm{M}+\mathrm{Na}]^{+}: 564.2105$ found: 564.2109 . 


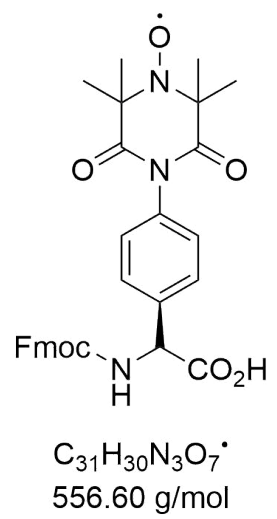

A solution of the amine $64(400 \mathrm{mg}, 740 \mu \mathrm{mol}, 1.00 \mathrm{eq})$ in DCM $(98.0 \mathrm{~mL})$ was cooled to $0{ }^{\circ} \mathrm{C}$ and upon the addition of a solution of $\mathrm{m}$-CPBA $(70 \%, 364 \mathrm{mg}, 1.48 \mathrm{mmol}, 2.00 \mathrm{eq})$ in $\operatorname{DCM}(2.0 \mathrm{~mL})$, the reaction mixture was stirred at $0{ }^{\circ} \mathrm{C}$ for $15 \mathrm{~min}$ and after warming up to room temperature for additional $5 \mathrm{~h}$. Then, the solvent was removed in vacuo and the residue was purified by flash column chromatography on $\mathrm{SiO}_{2}(\mathrm{DCM} / \mathrm{MeOH}$ containing $0.1 \% \mathrm{AcOH}, 98 / 2$ to $94 / 6, v / v)$ to yield the Fmoc-4-(3,3,5,5-tetramethyl-2,6dioxo-4-oxylpiperazine-1-yl)-L-Phg-OH 65 as an orange solid (317 mg, $571 \mu \mathrm{mol}, 77 \%$ ).

ESI-MS: $\mathrm{m} / z=557.2[\mathrm{M}+\mathrm{H}]^{+}, 574.2\left[\mathrm{M}+\mathrm{NH}_{4}\right]^{+}, 579.2[\mathrm{M}+\mathrm{Na}]^{+}$.

ESI-HRMS: $\mathrm{m} / z$ calcd. for $\mathrm{C}_{31} \mathrm{H}_{30} \mathrm{~N}_{3} \mathrm{O}_{7} \mathrm{H}[\mathrm{M}+\mathrm{H}]^{+}: 557.2157$ found: 557.2131, calcd. for $\mathrm{C}_{31} \mathrm{H}_{30} \mathrm{~N}_{3} \mathrm{O}_{7} \mathrm{NH}_{4}\left[\mathrm{M}+\mathrm{NH}_{4}\right]^{+}$: 574.2422 found: 574.2403, calcd. for $\mathrm{C}_{31} \mathrm{H}_{30} \mathrm{~N}_{3} \mathrm{O}_{7} \mathrm{Na}$ $[\mathrm{M}+\mathrm{Na}]^{+}: 579.1976$ found: 579.1960 .

\section{2-Nitrobenzyl Protected $\alpha$-TOPP Spin Label (66) ${ }^{[97]}$}

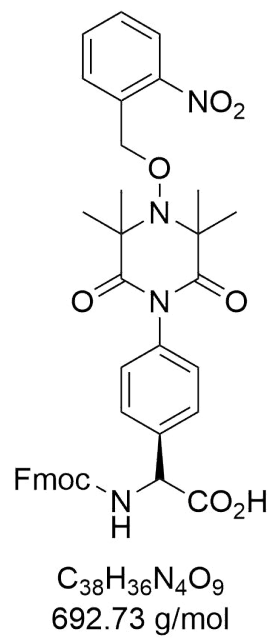

To a solution of the nitroxide $\mathbf{6 5}(500 \mathrm{mg}, 898 \mu \mathrm{mol}, 1.00 \mathrm{eq})$ in THF (5 mL) was added $20 \mathrm{w} \% \mathrm{Pd} / \mathrm{C}(100 \mathrm{mg})$ and the reaction mixture was purged with hydrogen and subsequently stirred under a hydrogen atmosphere at room temperature for $2 \mathrm{~h}$. Then, the 
reaction solution was purged with argon and $\mathrm{Et}_{3} \mathrm{~N}(0.37 \mathrm{~mL}, 2.69 \mathrm{mmol}, 3.00 \mathrm{eq})$ and 2nitrobenzyl bromide (291 mg, $1.35 \mathrm{mmol}, 1.50 \mathrm{eq})$ were added. The mixture was stirred at room temperature for $9 \mathrm{~h}$. Afterwards, the mixture was filtered through a pad of celite and the solvent was removed under reduced pressure. The residue was purified by flash column chromatography on $\mathrm{SiO}_{2}$ (DCM/MeOH, 98/2 to 90/10, $v / v$ ) to yield the 2-nitrobenzyl protected nitroxide as a colorless solid (131 mg, $189 \mu \mathrm{mol}, 21 \%)$.

ESI-MS: $\mathrm{m} / z=715.2[\mathrm{M}+\mathrm{Na}]^{+}, 710.3\left[\mathrm{M}+\mathrm{NH}_{4}\right]^{+}$.

ESI-HRMS: $\mathrm{m} / z$ calcd. for $\mathrm{C}_{38} \mathrm{H}_{36} \mathrm{~N}_{4} \mathrm{O}_{9} \mathrm{Na}[\mathrm{M}+\mathrm{Na}]^{+}: 715.2374$ found: 715.2358 , calcd. for $\mathrm{C}_{38} \mathrm{H}_{36} \mathrm{~N}_{4} \mathrm{O}_{9} \mathrm{NH}_{4}\left[\mathrm{M}+\mathrm{NH}_{4}\right]^{+}: 710.2821$ found: 710.2792 .

DMNB Protected $\alpha$-TOPP Spin Label $(67)^{[97]}$

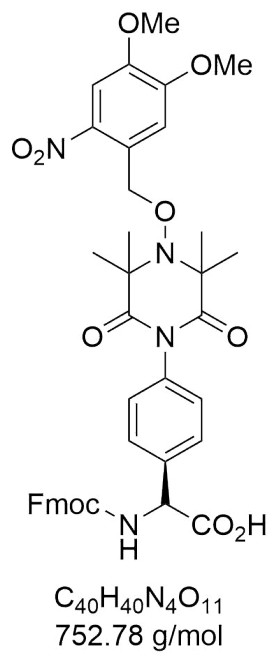

The DMNB protected nitroxide 67 was performed applying the same procedure as described for the 2-nitrobenzyl protected nitroxide 66, using the nitroxide $\mathbf{6 5}$ (100 mg, $180 \mu \mathrm{mol}, 1.00 \mathrm{eq}), 20 \mathrm{w} \% \mathrm{Pd} / \mathrm{C}(20 \mathrm{mg}), \mathrm{Et}_{3} \mathrm{~N}(0.07 \mathrm{~mL}, 0.54 \mathrm{mmol}, 3.00 \mathrm{eq})$ and $4,5-$ dimethoxy-2-nitrobenzyl bromide $(74.6 \mathrm{mg}, 0.27 \mathrm{mmol}, 1.50 \mathrm{eq})$. The desired product 67 was obtained as a colorless solid (24.5 mg, $32.6 \mu \mathrm{mol}, 24 \%)$.

ESI-MS: $\mathrm{m} / z=753.3[\mathrm{M}+\mathrm{H}]^{+}, 775.3[\mathrm{M}+\mathrm{H}]^{+}, 770.3\left[\mathrm{M}+\mathrm{NH}_{4}\right]^{+}$.

ESI-HRMS: $\mathrm{m} / z$ calcd. for $\mathrm{C}_{40} \mathrm{H}_{40} \mathrm{~N}_{4} \mathrm{O}_{11} \mathrm{H}[\mathrm{M}+\mathrm{H}]^{+}: 753.2766$ found: 753.2755 , calcd. for $\mathrm{C}_{40} \mathrm{H}_{40} \mathrm{~N}_{4} \mathrm{O}_{11} \mathrm{NH}_{4}\left[\mathrm{M}+\mathrm{NH}_{4}\right]^{+}: 770.3032$ found: 770.3019 , calcd. for $\mathrm{C}_{40} \mathrm{H}_{40} \mathrm{~N}_{4} \mathrm{O}_{11} \mathrm{Na}$ $[\mathrm{M}+\mathrm{Na}]^{+}: 775.2586$ found: 775.2577 . 


\section{Appendix}

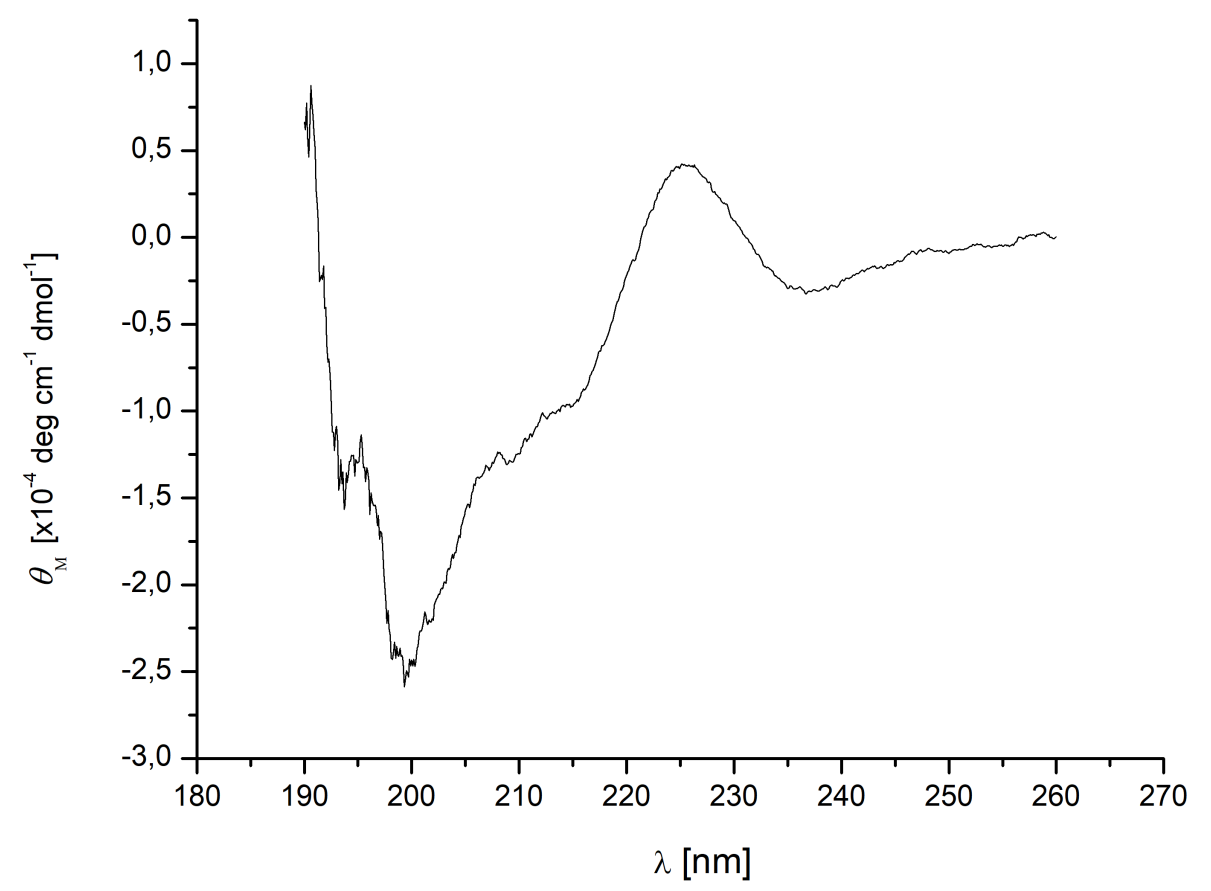

Figure 57: $\mathrm{CD}$ measurement of the azapeptide $\mathbf{5 1} \mathrm{in} \mathrm{MeOH}(50 \mu \mathrm{M})$ in the wavelength range from 260 to $190 \mathrm{~nm}$. 


\section{List of Abbreviations}
A alanine
AA amino acid
Abs absorption
$\mathrm{Ac}_{2} \mathrm{O} \quad$ acetic anhydride
AIBN azobisisobutyronitrile
Bn benzyl
Boc tert-butyloxycarbonyl
$\mathrm{Cbz}$ benzyl chloroformate
$\mathrm{CDCl}_{3} \quad$ deuterated chloroform
CDI 1,1'-carbonyldiimidazole
d doublet
DBU 1,8-diazabicyclo[5.4.0]undec-7-ene
DCM dichloromethane
DEAD diethyl azodicarboxylate
DEER double electron electron resonance
DIAD diisopropyl azodicarboxylate
DIC $\quad N, N^{\prime}$-diisopropylcarbodiimide
DIPEA $\quad N, N$ '-diisopropylethylamine
DMF dimethylformamide
DMNB dimethoxy nitrobenzyl
DMSO dimethyl sulfoxide
DMSO- $\mathrm{d}_{6}$ deuterated dimethyl sulfoxide
EPR electron paramagnetic resonance
ESI electron spray ionisation
EtOAc ethyl acetate
$\mathrm{EtOH}$ ethanol
Fmoc fluorenylmethyloxycarbonyl
G glycine
HATU 1-[Bis(dimethylamino)methylene]-1H-1,2,3-triazolo[4,5-b]-pyridinium-3-oxid hexafluorophosphate
HOAt 1-hydroxy-7-azabenzotriazole
HPLC high pressure liquid chromatography
HR high resolution
J coupling constant
K lysine 


\begin{tabular}{|c|c|}
\hline $\mathrm{kDa}$ & kilo daltons \\
\hline $\mathrm{m}$ & multiplet \\
\hline M & molar \\
\hline$m$-CPBA & meta-chloroperoxybenzoic acid \\
\hline $\mathrm{m} / z$ & mass-to-charge ratio \\
\hline $\mathrm{MeCN}$ & acetonitrile \\
\hline $\mathrm{MeOH}$ & methanol \\
\hline $\mathrm{MsCl}$ & mesitylene sulfochloride \\
\hline MTSL & $\begin{array}{l}S \text {-(1-oxyl-2,2,5,5-tetramethyl-2,5-dihydro-1H-pyrrol-3-yl)methyl } \\
\text { methanesulfonothioate }\end{array}$ \\
\hline NCL & Native chemical ligation \\
\hline NMR & Nuclear magnetic resonance \\
\hline PELDOR & Pulsed electron double resonance \\
\hline ppm & part per million \\
\hline py & pyridine \\
\hline$R_{f}$ & retention factor \\
\hline rt & room temperature \\
\hline s & singlet \\
\hline SDSL & side-directed spin labeling \\
\hline SET & single electron transfer \\
\hline SPPS & solid-phase peptide synthesis \\
\hline $\mathrm{t}$ & triplet \\
\hline$t$ & time \\
\hline$t \mathrm{Bu}$ & tert-butyl \\
\hline TEMPO & $(2,2,6,6$-Tetramethylpiperidin-1-yl)oxyl \\
\hline TFA & trifluoroacetic acid \\
\hline THF & tetrahydrofuran \\
\hline TIS & triisopropylsilane \\
\hline TLC & thin-layer chromatography \\
\hline TOAC & 2,2,6,6-tetramethyl- $N$-oxyl-4-amino-4-carboxylic acid \\
\hline TOPP & (3,3,5,5-tetramethyl-2,6-dioxo-4-oxylpiperazine-1-yl-L-phenylglycine \\
\hline$t_{R}$ & retention time \\
\hline UV & ultraviolet \\
\hline vis & visible \\
\hline $\operatorname{vol} \%$ & volume percent \\
\hline $\mathrm{vol} / \mathrm{vol}$ & volume per volume \\
\hline W & Tryptophane \\
\hline
\end{tabular}




\section{References}

[1] Sicoli, G.; Argirević, T.; Stubbe, J.; Tkach, I.; Bennati, M. Effects in $94 \mathrm{GHz}$ Orientation-Selected PELDOR on a Rigid Pair of Radicals with Non-Collinear Axes. Appl Magn Reson 2010, 37 (1-4), 539-548.

[2] Haugland, M. M.; Anderson, E. A.; Lovett, J. E. Tuning the properties of nitroxide spin labels for use in electron paramagnetic resonance spectroscopy through chemical modification of the nitroxide framework. In Electron Paramagnetic Resonance; Chechik, V., Murphy, D. M., Eds.; Electron Paramagnetic Resonance; Royal Society of Chemistry, 2016, pp 1-34.

[3] Stoller, S.; Sicoli, G.; Baranova, T. Y.; Bennati, M.; Diederichsen, U. TOPP: a novel nitroxide-labeled amino acid for EPR distance measurements. Angewandte Chemie (International ed. in English) 2011, 50 (41), 9743-9746.

[4] Halbmair, K.; Wegner, J.; Diederichsen, U.; Bennati, M. Pulse EPR Measurements of Intramolecular Distances in a TOPP-Labeled Transmembrane Peptide in Lipids. Biophysical Journal 2016, 111 (11), 2345-2348.

[5] Dawson, P. E.; Muir, T. W.; Clark-Lewis, I.; Kent, S. B. Synthesis of proteins by native chemical ligation. Science 1994, 266 (5186), 776-779.

[6] Agouridas, Vangelis; El Mahdi, Ouafaa; Diemer, Vincent; Cargoet, Marine; Monbaliu, Jean-Christophe M.; Melnyk, Oleg. Native Chemical Ligation and Extended Methods: Mechanisms, Catalysis, Scope, and Limitations. Chemical reviews 2019, 12 (119), 7328-7443.

[7] Marcelino, A. M. C.; Gierasch, L. M. Roles of beta-turns in protein folding: from peptide models to protein engineering. Biopolymers 2008, 89 (5), 380-391.

[8] Fielding, A. J.; Concilio, M. G.; Heaven, G.; Hollas, M. A. New developments in spin labels for pulsed dipolar EPR. Molecules (Basel, Switzerland) 2014, 19 (10), 16998-17025.

[9] Bowen, A. M.; Tait, C. E.; Timmel, C. R.; Harmer, J. R. Orientation-Selective DEER Using Rigid Spin Labels, Cofactors, Metals, and Clusters. In Structural Information from Spin-Labels and Intrinsic Paramagnetic Centres in the Biosciences; Timmel, C. R., Harmer, J. R., Eds.; Structure and Bonding Vol. 152; Springer Berlin Heidelberg, 2013, 283-327. DOI: 10.1007/430_2013_115. 
[10] Jeschke, G. DEER distance measurements on proteins. Annual review of physical chemistry 2012, 63, 419-446.

[11] Kay, L. E.; Gardner, K. H. Solution NMR spectroscopy beyond 25 kDa Current Opinion in Structural Biology 1997, 7, 722-731.

[12] Drescher, M. EPR in Protein Science. In EPR spectroscopy: Applications in chemistry and biology; Drescher, M., Jeschke, G., Bordignon, E., Eds.; Topics in Current Chemistry Vol. 321; Springer, 2012, 91-119. DOI: 10.1007/128_2011_235.

[13] Hemminga, M. A., Berliner, L. J., Eds. ESR spectroscopy in membrane biophysics; Biological Magnetic Resonance; Vol. 27; Springer, 2007, 129-174. DOI: 10.1007/9780-387-49367-1.

[14] Wang, J.-S.; Matyjaszewski, K. "Living"/Controlled Radical Polymerization. Transition-Metal-Catalyzed Atom Transfer Radical Polymerization in the Presence of a Conventional Radical Initiator, Macromolecules 1995, 28, 7572-7573.

[15] Sanchez, J.; Myers, T. N. Peroxides and Peroxide Compounds, Organic Peroxides. In Kirk-Othmer encyclopedia of chemical technology, [5. ed.]; Kroschwitz, J. I., Kirk, R. E., Othmer, D. F., Seidel, A., Eds.; A John Wiley \& Sons, Inc., publication; Wiley-Interscience, 2004. DOI: 10.1002/0471238961.1518070119011403.a01.

[16] Rozantzev, E. G.; Neiman, M. B. Organic Radical Reactions Involving No free Valence. Tetrahedron 1964, 20, 131-137

[17] Rozantsev, E. G.; Loshadkin, D. V. The history and modern problems of free radical chemistry. 100 years of free radical chemistry. Designed Monomers and Polymers 2001, 4 (4), 281-300.

[18] Rozantsev, E. G.; Scholle, V. D. Synthesis and Reactions of Stable Nitroxyl Radicals. Synthesis 1971, 401-414.

[19] Merbouh, N.; Bobbitt, J. M.; Brückner, C. Preparation of tetramethylpiperidine1-oxoammonium salts and their use as oxidants in organic chemistry. A Review. Organic Preparations and Procedures International 2004, 36 (1), 1-31.

[20] Hawker, C. J.; Bosman, A. W.; Harth, E. New polymer synthesis by nitroxide mediated living radical polymerizations. Chem. Rev. 2001, 101 (12), 3661-3688.

[21] Goldstein, S.; Samuni, A. Kinetics and mechanism of peroxyl radical reactions with nitroxides. J. Phys. Chem. A 2007, 111 (6), 1066-1072.

[22] Miura, Y.; Utsumi, H.; Hamada, A. Antioxidant activity of nitroxide radicals in lipid peroxidation of rat liver microsomes. Archives of Biochemistry and Biophysics Vol. 300, 1993, 148-156. DOI: 10.1006/abbi.1993.1021. 
[23] Pattison, D. I.; Lam, M.; Shinde, S. S.; Anderson, R. F.; Davies, M. J. The nitroxide TEMPO is an efficient scavenger of protein radicals: cellular and kinetic studies. Free Radical Biology and Medicine 2012, 53(9), 1664-1674.

[24] Christian Brückner. Nitroxide-Catalyzed Alcohol Oxidations in Organic Synthesis. In: Stable Radicals; John Wiley \& Sons, Ltd, 2010, pp 433-460.

DOI: $10.1002 / 9780470666975 . c h 12$.

[25] García Mancheño, O.; Stopka, T. TEMPO Derivatives as Alternative Mild Oxidants in Carbon-Carbon Coupling Reactions. Synthesis 2013, 45 (12), 1602-1611.

[26] Nakahara, K.; Oyaizu, K.; Nishide, H. Organic Radical Battery Approaching Practical Use. Chem. Lett. 2011, 40 (3), 222-227.

[27] Berliner, L. J. Spin Labeling: A Modern Perspective In: Stable radicals: Fundamentals and applied aspects of odd-electron compounds (eds: Hicks, R. G.); John Wiley \& Sons, Ltd, 2010, pp 521-535.

[28] Amar, M.; Bar, S.; Iron, M. A.; Toledo, H.; Tumanskii, B.; Shimon, L. J. W.; Botoshansky, M.; Fridman, N.; Szpilman, A. M. Design concept for $\alpha$-hydrogensubstituted nitroxides. Nature communications 2015, 6, 6070.

[29] Malatesta, V.; Ingold, K. U. Protonated nitroxide radicals. Journal of the American Chemical Society 1973, 95 (19), 6404-6407.

[30] Nilsen, A.; Braslau, R. Nitroxide decomposition: Implications toward nitroxide design for applications in living free-radical polymerization. J. Polym. Sci. A Polym. Chem. 2006, 44 (2), 697-717.

[31] Bleicken, S.; Assafa, T. E.; Zhang, H.; Elsner, C.; Ritsch, I.; Pink, M.; Rajca, S.; Jeschke, G.; Rajca, A.; Bordignon, E. gem-Diethyl Pyrroline Nitroxide Spin Labels: Synthesis, EPR Characterization, Rotamer Libraries and Biocompatibility. ChemistryOpen 2019, 8 (8), 1057-1065.

[32] Rajca, A.; Kathirvelu, V.; Roy, S. K.; Pink, M.; Rajca, S.; Sarkar, S.; Eaton, S. S.; Eaton, G. R. A spirocyclohexyl nitroxide amino acid spin label for pulsed EPR spectroscopy distance measurements. Chemistry 2010, 16 (19), 5778-5782.

[33] Jagtap, A. P.; Krstic, I.; Kunjir, N. C.; Hänsel, R.; Prisner, T. F.; Sigurdsson, S. T. Sterically shielded spin labels for in-cell EPR spectroscopy: analysis of stability in reducing environment. Free radical research 2015, 49 (1), 78-85.

[34] Paletta, J. T.; Pink, M.; Foley, B.; Rajca, S.; Rajca, A. Synthesis and reduction kinetics of sterically shielded pyrrolidine nitroxides. Org. Lett. 2012, 14 (20), $5322-5325$. 
[35] Ma, Y.; Loyns, C.; Price, P.; Chechik, V. Thermal decay of TEMPO in acidic media via an N-oxoammonium salt intermediate. Organic \& biomolecular chemistry 2011, 9 (15), 5573-5578.

[36] Gerken, J. B.; Pang, Y. Q.; Lauber, M. B.; Stahl, S. S. Structural Effects on the pHDependent Redox Properties of Organic Nitroxyls: Pourbaix Diagrams for TEMPO, ABNO, and Three TEMPO Analogs. The Journal of organic chemistry 2018, 83 (14), 7323-7330.

[37] Hakim Karoui; François Le Moigne; Olivier Ouari; Paul Tordo. Nitroxide Radicals: Properties, Synthesis and Applications. In: Stable Radicals; John Wiley \& Sons, Ltd, 2010, pp 173-229. DOI: 10.1002/9780470666975.ch5.

[38] Ryan, M. C.; Whitmire, L. D.; McCann, S. D.; Stahl, S. S. Copper/TEMPO Redox Redux: Analysis of PCET Oxidation of TEMPOH by Copper(II) and the Reaction of TEMPO with Copper(I). Inorg. Chem. 2019, 58 (15), 10194-10200.

[39] Haugland, M. M.; Lovett, J. E.; Anderson, E. A. Advances in the synthesis of nitroxide radicals for use in biomolecule spin labelling. Chemical Society reviews 2018, 47 (3), 668-680.

[40] Keana, J. F.; Pou, S.; Rosen, G. M. Nitroxides as potential contrast enhancing agents for MRI application: influence of structure on the rate of reduction by rat hepatocytes, whole liver homogenate, subcellular fractions, and ascorbate. Magn. Reson. Med. 1987, 5 (6), 525-536.

[41] Manda, S.; Nakanishi, I.; Ohkubo, K.; Yakumaru, H.; Matsumoto, K.; Ozawa, T.; Ikota, N.; Fukuzumi, S.; Anzai, K. Nitroxyl radicals: electrochemical redox behaviour and structure-activity relationships. Organic $\&$ biomolecular chemistry 2007, 5 (24), 3951-3955.

[42] Zhang, K.; Noble, B. B.; Mater, A. C.; Monteiro, M. J.; Coote, M. L.; Jia, Z. Effect of heteroatom and functionality substitution on the oxidation potential of cyclic nitroxide radicals: role of electrostatics in electrochemistry. Physical chemistry chemical physics : PCCP 2018, 20 (4), 2606-2614.

[43] Braun, T.; Drescher, M.; Summerer, D. Expanding the Genetic Code for SiteDirected Spin-Labeling. International journal of molecular sciences 2019, 20 (2).

[44] Roser, P.; Schmidt, M. J.; Drescher, M.; Summerer, D. Site-directed spin labeling of proteins for distance measurements in vitro and in cells. Organic $\mathcal{E}$ biomolecular chemistry 2016, 14 (24), 5468-5476. 
[45] Altenbach, C.; Marti, T.; Khorana, H. G.; Hubbell, W. L. Transmembrane protein structure: spin labeling of bacteriorhodopsin mutants. Science 1990, 248 (4959), 1088-1092.

[46] Barratt, M. D.; Davies, A. P.; Evans, M. T. Maleimide and isomaleimide pyrrolidinenitroxide spin labels. European Journal of Biochemistry 1971, 24 (2), 280-283.

[47] Pace, N. J.; Weerapana, E. Diverse functional roles of reactive cysteines. ACS Chem. Biol. 2013, 8 (2), 283-296.

[48] Poole, L. B. The basics of thiols and cysteines in redox biology and chemistry. Free Radical Biology and Medicine 2015, 80, 148-157.

[49] Kolb, H. C.; Finn, M. G.; Sharpless, K. B. Click Chemistry: Diverse Chemical Function from a Few Good Reactions. Angew. Chem. Int. Ed. 2001, 40 (11), 2004-2021.

[50] Rostovtsev, V. V.; Green, L. G.; Fokin, V. V.; Sharpless, K. B. A Stepwise Huisgen Cycloaddition Process: Copper(I)-Catalyzed Regioselective "Ligation" of Azides and Terminal Alkynes. Angew. Chem. Int. Ed. 2002, 41 (14), 2596-2599.

[51] Tornøe, C. W.; Christensen, C.; Meldal, M. Peptidotriazoles on solid phase: 1,2,3triazoles by regiospecific copper(i)-catalyzed 1,3-dipolar cycloadditions of terminal alkynes to azides. The Journal of organic chemistry 2002, 67 (9), 3057-3064.

[52] Agard, N. J.; Prescher, J. A.; Bertozzi, C. R. A strain-promoted 3+2 azide-alkyne cycloaddition for covalent modification of biomolecules in living systems. J. Am. Chem. Soc. 2004, 126 (46), 15046-15047.

[53] Kálai, T.; Hubbell, W.; Hideg, K. Click Reactions with Nitroxides. Synthesis 2009, 2009 (08), 1336-1340.

[54] Kucher, S.; Korneev, S.; Tyagi, S.; Apfelbaum, R.; Grohmann, D.; Lemke, E. A.; Klare, J. P.; Steinhoff, H.-J.; Klose, D. Orthogonal spin labeling using click chemistry for in vitro and in vivo applications. Journal of magnetic resonance (San Diego, Calif. : 1997) 2017, 275, 38-45.

[55] Kiick, K. L.; Saxon, E.; Tirrell, D. A.; Bertozzi, C. R. Incorporation of azides into recombinant proteins for chemoselective modification by the Staudinger ligation. Proceedings of the National Academy of Sciences 2002, 99 (1), 19-24.

[56] Widder, P.; Berner, F.; Summerer, D.; Drescher, M. Double Nitroxide Labeling by Copper-Catalyzed Azide-Alkyne Cycloadditions with Noncanonical Amino Acids for Electron Paramagnetic Resonance Spectroscopy. ACS Chem. Biol. 2019, 14 (5), 839-844. 
[57] Kálai, T.; Fleissner, M. R.; Jekő, J.; Hubbell, W. L.; Hideg, K. Synthesis of new spin labels for Cu-free click conjugation. Tetrahedron Letters 2011, 52 (21), 2747-2749.

[58] Marchetto, R.; Schreier, S.; Nakaie, C. R. A novel spin-labeled amino acid derivative for use in peptide synthesis: (9-fluorenylmethyloxycarbonyl)-2,2,6,6-tetramethylpiperidine-N-oxyl-4-amino-4-carboxylic acid. J. Am. Chem. Soc. 1993, 115 (23), $11042-11043$.

[59] Merrifield, R. B. Solid Phase Peptide Synthesis. I. The Synthesis of a Tetrapeptide. J. Am. Chem. Soc. 1963, 85 (14), 2149-2154.

[60] Merrifield, R. B.; Stewart, J. M.; Jernberg, N. Instrument for automated synthesis of peptides. Anal. Chem. 1966, 38 (13), 1905-1914.

[61] Barlos, K.; Gatos, D. 9-Fluorenylmethyloxycarbonyl/tbutyl-based convergent protein synthesis. Biopolymers 1999, 51 (4), 266-278.

[62] Carpino, L. A.; Han, G. Y. 9-Fluorenylmethoxycarbonyl function, a new basesensitive amino-protecting group. J. Am. Chem. Soc. 1970, 92 (19), 5748-5749.

[63] Flippen-Anderson, J. L.; George, C.; Valle, G.; Valente, E.; Bianco, A.; Formaggio, F.; Crisma, M.; Toniolo, C. Crystallographic characterization of geometry and conformation of TOAC, a nitroxide spin-labelled C alpha,alpha-disubstituted glycine, in simple derivatives and model peptides. International Journal of Peptide and Protein Research 1996, 47 (4), 231-238.

[64] Marsh, D. Orientation of TOAC amino-acid spin labels in alpha-helices and betastrands. Journal of magnetic resonance (San Diego, Calif. : 1997) 2006, 180 (2), 305-310.

[65] Wegner, J.; Valora, G.; Halbmair, K.; Kehl, A.; Worbs, B.; Bennati, M.; Diederichsen, U. Semi-Rigid Nitroxide Spin Label for Long-Range EPR Distance Measurements of Lipid Bilayer Embedded $\beta$-Peptides. Chemistry 2019, 25 (9), 2203-2207.

[66] Schmidt, M. J.; Fedoseev, A.; Bücker, D.; Borbas, J.; Peter, C.; Drescher, M.; Summerer, D. EPR Distance Measurements in Native Proteins with Genetically Encoded Spin Labels. ACS Chem. Biol. 2015, 10 (12), 2764-2771.

[67] Marsh, D. Orientation of TOAC amino-acid spin labels in alpha-helices and betastrands. Journal of magnetic resonance 2006, 180 (2), 305-310. 
[68] Balog, M.; Kálai, T.; Jekő, J.; Berente, Z.; Steinhoff, H.-J.; Engelhard, M.; Hideg, K. Synthesis of new conformationally rigid paramagnetic $\alpha$-amino acids. Tetrahedron Letters 2003, 44 (51), 9213-9217.

[69] Pelay-Gimeno, M.; Glas, A.; Koch, O.; Grossmann, T. N. Structure-Based Design of Inhibitors of Protein-Protein Interactions: Mimicking Peptide Binding. Angewandte Chemie (International ed. in English) 2015, 54 (31), 8896-8927.

[70] Nagai, U.; Sato, K. Synthesis of a bicyclic dipeptide with the shape of $\beta$-turn central part. Tetrahedron Letters 1985, 26 (5), 647-650.

[71] Millet, R.; Domarkas, J.; Rombaux, P.; Rigo, B.; Houssin, R.; Hénichart, J.-P. Synthesis of an azabicycloalkane amino acid scaffold as potential rigid dipeptide mimetic; Vol. 43, 2002. DOI: 10.1016/S0040-4039(02)00992-9.

[72] Haugland, M. M.; El-Sagheer, A. H.; Porter, R. J.; Peña, J.; Brown, T.; Anderson, E. A.; Lovett, J. E. 2'-Alkynylnucleotides: A Sequence- and Spin Label-Flexible Strategy for EPR Spectroscopy in DNA. J. Am. Chem. Soc. 2016, 138 (29), 9069-9072.

[73] Kálai, T. Synthesis and Reactions of a Symmetric Paramagnetic Pyrrolidine Diene. Synthesis 1999, 1999 (06), 973-980.

[74] Hideg, K.; Hankovszky, H. O.; Halasz, H. A. Conjugate Addition with Organometallics and Nitration of Nitroxide (Aminoxyl) Free Radicals. Synthesis of Potentially Useful Cross-Linking Spin Label Reagents. J. Chem. Soc. Perkin Trans. I 1988, 7, 2905-2911.

[75] Durand, J.-O.; Larcheveque, M.; Petit, Y. Reductive cyanation: A key step for a short synthesis of (-)-(2S,3S)-3-hydroxyproline. Tetrahedron Letters 1998, 39 (32), $5743-5746$.

[76] Chudinov, A. V.; Rozantsev, E. G.; Tarasov, V. F.; Sholle, V. D. The reaction of 2,2,6,6-tetramethyl-4-oxopiperidin-1-oxyl with sodium hypobromite. Translated from Izvestiya Akademii Nauk SSSR, Seriya Khimicheskaya, 1983, 2, 394-399.

[77] Kálai, T. Synthesis and Reactions of a Symmetric Paramagnetic Pyrrolidine Diene. Synthesis 1999, 1999 (06), 973-980.

[78] Kálai, T.; Balog, M.; Jekö, J.; Hideg, K. 3-Substituted 4-Bromo-2,2,5,5-tetramethyl2,5-dihydro-1H-pyrrol-1-yloxyl Radicals as Versatile Synthons for Synthesis of New Paramagnetic Heterocycles. Synthesis 1998, 1998 (10), 1476-1482.

[79] Steinebach, C.; Lindner, S.; Udeshi, N. D.; Mani, D. C.; Kehm, H.; Köpff, S.; Carr, S. A.; Gütschow, M.; Krönke, J. Homo-PROTACs for the Chemical Knockdown of Cereblon. ACS Chem. Biol. 2018, 13 (9), 2771-2782. 
[80] Mori, M.; Hashimoto, A.; Shibasaki, M. Novel synthesis of heterocycles using stannyl anion generated from Me3SiSnBu3 and F-. J. Org. Chem. 1993, 58, 6503-6504.

[81] Mori, M.; Isono, N.; Kaneta, N.; Shibasaki, M. Novel cyclization by stannyl anion generated from (trimethylsilyl)tributylstannane (Me3SiSnBu3) and fluoride ion. Application to natural product synthesis. J. Org. Chem. 1993, 58, 2972-2976.

[82] Kulcsár, G.; Kálai, T.; Jekő, J.; Hideg, K. Synthesis of Paramagnetic Carbo-and Heterocycles. Synthesis 2003, 2003 (09), 1361-1366.

[83] Jan Gerrits, P.; Zumbrägel, F.; Marcus, J. Analyzing the hydrocyanation reaction: chiral HPLC and the synthesis of racemic cyanohydrins. Tetrahedron 2001, 57 (41), 8691-8698.

[84] Boeglin, D.; Lubell, W. D. Aza-amino acid scanning of secondary structure suited for solid-phase peptide synthesis with fmoc chemistry and aza-amino acids with heteroatomic side chains. Journal of combinatorial chemistry 2005, 7 (6), 864-878.

[85] Freidinger, R. M.; Veber, D. F.; Perlow, D. S.; Brooks, J. R.; Saperstein, R. Bioactive conformation of luteinizing hormone-releasing hormone: evidence from a conformationally constrained analog. Science 1980, 210 (4470), 656-658.

[86] Chingle, R.; Proulx, C.; Lubell, W. D. Azapeptide Synthesis Methods for Expanding Side-Chain Diversity for Biomedical Applications. Accounts of chemical research 2017, 50 (7), 1541-1556.

[87] Hamdane, Y.; Chauhan, P. S.; Vutla, S.; Mulumba, M.; Ong, H.; Lubell, W. D. 5-Substituted N-Aminoimidazolone Peptide Mimic Synthesis by Organocatalyzed Reactions of Azopeptides and Use in the Analysis of Biologically Active Backbone and Side-Chain Topology. Organic letters 2021, 23 (9), 3491-3495.

[88] Bourguet, C. B.; Proulx, C.; Klocek, S.; Sabatino, D.; Lubell, W. D. Solution-phase submonomer diversification of aza-dipeptide building blocks and their application in aza-peptide and aza-DKP synthesis. Journal of peptide science : an official publication of the European Peptide Society 2010, 16 (6), 284-296.

[89] Sabatino, D.; Proulx, C.; Klocek, S.; Bourguet, C. B.; Boeglin, D.; Ong, H.; Lubell, W. D. Exploring side-chain diversity by submonomer solid-phase aza-peptide synthesis. Organic letters 2009, 11 (16), 3650-3653.

[90] Ohnishi, S.; Kamikubo, H.; Onitsuka, M.; Kataoka, M.; Shortle, D. Conformational preference of polyglycine in solution to elongated structure. Journal of the American Chemical Society 2006, 128 (50), 16338-16344. 
[91] Traoré, M.; Doan, N.-D.; Lubell, W. D. Diversity-oriented synthesis of azapeptides with basic amino acid residues: aza-lysine, aza-ornithine, and aza-arginine. Organic letters 2014, 16 (13), 3588-3591.

[92] Doan, N.-D.; Hopewell, R.; Lubell, W. D. N-aminoimidazolidin-2-one peptidomimetics. Organic letters 2014, 16 (8), 2232-2235.

[93] Bourguet, C. B.; Sabatino, D.; Lubell, W. D. Benzophenone semicarbazone protection strategy for synthesis of aza-glycine containing aza-peptides. Biopolymers 2008, 90 (6), 824-831.

[94] Hideg, K.; Csekö, J.; Hankovszky, H. O.; Sohár, P. Further syntheses with nitroxide $\alpha, \beta$-unsaturated aldehydes and allylic bromides. R. Can. J. Chem. 1986, 64, 1482-1490.

[95] McKinnie, S. M. K.; Wang, W.; Fischer, C.; McDonald, T.; Kalin, K. R.; Iturrioz, X.; Llorens-Cortes, C.; Oudit, G. Y.; Vederas, J. C. Synthetic Modification within the "RPRL" Region of Apelin Peptides: Impact on Cardiovascular Activity and Stability to Neprilysin and Plasma Degradation. Journal of medicinal chemistry 2017, 60 (14), 6408-6427.

[96] Bourguet, C. B.; Proulx, C.; Klocek, S.; Sabatino, D.; Lubell, W. D. Solution-phase submonomer diversification of aza-dipeptide building blocks and their application in aza-peptide and aza-DKP synthesis. Journal of peptide science : an official publication of the European Peptide Society 2010, 16 (6), 284-296.

[97] Seven, I.; Weinrich, T.; Gränz, M.; Grünewald, C.; Brüß, S.; Krstić, I.; Prisner, T. F.; Heckel, A.; Göbel, M. W. Photolabile Protecting Groups for Nitroxide Spin Labels. Eur. J. Org. Chem. 2014, 2014 (19), 4037-4043.

[98] Chalmers, B. A.; Morris, J. C.; Fairfull-Smith, K. E.; Grainger, R. S.; Bottle, S. E. A novel protecting group methodology for syntheses using nitroxides. Chemical communications (Cambridge, England) 2013, 49 (88), 10382-10384.

[99] Kaiser, E.; Colescott, R. L.; Bossinger, C. D.; Cook, P. I. Color test for detection of free terminal amino groups in the solid-phase synthesis of peptides. Analytical Biochemistry 1970, 34 (s), 595-598.

[100] Hara, I.; Ueno, T.; Ozaki, S.; Itoh, S.; Lee, K.; Ueyama, N.; Watanabe, Y. Oxidative modification of tryptophan 43 in the heme vicinity of the F43W/H64L myoglobin mutant. Journal of Biological Chemistry 2001, 276 (39), 36067-36070.

[101] Sabatino, D.; Proulx, C.; Klocek, S.; Bourguet, C. B.; Boeglin, D.; Ong, H.; Lubell, W. D. Exploring side-chain diversity by submonomer solid-phase aza-peptide synthesis. Organic letters 2009, 11 (16), 3650-3653. 
[102] Migliore, M.; Bonvicini, A.; Tognetti, V.; Guilhaudis, L.; Baaden, M.; Oulyadi, H.; Joubert, L.; Ségalas-Milazzo, I. Characterization of $\beta$-turns by electronic circular dichroism spectroscopy: a coupled molecular dynamics and time-dependent density functional theory computational study. Phys. Chem. Chem. Phys. 2020, 22 (3), 1611-1623.

[103] Chakrabartty, A.; Kortemme, T.; Padmanabhan, S.; Baldwin, R. L. Aromatic sidechain contribution to far-ultraviolet circular dichroism of helical peptides and its effect on measurement of helix propensities. Biochemistry 1993, 32 (21), 5560-5565.

[104] Becker, C. F. W.; Lausecker, K.; Balog, M.; Kálai, T.; Hideg, K.; Steinhoff, H.J.; Engelhard, M. Incorporation of spin-labelled amino acids into proteins. Magn. Reson. Chem. 2005, 43 Spec no (S1), 34-9. DOI: 10.1002/mrc.1688.

[105] Dawson, P. E.; Muir, T. W.; Clark-Lewis, I.; Kent, S. B. Synthesis of proteins by native chemical ligation. Science 1994, 266 (5186), 776-779.

[106] Widder, P.; Berner, F.; Summerer, D.; Drescher, M. Double Nitroxide Labeling by Copper-Catalyzed Azide-Alkyne Cycloadditions with Noncanonical Amino Acids for Electron Paramagnetic Resonance Spectroscopy. ACS chemical biology 2019, 14 (5), 839-844.

[107] Kirilyuk, I. A.; Polienko, Y. F.; Krumkacheva, O. A.; Strizhakov, R. K.; Gatilov, Y. V.; Grigor'ev, I. A.; Bagryanskaya, E. G. Synthesis of 2,5-bis(spirocyclohexane)substituted nitroxides of pyrroline and pyrrolidine series, including thiol-specific spin label: an analogue of MTSSL with long relaxation time. The Journal of organic chemistry 2012, 77 (18), 8016-8027.

[108] Cremers, C. M.; Jakob, U. Oxidant sensing by reversible disulfide bond formation; Vol. 288, 2013. DOI: 10.1074/jbc.R113.462929.

[109] Tsuda, S.; Yoshiya, T.; Mochizuki, M.; Nishiuchi, Y. Synthesis of cysteine-rich peptides by native chemical ligation without use of exogenous thiols. Org. Lett. 2015, 17 (7), 1806-1809.

[110] Cistrone, P. A.; Bird, M. J.; Flood, D. T.; Silvestri, A. P.; Hintzen, J. C. J.; Thompson, D. A.; Dawson, P. E. Native Chemical Ligation of Peptides and Proteins. Current Protocols in Chemical Biology 2019, 11 (1), e61.

[111] Wegner, J. Synthesis of Rigid Spin Labels for the Investigation of Transmembrane Peptides by EPR Spectroscopy. Dissertation, Göttingen, 2018

[112] Mallia, C. J.; Burton, P. M.; Smith, A. M. R.; Walter, G. C.; Baxendale, I. R. Catalytic Chan-Lam coupling using a 'tube-in-tube' reactor to deliver molecular oxygen as an oxidant. Beilstein journal of organic chemistry 2016, 12, 1598-1607. 
[113] Bailey, J. E.; Beaven, G. H.; Chignell, D. A.; Gratzer, W. B. An analysis of perturbations in the ultraviolet absorption spectra of proteins and model compounds. European Journal of Biochemistry 1968, 7 (1), 8-14. 


\section{Danksagung}

Zunächst möchte ich mich bei Prof. Dr. Ulf Diederichsen für das interessante Thema, seine Diskussionsbereitschaft und sein Vertrauen in meine Arbeit bedanken.

Prof. Dr. Marina Bennati danke ich für die angenehme Kooperation, ihre ständige Diskussionsbereitschaft und die Übernahme der Zweitbetreuung.

Desweiteren möchte ich mich bei den weiteren Mitgliedern der Prüfungskommission Dr. Holm Frauendorf, Dr. Michael John, Prof. Dr. Konrad Koszinowski und Prof. Dr. Kai Tittmann für ihr Interesse an meiner Arbeit und die investierte Zeit für die Begutachtung meiner Arbeit bedanken.

Außerdem möchte ich mich bei allen Mitarbeitern der Massenabteilung und der NMRAbteilung für die Messung zahlreicher Proben und ihre ständige Hilfsbereitschaft bei kleineren und größeren Problemen bedanken.

Frau Heinemann danke ich für ihre ständige und unermüdliche Hilfsbereitschaft in allen organisatorischen Belangen und ihre aufheiternde Art.

Mein Dank gilt auch allen Mitgliedern des AK Diederichsen für die angenehme Arbeitsatmosphäre, stete Diskussionsbereitschaft und die zahlreichen Ratschläge. Dabei möchte ich mich vor allem auch bei allen früheren und aktuellen Laborkollegen Amartya, Martin, Atida, Duc, und Felix für die tolle Zeit im Labor 130 bedanken. Ein besonderer Dank gilt Atida, die stets ein offenes Ohr für mich hatte und immer einen guten Ratschlag parat hatte.

Schließlich möchte ich mich bei meiner Familie, die mich in jeder Lebenslage unermüdlich unterstützt und immer an mich geglaubt hatte, bedanken. 